Portland State University

PDXScholar

\title{
Comprehensive School Reform Influence on Teacher Practice: Listening in the Classroom, an Examination of Powerful Learning Labs within the Accelerated Schools Project
}

Amy Daggett Petti

Portland State University

Follow this and additional works at: https://pdxscholar.library.pdx.edu/open_access_etds

Part of the Educational Administration and Supervision Commons, and the Educational Leadership Commons

Let us know how access to this document benefits you.

\section{Recommended Citation}

Petti, Amy Daggett, "Comprehensive School Reform Influence on Teacher Practice: Listening in the Classroom, an Examination of Powerful Learning Labs within the Accelerated Schools Project" (2002). Dissertations and Theses. Paper 614.

https://doi.org/10.15760/etd.614

This Dissertation is brought to you for free and open access. It has been accepted for inclusion in Dissertations and Theses by an authorized administrator of PDXScholar. Please contact us if we can make this document more accessible: pdxscholar@pdx.edu. 


\section{DISSERTATION APPROVAL}

The abstract and dissertation of Amy Daggett Petti for the Doctor of Education in

Educational Leadership: Administration were presented April 29, 2002, and accepted by the dissertation committee and the doctoral program.

\section{COMMITTEE APPROVALS:}

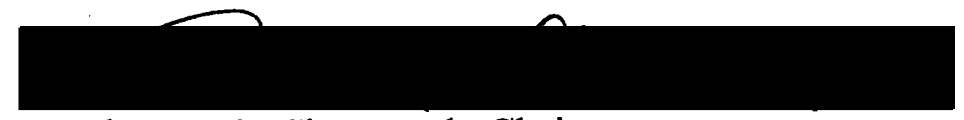

Thomas G. Chenoweth, Chair

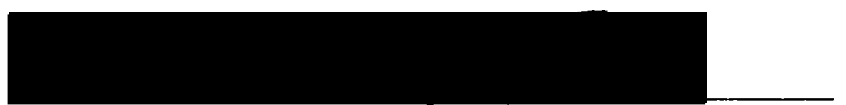

Robert B. Everhart

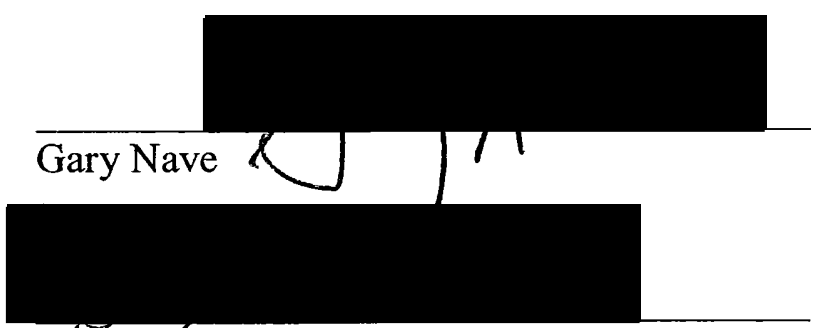

Gayle Thieman

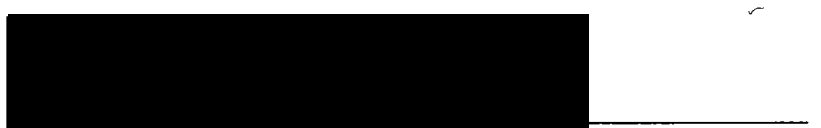

Martha Balshem

Representative of the Office of

Graduate Studies

DOCTORAL PROGRAM APPROVAL:

PhyYlis J. Edmundson, Dean

Graduate School of Education 


\begin{abstract}
An abstract of the dissertation of Amy Daggett Petti for the Doctor of Education in Educational Leadership: Administration presented April 29, 2002.

Title: Comprehensive School Reform Influence on Teacher Practice: Listening in the Classroom: An Examination of Powerful Learning Labs within the Accelerated Schools Project
\end{abstract}

Focusing on teacher learning, this study follows fifteen teachers in the crux of comprehensive school reform. These "regular" classroom teachers are the ubiquitous players of this theatre of school reform. "Regular" teacher is defined as a typical classroom teacher who is not actively involved in the district's school reform project or one who hasn't taken an active leadership role. The teachers in this study work in the challenging environment of a poor, diverse urban school district that was in its third year of a comprehensive school reform program, the Accelerated Schools Project. Fifteen teachers volunteered to take part in a teaching laboratory where they met, planned, taught, assessed and reflected on their practice. The study tells, analyzes and speculates about their journey.

The Accelerated Schools Project (ASP) is a national comprehensive school improvement model that provides professional development to schools. The study 
described the experiences of regular classroom teachers who engaged in a yearlong professional development program that is part of the ASP service to schools.

This study employs qualitative research methods in a multiple case study analysis. By examining the teaching practices of regular classroom teachers who are often depicted as "closing the door" to the outside influences of school, district, state or federal policy, the study seeks to fully understand the planning, teaching, assessing and reflecting of classroom teachers who are caught in the center of school reform.

The key findings of this study suggest teacher practice for all teacher cohorts (novice, mid-career and veteran) was influenced by participation in the Powerful Learning Laboratory. Each aspect of teaching (planning, teaching, assessing and reflection) was influenced, with differing emphasis by each cohort. The findings suggest the Powerful Learning Lab is a positive professional development experience for teachers, and that teacher learning labs should remain an integral part of the Accelerated Schools Project. 
COMPREHENSIVE SCHOOL REFORM INFLUENCE ON TEACHER

PRACTICE: LISTENING IN THE CLASSROOM:

AN EXAMINATION OF POWERFUL LEARNING LABS WITHIN THE

ACCELERATED SCHOOLS PROJECT

by

AMY DAGGETT PETTI

A dissertation submitted in partial fulfillment of the requirements for the degree of

DOCTOR OF EDUCATION

in

EDUCATIONAL LEADERSHIP: ADMINISTRATION

Portland State University

2002 


\section{DEDICATION}

This work is dedicated to my most extraordinary family, immediate and extended. To my late father, my mentor as a school administrator; I hope I can come close to the standard he set. To my mother, who was my first and most dedicated teacher. To my brothers and sisters, all excellent teachers, who led the way. To my daughters who can't fathom a mother who is still going to school, and who are the children I keep clośest to my heart. And finally and most importantly to my husband, Ron, who has lovingly supported, encouraged and inspired me to keep learning. 


\section{ACKNOWLEDGEMENTS}

I'd like to acknowledge and thank the superintendent, principals and teachers of the Hazelton District; you know who you are. Thanks for allowing me to tell your story, and for opening your minds and hearts so willingly.

I'd also like to acknowledge my dissertation committee for continued support; and especially to Robert Everhart, who posed the question in policy analysis class, "Can policy affect practice?" and started this journey, and to my advisor, Tom Chenoweth. Tom, you've taught me so much about change, leadership, and perseverance; I'll always be grateful. 


\section{TABLE OF CONTENTS}

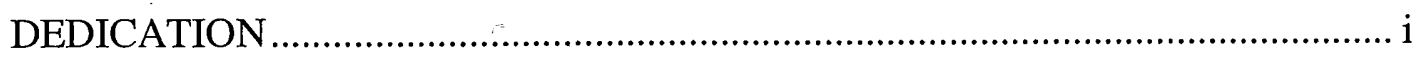

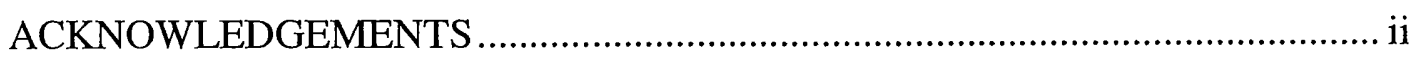

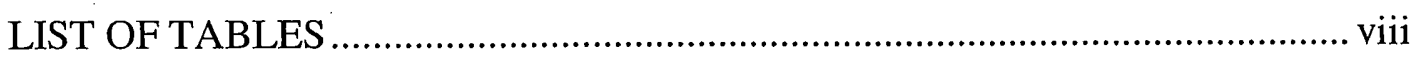

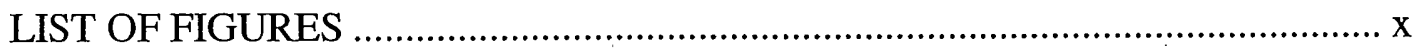

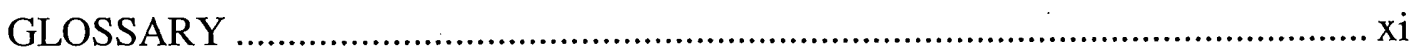

CHAPTER

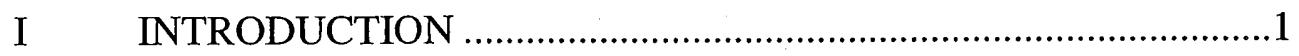

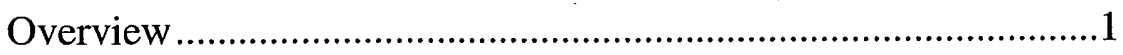

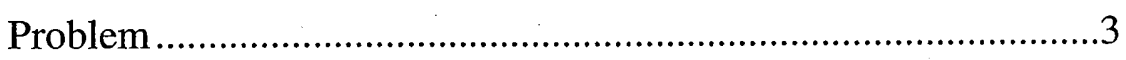

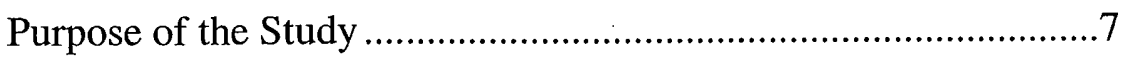

Purpose Related to the Accelerated Schools Project .............10

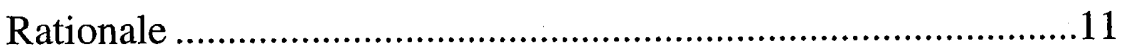

To Inform the Development of Future Powerful

Learning Labs and the Accelerated

Schools Project ..................................................................11

To Consider the Importance of Context of School Reform........................................................18

To Inform Teacher Preparation Programs .............................19

To Inform School Leadership ..............................................21

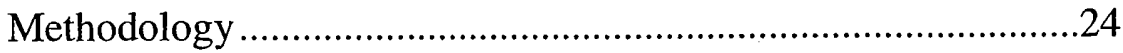

Powerful Learning Lab Organization ...................................25 
Summary .26

End Notes.

.29

II REVIEW OF THE LITERATURE ............................................30

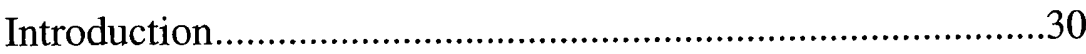

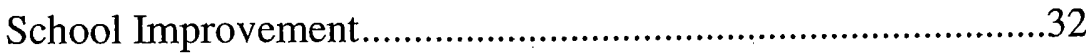

Principle Based Reform and the Accelerated Schools Project ..............................................45

Teachers as Constructivists......................................................54

Adult Learning .......................................................................63

Andragogy Theory.............................................................64

Self-Directed Learning .......................................................65

Transformative Learning Theory .....................................67

Postmodernist Perspectives ..................................................68

Emotions, Learning and the Brain .......................................72

Teacher Development .................................................................

Professional Development .........................................................79

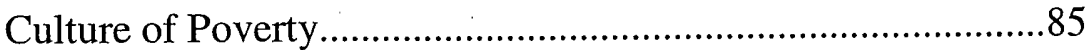

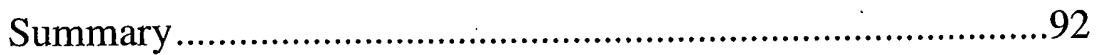

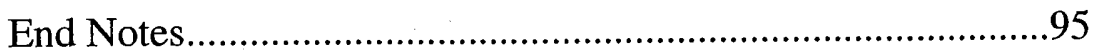

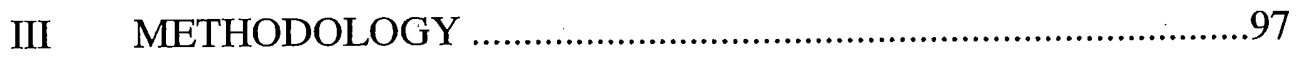

Overview, Goals, Significance …………………….................97

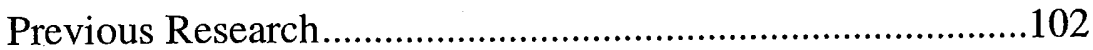

Approach and Methodology …………....................................103

Research and Study Questions .......................................105 


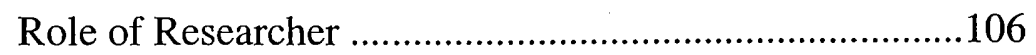

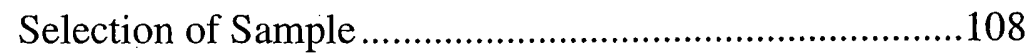

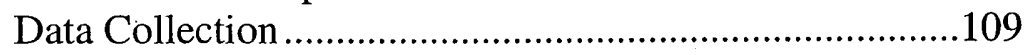

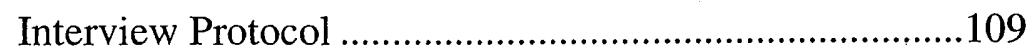

Obseryation Protocol .......................................................111

Portfolios and Writing Reflection Protocol ........................113

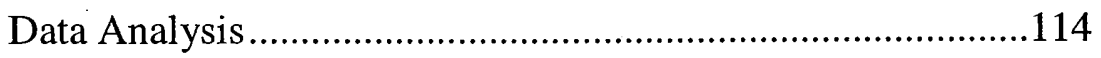

Standards of Qualitative Research...........................................117

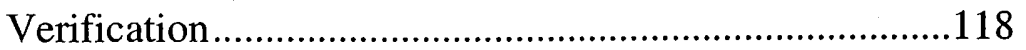

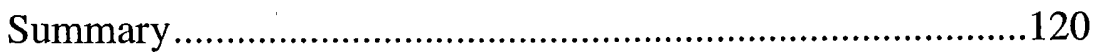

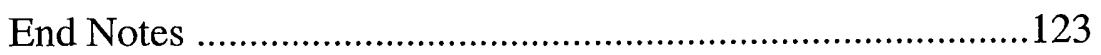

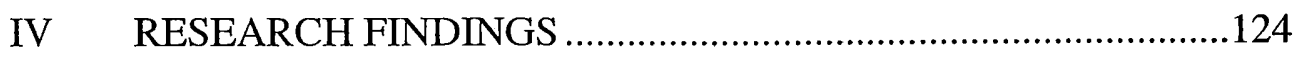

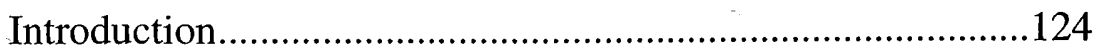

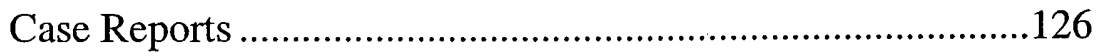

Case One: Novice Cohort.............................................126

Case Two: Mid-Career Cohort .....................................139

Case Three: Veteran Cohort ...........................................152

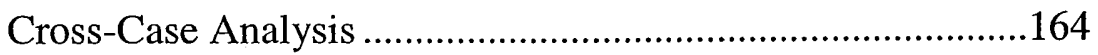

Cross-Case Analysis of Teaching Practice

Between Experiential Cohorts ......................................165

Characteristics of Cases and Emerging Themes ...............183

Secondary Research Question Findings .............................193

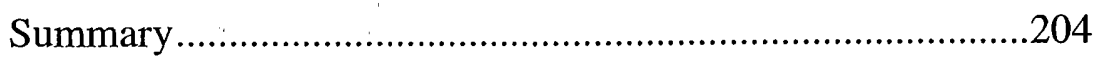

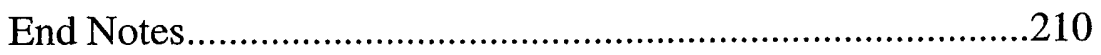

V DISCUSSION, SPECULATIONS, IMPLICATIONS

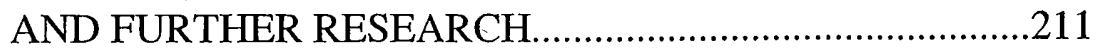

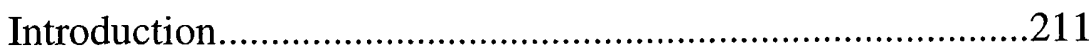


Discussion and Speculations of Findings

From A Perspective of Adult and

Teacher Development

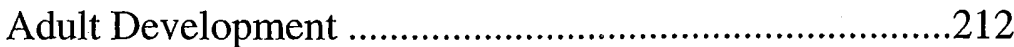

Teacher Development......................................................221

Discussion and Speculations of Findings From a

Perspective of Professional Development .........................225

National Study: The Eisenhower Study ……………….....225

Local Study: The Hazelton Study......................................227

Writing for Professional Development and Learning ......230

Implications for Accelerated Schools Project..................................233

Implications for Teacher Preparation.............................................237

Implications for School Leaders ....................................................239

Suggestions for Further Research ..............................................244

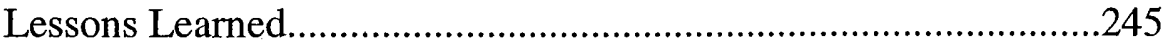

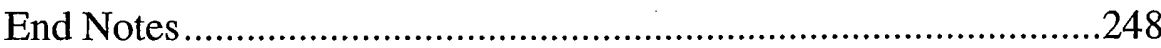

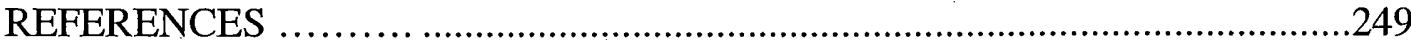

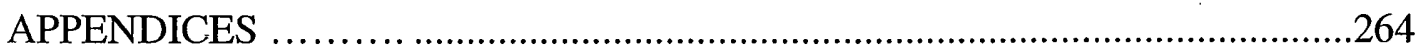

A POWERFUL LEARNING FRAME WORK ACCELERATED SCHOOLS PROJECT ….............................264

B POWERFUL LEARNING LAB SUMMARY ..............................267

C POWERUL LEARNING LAB PORTFOLIO ...............................270

D ACCELERATEDSCHOOLS PROCESS ….................................329

E ACCELERATED SCHOOLS BASIC PARTNERSHIP AGREEMENT 


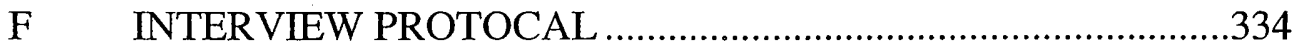

G CLASSROOM OBSERVATION PROTOCOL .............................339

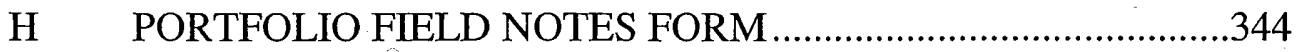




\section{LIST OF TABLES}

TABLE

PAGE

1. 2000-2001 Powerful Learning Lab Design Components .................16

2. Comparison of R \& D and School-Based Faculty Centered Improvement Efforts

3. First, Second and Third Wave School Improvement Designs

4. Bodilly's (1998) District Factors that Support

School Reform Implementation

$5 \quad$ Five Principles of Constructivism and

ASP Powerful Learning Lab

6. Grow's Model of Stages of Self-Directed Learning

7. Hawley \& Valli's Design Principles for Professional

Development and Corresponding Powerful

Learning Lab Components

8. Teacher Practices Studied .99

9. Teacher Practices Defined by Washington Teacher

Certification Criteria 100

10. Initial Subject Codes 104

11. Types of Data Collection, Method, Purpose, Benefits and Limitations.

12. Base Data of Case One: Novice Cohort

13. Base Data of Case Two: Mid-Career Cohort

14. Base Data of Case Three: Veteran Cohort 
15. Cross-Case Analysis of Data Characteristics And Learning Preference 183

16. Case Orientation and Teaching Practice Emphasis 185

17. Emerging Themes of Research Findings 185

18. Teachers' Perception of District Support Factors for Teacher Learning by Percent 194

19. Teachers' Perception of Factors Contributing to Student Achievement by Percent 196

20. Recommendations for Teacher Preparation Programs by Percent .198

21. Teachers' Perception of Benefits of Powerful

Learning Lab by Percent .200

22. Teachers' Perception of Limitations of Powerful Learning Lab by Percent. .203 


\section{LIST OF FIGURES}

FIGURE

PAGE

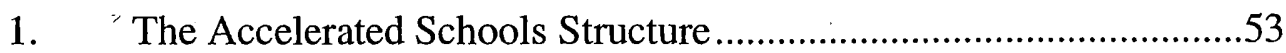

2. Interacting Areas of Hertzberg's "Factors" with Mazlow's "Stages"

3. Fessler and Christensen's Teacher Career Cycle...............................77

4. Novice Cohort's Cyclical View of Teaching Practice ....................131

5. Mid-Career and Veteran Teachers' Overlapping and Holistic View of Teaching Practice.

6. Comparison of Planning Between Novice, Mid-Career and Veteran Cohorts 166

7. Comparison of Teaching Between Novice, Mid-Career and Veteran Cohorts.

8. Comparison of Assessment Between Novice, Mid-Career and Veteran Cohorts. 176

9. Comparison of Reflection Between Novice, Mid-Career and Veteran Cohorts

10. Diagram of Collaboration, Critical Thinking and

Writing to Learn and their Influence on

Teacher Practice 


\section{GLOSSARY}

Accelerated Schools Project (ASP): A national comprehensive school improvement model affiliated with New American Schools. ASP is a principlebased reform model. ASP employs a governance structure that emphasizes community participation and is centered on guiding principles of: empowerment with responsibility, unity of purpose, and building on strengths. The ASP philosophy believes that through acceleration with a constructivist learning approach (powerful learning) all students can be brought into the educational mainstream, even those students often considered "at risk". The model originated in 1986 and has undergone continuous improvement and modification based on data gathered in their schools.

Basic Partnership Agreement (BPA): The contract entered between a school and the Satellite Center for Accelerated Schools that will guide the professional development and technical assistance to that school.

Coach: Accelerated Schools facilitator that is on site at a school mentoring teachers and keeping the ASP process going.

Coalition for Essential Schools (CES): A comprehensive school improvement model most often associated with high schools. This model was developed by Ted Sizer, and in a principle-base reform model similar to ASP.

Comprehensive School Reform Demonstration (CSRD): The 1998 authorization of federal funding which aims to raise student achievement by helping public schools across the country to implement successful, comprehensive school reforms that are based on reliable research and effective practices, and that include an emphasis on basic academics and parental involvement.

Comprehensive School Reform (CSR): The Leave No Child Behind Act of 2001, dropped the " $D$ " in CSRD, as the program is no longer considered a "demonstration program". For this paper CSR will be capitalized when I'm referring to the federally funded Elementary and Secondary Education Act (ESEA) program, comprehensive school reform in lower case letters will reflect the more general term, that is not necessarily tied to federal funding, but to comprehensive efforts at reforming schools. 
Constructivist Learning Theory: An epistemology that offers an explanation of the nature of knowledge and how human beings learn.

Constructivism purports that individuals create or construct their own new understandings through the interaction of what they already know and believe with new ideas, events, and activities in which they come in contact (Cannella \& Reiff,1994) .

Elementary and Secondary Education Act (ESEA): The giant federal policy program begun in 1965 and still influencing schools that allocates program, federal funds and accountability measures for poor schools, with "poor" being determined by the schools' Free and Reduced Lunch Program (FRLP).

Essential Academic Learning Requirements (EALRs): State standards for Washington.

Free and Reduced Lunch Program (FRLP): A federal program funded under ESEA that allows students to receive free lunch (and often free breakfast) at public schools. Schools with 50\% or greater FRLP are considered "high poverty".

National Center for Accelerated Schools: Located in the Neag School of Education at the University of Connecticut, this is the national home of the Accelerated Schools Project that sets policy for Satellite Centers and directs the national movement for ASP.

Satellite Centers for Accelerated Schools: These are regional centers that engage in providing local schools with technical assistance and professional development that allows schools to implement the ASP process. These centers are often affiliated with universities that provide teacher and school administrator preparation programs.

Study Sample: The following definitions help distinguish the sample groups referred to in this study.

- Case: refers to one of fifteen individual teachers who were part of the study's sample

- Cohort or PLL Cohort: Unless otherwise defined refers to the complete 2000-2001 Powerful Learning Lab cohort which included 42 teachers from eight schools throughout the northwest.

- Experiential Cohort: refers to the bounded "cases" where individual case teachers were bound to experiential group cohorts to tell a more coherent story. The experiential cohorts for this study include: novice teachers, mid-career teachers and veteran teachers 
Washington Assessment for Student Learning (WASL): Statewide highstakes student achievement tests. 


\section{CHAPTER I}

\section{INTRODUCTION}

I have always felt that the true text book for the pupil is his teacher. (Mohandas K. Gandhi in Maggio, 1997, p. 20)

\section{Overview}

This study is about teacher learning, as it follows fifteen teachers in the crux of comprehensive school reform. Regular classroom teachers are the ubiquitous players of this theatre of school reform. I define "regular" teacher as a typical classroom teacher who is not actively involved in the district's school reform project or one who hasn't taken an active leadership role. This is the teacher whose primary responsibility is the instruction of students, who engages daily with students and who does not have alternate responsibilities such as a Teacher on Special Assignment (TOSA) or an administrative internship. Every school has regular teachers, those who daily engage in the work of teaching and learning. The teachers in this study work in the challenging environment of Hazelton (a pseudonym) a poor, diverse urban school district in its third year of a comprehensive school reform program, the Accelerated Schools Project. Fifteen teachers volunteered to take part in a teaching laboratory where they met, planned, 
taught, assessed and reflected on their practice. The study tells, analyzes and speculates about their journey.

I and others believe it is the classroom teacher who has the most direct contact and impact on students and student achievement (Deal \& Peterson, 1999; Haberman, 1995; Hargreaves \& Fullan, 1998; Hawley \& Rosenholtz, 1984; Hess, 1999; Wang, Haertel \& Walberg, 1993-1994).

Robert Fried (1995) explains, Any worthwhile school change efforts must be owned by teachers working together, or they are unlikely to last. Veteran teachers tell me that almost any innovation or change that teachers don't care for can be undermined or simply ignored; eventually it will just go away. They have seen it happen dozens of times. (p. 49)

Accordingly, this study examines the teaching practices of regular classroom teachers who are often depicted as "closing the door" to the outside influences of school, district, state or federal policy. Through listening and a triangulation of data resources and methods, I seek to fully understand the planning, teaching, assessing and reflecting of classroom teachers who are caught in the crux of school reform.

This chapter provides the reader with an overview to the problem of school reform, the purpose of the study, and the rationale for this study. The methodology of the study is briefly explained and finally, the remaining chapters are summarized. 
Problem

Does Comprehensive School Reform Influence Regular Teacher Practice?

This study investigates whether or not participation in Comprehensive School Reform, specifically participation in the Accelerated Schools Project Powerful Learning Lab, influences regular teachers' practices. The problem of school reform has been debated for decades. John Dewey was an early proponent for school reform in the 1930s. There have been many attempts to improve individual schools: the progressive ideas of the 1930s through the 1950s, the curriculum and academic reform movements of the 1950-60s, the 1965 enactment of the Elementary and Secondary Education Act (ESEA) as a response to the "War on Poverty", and the first, second, and third waves of school reforms that followed

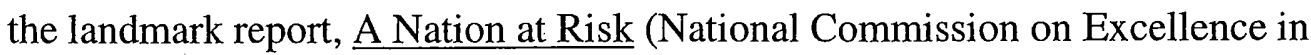
Education, 1983).

The more recent school improvement effort, since the early 1990's, has been the standards movement. Part of the standards movement was the 1998 federal allocation of Comprehensive School Reform Demonstration (CSRD) grants, a policy effort intended to resuscitate the 35 year old ESEA and improve student achievement in the United State's most challenging schools. The new ESEA 2002 reauthorization, often referred to as the "No Child Left Behind" Act of $2001^{1}$, retains CSRD, now referred to as CSR (Comprehensive School Reform). Yet, even 
with seventy years of rhetoric, effort and resources directed to school improvement, sustaining on-going school improvement has proved very difficult.

Often when a key individual, such as the principal or superintendent moves on, school improvement dies (Hart, 1993; Hess, 1999; Levin, 1997; Slovacek, 1996). One reason for this problem is the dilemma of four complex (and at times competing) systems: the individual classroom site, the school site, and the larger school district, and the even larger and more complex state and federal departments of education. Michael Fullan (1993), a change author and educator, states that neither top-down nor bottom-up change works.

This study takes place during the phenomena of simultaneous "top-down" and bottom up school change for improvement through the eyes of a "regular" classroom teacher. The change is top down as both state and district administrators demanded improvement. The change is bottom up, because the teachers of each school ultimately selected the Accelerated Schools Model as their chosen reform model. The participating teachers are situated in poor, urban, and diverse schools that were in the third year of Comprehensive School Reform Demonstration (CSRD). Specifically, the schools are implementing the Accelerated Schools Project, one of many comprehensive school improvement designs. While each school was free to determine their own selection of a CSRD model, there was distinct pressure to select something and no real opportunity for a school to opt out. This top-down pressure was reported in Chenoweth \& Petti (2000): 
The [Hazelton] superintendent gave a clear concise vision of the future when he stated, 'Our vision, is for the entire class of 2006 to walk across the stage at graduation.' Indeed, such a statement reflects the accountability and pressure of the Washington State Legislature, which requires all high school graduates to have passing scores on the state's assessment in all core areas. (p. 15)

The district environment is challenging as its students are poor, extremely diverse often with the school being their first experience in America. This district environment is complicated by an extremely accountability-driven state department of education. The additional pressures of a top-down state standards movement, which attempts to hold schools accountable for students to meet challenging state standards influences the concentric environmental circles of district, school, and classroom. Most recently the state superintendent of public instruction, Dr. Terry Bergeson announced the purpose of the Washington A+ Commission in her State of Education Address to Washington State School Directors Association (2002, Fall). She stated,

A top priority of my budget supported by the A+Commission's recommendations is to fund regional ESD/OSPI School improvement teams. This core staff will help put in place a statewide professional development and capacity-building system to ensure continued improvement and shared accountability. We need a helping system for the classroom and for the school districts. My vision is that they will work with your best people to ultimately make every school a learning center of caring and excellence.

Bergeson further explains a definite shift in the Office of the Superintendent of Public Instruction's (OSPI's) policies and resources from student oriented 
services and accountability measures to that of teacher accountability. She continues in the same address,

Within the context of the education reform timeline, we've spent much of the LAST seven years focusing on the students deciding what skills are most critical to teach, and how to assess these skills. The NEXT four years must be spent helping teachers so they can successfully lead their students in meeting these new challenges. Never before has the classroom demanded so much of teachers. Quite frankly, the new demands have been overwhelming to many. And in the next four years, teachers must get whatever help they need in learning to teach the Essential Academic Learning Requirements. They must have time to reflect individually and to collaborate as a team at school. They must have good curriculum resources aligned to the Essential Academic Learning Requirements.

This shift in Washington State policy to support and examine teacher practices more closely further explains the importance of this study. Never before have Washington's teachers been under such scrutiny by the state. Regular teachers continue to carry the burden of responsibility for school reform.

Extrapolating patterns and understanding the experiences of the most ubiquitous figure in this complex system, the classroom teacher is paramount to understanding the complexity of school improvement. The study is really about the teachers' stories, as they navigate through a year of decision making about planning, teaching, assessing, and then reflecting on their practice. This study tells some of those teacher's stories, and unravels some of the complexity. Since the participants of this study were not affiliated with district leadership teams, they represent the typical, average teacher, who comes to school, stays out of the 
political fray and does his or her job. These teachers represent the "bottom-up" contingency because they were not involved in leadership at the district. The study seeks to study the problem of school reform through the eyes of the "regular" classroom teacher, answering the question, "Does Comprehensive School Reform Influence Regular Teacher Practice?"

Purpose of the Study

The purpose of this study is to determine if all of the effort, resources, and organizational change required in CSRD schools, and specifically participation in the Accelerated School Project's Powerful Learning Lab, is making a difference to what others describe as the "core technology" of schools, that of teaching and learning (Bodilly, 1998; Calhoun \& Joyce, 1998; Hill, Campbell \& Harvey, 2000). These core technologies include teacher planning, teaching (instructional practice), student assessment and teacher reflection, the same areas examined in the study.

Many reforms have come and gone in the last three decades with little or no measurable impact on the core technology of teaching and learning (Calhoun \& Joyce, 1998; Hess, 1999; Hill et al., 2000; Schlechty, 1997; U.S. Department of Education [DOE], 1996). Listening at the teacher level enabled me to describe the teacher practices of those at the front line of school reform. The practices examined in the study were teacher planning, teaching, assessing, and reflecting by 
Hazelton teachers. The intervention examined was the teachers' participation in the Accelerated Schools Project's Powerful Learning Lab (PLL).

Forty-two teachers volunteered to participate in the Powerful Learning Lab (PLL) 2000-2001, for a period of eight months between August and March. This large group is referred to as the Powerful Learning Lab cohort and they represented eight regional Accelerated Schools. This study involved approximately a third of the Powerful Learning cohort, the teachers who taught in the Hazelton district. The Powerful Learning Lab began in August, 2000, and the last face-to-face session concluded in March 2001; yet the teachers taught lessons related to the lab until the end of the school year, so the study encompassed teacher planning, teaching, assessments, reflections and learning for an entire school year. Specific details about the Powerful Learning Lab are discussed later in this chapter.

Another purpose of the study is to examine school reform from the bottom up. Much is written about school leadership roles in school reform (Garmston \& Wellman, 1999; Hess, 1999; Lambert, 1995; Leithwood, Jantzi \& Steinbach, 1999; Wheatley, 1999) yet little has been written capturing the regular teacher's voice. Even though Hawley and Rosenholtz (1984) determined in a meta-analysis of factors related to student achievement that the teacher was the most significant factor.

The study examined teacher practices by following the participants through a professional development program initiated by the Accelerated Schools Project 
called the Powerful Learning Lab (PLL). A requirement for the PLL was that the teachers must write, teach, assess student work and reflect on ten lessons taught throughout the school year. The study examined their perception of their experience in the lab through interviews and written reflections, through classroom observations and through examining their lab portfolio which contained the written record of their planning, examples of their student work and their written reflections on the planning. The teachers' voices are the subject, as they tell and write about their teaching experience for most of the school year. An explicit bias of mine is that it is the teachers who will ultimately affect school improvement more than well-intentioned policy.

Major premises of the study include:

- If student performance is to improve, must teacher performance must also improve

- The teacher is the most influential factor affecting student achievement

- Professional development practices that are longitudinal and multi-dimensional reflect best practice

Knowing that the teacher is so vital to improving achievement for students, this study is significant to school improvement efforts, policy makers, administrators, departments of education, but it is also has a purpose to inform teacher preparation programs as many of the participating teachers are in their first 
few years of teaching, and to inform school leadership. Documenting and describing the planning, teaching, assessing and reflecting of teachers involved in CSRD and situated in a poor, urban and diverse setting will contribute to understanding the context of school reform in the nation's most challenging schools.

\section{Purpose Related to the Accelerated Schools Project}

Embedded in the design of this study is the Accelerated Schools Project, a . comprehensive school reform model. A more thorough discussion of the Accelerated Schools Project is provided in Chapter II. The Accelerated Schools Project (ASP) is a major comprehensive school improvement initiative having served over 1300 schools nationwide and over 100 schools internationally (Australia, China, Chile). The Accelerated Schools Project (ASP), founded in 1986 by Dr. Henry M. Levin, professor emeritus at Stanford University attempts to transform school communities and classrooms into powerful learning environments where all children can learn, succeed, and achieve at high levels. Integrated into the philosophy of the Accelerated Schools Project is that all children deserve the rich, powerful learning experiences that were traditionally reserved for talented and gifted students. Levin found that when all children received an enriching learning experience, that students accelerated their learning, especially students who were considered "at risk". In order to ensure that accelerated, powerful learning was happening in schools, the professional development components of ASP's training 
in schools needed to focus on classroom teachers and the teaching and learning process. The purpose of this study was to examine one of the key components to the Accelerated School's professional development services, the Powerful Learning Lab (PLL). A detailed description of the evolution of the PLL follows in the rationale section of this chapter.

\section{Rationale}

The rationale for this study addresses four major areas: 1) to inform the future development of the Powerful Learning Labs at both the national and regional levels, 2) to consider the context of school reform in a poor, urban and diverse school district, 3) to inform teacher preparation programs, and 4) to inform school leadership.

\section{To Inform the Development of Future}

Powerful Learning Labs and the

Accelerated Schools Project

The most significant rationale for this study is its contribution to the work and metamorphosis of the Accelerated Schools Project. Begun in 1986, ASP was originally more focused on the organizational elements of school reform. However, due to an increasing commonality of site-based management, and a response to research $^{2}$ that indicated reform models were not touching core technologies, ASP developed the Powerful Learning Lab concept. The PLL is in the early research and development phase as a response to criticism that "first and second wave"3 
reforms neglected the core technologies of teaching and learning (Bradley \& Olson, 1993; Garmston \& Wellman, 1999; Hess, 1999; Hill, et al., 1999; Slavin, 1998).

The Powerful Learning Lab integrates the Powerful Learning Framework, developed by the National Center for Accelerated Schools, which is based on constructivist learning principles. So while the study will apply to a broad audience of educators interested in school improvement efforts in poor, urban and diverse settings; the study will also serve as formative data for ASP's further development of Powerful Learning Labs.

Evolution of Powerful Learning Labs (PLL). During the early phases (1986-1988) of the Accelerated Schools Project implementation there were considerable challenges to transforming the practices and paradigms of classroom . teachers away from remediation toward an embedded philosophy and practice of acceleration. Levin (1999) describes the problem:

Most teachers and principals did not believe that an enrichment approach was appropriate for children in at-risk situations. Instead, they viewed an accelerated school as one that followed the procedures that we had formulated to shift from remediation to acceleration without too much concern about their own classrooms. Indeed, it was easier for us to engage schools in taking stock, vision, and inquiry than to connect these phases to enrichment. (p. 2)

Levin's findings were consistent with the criticism (Bodilly, 1998; Hess, 1999; Schlechty, 1997; Slavin, 1998) of other school reform models that neglected the core technology of teaching and learning. Because of the problem of getting "acceleration" through the threshold of the classroom, in 1988 the National Center 
for Accelerated Schools began a review of the literature of current best practices and comprehensive school change. The result of this review of the literature was the framework for powerful learning, which included the Accelerated Schools Triangle (curriculum, instruction and organization), which is further defined in Chapter II ("Powerful Learning in Action", 1994, Spring).

By 1993, ASP had accumulated considerable research on powerful learning and had published The Accelerated Schools Resource Guide, which devotes four chapters on the development of powerful learning in classrooms (Hopfenberg \& Levin, 1993). However, ASP practitioners demanded more concrete materials related to powerful learning. Much of ASP's early work in Powerful Learning was vague, and the framework remains one that is difficult for practitioners to embrace because it is ambiguous. Even though the terms of the components sound indisputable, it is often difficult to operationalize learning that is authentic, interactive, learner-centered, inclusive, and continuous consistently throughout a school. Thus in 1994 with support from the Annenberg Foundation, the ASP National Center developed a three phase project to further understand and implement powerful learning. The project involved: 1) observations of powerful learning in schools of various stages of the ASP process, 2) analysis of these observations to derive generic tools for the implementation of Powerful Learning, and 3) the grounding of Powerful Learning to cognitive research. 
At the same time, ASP was moving to a more decentralized structure that supported regional satellite centers providing technical assistance to schools, rather than all schools being supported through the National Center. The research question that was posed was "how [can] we share the powerful learning findings among our satellite centers and individual schools in a more active way?"' (Levin, 1999, p. 3). The answer was the first generation of the Powerful Learning Lab (PLL), which was funded by the Danforth Foundation. These labs were initiated in the summer of 1997 in San Jose, CA. The first summer lab involved participant teachers in a consecutive two-week PLL that involved teachers working in a collaborative setting to operationalize the Powerful Learning components through lesson design, implementation of lessons in a concurrent summer school, and then a debriefing of those lessons in teams.

Since 1997, regional variations of the Powerful Learning Lab (PLL) have evolved. During the summer of 1999 a PLL was developed and implemented by Chenoweth and Petti. This lab was configured as a week-long institute taking place entirely during the summer. In the 1999 lab, teachers spent the afternoons with Chenoweth and Petti, and mornings teaching in the district's summer school program. Feedback was gathered from the summer 1999 PLL, such as the participants' suggestion that the lab focus more on teacher learning and planning without the immediate instructional component of teaching the same day in summer school. Participants expressed the desire to ponder and reflect longer on 
pedagogical discourse in order to develop more thoughtful lessons. The 20002001 Powerful Learning Lab (PLL) at Portland State University was developed with the benefit of formative feedback from those first three years of PLL, the influence of research on staff development (Darling- Hammond \& Sykes, 1999;

Lambert, 1995; Putnam \& Borko, 2000; Sykes, 1999), and the 1999 pilot PLL developed by Chenoweth and Petti. The 2000-2001 PLL design incorporates lessons learned by ASP during the past three years. Appendix B provides an example of the 2000-2001 PLL portfolio. Table 1 outlines the design components of PLL that are pertinent to understanding the study.

Since ASP is a principle-based reform model, and the "what" of the reform is really professional development, the study was really a study of ASP's professional development service to schools. The study described the experiences of classroom teachers caught in the crux of comprehensive school reform who are engaging in a year long professional development program. Their stories will inform the evolution of the PLL as well as educators and policy makers about the impact of this type of professional development on teacher learning. 
Table 1

2000-2001 Powerful Learning Lab Design Components

\begin{tabular}{|c|c|}
\hline $\begin{array}{l}\text { Duration \& } \\
\text { Span }\end{array}$ & $\begin{array}{l}8 \text { days } \\
4 \text { sessions- } 2 \text { days each during August, October, January and March }\end{array}$ \\
\hline Participants & Minimum 5 member school teams, certified teachers \\
\hline Texts & $\begin{array}{l}\text { Models of Teaching, 6th Ed. Joyce, B. et al } \\
\text { Powerful Learning Lab Portfolio (see Appendix C) }\end{array}$ \\
\hline $\begin{array}{l}\text { Content by } \\
\text { Session }\end{array}$ & $\begin{array}{l}\text { 1-2 The Social Family of Models } \\
\text { Chapters 3-7 } \\
\text { Powerful Learning Focus: Interactive } \\
\text { Additional Content: Learning inventories } \\
\text { \& grouping of students } \\
\text { Labs 3-4 The Information-Processing Family of Models } \\
\text { Chapters 8-15 } \\
\text { Powerful Learning Focus: Continuous \& Inclusive } \\
\text { Additional Content: Peer Coaching } \\
\text { Labs 5-6 The Personal Family of Models } \\
\text { Chapter 16-18 } \\
\text { Powerful Learning Focus: Learner-Centered } \\
\text { Additional Content: Culture of Poverty } \\
\text { Labs 7-8 The Behavior Systems Family of Models } \\
\text { Chapters 19-22 } \\
\text { Powerful Learning Focus: Authentic } \\
\text { Additional Content: Differentiated Instruction }\end{array}$ \\
\hline $\begin{array}{l}\text { Assignments } \\
\text { outside of PLL }\end{array}$ & $\begin{array}{l}\text { Develop } 10 \text { lessons, implement lessons, collect student work samples, } \\
\text { written reflection; peer coaching \& debriefing }\end{array}$ \\
\hline $\begin{array}{l}\text { Instructional } \\
\text { activities: }\end{array}$ & $\begin{array}{l}\text { Pair sharing } \\
\text { Interest based study groups } \\
\text { Cooperative learning strategies (jigsaw) } \\
\text { Reciprocal teaching } \\
\text { Peer teaching } \\
\text { Individual reflection (journaling) }\end{array}$ \\
\hline
\end{tabular}

The Accelerated Schools Project is truly at a critical juncture. ASP is in its sixteenth year, the movement has recently established a new National Center with close affiliation to the work of Joseph Renzulli, who has been a scholar and practitioner in strategies related to talented and gifted students. ASP is no longer one of a handful of school reform models available to schools. There is definitely 
more competition with over 300 different reform models currently being implemented. Also, federal legislation, such as CSR and Schoolwide Title I implies that schools will work with an outside technical assistance provider, such as a comprehensive school design. ASP is one of an elite group of models that are affiliated with the New American Schools program, a national clearinghouse of school improvement designs. New America School designs must meet rigorous standards to maintain affiliation. ASP was certified as a New American Schools model in 2000 . So, the competition is fierce, the'standards are high, and schools are in more need of high quality technical assistance than ever before. ASP must be able to firmly establish itself as a third wave school improvement model with specific tools for improving teaching and learning in the nation's most challenging schools. Despite a huge influx of new schools in $1998-99$ as a result of the first distribution of Comprehensive School Reform Demonstration (CSRD) grants, there were far fewer new ASP schools begun in 1999-2000 or 2000-2001. When secondround CSRD funding became available in 2001-2002 more CSRD schools are expected to enroll as ASP schools at the close of 2002. As a movement, ASP must determine what it can offer schools in terms of technical support that will influence teaching practice in order to be able to retain schools beyond a three-year funding cycle. 
To Consider the Importance of Context of School Reform

Part of the rationale for a careful examination of teacher practice is determining what works given a specific context. This study examined an inherent dilemma of these democratically based schools reforms (e.g. ASP and Coalition of Essential Schools [CES] value greater school autonomy) and the historical structure of top-down central office coordination and support. Levin described the historical context of top down structures in his comments at the Accelerated Schools Special Interest Group at the Annual American Educational Research Association [AERA] meeting in Montreal, CA, (April, 1999), "school districts are part of larger state systems, which are part of larger federal systems, which all have a rich history of autocratic organization."

The intent of the study is to document and describe the planning, teaching, assessing and reflecting of classroom teachers who face the challenging task of teaching in poor, urban, and diverse settings. The emphasis on context is important as the highest percent of low performing students are in urban and poor communities (Lippman, Burns \& McArthur, 1996). The contextual implications of school improvement are well noted in ethnographic and portraiture research (Creswell, 1998; Lawrence-Lightfoot \& Davis, 1997; Patton, 1987; Spindler, 1982; Wilcox; 1982; Wolcott, 1973). School reform models may be very context-specific, as the Consortium for Policy Research in Education (CPRE) determined in their 
five years of research from 1990-1995 on public policy and school reform. The report, Public Policy and School Reform: A Research Summary (1996), states, Reforms are not always realistic or based on understanding of what will actually work. Knowledge of what types of policy and education reform work in different contexts, or of how to transform successful demonstration projects into large-scale reforms, is more limited than many like to admit. This is one reason why the rhetoric of reform often exceeds the accomplishments that are actually made. (p. 1)

Therefore, studying a district's teachers who are in their third year of Accelerated Schools justifiably contributes to the issue of context, by examining how this principle-based reform model is faring in a the challenging setting of a poor, urban, and diverse school district.

\section{$\underline{\text { To Inform Teacher Preparation Programs }}$}

This study has implications for teacher preparation programs as well. Many of the study's participants are in their first two years of teaching. The northwest, like the nation is facing a critical teacher shortage (Bradley, 1999, Chaika, 2000, National Center for Policy Analysis, 2001). Even more distressing is the rising number of new teachers who are abandoning their teaching careers within the first few years. There are reports that thirty percent of new teachers quit within their first five years (Archer, 1999). With so much at stake, teacher preparation programs need to hear from teachers involved in improving their practice, especially beginning teachers. Data collected from this study may help teacher 
education institutions understand the plight of new teachers in poor, urban and diverse settings.

There have been numerous suggestions as to how to improve teacher preparation programs, especially since the publication of A Nation at Risk. Most of the recommendations have been related to structural elements of teacher preparation programs, such as the National Teachers' Exam requirements, and the shift in licensure programs from Baccalaureate to Master's Degree programs.

Teacher preparation programs have been criticized as lacking in higher level thinking opportunities for perspective teachers (Ball \& Cohen, 1999; Goodlad, 1994; Lambert \& Ball, 1999). Furthermore, while constructivism may be given lip service in terms of establishing learning communities in teacher preparation programs, and students may at times pursue some level of group projects, there is a severe lack of application of best practice strategies in higher education coursework. Lambert and Ball explain,

A second gap in teacher education lies between reform visions of teaching and the traditional pedagogy of teacher education. Prospective and practicing teachers learn about constructivist theories of learning, communities of learners, and authentic tasks, but often the courses and workshops in which they hear about these ideas are taught in ways that do not make use of the very same ideas. With little or no firsthand experience with learning of the kind that reformers advocate, neither beginning nor experienced teachers have adequate images of what these ideas mean, what it might mean to draw on them in practice, and the complications they raise for teaching and learning. (p. 39)

The planning and design of the Powerful Learning Lab incorporates the establishment of a learning community or what Goodlad (1994) described as a 
"center of pedagogy" (p. 2). The longitudinal nature of PLL may have implications for redesign of teacher preparation programs. So while the study is an investigation of a specific treatment, that of the PLL, I believe the lessons learned from teachers in the center of school reform in a challenging setting will have implications for teacher preparation programs. The Accelerated Schools Project is organized through regional satellite centers that are associated with universities that provide teacher preparation programs. The findings of this study will inform those programs. This rationale is even more critical now than when the data was collected, as a key component to the 2002 reauthorization of ESEA, "No Child Left Behind" is that all schools will employ "highly qualified" teachers (Olson, 2002, p. 1).

To Inform School Leadership

This study is based on the premise that if student performance is to improve, then teacher performance must also increase or improve. If school leaders are interested in improving teacher performance, then school leaders need to understand teacher behavior, beliefs, and learning. School leaders must be leaders of teachers. The instructional leadership role for a school principal or superintendent is paramount to improving student achievement. Often it is difficult for a school principal to be perceived as a strong instructional leader by teachers, especially if his or her classroom experience was limited. School principals must 
be able to facilitate teacher learning in order to assume that instructional leader role. This study informs school leaders about teacher learning.

Another premise is the often-repeated practitioner belief that educational policies, superintendents, and administrators may come and go, but what really happens between students and teachers is between students and teachers. Wang, Haertel, and Walberg (1993-1994) concurred that state-level policies and district demographics were the least influential of 28 categories that improve student learning in their meta- analysis of student achievement. The same study isolated twenty-eight categories that influence student achievement. Those twenty-eight categories were grouped into six broad types of influences, with classroom instruction and climate being the largest broad area. Wang et al. state,

When averaged together, the different kinds of classroom instruction and climate had nearly as much impact on learning as the student aptitude categories. The most influential category (within classroom instruction and climate) was classroom mànagement, [which includes] group alerting, learner accountability, smooth transitions, and teacher 'with-it-ness') Effective classroom management increases student engagement, decreases disruptive behaviors, and makes good use of instructional time. (p. 76).

Wang et al. continue to further define the importance of student teacher social interactions, quantity of instruction, classroom climate, classroom instructional strategies, academic interactions, and classroom assessment as part of the classroom instruction and climate group. Each of these categories operationalizes the practice of teaching and highlights the importance of the 
teacher's role in improving student achievement. Goodlad (1994); Haberman (1995); Hawley \& Rosenholtz (1984); Sykes (1999), all determined that teachers play the most significant role in student achievement.

Blair (2000) reports about a study on teacher quality and test scores,

In sum, this study shows not only that teachers matter most, but how they most matter. .... What really matters is not where teachers come from, but what they do in the classroom. ${ }^{4}$

Since the research defends that teachers are the most influential factor in student achievement, it makes sense that school leaders should be informed about teacher's perceptions about teacher learning. This study provides descriptions and details to school leaders about these perceptions and conditions for teacher learning.

Since teachers are the most prevalent players in school improvement, studies that examine real teacher's lives and tell their stories are particularly of value to other teachers. They are also the most trusted and believed source of information for classroom teachers about teacher learning (Putnam \& Borko, 2000). Teachers trust other teacher's testimony more than statistical data. In Putnam and Borko's study they define teacher cognition in three conceptual circles. They define cognition as 1) situated, 2) social, and 3) distributed. The design of this study meets all three cognition concepts, as both the interviews and the Powerful Learning Lab are situated in the authentic context of the regular teacher's work; their learning in the Powerful Learning Lab is social as teachers are expected 
to participate in reciprocal teaching, cooperative learning, and peer coaching activities; and it is distributed, as the lab participants are part of a school group and district engaged in ASP, not just isolated individual teachers. Because this study employs all of Putnam \& Borko's (2000) conceptual circles of cognition, the results of the study should at minimum inform the teachers and leadership of the Hazelton district, and more likely inform a broader audience of teachers and school leaders as well.

\section{Methodology}

This qualitative multiple-case study utilizes ethnographic techniques: in depth teacher interviews, classroom observations, and examination of participant artifacts (portfolios). The sample size was fifteen classroom teachers in grades K-8 at the elementary and middle school level. The sample was purposive rather than random. Purposive sampling is a consistent sampling strategy in qualitative research. The sample was defined by its work group, all members of the sample were in one school district, and sample participants attended the lab voluntarily (Miles \& Huberman, 1994). The district received CSRD grant funds. All participants work in schools which employ the ASP process and are characterized by high poverty and ethnic diversity in an urban setting. A complete discussion of the methodology of the study follows in Chapter III. 


\section{Powerful Learning Lab Organization}

Participants volunteered to attend the Accelerated Schools Powerful Learning Lab, which was a professional development cohort that met for a span of eight months from August 2000 through March 2001. Participants completed assignments outside of the lab meeting times through June of 2001. The face-toface duration of the lab was four two-day laboratory sessions (total of eight days) conducted at Portland State University. Following each of the lab sessions (two days in August, October, January, and March respectively) the participant teachers taught lessons that were planned during the labs, collected student work samples, observed peers during their teaching, debriefed with peers, and completed a written personal reflection about the lesson. Lessons were planned integrating the Accelerated Schools Project Powerful Learning Framework (see Appendix A) and strategies from Joyce, Weil \& Calhoun's (2000) Models of Teaching $\left(6^{\text {th }}\right.$ Ed). The decision to use Models of Teaching was a modification of an earlier course designed by Chenoweth (Theory of Instruction, 1992). Incorporating the reciprocal teaching strategies employed in Chenoweth's Theory of Instruction course and the Models of Teaching text was a critical decision made to provide more specificity to the Powerful Learning framework. Joyce, Weil, and Calhoun described teaching strategies in four families: social, information-processing, personal, and behavioral. All of the lesson plans, student work samples, debriefing notes, and personal reflections were archived in each participant's Powerful Learning Lab Portfolio 
(Appendix B). I co-developed the Powerful Learning Lab Portfolio with the National Center for Accelerated Schools. This was a pilot version of the portfolio, so lessons learned from this study will greatly influence further development of the portfolio and the Powerful Learning Lab.

The sample represented four school teams (three elementary and one middle school) who have participated in the Powerful Learning Lab since August 2000.

The data collection took place after the cohort's third meeting in January 2001, and continued through January, 2002. My role as researcher was a participant-observer. Data were collected over a ten month time period, with the majority collected in the spring of 2001. Preliminary data was analyzed, and I kept a journal of early findings. Methodology details are further described in Chapter III.

\section{Summary}

Hazelton was the first K-12 school system in Washington to have all of its schools involved in compatible comprehensive school improvement designs. Furthermore, leadership is stable and supportive. Studying the influence of comprehensive school reform (specifically ASP and participation in PLL) on regular teacher practice in an ethnically diverse, high poverty, and urban school district provides us with significant answers about how to improve our nation's low achieving urban schools. 
Subsequently, lessons learned from teachers who are in the crux of school reform, in what many consider a challenging environment, may help shape teacher preparation programs at a time when the nation is facing an enormous teacher shortage. Since the samples studied represented a recent group of first and second year teachers, their story is particularly important to teacher preparation programs as they represent one of the most recently graduated classes of teachers.

Similarly, as Putnam and Borko (2000) note, teachers listen to other teachers. They are more moved by colleagues' stories than statistical data (Darling-Hammond \& Sykes, 1999; Haberman, 1995; Putnam \& Borko, 2000; Sykes, 1999). So sharing stories of teachers who struggle with school improvement with other teachers in similar situations should help existing teachers examine and improve their practice.

Additionally, school leaders, school principals in particular are expected to be instructional leaders. For school principals to lead instruction in schools they must understand the classroom teacher's experiences, especially when many principals have limited classroom experience themselves. It is imperative for school principals to learn from research and literature about teacher learning if they desire to affect teacher learning.

Finally, as the Accelerated Schools Movement rides the "third wave" and even pushes toward a fourth (yet-to-be-defined) wave of school improvement, there is a compelling need to gather data about what works and what doesn't. Never has 
there been a more critical time for ASP to directly address how schools cope with the ambiguous rhetoric of acceleration and powerful learning. The Powerful Learning Labs are based on a constructivist instructional theory; this study was a small attempt to see if theory and policy can indeed influence practice and perhaps begin to answer "why" or "why not". Chapter II explores the literature related to comprehensive school reform, the Accelerated Schools Project, and teacher learning. Chapter III describes the methodology of the study. Findings are presented in Chapter IV, and Chapter V contains further discussion, recommendations and suggestions for future research. 


\section{End Notes}

1. In January, 2002, President George Bush signed the reauthorization of ESEA into law; this law retained the Comprehensive School Reform funding (dropping the $\mathrm{D}$ for demonstration, as the grants are no longer considered demonstration grants). This act is commonly referred to in press as the "No Child Left Behind" Act. See, for example, Olson, L. (2002, January 16) States gear up for new federal law. Education Week for example.

2. For example: U.S. Department of Education studies related to the assessment of Title 1 (1996), Kirst (1990), and Passow (1990), Olson and Rothman (1993).

3. A more complete discussion of first, second and third wave of school reform is provided in Chapter II.

4. Blair, J. (2000, October 25). Citing author, Harold H. Wenglinsky in his report "How Teaching Matters: Bring the Classroom Back into Discussions of Teacher Quality" in "ETS Study Link Effective Teaching Methods to Test-Score Gains" in Education Week, 20 (8), 24 


\section{CHAPTER II}

\section{REVIEW OF THE LITERATURE}

We will fail....to improve schooling for children until we acknowledge the importance of schools not only as places for teachers to work but also as places for teachers to learn.( Smylie, $p$. 92)

\section{Introduction}

This study is based on the premise that if student performance is to improve, then teacher performance must also improve. Thus the investigation centered on the actions of teachers who participated in school improvement by volunteering to participate in the Accelerated Schools Project Powerful Learning Lab, which was a professional development cohort that met for most of a school year. Goodlad (1994), Haberman (1995), Hawley and Rosenholtz (1984), and Sykes (1999), all determined that teachers play the most significant role in student achievement. This study examined the plans, teaching, assessments and reflections of teachers in the middle of comprehensive school improvement through their eight-month participation in the Accelerated Schools Project Powerful Learning Lab (PLL). The Powerful Learning Lab is in the early research and development phase as a response to criticism that "first wave" schools neglected the core technologies of teaching and learning (Bradley \& Olson, 1993; Garmston \& 
Wellman, 1999; Hess, 1999; Hill, et al., 2000; Slavin,1998). The Powerful Learning Lab integrated the powerful learning framework, developed by the National Center for Accelerated Schools, which is based on constructivist learning principles.

The context of this study is a poor, diverse, urban and relatively small (2500 student) district. While the students in the Hazelton District are poor reflected by a high free and reduced lunch percentage (58\%), at the time of the study the district was relatively well-funded. All five schools have been recently rebuilt or extensively remodeled, there is excellent access to technology, and class size is not high. The importance of context in ethnographic studies has been documented for decades (Bradley, 1999; Bradly \& Olson,1993; Lortie, 1975; Spindler, 1982). As Comprehensive School Reform designs are becoming more prevalent in the last decade, there is a need to determine which designs are appropriate in which specific contexts. Olson (1999) explains, "The next educational frontier is determining which designs work under what circumstances" (p. 28). While this study did not examine other designs, it does inform as to whether or not the Accelerated Schools Project is making a difference in teachers' practices in a poor, urban and diverse setting.

The areas of research related to the study explored in this chapter are: 1) School Improvement (specifically principle-based reform and the Accelerated Schools Project), 2) Teachers as Constructivists, 3) Adult Learning, 4) Teacher Development, 5) Professional Development and 6) the Context of Poverty. 


\section{School Improvement}

School improvement or school reform is complex and messy. The term "reform" presupposes that current school organization, pedagogy, or student achievement is inadequate, thus needing reformation. School improvement is somewhat more palatable than "school reform" to practitioners as it honors the possibility that some organizational elements might be successful while others need improving. This study will use the terms school improvement and school reform, interchangeably, recognizing that the literature reviewed is often located by researching school reform as well as school improvement.

School improvement is hardly a new topic; American school improvement has been called for almost since the inception of the free public school. As far back as the turn of the $19^{\text {th }}$ century, education and business leaders were demanding school reform. John Dewey, a progressive educator and professor of philosophy, psychology, and pedagogy at the University of Chicago (1894-1904) and Columbia University (1904-1931) lectured, wrote about, and implemented school reform. Dewey tested his theories of educational principles in the famous Laboratory School established by the University of Chicago in 1896. Dewey's principles emphasized a child-centered curriculum of real world problem-solving and authentic learning where students were actively engaged in learning. The rhetoric of Dewey's time is echoed in many school improvement efforts, including the Accelerated Schools Project. 
Dewey's many writings (e.g., Democracy and Education, The School and Society, The Child and the Curriculum, and Experience and Education) all have a reform agenda. Dewey is often associated with the progressive or pragmatic education movement. Progressive education moves away from a traditional education [where the learner was a passive recipient of a well-defined (by textbook) curriculum delivered through a variety of experiences designed by a teacher], toward a more child-centered curriculum where students were engaged in problem solving related to authentic world issues. However, in his later work Experience and Education (1938) Dewey proclaimed that neither traditional education nor progressive education alone would meet the needs of future learners, but an application of both would be necessary. Dewey believed students and educators must learn from the past in order to be better situated for success in the present and the future. It is the quality of experiences that determine whether or not a person would be educated. Dewey (1938) described this dilemma,

Hence the central problem of an education based upon experience is to select the kind of present experiences that live fruitfully and creatively in the subsequent experiences. (p.7)

In many ways Dewey called for a balance of educational theory that doesn't box in educators to an either/or dichotomy, but rather he embraced what now would be considered a more ecological perspective (Darling-Hammond \& Sykes, 1999; Lambert et al., 1995; Wheatley, 1999) to educational reform that takes into consideration the best of the past, the context of the present, and the need to combine both to meet the demands of the future. An ecological perspective views 
schools and learning as an ecological system that includes concepts such as: interdependence, sustainability, cycles (learning cycle), energy flow (construction of meaning), partnership, and flexibility. Wheatley (1999) explains that using an ecological perspective or ecological thinking toward school reform requires us to perceive the reform as "systems" rather than "isolated parts"( p. 158). The literature on learning communities (Boyer, 1995; Senge, 1990; Sergiovanni, 1994; Wheatley, 1999) supports an ecological or systemic view of school improvement. While Dewey's ideas and progressivism are similar to many comprehensive school improvements today, work during other decades have also contributed to the knowledge base of school improvement. School improvements in the 1930's through the 1950 's were heavily concentrated in ideas and theory, still referred to as the progressive era (Calhoun \& Joyce, 1998; Garmston \& Wellman, 1999; Tyack \& Cuban, 1997). Curriculum and academic reform followed the 1957 launch of Sputnik, and many reforms aimed at the "War on Poverty" begun after 1965, such as Head Start (1965) and Sesame Street ${ }^{\mathrm{TM}}$ (1970) which attempted to better prepare students for school. The 1970s emphasized school organizational health and the stages in the change process.

Calhoun and Joyce (1998) refer to two distinct school improvement strategies of the 1980s-1990s; 1) the external Research and Design (R \& D) approach and 2) the school-based, faculty-centered approach. The simple distinction between the two is that the R \& D approach employed external experts to reinvent or improve the school, while the faculty-centered approach attempted to improve schools from 
within. These approaches are characterized more specifically in Table 2 . The Accelerated Schools Project is anchored firmly in the school-based, faculty centered approach to school improvement, yet ASP does provide external technical assistance to schools, which is an element of the R \& D approach.

During the mid 1980 's a political cry for reform resulted from response to $\underline{\mathrm{A}}$ Nation At Risk (1983), the infamous and grim report from the National Commission on Excellence in Education (NCEE) summarizing the current state of American education as, " a rising tide of mediocrity" (p.1). This shocking and later controversial assessment of the state of American public education initiated numerous changes in educational policy and served as a catalyst for more than a decade of educational improvement programs and policies. 
Table 2

\section{Comparison of R \& D and School-Based Faculty Centered Improvement Efforts}

\begin{tabular}{|c|c|}
\hline$R \& D$ Approach & School-Based, Faculty Centered Approach \\
\hline Using scholars \& experts to design programs & $\begin{array}{l}\text { Shared decision-making between teachers and } \\
\text { school administrators }\end{array}$ \\
\hline $\begin{array}{l}\text { Using in-school practitioners to field-test } \\
\text { materials and strategies, but not to design them }\end{array}$ & $\begin{array}{l}\text { Representative decision making council: Site } \\
\text { council, School Leadership Team, etc. }\end{array}$ \\
\hline $\begin{array}{l}\text { Building an in-depth, carefully rationalized } \\
\text { curriculum }\end{array}$ & $\begin{array}{l}\text { Site based decision making required school } \\
\text { board approval }\end{array}$ \\
\hline $\begin{array}{l}\text { Studying the knowledge base internal \& } \\
\text { external to education for information, } \\
\text { instructional strategies and materials to support } \\
\text { student interaction with this curriculum }\end{array}$ & $\begin{array}{l}\text { Site based decision making teams have some } \\
\text { or great budget control }\end{array}$ \\
\hline $\begin{array}{l}\text { Maintaining high levels of quality in programs } \\
\text { materials "teacher-proofing" the curriculum }\end{array}$ & $\begin{array}{l}\text { School improvement plan generally developed } \\
\text { by site based decision making team }\end{array}$ \\
\hline $\begin{array}{l}\text { Careful field-testing of developed materials and } \\
\text { instructional strategies }\end{array}$ & $\begin{array}{l}\text { Schools often belong to a network of similar } \\
\text { schools }\end{array}$ \\
\hline $\begin{array}{l}\text { Lessons Learned: } \\
\text { - Products developed outside of schools } \\
\text { were not readily accepted or implemented } \\
\text { by teachers } \\
\text { - Top-down perception from teachers was } \\
\text { received negatively } \\
\text { - Developers greatly underestimated the } \\
\text { amount and type of training necessary for } \\
\text { implementation } \\
\text { - A number of programs were developed } \\
\text { that had substantial effects on student } \\
\text { learning where field-tests, yet these } \\
\text { programs encountered great difficulties in } \\
\text { dissemination (didn't survive in "real } \\
\text { school settings") }\end{array}$ & $\begin{array}{l}\text { Lessons Learned: } \\
\text { - Process orientation is not enough for } \\
\text { most schools, many required outside } \\
\text { facilitator } \\
\text { - Faculties need sustained technical } \\
\text { assistance over several years } \\
\text { - Few schools have the colleagueship to } \\
\text { overcome the idiosyncratic normative } \\
\text { structures and become "stuck" } \\
\text { - Few faculties pursed school wide efforts } \\
\text { in curriculum, instruction, or technology, } \\
\text { instead focusing on changing working } \\
\text { conditions or focused on externals such } \\
\text { as home environment } \\
\text { - Not enough substantive staff } \\
\text { development or follow-up support }\end{array}$ \\
\hline $\begin{array}{l}\text { Dissemination of only those programs that } \\
\text { documented positive effects on students }\end{array}$ & $\begin{array}{l}\text { Premises: school faculties have the capability } \\
\text { to engage in site based research and } \\
\text { development, organizational constraints will } \\
\text { be changed to accommodate site based } \\
\text { management, } \\
\text { External R \& D denigrates teacher capability } \\
\text { and dignity } \\
\text { Unique school problems require unique } \\
\text { solutions, which hampers unilateral practices }\end{array}$ \\
\hline $\begin{array}{l}\text { Examples: MACOS: Man : A Course of Study, } \\
\text { S-APA: Science } 0 \text { A Process Approach }\end{array}$ & $\begin{array}{l}\text { Examples: Coalition of Essential Schools } \\
\text { (CES), Accelerated Schools Project (ASP), } \\
\text { Total Quality Management (TQM), California } \\
\text { School Improvement Program (SIP) }\end{array}$ \\
\hline
\end{tabular}


School improvement designs are inextricably linked to school policy. One of the more dramatic school policy changes came with the 1994 reallocation of the Elementary and Secondary Education Act (ESEA) via the Improving America's Schools Act (IASA) and subsequently the Comprehensive School Reform Demonstration (CSRD) grants. Both these acts attempted to allow less regulation and the opportunity to combine federal educational funds for more holistic or comprehensive school reform. Passed into law in January 2002 the reauthorization of ESEA, the No Child Left Behind Act of 2001, continues CSR (the $\mathrm{D}$ is dropped as the program is no longer considered a "demonstration" program) allocations to schools. While educators are still trying to figure out the specifics of the latest ESEA reauthorization, the pendulum is swinging away from local and state control to more centralized control which by-passes the U.S. Department of Education and comes directly from the rhetoric of the oval office ${ }^{1}$.

The 1965 Elementary and Secondary Education Act (ESEA), the 1994 reauthorization of the ESEA, known as the Improving America's Schools Act (IASA), and specifically, the policy programs within the ESEA that distribute funding to schools located in the Northwest, especially the Comprehensive School Reform Demonstration (CSRD) grants (first allocated in July, 1998) are the school improvement policies directly related to the schools during the time of this study. ESEA policies such as CSRD, Schoolwide Title I, and the No Child Left Behind Act . of 2001 are sources of funding ASP technical support. A brief historical summation 
of these policies is important to understand the complexity of school improvement and the role of the context of poverty that pertains to the Hazelton School District.

The ESEA was enacted in 1965 as an attempt by the federal government to equalize resources to public schools. At this time per pupil costs ranged widely from school to school and from state to state. ESEA was the single largest federal aide to education program, in which schools impacted by poverty were to be the recipients (Lester and Stewart, 1996). Throughout the 39-year history of ESEA, policies have moved through the policy cycle (Lester and Stewart, 1996) of: agenda setting, policy formulation, policy implementation, policy evaluation, policy change, and policy termination.

The ESEA constitutes the over-arching umbrella from which other school improvement policies are found. The policies that reside under the ESEA umbrella consist of all "Title" programs, most familiar being the Title I federal program, which allocates money to schools with high free and reduced lunch programs (FRLP). Schoolwide Title I refers to schools that are at or above the 50\% FRLP, and the IASA reauthorization for Schoolwide Title I programs allowed schools to pool federal funds to provide whole school services for all children. CSRD is the more recent (1998) reallocation of ESEA. CSRD awarded a minimum of $\$ 50,000$ per school for comprehensive school improvement. Putting the $\$ 50,000$ in perspective, that is the approximate equivalent cost of one teacher with benefits. All of the Hazelton schools qualify for Schoolwide Title I funds (based on poverty) 
and all schools qualified for CSRD, yet only two schools applied for and received

CSRD. The other two schools didn't submit the paperwork, but met all the criteria.

Closely tied to the Schoolwide Title I and CSRD funding sources is the standards movement. The pervasive standards movement has been embedded in the language of Schoolwide Title I and CSRD, with often repeated phrases that reflect all students reaching high standards. Since the 1990's the standards movement has been the driving force for school improvement. The "Public Policy and School Reform" study from the University of Pennsylvania extrapolated several key themes about recent public policy and its relation to school improvement (Consortium for Policy Research in Education, 1996). Included in these themes are:

- Schools in the United States have demonstrated important, positive changes, particularly in practice, attitude and student achievement. Standards based reforms and increased professional development focused on content area contribute to the changes.

- Most states and many districts have adopted standard-based reforms, in an effort to forge more coherent policy. These efforts have faced considerable obstacles, including a lack of public consensus on what standards should be and serious shortfalls in the "capacity" of many schools to strive for higher standards.

- Educational policy has not yet provided coherent, effective guidance on how to improve instruction in the United States. Policy alone is not enough to bring about successful school reform. Other key factors include educator's knowledge and skill, the efforts of professional associates and reform organizations, and parent and community engagement. 
- Reforms are not always realistic, or based on understanding of what will actually work. Knowledge of what types of policy and education reform work in different contexts, or of how to transform successful demonstration projects into large-scale reforms, is more limited than many like to admit. This is one reason why the rhetoric or reform often exceeds the accomplishments that are actually made.

- Reformers often put too much emphasis on structural changes, such as lengthened class periods or common teaching planning time, and pay inadequate attention to highquality instruction, because they wrongly assume that structural changes will automatically boost achievement.

- Policy makers do not pay enough attention to the roles that students could play in raising their achievement. They especially neglect ways in which students' effort and readiness to learn could be improved. (p.1)

These findings support the complexity and ambiguity of school improvement. There is inherent tension when individual schools adopt school improvement models that are democratic, and designed to support site-based decision making, as these schools exist within hierarchal, bureaucratic school districts, which exist within equally hierarchal and bureaucratic state school systems. Often the districts and states are pressured to push through mandates that may conflict with school-based decision-making. The push-pull of site versus district versus state promotes interesting dynamics as the two opposing organizational elements of bottom-up and top-down must coexist.

School reform has evolved from ideas and theory to better-defined design models. Numerous school reform models have emerged in the last twenty years to accommodate the changing political and policy driven climate of public schooling. 
Many models have disappeared or appear to be withering (Atlas Communities, Audrey Cohen College: Purpose Centered Communities, Modern Red School House, Paideia ${ }^{2}$ ) while others (Success for All, Accelerated Schools, Coalition of Essential Schools) appear to be gaining momentum and increasing their membership ${ }^{3}$.

One of the lessons learned from the last decade of school reform is that individual school sites that show improvement or what Perkins (1992) calls, "victory gardens" are difficult to sustain ( p. 56). Perkins refers to small, isolated one teacher or one school successes such as Jaime Escalante's success with poor Hispanic students learning advanced calculus as "victory gardens" or isolated plots of success. The challenge in school reform is how to bring these "victories" to scale.

The New American Schools (NAS) Corporation has become somewhat of a clearinghouse for school reform models with proven track records. NAS, a privately funded nonprofit corporation, was established in 1991 to help existing schools transform themselves into high-performing schools. NAS was founded by the chief executives of our country's most successful businesses; it is a nonpartisan, nonprofit organization that works to increase student achievement through comprehensive school improvement.

New American School's first initiative was originated to support and document four stages of school improvement utilizing whole-school designs: 1) the competition phase (1991), included a request for proposals (RFP) where 
comprehensive school reform designs competed for funding, 2) the phase for further design development (1992-93), where these design teams were awarded funds to further develop their designs, 3) a demonstration phase (1993-95), where the designs were implemented in real schools, and 4) a scale-up phase (19951997). Scale-up is defined as the process of taking whole school improvement designs to multiple schools (Bodilly, 1998). While ASP was not one of the original (1991) designs that received funding from NAS, the scale-up phase research conducted by RAND on the NAS designs greatly enhanced the development of the ASP design model. In November 2000, the Accelerated Schools Project was approved as a NAS comprehensive school improvement design.

Another descriptor of the range of school reform or improvement efforts since Nation At Risk, is first, second and third wave reforms (Hess, 1999) (see Table 3). Hess cites Passow (1990), Kirst (1990), and Olson and Rothman (1993) as designating first wave reforms as ones that focus on delivery systems, especially curriculum reform, longer schools days and school years, more highly qualified teachers (primarily Master's degree programs), and more homework. 
Table 3

First, Second and Third Wave School Improvement Designs

\begin{tabular}{|c|c|c|c|c|}
\hline Wave & Characteristics & Example & $\begin{array}{l}\text { Limitations \& } \\
\text { criticism }\end{array}$ & $\begin{array}{l}\text { Further } \\
\text { reading }\end{array}$ \\
\hline First & $\begin{array}{l}\text { Top-down } \\
\text { Improve existing } \\
\text { delivery systems } \\
\text { More rigorous } \\
\text { academic } \\
\text { curriculum \& } \\
\text { standards } \\
\text { Higher teacher } \\
\text { professional } \\
\text { standards } \\
\text { Longer days } \\
\text { More homework }\end{array}$ & $\begin{array}{l}\text { Attempted to } \\
\text { eliminate tracking in } \\
\text { high schools, i.e. all } \\
\text { students take algebra } \\
\text { Success for All } \\
\text { State standards } \\
\text { movement. NTE } \\
\text { required for teacher } \\
\text { licensure. District } \\
\text { wide homework } \\
\text { policies }\end{array}$ & $\begin{array}{l}\text { Top down (usually at } \\
\text { state level) ignored } \\
\text { and/or resented by } \\
\text { teachers } \\
\text { Increased drop out } \\
\text { rate. No effect on } \\
\text { instructional } \\
\text { strategies } \\
\text { No significant gain in } \\
\text { student achievement }\end{array}$ & $\begin{array}{l}\text { Passow, A. } \\
\text { (1990) How } \\
\text { it Happened, } \\
\text { Wave by } \\
\text { Wave in } \\
\text { Education } \\
\text { Reform: } \\
\text { Making } \\
\text { Sense of it } \\
\text { All }\end{array}$ \\
\hline 2nd & $\begin{array}{l}\text { School-level } \\
\text { change } \\
\text { New forms of } \\
\text { accountability } \\
\text { School } \\
\text { restructuring } \\
\text { Site-based } \\
\text { management } \\
\text { Teacher } \\
\text { empowerment } \\
\text { Teacher } \\
\text { professionalism }\end{array}$ & $\begin{array}{l}\text { Accelerated Schools } \\
\text { Project, Modern Red } \\
\text { Schoolhouse } \\
\text { Professional } \\
\text { Development plans } \\
\text { for teachers. } \\
\text { Master's Degree } \\
\text { programs for teacher } \\
\text { licensure }\end{array}$ & $\begin{array}{l}\text { School level change } \\
\text { too difficult to } \\
\text { sustain, need district } \\
\text { support } \\
\text { Principal succession } \\
\text { killed many reform } \\
\text { efforts } \\
\text { Teacher efficacy } \\
\text { required outside } \\
\text { support }\end{array}$ & $\begin{array}{l}\text { Kirst, M } \\
\text { (1990) The } \\
\text { Crash of the } \\
\text { First Wave in } \\
\text { Education } \\
\text { Reform: } \\
\text { Making } \\
\text { Sense of it } \\
\text { All. } \\
\text { And Passow } \\
\text { (1990) }\end{array}$ \\
\hline $3 \mathrm{rd}$ & $\begin{array}{l}\text { Clusters of schools } \\
\text { and whole district } \\
\text { school reform } \\
\text { (systemic } \\
\text { reform).Decentrali } \\
\text { zation of power \& } \\
\text { resources } \\
\text { Increased teacher } \\
\text { planning \& } \\
\text { preparation time. } \\
\text { Teacher role shifts } \\
\text { toward facilitator } \\
\text { Alternative } \\
\text { assessments } \\
\text { Grouping } \\
\text { strategies } \\
\text { Team teaching }\end{array}$ & $\begin{array}{l}\text { District wide reform } \\
\text { strategies, i.e. Dade } \\
\text { County schools } \\
\text { adopted SFA. } \\
\text { Reauthorization of } \\
\text { Title I funds for } \\
\text { more teachers, fewer } \\
\text { administrators } \\
\text { Multiple assessments } \\
\text { (portfolios) } \\
\text { Cooperative learning } \\
\text { groups }\end{array}$ & $\begin{array}{l}\text { Current wave, } \\
\text { criticism yet to be } \\
\text { described }\end{array}$ & $\begin{array}{l}\text { Olson \& } \\
\text { Rothman } \\
\text { (1993)). The } \\
\text { Road Map to } \\
\text { Reform. In } \\
\text { From Risk to } \\
\text { Renewal: } \\
\text { Charting a } \\
\text { Course for } \\
\text { Reform. } \\
\text { Washington, } \\
\text { D.C. : } \\
\text { Education } \\
\text { Week. }\end{array}$ \\
\hline
\end{tabular}


Second wave programs emerged in the late 1980's, and focused on organizational elements of school-level changes, such as: new forms of school accountability, site-based management, school restructuring, and teacher empowerment. Second wave reforms emphasized the need to remake schools from within, one building at a time. The Accelerated Schools Project was initiated as a second wave reform effort. However, feedback and evaluations from those early ASP schools indicated the need to move to a more direct focus on teaching and learning.

Third wave reforms were premised on the failure of the first two waves, because these waves lacked sensitivity to district level or systemic reform. Olson and Rothman (1993) describe third wave reforms as ones which typically included: decentralizing power within school districts, increasing time for teacher planning and preparation, changing the classroom role of the teacher from lecturer to facilitator, emphasizing problem-solving skills, using alternative assessments, grouping students, integrating more small group and tutorial instruction, and clustering teachers into teams.

Therefore the quest for school improvement has been a challenge for at least seventy years. The political and social climate that underlie improvement has changed and will continue to change. The dynamics of the Hazelton School District set in what many would consider extreme challenges (urban, poor, and extremely diverse) make it an interesting site for study. The fact that a highly challenged district selected what Calhoun and Joyce (1998) and Slavin (1998) 
consider a difficult model make Hazelton all the more interesting. Calhoun and Joyce and Slavin consider ASP difficult, because it relies on the capacity of the professionals in schools to create and sustain informed change, rather than simply implement what Levin ${ }^{4}$ calls a "cookie cutter" and Slavin (1998) calls "a brick," packaged programs that can be almost teacher-proof. The following section explores in more detail the infrastructure of principal-based school improvement and specifically the Accelerated Schools Project.

Principle Based Reform and the Accelerated Schools Project

Hazelton School District selected two high-quality, philosophically compatible reform models for comprehensive school reform: Coalition of Essential Schools (CES) for the high school, and the Accelerated Schools Project (ASP) for the district's middle school and three elementary schools. These models are both democratically based, emphasizing investments in people, process, dialogue, and change over investments in products such as curriculum materials. These processoriented reform models are very similar. Both CES and ASP adhere to core principles that determine the course of decision-making at the organizational, instructional and curricular levels.

These core principles are intended to serve not as a blueprint for education reform, but as a set of guidelines to help schools redesign themselves. These principles form the basis for on-going staff dialogue about school improvement. While both reform models have unique vocabulary and components, there is a core 
principles form the basis for on-going staff dialogue about school improvement.

While both reform models have unique vocabulary and components, there is a core of common, salient values, so that district wide implementation of these two models should be cohesive. ASP is a non-prescriptive model, or as Chenoweth and Petti (2000) describe, a "principle-based" model. Calhoun and Joyce (1998) refer to this type of model as school-based, faculty-centered. Principle-based models support much higher teacher efficacy than more prescriptive school improvement designs. Both principle-based and school-based models emphasize teacher and school community intelligence to solve their own problems. Both models require higher levels of teacher professionalism and commitment; district support; and outside mentoring. These factors, identified by Bodilly (1998) that support implementation, appear to be in place. Chenoweth and Petti reported that six of seven factors, previously identified by Bodilly as supporting implementation, appeared to be in place (see Table 4).

Table 4

Bodilly's (1998) District Factors that Support School Reform Implementation

\begin{tabular}{|l|l|}
\hline Factor & In Place in Hazelton \\
\hline Central Placement of Effort & Yes \\
\hline Stable Leadership (superintendent) & Yes \\
\hline Lack of Crisis & No \\
\hline Culture of Cooperation \& Trust & Yes \\
\hline School Authority/Autonomy & Yes \\
\hline Available Resources & Yes \\
\hline Aligned Assessments & Yes \\
\hline \multicolumn{2}{|l|}{ Note: Originally reported in Chenoweth \& Petti, 2000, p. 14-19 }
\end{tabular}


This study examined what teachers in ASP schools are experiencing as they implement principle-based, district wide school improvement. The context of the four schools in this study is that of poverty, diversity, and urbanity. Building on Bodilly's work, Chenoweth and Petti (2000) developed a continuum, which described school improvement designs as either prescriptive or principle-based.

As opposed to principle-based reforms, prescriptive reforms (e.g., Success for All, Core Knowledge) espouse that school reform needs to be explicit or prescriptive to achieve results. Bodilly described these prescriptive reform models as keyed to specific tasks and instructional practices (e.g. content or curriculum). In contrast Bodilly described principle-based reform efforts as ones that call for the professional development of teachers which leads practitioners to define tasks and processes themselves. Bodilly (1998) described prescriptive reforms as those keyed to "quickly implemented, task level change to core elements", and principlebased reforms as those keyed to "longer-term change and building school level capacity to promote self-improvement" (p. 113). ASP and CES are principle-based reform models. These guiding principles drive decision-making, structural design, human resources, political and symbolic leadership, which are "frames" of organizational theory (structure, human resource, political, and symbolic) discussed by Bolman and Deal (1997).

While the Hazelton district implemented both CES and ASP, two principlebase reform designs, for the purpose of this study (which examines the planning, actions and reflections of elementary and middle school teachers) the Accelerated 
Schools Project reform design was the only design model that was studied. The remaining section of this chapter will focus on the Accelerated Schools Project design.

The Accelerated Schools Project (ASP) originated in research on the demography and educational outcomes of at-risk students conducted by Dr. Henry Levin, then of Stanford University, and his colleagues. The resulting two nationally acclaimed reports ${ }^{5}$, The Educationally Disadvantaged: A National Crisis (1985) and Educational Reform for Disadvantaged Students: An Emerging Crisis (1986), revealed an emerging crisis in educating students in at-risk situations.

Students who were determined to be in at-risk situations were those who were unlikely to succeed in school as they brought a different set of skills, resources, and experiences than those on which school success is traditionally based. These students were caught in a mismatch between home experience and school expectations. The students most likely to be in a situation at-risk were those who were poor, or attended Title I schools. It was clear that the number of such students was large and increasing, and existing approaches to address their needs were mostly unsuccessful. These findings were consistent with the landmark report, A Nation at Risk (1983), which states,

The educational gaps between advantaged and disadvantaged students are huge, handicapping poor children in their pursuit of higher education, good jobs, and a better life. In today's schools, far too many disadvantaged and minority students are not being challenged. Far too many are left to fend for themselves when they need instruction and direction from highly qualified teachers. Far too many are passed from grade to grade, left to sink or swim. 
Far too many are advanced without ever learning how to read, though proven methods of teaching reading are now well-known. They are given shoddy imitations of real academic content, today's equivalent of Jim Crow math and back-of-the-bus science. (p. 4)

However, the recommendations from A Nation at Risk, are considerably different than the philosophy of ASP. The 1983 report recommended changes in content, expectations, time, and teaching. While these areas may sound comprehensive in reality the report resulted in increased seat time in core subjects for high school students, increased homework, a longer school day and year, and more rigorous teacher preparation requirements, such as the implementation of the National Teachers' Exam. The result was still a fragmented approach to school improvement as evidenced by criticism of first wave school improvement efforts (see Table 2).

ASP focuses on whole school transformation including curriculum, instruction and organizational structures. Ultimately, Levin's research led to the development of a model of school transformation built upon the ideal that all children's learning should be accelerated rather than remediated, and that all members of the school community share responsibility and are empowered to create such a school. The model uses the term "accelerated" because in order for students who are behind to achieve the goal of being at grade level by the end of their tenure in a school, their learning must be accelerated rather than remediated. This acceleration occurs when schools employ the strategies that are proven best 
practice for gifted children to all children. The first Accelerated Schools were launched in 1986 in the San Francisco area.

Becoming an Accelerated School requires a total transformation of the school's culture, organization, and teaching in order to assure that all students succeed. The ASP design model moves the school through the necessary steps to make this transformation: taking stock, forging a vision, creating a participatory governance structure, and creating powerful learning opportunities for every student. The school organizes instruction around standards and powerful learning experiences for all students, i.e. instruction that includes the five powerful learning components and embeds the powerful learning framework (see Appendix A).

In ASP a prescribed curriculum is not provided, as the focus of ASP is on building teachers' capacity to make effective decisions about curriculum content, instructional strategies, and the context of instruction. ASP recognized that teachers and students differ considerably, as do their communities. One size does not fit all teachers, students or communities, so the ASP model is about making informed, articulated choices about content, instruction and context. Currently there are over 1300 Accelerated Schools across the United States and approximately 100 international schools. These schools most frequently serve some of the nation's poorest and most underserved students. There are five components of ASP described in this chapter: 1) Guiding Principles, 2) Values, 3) Powerful Learning Framework, 4) The ASP Structure, and 5) The ASP Process. 
1. Guiding Principles: These three principles form the philosophical foundation for decision making in the school.

- Unity of Purpose: In accelerated schools, all members of the school community share a dream for the school and work together toward a common set of goals that will benefit all students.

- Empowerment Coupled with Responsibility: Every member of the school community is empowered to participate in a shared decisionmaking process, to share in the responsibility for implementing these decisions, and to be held accountable for the outcomes of these decisions.

- Building on Strengths: In creating their dream school, accelerated school communities recognize and utilize the knowledge, talents, and resources of every member of the school community. Often in the quest to place blame for the failed achievement of students there is a desire to define weaknesses and ignore strengths. The ASP philosophy recognizes that all students, teachers, and communities have strengths, and through the development of those strengths students can truly be accelerated to achieve at higher levels. In the ASP philosophy it is not the students themselves who are "at-risk" but they are often in "at-risk situations" (Hopfenberg \& Levin, 1993). One of the transforming goals of ASP is to eliminate the school as an "at-risk situation" and in many 
ways ASP schools need to reorganize to be ready for all learners, rather than place readiness as a responsibility of the students.

2. Values: There are nine inherent values of the Accelerated Schools Project. These values are critical aspects of school improvement, as many researchers have indicated that unless there is a clear fit with individual's values, school improvement efforts almost always fail (Fullan 1993; Chenoweth \& Kushman 1996; Calhoun \& Joyce, 1998). The nine values of ASP are: equity, communication and collaboration, community spirit, participation, school-as-thecenter-of-expertise, reflection, risk taking, experimentation and trust (Hopfenberg \& Levin, 1993). Hargreaves and Fullan (1998) note that most educational improvement efforts fail, as the designers fail to note the power of individual beliefs, attitudes, and values.

3. Powerful Learning Framework: In accelerated schools, the best research and practice in education that is usually reserved for gifted and talented students is shared with all students. The school community commits to transform every classroom into a powerful learning environment where students and teachers are encouraged to think creatively, explore their interests, and build their capacity to achieve at high levels. Teachers and staff participate in professional to incorporate the five descriptors of powerful learning: authentic, interactive, learner-centered, inclusive, and continuous. (See Appendix A) Through the multi-year implementation of powerful learning professional development, teachers get involved for continual improvement of the teaching and learning process. 
4. The Accelerated Schools Structure: ASP as a school improvement design incorporates three elements of comprehensive reform: school curriculum, classroom instruction, and organizational structures. (See Figure 1.) These elements represent the integrated and complex elements that typically are challenges for schools. ASP schools continually measure their curriculum, instructional practices and organization against the schools' vision, determining if the school is transforming in alignment with established priorities. Early Accelerated Schools spent too much time on the organizational side of the ASP triangle, and delayed addressing curriculum and instruction issues. We now understand that curriculum alignment to standards and instruction must be addressed early in the ASP process.
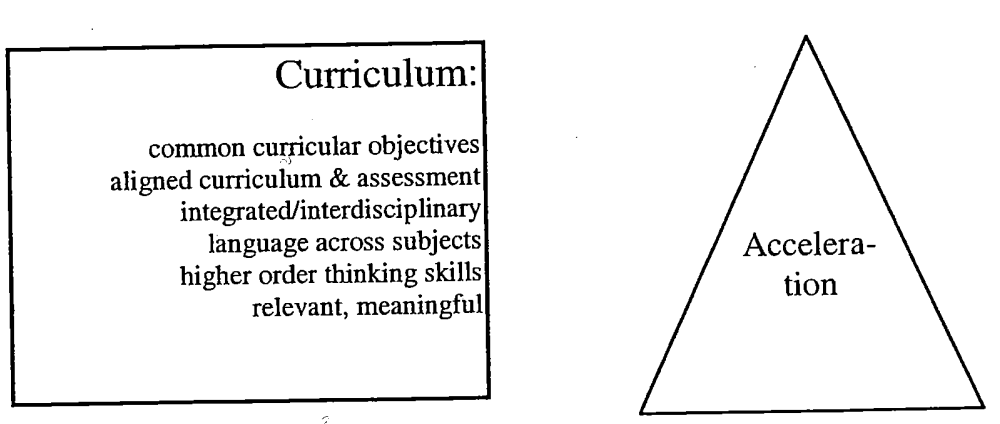

Instruction: active learning primary sources projects \& problem based learning peer tutoring cooperative learning integrated technology authentic assessment heterogeneous groupings affective \&

emotional intelligence strategies

\begin{tabular}{|c|}
\hline Organization: \\
collaborative decision-making \\
parents in partnerships \\
flexible scheduling \\
faculty committees for inquiry \\
central office staff collaboration \\
principal as facilitator \\
community resources
\end{tabular}

Figure 1. The Accelerated schools structure. Based on original diagram in the Accelerated Schools Resource Guide (1993), p. 161. 
5. The Accelerated Schools Process: Accelerated school communities use a systematic process involving collaborative and informed decision-making to transform an entire school rather than focusing on a particular grade, curriculum, or approach to teaching. The transformation begins with the entire school community taking a deep look into its present situation through a process called taking stock. The entire school community then forges a shared vision of what it wants the school to be. By comparing the vision to its present situation, the school community idéntifies priority challenge areas. Groups then set out to address those priority challenge areas, working through an accelerated schools governance structure and analyzing their challenge areas using the inquiry process. The inquiry process is a systematic method that helps school communities clearly understand problems, find and implement solutions and then assess the results. (See Appendix D.) The next section builds on the ASP framework for powerful learning, which was developed on constructivist ideas about teaching and learning.

\section{Teachers as Constructivists}

Given the premise that better teachers make better schools and contribute to higher student achievement, this study examines the thinking, behaviors, and reflections of regular teachers who are committed to an eight-day, eight-month professional development cohort with the Accelerated Schools Powerful Learning Lab. The study's participants were also required to teach ten lessons beyond the 
eight-day face-to-face sessions in the PLL. This PLL was designed in response to ASP's efforts to move its design into the third wave (Hess, 1999), and to respond to criticism that the Accelerated Schools Project was too process-oriented and failed to address the "core technologies" of teaching (Slavin,1998).

Core technologies are typically referred to as the acts of planning, teaching, assessing, and reflecting of classroom teachers (Bodilly, 1998; Garmston \& Wellman, 1999; Hess, 1999). The Accelerated Schools Project philosophy concurs with Lambert et al. (1995), "The lives of children and adults are inextricably intertwined."' (p. xi). In other words, as we come to understand "best practice" (Zemelmen, Daniels \& Hyde, 1998) for children, those practices should reflect what is best for adults as well. Therefore, the planning of the Powerful Learning Lab reflects regular teachers experiencing powerful learning as well. The Powerful Learning Lab is intended to model and support the five components of powerful learning for the teacher participants, as well as have a ripple effect into those teachers' classrooms.

One premise of the development of ASP's Powerful Learning Lab, and indeed this study, is for teachers to become constructivist teachers, they must experience learning in a constructivist manner. Therefore the entire planning of the lab, and its teacher portfolio (see Appendix C) was for the teacher to experience the learner role through the constructivist paradigm. Barbara Talbert Jackson, explains, 
The first is that in order for learning to take place in schools, teachers must become constructivists, that is, in the classroom, they must provide a learning environment where students search for meaning appreciate uncertainty, and inquire responsibly. ${ }^{6}$

The lab reflects this thinking, with the participant teachers in the role of student. It was the intention of the Powerful Learning Lab for teachers to become immersed in the overarching principles of constructivist pedagogy. The teachers must experience constructivist learning in order to embrace it. These constructivist principles are described in Brooks \& Brooks (1993).

Five Overarching Principles of Constructivist Pedagogy

"1. Posing problems of emerging relevance to learning

2. Structuring learning around "big ideas" or primary concepts

3. Seeking and valuing students' points of view

4. Adapting curriculum to address students' suppositions

5. Assessing student learning in the context of teaching These principles are addressed specifically in the Powerful Learning Lab as illustrated in Table 5 . 
Table 5

Five Principles of Constructivism and ASP Powerful Learning Lab

\begin{tabular}{|l|l|}
\hline Principle of Constructivism & Powerful Learning Lab \\
\hline $\begin{array}{l}\text { Posing problems of emerging relevance to } \\
\text { learning }\end{array}$ & $\begin{array}{l}\text { Teachers given problem of designing, } \\
\text { implementing, assessing and reflecting } \\
\text { on lessons that integrate ASP Powerful } \\
\text { Learning Components \& strategies } \\
\text { from Models of Teaching }\end{array}$ \\
\hline $\begin{array}{l}\text { Structuring learning around "big ideas" or } \\
\text { primary concepts }\end{array}$ & $\begin{array}{l}\text { All lessons, activities and research are } \\
\text { centered on 5 components of PL, the } \\
\text { "big ideas" about best practice }\end{array}$ \\
\hline Seeking and valuing students' points of view & $\begin{array}{l}\text { The lab is designed for continuous } \\
\text { participant teacher input, participating } \\
\text { teacher model strategies for other } \\
\text { teachers during the lab, and a } \\
\text { debriefing seminar is held, soliciting } \\
\text { input from entire cohort }\end{array}$ \\
\hline $\begin{array}{l}\text { Adapting curriculum to address students' } \\
\text { suppositions }\end{array}$ & $\begin{array}{l}\text { Thumbnail curriculum is planned, but } \\
\text { through teacher sharing of progress and } \\
\text { results, curriculum is modified to meet } \\
\text { group's and individual's needs. }\end{array}$ \\
\hline $\begin{array}{l}\text { Assessing student learning in the context of } \\
\text { teaching }\end{array}$ & $\begin{array}{l}\text { Teachers participate in peer observation } \\
\text { \& coaching, self reflection, and group } \\
\text { debriefing throughout the sample } \\
\text { lessons }\end{array}$ \\
\hline
\end{tabular}

The stated purpose of the Powerful Learning Lab is to improve instruction.

Underlying this simple, yet lofty purpose is the foundation of constructivist

learning theory. The literature on constructivism is extensive, even though the term

constructivism has been used for less than a few decades. Defining

"constructivism" is somewhat like pinning Jell-O to a wall. There are many

definitions, description and metaphors for a term that is widely circulated in

education, yet somewhat difficult to pinpoint. David Perkins (1999) attributes D.C.

Phillips ${ }^{7}$ as identifying three distinct roles of constructivism: 
1. The Active Learner: Knowledge and understanding are actively acquired. This role conjures a learner who is discussing, debating, hypothesizing, investigating, and interacting.

2. The Social Learner: Knowledge and understanding are socially constructed. This role explains the emphasis on cooperative learning strategies, group investigation and inquiry, and interactive learning.

3. The Creative Learner: Knowledge and understanding is created or recreated. This role depicts the learner as an active participant in the creation of products and curriculum in an interested based, learner-centered, integrated way.

There may be considerable debate on the semantics of constructivism, and whether it is a learning theory, epistemology, or even an instructional strategy. Brooks and Brooks (1999) define constructivism as " a theory of learning that describes the central role that learner's mental schemes play in their cognitive growth" (p. 18). Scherer (1999) is more global in her discussion, "The C word that stands for constructivism stands also for its challenges to both students and teachers and for the courage that it takes to practice it" (p. 5). Scherer speaks nobly to the ambiguity and challenge of teaching with a constructivist view, there is not doubt that the $\mathrm{C}$ word's presence in educational literature, research, and dialogue is prevalent. Historically, constructivism is rooted in the learning theory of cognitive field psychology, and is influenced by social anthropology, philosophy and science 
(Brooks \& Brooks, 1993; DeVries \& Kohlberg, 1990; Freiberg \& Driscoll, 1992;

Lambert et al. 1995). John Dewey, Jean Piaget, Lev Vygotsky, Reuven

Feurerstein, Howard Gardner and Marian Diamond all fall into the constructivist camp (Fogarty, 1999).

While definitions of constructivism vary slightly, most are consistent with Cannella and Reiff ‘s (1994) and Richardson's (1997) definition that depicts constructivism as an epistemology, a learning or meaning-making theory, that offers an explanation of the nature of knowledge and how human beings learn. Constructivism purports that individuals create or construct their own new understandings through the interaction of what they already know and believe with new ideas, events, and activities in which they come in contact. The linkage of prior knowledge to new concepts, which then transforms or constructs new levels of knowledge or deeper understanding, is the basis of the constructivist premise.

This prevalent learning theory has its roots in the progressive constructivist writing of John Dewey (circa 1916-1950), and includes such scholars as: Piaget (1929), Bruner (1962), Vygotsky (1962), Gardner, (1991), Rosenshine and Meister (1992), and Lewin, Allport and Bruner (Bigge, 1999). Lambert, et al. (1995) defines constructivism as,

Based on assumptions from community of learners/leaders theory, students construct meaning from personal values, beliefs, and experiences. The development of personal schemas and the ability to reflect on one's experiences are key theoretical principles. Unlike in traditional thought, it is believed that knowledge exists within the learner. The social nature of learning is emphasized: Shared inquiry is a central activity. Multiple outcomes are expected and encouraged, 
with assessment being integral to the process. Human growth is a moral imperative. (p.5)

In the Powerful Learning Lab, Lambert's definition of constructivism is employed on the "forced fit" of the five components of powerful learning (which are big, general ideas), and the integration of historically proven teaching strategies presented in Joyce, Weil, and Calhoun's (2000) Models of Teaching. The decision to provide more content about teaching strategies that support the powerful learning framework, came from numerous suggestions from teachers who indicated they wanted to know what powerful learning looked like. We realized that we needed a vehicle for discussion and a way to apply ASP philosophy and powerful learning components to some of the existing research on best practices in education.

Models of Teaching (2000) described several teaching strategies in detail, arranging those strategies in "families". While some strategies from Models of Teaching, such as cooperative learning from the social family integrate quite easily with the interactive component of powerful learning; other strategies and families, such as the information processing and behaviorist families, created more cognitive dissonance, as the language did not fit as easily. Teachers had to really think and construct ways to link the two semantic structures of Models of Teaching and the ASP Powerful learning framework.

One example of this struggle, was when a reciprocal teaching group selected the strategy of concept attainment (which was introduced in the October, 2000) lab. Participant teachers had to identify ways in which this cognitive 
strategy integrated with the inclusive and/or continuous component of powerful learning. Through a peer-teaching demonstration, the group clearly demonstrated that some students, who previously were not perceived as smart by others, rapidly grasped the concept attainment lesson because it was demonstrated in a non-verbal way. This lesson provided an excellent example of the inclusive component of powerful learning.

Another aspect of the constructivist paradigm that permeated the Powerful Learning Lab was the establishment and maintenance of relationships. The benefit of relationships and community building, or school culture that promotes learning is strongly supported in the literature (Costa \& Garmston, 1994; Garmston \& Wellman, 1999; Lambert et al., 1995; Leithwood, Jantzi \& Steinbach, 1999; Poplin \& Weeres, 1992; Sergiovanni, 1994; Wheatley, 1999.) The Lab was designed to forge relationships both within school-site-based teams for the peer coaching activities that took place between labs, and within cross-site teams, when participants came together during the actual PLL sessions. Early feedback from lab participants indicated that this collaboration was greatly valued.

The role of language, dialogue, and writing cannot be underestimated in both constructivism and the Powerful Learning Lab. The constructivists believe that language (spoken, written, and inner) is key to learning (Bruner, 1962; Cooper, 1995; Lambert et al., 1995; Palmer, 1998; Routman,1988; Vygotsky, 1962). Dialogue, conversation, discussion and written reflection were continuously integrated into the Powerful Learning Lab's instructional practices as well as 
incorporated in the homework assigned between labs. Small group dialogue was shared and recorded for the entire group's benefit. This open participation in professional dialogue and the initiation of conversation about teaching and learning is one of the key elements of school improvement (Barth, 2001; Cooper, 1995; Darling-Hammond \& McLaughlin, 1999; Goodlad, 1994; Hawley \& Valli, 1999; Sykes, 1999).

This study was designed to explore the participating teachers' planning which is representation of their thinking, their teaching (as represented by their self reporting on the lessons, their assessments of student work and their reflections on their teaching. For as Brooks and Brooks (1999) state, "Learners control their learning. This simple truth lies at the heart of the constructivist approach to education" (p. 21). This straightforward statement supported the rationale for the study, as it is only through deprivatizing the teaching process that we can learn what teachers (who are in the crux of school reform) are learning. It is ultimately up to the regular teachers in schools across the United States to make a difference (or not) to students and student achievement. For as Hawley and Rosenholtz (1984) explain in their comprehensive review of research on alternative explanations for student achievement conducted for the U.S. Department of Education in the mid- 1980's:

In virtually every instance in which researchers have examined the factors that account for student performance, teachers prove to have a greater impact than program. This is true for average students and exceptional students, for normal classrooms and special classrooms. ... There is an enormous amount of evidence 
that teachers have a significant impact on efforts to change schools and on the nature of the students' experience, whatever the formal policies and curriculum of a school or classroom might be. (p. 3)

The Powerful Learning Lab was designed based on constructivist paradigms. Building on the constructivist learning paradigm, the PLL design was also influenced by adult learning theories. Adult Learning is explored in the next section

\section{Adult Learning}

Adult development theories are gaining more attention in cognitive psychology and research. Historically, adult learning theories and debates center on a few essential questions: Does the ability to learn diminish with age? Are there differences between the learning process of adults and children? These questions have prompted an evolving view of adult learning; that has progressed from early phase and stages of development (Levine, 1989) to the 1970's research of the andragogy theory presented by Malcolm Knowles. The ideas of self-directed learning (SDL) built upon Knowles' theory and were explored in the 1970's and 1980's. Mezirow's 1990's transformational learning was developed on the foundation of SDL and andragogy. Today twenty first century pioneers are exploring adult learning from a postmodernist perspective, including borrowed components from feminist theory and pedagogy, situated cognition, and the emerging research that integrates emotions, cognition and brain research. 
While acknowledging the foundational work of "phase and stage" theorists such as Erik Erickson, Daniel Levinson, Jean Piaget, Lawrence Kohlberg, and Jane Loevinger, this paper will discuss the literature from the more recent perspectives of adult learning. Since the PPL is designed for teacher learning to take place, and teachers are adults, it was important to ground the PLL design in the adult learning literature.

\section{Andragogy Theory}

The theory of andragogy, researched in the 1970's and popularized in the 1980 's is based on Malcolm Knowles' work. Knowles asserted that there were five assumptions of adult learning:

1. Adults have an independent self-concept and can direct their own learning.

2. Adults have accumulated a reservoir of experience that is a rich resource for learning.

3. Adults have learning needs closely related to changing social roles.

4. Adults are problem-centered and interested in immediate application of knowledge.

5. Adults are motivated to learn by internal rather than external factors. ${ }^{8}$ One of the criticisms of Knowles' work is that his findings are not necessarily limited to adult learning (Merriam, 2001; Tennant, 1986; Zemke \& Zemke, 1996). In fact, Knowles (1984) himself acknowledged there are children 
who are "very self-directing in their work outside of school .... [who] could also be more self-directed in school" (p. 13). His assertions are solidly from a constructivist point of view, in fact, almost a complete parallel with Accelerated Schools' powerful learning framework. The ASP notion that learning should be powerful for both the teachers involved in professional development and for their prospective students is key to both the principles of ASP, and to the findings. Knowles' assumptions mirror powerful learning:

1. Adults have an independent self-concept and who can direct their own learning. (Learner-centered)

2. Adults have accumulated a reservoir of experience that are a rich resource for learning. (Continuous)

3. Adults have learning needs closely related to changing social roles. (Interactive)

4. Adults are problem-centered and interested in immediate application of knowledge. (Authentic)

5. Adults are motivated to learn by internal rather than external factors. (Learner-centered)

\section{Self-directed Learning}

Self-directed learning (SDL) theory posits a melioristic view of learning, that humans are basically good and accept responsibility for their learning (Knowles, 1984; Tough, 1971; Brockett \& Hiemstra, 1991). SDL theory was 
articulated by Tough, but supported by Knowles andragogy theory, and supplemented by Mezirow's transformative learning theory which follows this section. One of the more critical aspects of discussing SDL is how instructors can foster self-directed learning and student control of learning. In a study that developed a model for Staged Self-Directed Learning (SSDL), Grow presents a matrix for learners. The matrix allows learners to locate themselves in terms of readiness for self-direction, and instructors can match the learner's stage with appropriate instructional strategies (see Table 6).

Table 6

Grow's Model of Stages of Self-Directed Learning

\begin{tabular}{|c|c|c|l|}
\hline & $\begin{array}{c}\text { Adult } \\
\text { Learner }\end{array}$ & $\begin{array}{c}\text { Adult } \\
\text { Instructor }\end{array}$ & \multicolumn{1}{|c|}{ Examples } \\
\hline $\begin{array}{c}\text { Stage } \\
1\end{array}$ & Dependent & $\begin{array}{c}\text { Authority, } \\
\text { coach }\end{array}$ & $\begin{array}{l}\text { Coaching with immediate feedback. } \\
\text { Drill. Informational lecture. Overcoming } \\
\text { deficiencies and resistance. }\end{array}$ \\
\hline $\begin{array}{c}\text { Stage } \\
2\end{array}$ & Interested & $\begin{array}{c}\text { Motivator, } \\
\text { guide }\end{array}$ & $\begin{array}{l}\text { Inspiring lecture plus guided discussion. } \\
\text { Goal-setting and learning strategies. }\end{array}$ \\
\hline $\begin{array}{c}\text { Stage } \\
3\end{array}$ & Involved & Facilitator & $\begin{array}{l}\text { Discussion facilitated by teacher who } \\
\text { participates as equal. Seminar. Group } \\
\text { projects. }\end{array}$ \\
\hline $\begin{array}{c}\text { Stage } \\
4\end{array}$ & $\begin{array}{c}\text { Self- } \\
\text { Directed }\end{array}$ & $\begin{array}{c}\text { Consultant, } \\
\text { delegator }\end{array}$ & $\begin{array}{l}\text { Internship, dissertation, individual work } \\
\text { or self-directed study group }\end{array}$ \\
\hline
\end{tabular}

This matrix is particularly pertinent to the reoccurring finding that participants wanted more differentiation in the Powerful Learning Labs. The lab was designed to move the PLL participants from the dependent role toward more self-direction. The first day of each of the 2-day sessions included more direct 
instruction, mini-lectures, and graphic organizers to support new concepts. The second part of the first day and the second day of each lab session was designed for peer teaching, jigsaw and teacher planning time reflecting examples of more selfdirected activity.

\section{Transformative Learning Theory}

Jack Mezirow popularized the theory of transformative learning. Mezirow (1997) summarizes this theory as "the process of effecting change in a frame of reference."(p. 5). Frames of reference (for Mezirow) are the associations, concepts, values, feelings and conditioned responses that adults acquire. These structures or assumptions that make up our frames of reference determine, shape and limit adult expectations, perceptions, cognition, feelings and emotions. When transformative learning occurs, there is a shift in one's frame of reference.

Transformative learning theory suggests that adult frames of reference are transformed through critical reflection on the assumptions that every adult internalizes. This critical reflection can occur through a variety of activities: reading, listening to a colleague or speaker, engaging in problem solving, or selfreflecting through writing and thinking. Each of these reflective activities were built into the PLL design. By design, the intent of the PLL was for teachers to have multiple opportunities for critical reflection, as well as multiple ways to reflect (writing, talking, dialogue, and peer-observation). 
The second major component of transformative learning relates to an adult's point of view. Mezirow asserts that learning occurs when an adult's point of view is changed. One of the intentions of the PLL design was to place the participants in many work groups, so they could hear from other teachers who might have a different point of view or opinion about teaching and learning. Also, assigning the written reflection as part of the PLL portfolio contents, forces the teachers to write about their practice which typically evokes a more critical point of view of their practice.

\section{$\underline{\text { Postmodernist Perspectives }}$}

The postmodernist perspectives of adult learning that are discussed in this section include feminist theory, situated cognition, and the connection between emotion and learning. These theories are mentioned as an acknowledgement of current ideas about adult learning. All three theories are relatively new, unconfirmed and somewhat controversial. However, if the Accelerated Schools Project is to remain current in its knowledge base of applying adult learning to its professional development design, it is important to keep an eye on the theories and ideas that are emerging. Feminist theory is applicable to this study, as it raises the controversy that women experience life's situations, learning, and context from a unique perspective that is under represented in the literature on adult development. Since most teachers (and the majority of participants in this study) are women, an understanding of adult development from a feminist perspective is warranted. 
Another important reason to consider feminist theory is that ASP is still largely an elementary school project, and women represent the vast majority of elementary teachers nationwide.

Feminist theories about adult learning, purport that traditional adult learning theories were developed based on earlier theories that had a male-orientation or bias (e.g. Erik Erikson's theory of the phases of human development follow a male orientation to development, or Levinson's, The Seasons of a Man's Life). Theories that specialize in either how women learn or the differences between men and women's learning are relatively new and somewhat simplistic. Elisabeth Hayes (2001) explains.

Several years ago, I and a colleague, Daniele Flannery reviewed a large body of the literature on women, learning and education, hoping to develop a comprehensive picture of women's learning. In some literature, we found a litany of characteristics reminiscent of Men Are from Mars, Women Are from Venus (Gray, 1992). Women and men learners have been described as speaking 'different languages'. Women are oriented toward sharing feelings and communicating empathy, while men share information and give advice; women are thought to prefer solving problems in groups, while men prefer independent problem solving. The descriptions have some disturbing similarities to centuries-old stereotypes of women, stereotypes that were used to question women's learning capacities. (p. 36)

Perhaps the most accepted contribution to the perspective of women's learning is the concept of "connected knowing" which was introduced in Women's Ways of Knowing (Belenky, Clinchy, Goldberger \& Tarule, 1986). Hayes (2000) explains the theory of "connected knowing", 
Connected knowing was described as embracing new ideas and seeking to understand different points of view. Connected knowing was contrasted with 'separate knowing,' characterized by taking a more adversarial stance toward new ideas and looking for flaws in logic and reasoning. .... They [authors Belenky et al.) proposed that connected learning was preferred by the largest number [of women]. They proposed 'connected teaching' to support this way of knowing. Connected teaching was intended to contrast with traditional modes of education that emphasize separate knowing, and, presumably, conflict with women's preferred modes of learning. ... (p. 37)

The idea that women tend to connect new ideas to existing ones is similar to the foundations of constructivism. Some consider that men tend to pull apart ideas analytically, while women tend to build on to existing ideas more like Benjamin Bloom's synthesis of building of new ideas on the foundations of older ones (Cranton, 1997; Hayes, 2001).

Building on participant's relationships with their peers is an example of how Accelerated Schools Project guiding principals work. The PLL design was inundated with opportunities to collaborate, specifically we employed a "pairshare" strategy, where lab participants met with a partner (often the same partner) to dialogue about the lessons taught between sessions, this strategy was given thirty minutes during lab sessions three through eight, which is precious time considering the PLL's packed agendas.

The idea that relationships figure prominently in the lives of many women is hardly surprising given women's traditional roles as caretakers in the home and their concentration in caretaking roles in the workplace, such as teaching and nursing. While the controversy around feminist research is likely to remain in terms 
of whether or not women learn differently than mean, the fact that the corps of teachers are mostly women remains. This was especially true of the participants of this study with twelve of the fifteen participants being women. Following feminist theory is an important and responsible action for further development of the Powerful Learning Labs.

Another postmodern perspective, situated learning theory or situated cognition, is based on the core assumption that learning is inherently social in nature (Hansman, 2001). Glickman, Gordon and Ross-Gordon (1998) further explain the theory as it related to adults.

Wilson (1993) extended the application of this theory [situated learning] specifically to adult learning and education, describing learning that is 'fundamentally situated' as that which is social in nature, tool dependent (using the mechanisms provided by the setting, such as computers, maps, or measuring cups), and interactive with the setting. Linking situated cognition to Schon's (1983) work on acquisition of professional knowledge through 'knowing-in-action,' he suggests adult learn in experience as they act in situations and are acted upon by situations, rather than the traditional assumption that adults learn from experience. (p. 54)

Situated learning is the theoretical basis for authentic learning which is a component of powerful learning. Learning is authentic when it is situated in the real world or addresses a real-world problem. The PLL design was intended to be situated in the act of teaching. We came together to learn about teaching, go out and teach, and then compare our original ideas to the reality of the teaching experience. 
Emotions, Learning and the Brain

Emotions play a powerful role in learning, either as an impediment or as motivation (Dirkx, 2001). From a Darwinian perspective, emotions fuel human's need to survive, explained in the body's flight or fight response; when a person experiences an extreme emotion, such as rage, love or fear, the brain produces neurotransmitters and hormones that allow a person to fight, seek a mate, or run from a predator or dangerous situation. An example of the role of emotions on learning, and especially on retention (or memory) can be illustrated by asking oneself, "Where were you when [insert an emotionally charged incident]?" For example, "Where were you when the space shuttle Challenger exploded?" For many educators, this was an incredibly emotionally charged incident, as the fatal explosion carried Christa McAuliffe the first teacher into space. For me, I can remember exactly where I was, watching in horror with my fifth graders at Sunset Elementary School, on a sunny warm, morning. I remember what I was wearing, and many details from the moment and the day; where as, I' $d$ be very hard-pressed to recall anything else from that year with even remotely similar detail.

Dirkx contends that emotions and learning are inexorably connected, emphasizing emotionally charged images precede and permeate learning. The recent emergence of "emotional intelligence" (Goleman, 1995) and other brainbased theories of learning connecting emotions to learning (Damasio, 1999; Jensen, 1998) are becoming more accepted in mainstream educational organizations such as the Association for Supervision and Curriculum Development (ASCD). The 
most important aspect of brain research we considered in designing the PLL, was the "absence of threat" (Jensen, 1998, p. 59). We made many accommodations to the room, the setting, and at times the agenda to be responsive to the participant's feedback. We were determined to create a climate of trust and risk-taking with the entire PLL cohort.

There is no clear emergent, preemptory theory on adult learning. Instead there is an emerging set of theories or principles that have some common threads. Merriam (2001) elaborates, "What we do have [in adult learning] is a mosaic of theories, models, sets of principles, and explanation that, combined, compose the knowledge base of adult learning" (p. 3). This mosaic of models and principles is further defined by the more narrow research on teacher development. Teacher Development is explored in the next section.

\section{Teacher Development}

The literature on teacher development as a subset of adult development considers the unique career situation of the classroom teacher. Most models of teacher development follow a hierarchal phase or stage sequence (Evans, 1996; Fessler \& Christensen, 1992; Levine, 1989; Steffy, 1989) with beginning stages advancing to more desirable stages, where higher stages are considered better (Levine, 1989). Occasionally the final stage can depict a situation of despair or decline, but as a generalization, the stages evolve into more advanced and complex settings with titles such as "expert" or "master" teacher. Most of the phase and 
stage theories of teacher development are founded on equally hierarchal aspects of adult development such as Erikson's Life Phases which focus on sequential and distinct conflicts (e.g. intimacy vs. isolation), or Levinson's Developmental Periods chronicled in his book The Seasons of a Man's Life which depicts classic male transitions as men encounter life's tasks, such as forming an occupation.

Additional theorists that purport a hierarchal perspective of adult development include: 1) Kohlberg's Six Moral Stages, which depicts human development through a lens of moral decision making such as a person's perception of "what is right"; 2) Abraham Mazlow's Framework For Understanding Human Motivation, which begins with basic physiological needs and progresses through five hierarchal levels until one reaches self-actualization; and 3) Hertzberg's Motivation Factors of Work, which was developed after studying dissatisfied and satisfied workers (Levine, 1989).

Hertzberg's work revealed that dissatisfied workers tend to remain entrenched in work factors around what he calls "hygiene factors" issues such as salary, working conditions, and policy. Where as satisfied workers were motivated by more abstract factors such as possibility of growth, recognition, and achievement. Theorists that study the teacher workplace and teacher motivation often link Mazlow's and Hertzberg's work (Sergiovanni \& Carver, 1973; Glickman, Gordon \& Ross-Gordon 2001) (see Figure 2). 


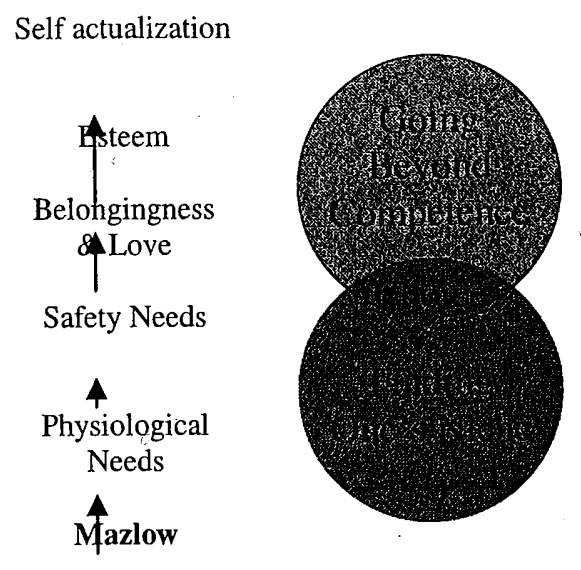
$\left.\begin{array}{l}\text { Achievement } \\ \text { Responsibility } \\ \text { Recognition } \\ \text { Advancement }\end{array}\right\} \begin{aligned} & \text { Motivating } \\ & \text { Factors }\end{aligned}$ Possibility of Growth

Status Interpersonal Relations Hygiene Supervision-Technical $>$ Factors School Policy \& Administration Personal Life Job Security Working Conditions Salary

\section{Hertzberg}

Figure 2. Interacting areas of Hertzberg's "factors" with Mazlow's "stages". 9

A key PLL design concept lies in the intersection of the Venn diagram:

Choice. All participants had a tremendous degree of choice. They were voluntary participants. They had chosen to be there, and they could choose to remain or not. In terms of the Mazlow side of the diagram, throughout the lab, we solicited feedback from the participants regarding their physiological needs, and adjustments were made. For example, the breakfast menu was altered based on participant feedback, and water was brought in for the entire session to accommodate their physical needs.

In terms of work hygiene factors, none of the participants were active in the local teacher's union or district leadership groups. They were selected for their "regular" status. The absence of the distraction of work hygiene factors hopefully 
allowed participants to be more available and receptive to the motivation factors described in Hertzberg's theory. The voluntary nature of the lab and the willingness to forge a somewhat negotiated agenda contributed to a PLL design that supported teacher development.

The experiential cohorts (bounded cases) of the study were clearly determined with the benefit of the literature on teacher development. A closer examination of the experiential cohorts through the lens of Fessler and Christensen's Teacher Career Cycle follows (see Figure 3). The novice cohort straddled the phases of induction and competency building as this cohort included both first and second year teachers. Perhaps the most significant difference between the novice case and the typical novice teacher is they were not alone, the lab experience allowed them access to experienced peers prior to the start of the school year. The competency building phase is described by Burke and McDonnel (1992) as,

During this stage of the career cycle, the teacher is striving to improve teaching skills and abilities. The teacher seeks out new materials, methods, and strategies. Teachers at this stage are receptive to new ideas, attend workshops and conferences willingly, and enroll in graduate programs through their own initiative. Their job is seen as challenging, and they are eager to improve their repertoire of skills. (p. 87) 


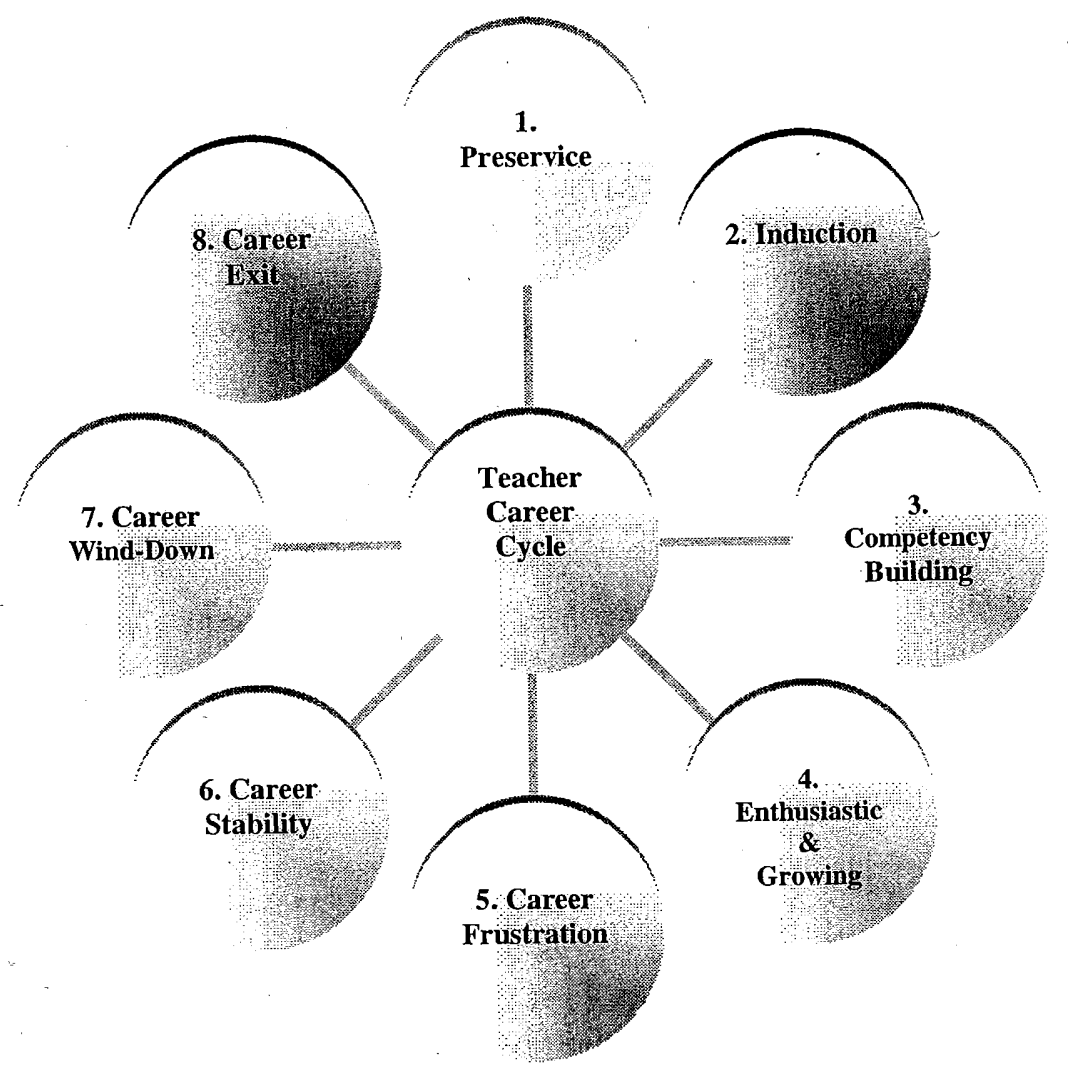

Figure 3. Fessler and Christensen's teacher career cycle (p. 36).

Other models of teacher career development call the competency building phase of teaching "consolidation" (Feiman \& Floden, 1980, cited in Fessler \& Christensen, 1992), or “adjustment" (Burden, 1982, cited in Fessler \& Christensen); but regardless of the name associated with this phase of teaching, the honing of the skills and strategies of effective teachers are consistent along with an attitude of positive confidence.

The teacher career cycle model suggests a clockwise or forward progression from stage to stage, but that is not necessarily accurate. At any time a teacher can 
remain fixed at a stage, or through a negative experience can skip ahead to career frustration or exit. The radial diagram is only to suggest a cyclical progression, but each individual teacher's journey through the cycle is unique. A critical aspect of the competency building phase is the teacher's search for a mentor (Glickman, 2002; Krupp, 1981; Steffy, 1989). Mentorships were built into the lab designs, when teacher met in grade similar groups, there was the opportunity for novice, mid-career and veteran teachers to collaborate. The fourth phase (enthusiastic and growing) of the teacher career cycle model is described by Burke and McDonnell (1992) as,

At this stage, teachers have reached a high level of competence in their job, but continue to progress as professionals. Enthusiastic and growing teachers love their jobs, look forward to going to school and to the interactions with their students, and are constantly seeking new ways to enrich their teaching. Key ingredients here are enthusiasm and high levels of job commitment and satisfaction. These teachers are often supportive and helpful in identifying appropriate staff development activities for their schools. (p. 119)

The characteristics of high levels of competence and desire for continued professional growth are characteristics of "gourmet omnivores" (Joyce, et al., 2000). Many of the women of the veteran cohort made a conscious decision to suspend family and other commitments to participate in the Powerful Learning Lab. The basic level of commitment to attend the lab throughout the school year, which was at least a three hour drive from the participants' homes was evidence that these teachers were willing to make an effort to engage in the activities of the PLL. 
The career frustration period of teacher development was a definite possibility. The PLL design didn't address any type of negative participation other than through the early establishments of norms or ground rules for participation. Additionally, the fact the PLL was voluntary, made willing participation more likely.

The remaining phases (stability, wind-down and exit) of the teacher career cycle carry negative connotations, or at minimum are less positive. Career stability is depicted as a fair day's work for a fair day's pay, but a reduction of enthusiasm, or shifting into a maintenance mode of work. Given the large PL cohort included a range of ages and experience from 22 and a first year teacher to 50 plus and a thirty-year veteran, it was definitely possible that the participants might be entering the stability or wind down phase of teacher career cycle. This was one of the dilemmas with designing an inclusive lab that would involve participants from every level of the teaching career cycle. Professional development that can meet the needs of the career span of teachers in K-8 schools is challenging indeed. Professional development literature is discussed in the subsequent section.

\section{Professional Development}

Professional development is what the Accelerated Schools Project delivers to schools. ASP isn't a curriculum package, it is a process model that provides professional development to schools. Each school that affiliates with ASP enters into a Basic Partnership Agreement (BPA) (see Appendix E) with either a Satellite 
Center for ASP or the National Center for Accelerated Schools. The BPA includes a minimum of eight days of professional development activities. The PLL was designed for schools in the second year and beyond to engage their classroom teachers in professional development about powerful learning.

Historically, the Accelerated Schools Project has wrestled with effective professional development delivery models since its inception. The first Accelerated Schools involved whole schools in a few days of professional development at the beginning of the school year. Later a principal's training was added to include additional professional development for school principals.

By the mid 1990's ASP professional development moved to the trainer of trainers model, when ASP targeted leadership teams from schools for training, with the conviction that the team would then return to school to train the remaining staff and community. This trainer of trainers included the addition of an ASP coach. The coach's role has evolved over the past decade to include more time (e.g., originally .24 FTE was a typical coach's release time for ASP work, now .5-1.0 F.T.E is recommended), and more responsibility as a teacher leader and mentor of powerful learning. ${ }^{10}$

The problems of principal succession and high coach turnover prompted the Accelerated Schools model to modify its BPA with schools to include the training of five member leadership teams. These teams promote what Sergiovanni (1994) terms leadership density, or the extent to which leadership roles are shared. In a meta-analysis of change and leadership literature, Schwann and Spady (1998) 
confirm the necessity for leaders to build capacity for leadership within organizations,

Acknowledge power, which results in empowered and committed personnel. Total Leaders don't believe they actually make people powerful or actively empower them. Instead, they believe that a tremendous amount of power lies within each person and that their role is to create work environments that let that power and capability emerge. (p. 21)

Typically, the professional development for an ASP school team involved the school principal, the ASP coach, and three other school community members, most often teacher-leaders, but at times included para-professionals and or community members. When I assumed the satellite co-director position, we trained a leadership team from each school. An inherent dilemma in this professional development delivery model was that the leadership team didn't always penetrate the regular teacher's routine. ASP training was still fragmented, and didn't target curriculum and instruction enough to make it meaningful for teachers or effect large enough gains in student achievement. Stigler, interviewed by Willis (2002), concurs,

Over the past 5-10 years, professional development has changed a lot. The standards movement has created a real need for teacher learning, so people are looking critically at the kinds of learning experiences we're providing for teachers.

Today, people believe that professional development should be targeted and directly related to teachers' practice. It should be site-based and long-term. I should be ongoing - part of a teacher's workweek, not something that's tacked on. And it should be curriculum -based, to the extent possible, so that it helps teachers help their students master the curriculum at a higher level (p. 6). 
Based on research and practice such as Stigler's, the PLL labs were designed to work directly with teachers in curriculum and instruction. We knew that teachers believed they were instrumental to school improvement. In addition the influence of teachers on other teachers' practice is documented (Ball \& Cohen, 1999; Putnam \& Borko, 2000; Featherstone, Munby, \& Russell, 1997; Goodlad, 1994). Lambert and Ball (1999) explain, "Student teachers are often in the end most influenced by what they see their cooperating teachers do or by their own memories from school" (p. 38). Given that teachers believe they influence each other; the PLL was purposefully designed to engage regular teachers in a collaborative, longitudinal professional development experience.

The Powerful Learning Labs seized the leadership density opportunity and diffused it to the most obvious participant in school improvement, the classroom teacher. While these "regular" teachers were not expected to teach others, we speculated that some natural mentoring would follow at their home school sites. Further research on professional development influenced the planning and design of PLL. Hawley and Valli (1999, p. 138) identify eight design principles of characteristics of effective professional development that are supported through a synthesis of research on learning. Those principles and the corresponding component of PPL are identified in Table 7. 
Table 7

Hawley and Valli's Design Principles for Professional Development and Corresponding Powerful Learning Lab Components

\begin{tabular}{|c|c|}
\hline Design Principle & PPL Component \\
\hline $\begin{array}{l}\text { Driven by analyses of differences between 1) } \\
\text { goals and standards for student learning and 2) } \\
\text { student performance }\end{array}$ & $\begin{array}{l}\text { PPL lesson plan requires identification of a } \\
\text { state standard prior to planning, utilizes } \\
\text { "design down" method. Written lesson } \\
\text { plans were to be linked to standards. }\end{array}$ \\
\hline $\begin{array}{l}\text { Involves learners (teachers) in the identification } \\
\text { of their learning needs, and the development of } \\
\text { the learning opportunity and/or process }\end{array}$ & $\begin{array}{l}\text { Teachers volunteer to participate in PLL. } \\
\text { Teachers also select curriculum area of } \\
\text { focus for lesson design and data collection; } \\
\text { builds on ASP guiding principle } \\
\text { empowerment }\end{array}$ \\
\hline $\begin{array}{l}\text { Involvement is school based and integral to } \\
\text { school operations }\end{array}$ & $\begin{array}{l}\text { All activities and assignments relate to } \\
\text { classroom instruction, participants work in } \\
\text { school based teams; supports ASP value } \\
\text { school-as-the-center-of-expertise }\end{array}$ \\
\hline $\begin{array}{l}\text { Provides learning opportunities that relate to } \\
\text { individual needs but are organized around } \\
\text { collaborative problem solving }\end{array}$ & $\begin{array}{l}\text { Participants plan and implement individual } \\
\text { lessons, yet collaborate on peer support } \\
\text { teams for peer coaching; supports ASP } \\
\text { value of collaboration and } \\
\text { communication }\end{array}$ \\
\hline $\begin{array}{l}\text { Is continuous and ongoing, involving follow-up } \\
\text { and support for further learning, including } \\
\text { support from sources external to the school. }\end{array}$ & $\begin{array}{c}8 \text { month, on-going collegial and external } \\
\text { support. ASP staff visit participants at } \\
\text { school site, embodies PL continuous } \\
\text { component }\end{array}$ \\
\hline $\begin{array}{l}\text { Incorporates evaluation of multiple sources of } \\
\text { information on outcomes for students and } \\
\text { processes involved in implementing lesson } \\
\text { learned through professional development }\end{array}$ & $\begin{array}{l}\text { Written, oral, and visual reflections and } \\
\text { evaluations are consistently used in the } \\
\text { PLL and in the PLL portfolio }\end{array}$ \\
\hline $\begin{array}{l}\text { Provides opportunities to develop a theoretical } \\
\text { understanding of the knowledge and skills to be } \\
\text { learned. }\end{array}$ & $\begin{array}{l}\text { Essential component of the cooperative } \\
\text { jigsaw of Models of Teaching (which } \\
\text { include learning theories) and PL } \\
\text { components (constructivist theory) }\end{array}$ \\
\hline $\begin{array}{l}\text { Integrates a comprehensive change process that } \\
\text { deals with the full range of impediments to and } \\
\text { facilitators of student learning }\end{array}$ & $\begin{array}{l}\text { Peer debriefing and pair sharing offer } \\
\text { opportunities for teachers to tap the } \\
\text { expertise of the group and technical support } \\
\text { providers, supports ASP inquiry by clearly } \\
\text { understanding the problem. }\end{array}$ \\
\hline
\end{tabular}

Another perspective is Gary Sykes (1999) who argues that the three most

pressing issues related to professional development are: 
1. Teacher preparation in conjunction with policy-driven change

2. Advances in research-based instruction practice, engaging teachers in new knowledge of learning and the production of that knowledge (e.g. action research)

3. New demands for more ambitious learning for a more diverse and demanding student body, a nationwide commitment to educating all children to high levels of accomplishment, knowledge and skill

All three issues are supported in the on-going development of the Powerful Learning Labs. Teachers who participated in the PLL were doing so as part of their ASP Basic Partnership Agreement (BPA), which is a policy-driven change based on the school's participation in CSRD and Schoolwide Title I. Teachers were following six students throughout the year, analyzing their work in relation to the powerful learning framework, which is an example of action research.

The PLL included some aspects of the challenges and demands for teaching in the demanding setting of poverty. Additionally the 2000-2001 PLL included an optional extra day of professional development in the areas of classroom management, literacy, special needs and math, all challenge areas identified by the school. Each generation of PLL incorporates new change issues, recent research and best practices, and the complexity of educating a diverse student body. 
Perhaps the most compelling demographic that affects the Hazelton School District is that of poverty. What is also essential to understanding how teachers and their practice are influenced is to know where they work. The context of any given school is extremely relevant to any conclusions that can be drawn about that school. In the next section, the prevailing demographic construct of poverty is examined.

\section{Culture of Poverty}

Whenever school improvement models are pursued, there is a need to understand the context of that school and or the district. Hazelton is a school district that over the last thirteen years has changed dramatically. It is important to recognize the contributions of systems theory (Owens, 1991) that single schools exist in a context or environment of larger systems, including the district, the community, and the state. A brief description of the community is warranted for better reader understanding. As stated earlier, the Hazelton District is located in a working class area south of a major Northwest city. While some might consider the community a suburb, the urban appearance and context is prevalent.

Hazelton is a compact city of 7.5 square miles of intersecting freeways, commercial property, multiple family dwellings and small residential areas. The community of 15,000 was incorporated in 1908 , and offers a blend of businesses, churches, parks and abundant multi-family housing. The city straddles two major freeways between two major cities. Hazelton is business dense with a large 
shopping mall, an aerospace company, and other retail, office, high tech, and industrial complexes. The community is quite ethnically and racially diverse, with over 40 world languages spoken by students. Voters have consistently supported school levies and bond issues, although there is a definite trend of high white voter turnout in an area that is more populated by people of color.

Approximately 2500 students are enrolled in the five-school district, with the three elementary schools at approximately 400 students each, the middle school at 625 , and the high school at 712. Twenty-three percent of the students are English Speakers of Other Languages (ESOL). . Fifty-eight percent of the students are eligible for free or reduced school meals. The student population has grown more diverse each year for the past five years. Many families emigrate to this community from Africa, and Eastern Europe. Spanish is the second most common language after English. Bosnian refugees are the fastest growing minority population.

The poverty rate in the district has tripled in the past thirteen years. This escalating poverty has changed the context of the district as it moved from a

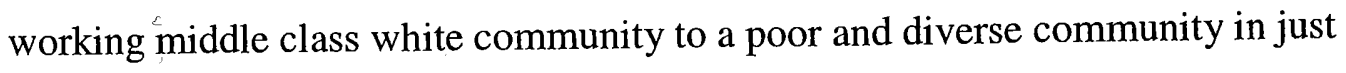
over a decade. Understanding the culture of poverty is essential to understanding the culture of Hazelton's children and families. Most elementary, middle and high school teachers were not raised in a culture of poverty, yet the majority of students of the Hazelton District are poor. 
So, there is an inherent mismatch between teacher culture and experience and those of the students. Because of this mis-match, the culture of poverty became a significant curriculum content area for the PLL. While the culture of poverty was planned as a one hour lecture and discussion, the PLL participants demanded a longer session, poverty was a topic of intense interest for the PLL participants. The children who now attend the Hazelton District are much different in appearance, family background, and language than the children who attended a decade ago. This shift in who is coming to school dramatically affects the teaching and learning process as Schlechty (1997) concurs

The demand that schools be changed or returned to their former good state is clearly not new. Indeed, the problems the current group of critics have identified -for example, low standards and poor discipline - have been identified in the past as well.

Apparently, the good old days were not nearly as good as the people who would take us back to those days would have us believe. What has changed is the context in which these problems are manifested, for the schools themselves have changed very little-and that is the problem. Unless the schools can be changed to accommodate the new context in which they exist, they not only will not get better; they are almost certain to get worse. (p. 7)

Therefore, a brief discussion of the current literature about poverty as a prevalent context for Hazelton is warranted. The correlation between poverty and low student achievement has been documented for decades, and indeed was the catalyst for the ESEA. Riordan (1997) concurs,

The most important of the home background variable is socioeconomic status (SES). The higher the social class of the home, the higher the achievement of students. This is true regardless of which indicators are used for SES or for achievement. This relationship has been found consistently in 
literally thousand of studies. Students' SES is related to grades, achievement test scores, curriculum placement, dropout rates, college plans, and educational attainment. The relationships hold even when other background and school effects are controlled. And, the relationship has been demonstrated in virtually every Western society. (p. 70)

Understanding some of the cultural aspects of poverty and their effects and influences on schools is a more recent inquiry (Haberman, 1995; Hill, et al., 2000; Payne, 1998; Riordan, 1997). The impact of poverty on children is increasing. In 2000 , in the U.S. 16.2 percent of individuals under the age of 18 was living in poverty (Delaker, 2001). Poverty is caused by interrelated factors: parental employment, status and earnings, family structure, and parental education (Payne, 1998). Payne also makes several key points about poverty that are pertinent to this study:

1. Poverty is relative. If everyone around you has similar circumstance, the notion of poverty and wealth is vague. Poverty or wealth only exists in relationship to known quantities or expectations. (This applies to Hazelton, since 41 percent of the students are not on FRLP, therefore the teachers in Hazelton deal with the tension between poor and non-poor).

2. Poverty occurs in all races and in all countries. The notion of middle class as a large segment of society is a phenomenon of this century. The percentage of the population that is poor is subject to definition and circumstance.

3. Economic class is a continuous line, not a clear-cut distinction. In 1994, the poverty line was considered $\$ 14,340$ for a family of four, in $1994,7 \%$ of the population made more than $\$ 100,000$ per year. 
4. Generational poverty and situational poverty are different. Generational poverty is defined as being in poverty for two generations or longer. Situational poverty is a shorter time and is caused by circumstance (i.e., death, illness, divorce, etc.) For many Hazelton students the circumstances that cause situational poverty is immigration and language.

5. Poverty studies are based on patterns. All patterns have exceptions

6. An individual brings with him/her the hidden rules of the class in which he/she was raised. Even though the income of the individuals may rise significantly, many of the patterns of thought, social interaction, cognitive strategies, etc. remain with the individual.

7. Schools and businesses operate from middle-class norms and use the hidden rules of middle class. These norms and hidden rules are not directly taught in schools or in businesses.

8. For our students to be successful, we must understand their hidden rules and teach them the rules that will make them successful at school and at work.

9. We can neither excuse students nor scold them for not knowing; as educators we must teach them and provide support, insistence, and expectations.

10. To move from poverty to middle class or middle class to wealth, an individual must give up relationships for achievement (at least for some period of time). (pp. 1011)

Using Payne's key points, the PLL participants engaged in discussion and problem solving about teaching the hidden rules of class, and how to explicitly teach the rules of the middle class school culture to students who've never experienced middle class values at home. The complexity of the infrastructure of 
poverty involves complex, multi-faceted approaches to improving student achievement. There is no quick-fix or silver bullet to mend the ills of low performing students in the complex context of poor, urban and diverse schools. The efforts to assist the poor of the United States have spanned decades and political parties.

The Democratic party of John F. Kennedy and Lyndon B. Johnson created the ESEA, while the Republican party of the Richard Nixon era urged enactment of desegregation assistance in 1972. Democrats have remained supporters of ESEA and Title I policies and Republicans Jacob Javits and Richard Schweider have committed to numerous education reform strategies including Title IX, X and CSRD. The bi-partisan team of Obey and Porter wrote the original CSRD bill. However, as Hill, et al. (2000) surmise,

And yet more than three decades after the legislative triumphs that translated these ideals (of assistance to poor schools) into national and state policy, the results fall short of what their sponsors had expected. (p. 2)

At the national level, studies report the rather disappointing efforts to remedy student achievement in the nation's poorest schools. The Hazelton District is one challenged by poverty, diversity, and the complexities of an urban setting, and it has selected a school improvement model that is more difficult to implement, than most others (Bodilly, 1998; Calhoun \& Joyce, 1998; Slavin, 1998). So this district has invested in a long-term solution and at this point, entering its third year, is willing to "stay the course" and stick with a process oriented, principle-based 
model. Hazelton has demonstrated a persistence that has eluded many larger district efforts at school improvement in poor, urban and diverse settings (Chenoweth \& Petti, 2000).

Hill et al. (2000) describes the impact of school experiences for poor children,

It is precisely because they (poor students) do not get the out-ofschool experiences middle- and upper-middle -income children receive that low-income students rely so heavily on the public schools. Formal learning opportunities for low-income minority young people are largely restricted to what they have the opportunity to learn in school, unsupplemented by museum trips, access to computers and the Internet at home, vacation visits to the nation's great landmarks and national parks, or opportunities to spend a few weeks traveling abroad. (pp. 3-4)

Thus the experiences students receive and participate in during the school day gain even more significance. For it is the hours that poor students spend in public schools that most determine their future. Haberman (1995) concurs in his passionate statement,

For the children and youth in poverty from diverse cultural backgrounds who attend urban schools, having effective teachers is a matter of life and death. These children have no life options for achieving decent lives other than by experiencing success in school. For them, the stakes involved in schooling are extremely high. Teaching in these situations is not a job, or even a career. Dealing as it does with psychological as well as physical life and death, teaching in these situations is an extraordinary life experience - a volatile, highly charged, emotionally draining, physically exhausting experience for even the most competent, experienced teacher. .... The least accurate language would describe the first year of teaching in an urban school system as a manageable or even reasonable 'job'. (p.1) 
The significance of high quality teachers in poor, diverse, and urban contexts cannot be underestimated. The foundational premise of this study is that building high quality teachers is essential to improving student achievement in the nation's most challenging schools. The emphasis on teacher support and development is well supported in the literature of school improvement ( Goodlad, 1994; Hill, P. et al. 2000; Johnson and Kardos, 2002; Little, 1999; Peterson, 1995; Willis, 2002)

This study probed the practice of regular teachers in the vortex of school improvement, and their story has implications beyond the narrowness of one school district. For many low performing schools, the teachers of this study represent a much larger sample, as their demographics are consistent with other low performing schools across the nation. The documentation of these teachers' journey toward school improvement is critical.

As the study focused an introspective lens from the wide-angle of school improvement to the more clearly defined Accelerated Schools Project and even more sharply on the Powerful Learning Lab, the most clear and precise image is that of teachers constructing their own meaning about what it means to plan, teach, assèss and reflect in schools that are challenged by poverty, urbanity, and diversity.

\section{Summary}

The history of school improvement, and specifically schools in the principal-based design of the Accelerated Schools Project frame the setting of this 
study. Understanding that school improvement is the context from which these schools and these teachers work is important to applying the findings of the study to other situations.

The importance of a review of the historical significance of the Elementary and Secondary Education Act and specifically a review of the emerging literature of Comprehensive School Reform (CSR) is essential to the context of this study and to the Accelerated Schools Project. Comprehensive School Reform targets our nation's high poverty schools where student achievement is critically low. The literature that frames the foundation of the CSR movement is grounded in school improvement rhetoric. Since all of the participant teachers in this study teach in high poyerty CSR or Schoolwide Title I schools, their story is particularly important to apply to other high poverty schools and their school leaders.

The theories of constructivism and adult learning influenced the powerful learning lab design, which is one of the significant professional development opportunities that the Accelerated Schools Project provides for its affiliated schools. Clear understanding and articulation of constructivism is crucial to presenting the Powerful Learning Framework as a research-based instructional strategy.

For the Accelerated Schools Project to continue to serve new schools and in order to retain existing schools, we must understand adult learning, teacher development and professional development. We work directly with adults who work in schools, and we need to work more closely and more directly with 
classroom teachers. While good teaching strategies can cross developmental boundaries, it is important for ASP personnel who work with teachers to be more proficient at understanding how adults learn and how teachers develop.

The context of poverty is the most prevalent demographic in the Accelerated Schools Project movement. At the national level, eighty seven percent of ASP schools are above the poverty line measured by greater than fifty percent participation in the federal free and reduced lunch program. All of the Hazelton schools in the study are considered poor, with free and reduced lunch participation exceeding 50 percent and as high as 85 percent in one Hazelton School. The components of this study (school improvement, constructivism, adult learning, professional development and poverty) are influenced by a review of the pertinent literature. The literature review supports the philosophical foundation for the methodology and design of the Hazelton study. A more complete description of the study's methodology follows in Chapter III. 


\section{End Notes}

${ }^{1}$ This view point was expressed in a keynote speech by Accelerated Schools Project National Director, Gene Chasin in an address at the Western Regional Conference for Accelerated Schools at Seattle, WA on March 23, 2002. Chasin sits on several national policy boards in relation to his work with ASP.

${ }^{2}$ Statistics from Northwest Regional Educational Laboratory's Catalog of School Reform Models. http://www.nwrel.org/scpd/natspec/catalog/

${ }^{3}$ Based on a search of the Northwest Regional Educational Laboratories data base of CSRD awards to school reform models. [On-line]. Available: http://www.sedl.org/csrd/awards.html

${ }^{4}$ Henry M. Levin consistently referred to the term "cookie cutter" in his early writings about the Accelerated Schools Model, as well as in the ASP Resource guide.

${ }^{5}$ Although H. M. Levin wrote numerous articles and participated in multiple studies of school and program effectiveness, these two studies provided the research background for what is now the Accelerated Schools Project.

${ }^{6}$ Jackson, B. T. in forward of Brooks, J.G. \& Brooks, M.G. (1993) In Search of Understanding: The Case for Constructivist Classrooms. Arlington, VA: ASCD. p. v.

${ }^{7}$ Perkins, D. (1999) cites D.C. Phillips (1995) The Good, the Bad, and the Ugly: The Many Faces of Constructivism. Educational Researcher, 24 (7), p. 5-12 In The Many Faces of Constructivism. In Educational Leadership, 57 (3) p. 7.

${ }^{8}$ Summarized from Merriam, S. B. (2001, Spring). Andragogy and Self-Directed learning: Pillars of Adult Learning Theory. In S.B. Merriam, (Ed.). The New Update on Adult Learning Theory: New Directions for Adult and Continuing Education. (89), p. 5. San Francisco: Jossey-Bass. 
9 Source of diagram: Glickman, C. Gordon, S.\& Ross-Gordon, J. (2001). Supervision of Instruction A Developmental Approach, $\left(4^{\text {th }}\right.$ ed). San Francisco: Jossey Bass. Originally adapted from: Herzberg, F. Mausner, B. \& Snyderman, B. (1959). The Motivation to Work. New York: Wiley, and Maslow, A. (1954). Motivation and Personality. New York: Harper \& Row.

${ }^{10}$ See ASP website: www.acceleratedschools.net for an expanded discussion on the role of the coach. 


\section{CHAPTER III}

\section{METHODOLOGY}

Overview, Goals and Significance

This study was a multiple-case study of regular classroom teachers who are participating in comprehensive school reform via the Accelerated Schools Project Powerful Learning Lab (PLL). Participants were part of what Creswell (1998) terms a "bounded system" (p. 249) as they were all bounded by time (the duration of the PLL) and place (the Hazelton School District). Data were collected and triangulated ùsing interviews, classroom observations, and analyses of written artifacts (the PPL portfolio).

There were multiple goals of the study, both for the participants and the researcher. The goals of the study were to:

- Inform further research and development of the Accelerated Schools Powerful Learning Labs.

- Provide information to enhance service to the Hazelton District by the Northwest Satellite Center for Accelerated Schools.

- Extrapolate patterns of teacher learning to enhance teacher preparation programs and further development of PLL 
- Share participant teacher expertise with the PLL cohort (the PLL cohort consists of all 42 PLL participants, although the study sample is 15), exemplifying the Accelerated Schools values of the school is the center of expertise, risk-taking, and collaboration.

The significance of this study was to determine if the effort, resources, and organizational change required in Comprehensive School Reform (CSR) is making a difference to what others (Bodilly, 1998; Calhoun \& Joyce, 1998; Hill, et al., 2000) describe as the "core technology" of schools, that of teaching and learning. Many reforms have come and gone in the last three decades with little or no measurable impact on the core technology of teaching and learning (U.S. Department of Education, 1996; Schlechty, 1997; Calhoun \& Joyce, 1998; Hess, 1999; and Hill, et al., 2000). Listening at the teacher level enabled me to describe the practices of those at the front line of school reform, i.e., regular teachers. The teaching practices examined in the study were teacher planning, teaching, assessing, and reflecting (see Table 8).

The intervention examined was the teachers' participation in the Accelerated Schools Project's Powerful Learning Lab (PLL). All teacher participants volunteered to participate in the Powerful Learning Lab for a period of eight months between August, 2000 and March, 2001. So the study encompassed teacher planning, teaching, assessing and reflecting for most of a school year. Much is written about school leadership roles in school reform (Garmston \& Wellman, 1999; Hess, 1999; Lambert, et al., 1995; Leithwood, et al., 1999; 
Wheatley, 1999) yet little has been written capturing the regular teacher's voice. Even though, Hawley and Rosenholtz (1984) determined in a meta-analysis of factors related to student achievement that the teacher was the most significant factor.

Table 8

Teacher Practices Studied

\begin{tabular}{|l|l|l|}
\hline Teacher Practice & \multicolumn{1}{|c|}{ Evidence } & \multicolumn{1}{c|}{ How examined } \\
\hline Planning & $\begin{array}{l}\text { Lesson plans } \\
\text { Reflective essays } \\
\text { Interviews }\end{array}$ & $\begin{array}{l}\text { Powerful learning portfolio } \\
\text { Interviews } \\
\text { Peer debriefing forms }\end{array}$ \\
\hline Teaching & $\begin{array}{l}\text { Classroom instruction } \\
\text { interviews }\end{array}$ & $\begin{array}{l}\text { Classroom observations } \\
\text { Powerful learning portfolio } \\
\text { Peer debriefing forms }\end{array}$ \\
\hline Assessment & $\begin{array}{l}\text { Student work samples } \\
\text { interviews }\end{array}$ & $\begin{array}{l}\text { Powerful Learning Portfolio } \\
\text { Classroom Observation } \\
\text { Interviews } \\
\text { Peer debriefing forms }\end{array}$ \\
\hline Reflections & $\begin{array}{l}\text { Written reflections } \\
\text { interview }\end{array}$ & $\begin{array}{l}\text { Powerful Learning Portfolio } \\
\text { Self-assessment } \\
\text { Interviews } \\
\text { Peer debriefing forms }\end{array}$ \\
\hline
\end{tabular}

The study describes four teacher practices: planning, teaching, assessing and reflecting of teachers in the middle of CSR. The rationale for defining teaching practice by these four terms or actions is that these four actions are identified as typical actions that define teaching (Ball \& Cohen, 1999; Darling-Hammond \& Sykes, 1999; Freiberg \& Driscoll, 1992; Glickman, 2002; Goodlad, 1994). Additionally the Washington State Teacher Certification Board identifies 17 criteria for state certification of teachers. Twelve of those criteria can be interpreted 
as aspects of planning, teaching, assessing or reflecting (see Table 9 for further explanation).

\section{Table 9}

Teacher Practices Defined by Washington Teacher Certification Criteria

\begin{tabular}{|l|l|}
\hline $\begin{array}{l}\text { Teacher } \\
\text { Practice }\end{array}$ & \multicolumn{1}{|c|}{ Washington Teacher Certification Criteria } \\
\hline Planning & $\begin{array}{l}\text { Designing and/or adapting challenging curriculum that is developmentally } \\
\text { appropriate } \\
\text { Establishing and maintaining a positive, student focused, learning environment } \\
\text { Advocating for curriculum, instruction, and learning environments which meet the } \\
\text { diverse needs of students }\end{array}$ \\
\hline Teaching & $\begin{array}{l}\text { Effective teaching practices } \\
\text { Demonstrating cultural sensitivity in teaching and in relationships with students, } \\
\text { parents, and community members } \\
\text { Demonstrating communication skills and/or strategies that facilitate group } \\
\text { decision making }\end{array}$ \\
\hline Assessing & $\begin{array}{l}\text { Using assessment to monitor and improve instruction } \\
\text { Using information on student achievement and performance to advise and involve } \\
\text { students and families } \\
\text { Integrating technology into instruction and assessment }\end{array}$ \\
\hline Reflecting & $\begin{array}{l}\text { Evaluating the effects of his/her teaching through feedback and reflection } \\
\text { Designing and implementing personal professional growth programs } \\
\text { Remaining current in subject areas, theories, practice, and research }\end{array}$ \\
\hline
\end{tabular}

Another significant rationale for this study is related to the work and metamorphosis of the Accelerated Schools Project. Selecting a relevant work-related problem for doctoral study was supported in Bridges and Hallinger (1995) who sought a way to develop more "productive linkages among research, theory, and practice in the context of our professional students' doctoral research" (p. 114). Much as the PLL.was founded on constructivist learning theory; I selected a constructivist, problem-based learning approach to the design of this study. 
Developing a strong PLL is essential to the future of ASP. Begun in 1986, ASP was originally more focused on the organizational elements of school reform. However, due to an increasing commonality of site-based management, and a response to research ${ }^{1}$ that indicated reform models were not touching core technologies, ASP developed the Powerful Learning Lab concept. Several ASP Satellite Centers developed local models for PLL. This study investigated the PLL developed at the NW Satellite Center for ASP. The Powerful Learning Lab is in the early research and development phase as a response to criticism that "first and second wave" schools neglected the core technologies of teaching and learning (Bradley \& Olson, 1993; Slavin, 1998; Garmston \& Wellman, 1999; Hess, 1999; Hill, et.al., 2000).

The Powerful Learning Lab integrates the Powerful Learning Framework, developed by the National Center for Accelerated Schools, which is based on constructivist learning principles. So while the study applies to a broad audience of educators interested in school improvement efforts in poor, urban and diverse settings; the study will also serve as formative data for ASP's further development of Powerful Learning Labs. This investigation that described the experience of classrooms teachers caught in the crux of comprehensive school reform will inform educators and policy makers about the impact of these reforms on classroom instruction and student learning.

Recognizing that the teacher is so vital to improving achievement for students, this study is significant to school improvement efforts, policy makers, 
administrators, departments of education, but also, it is important to teacher preparation programs as many of the participating teachers are in their first few years of teaching. Documenting and describing the planning, teaching, assessing and reflections of teachers involved in CSR and situated in a poor, urban and diverse setting will contribute to understanding the context of school reform in the nation's most challenging schools.

\section{Previous Research}

Dr. Thomas G. Chenoweth and I conducted previous research related to district factors that enhance or hinder district wide implementation of CSR in the Hazelton School District. This previous study examined the roles of the district's leadership team, which included the superintendent, curriculum director, director of student services, building principals, building APS coaches and internal facilitators. These unique ASP roles are further described in the glossary. Each of the participants in the previous study was an initial leader of the ASP movement.

The current study focused the lens more sharply on the work of regular classroom teachers. Others have investigated broader populations on school reform (Bauer \& Mesa, 1999; Hess, 1999; Barth, 2000; Leithwood, et al., 2000; Marsh, 2000) and fewer have pursued the teacher voice in highly challenged schools (Ladson-Billings, 1994; Lortie, 1975). Additionally, the CSR (D) movement is so new (implemented first in July of 1998) that there is little published on the teacher role in this comprehensive process. 
Early research surrounding CSR(D) has begun to emerge ${ }^{2}$, yet those studies were done during the first year of implementation and involved brief site visits and a few interviews with key district and community members (principals, superintendents, curriculum directors, and parents), not regular classroom teachers.

\section{Approach and Methodology}

The intent of the study was to document and describe the self-reported inner thoughts about teaching (through lesson planning), actions (teaching and assessment), and reflections (more evidence of thinking) of classroom teachers who face the challenging task of teaching in poor, urban, and diverse settings. The emphasis on context is important as the highest percent of low performing students are in urban and poor communities (Lippman, Burns \& McArthur, 1996). The contextual implications of school improvement are well noted in ethnographic and portraiture research (Wolcott, 1973; Wilcox; 1982; Spindler, 1982; Patton, 1987; Lawrence-Lightfoot \& Davis, 1997; Creswell, 1998).

The study was naturalist in that participants were interviewed and observed in their natural setting. It was a multiple case study that employed an ethnographic approach. The term multiple-case applies, as the participants are part of a cohort of teachers who are involved in both comprehensive school reform and the ASP Powerful Learning Lab, yet each teacher was treated as a separated "case" or unit of analysis for initial data collection. After each individual case was coded (see Table 10) and analyzed, I completed a series of data reductions through the iterative process 
of data collection, data reduction, and data display, sorting the individual cases into various bound cases, including binding the cases by gender, age and grade level.

These early groupings of the cases were not valid as the sample's gender was not balanced with only four men; sorting by age resulted in difficult divisions and no clear patterns to the results, and grade level was heavily skewed toward primary teachers. As a result of this preliminary data analysis, I found that the individual teacher "cases" merged into three experiential cohorts of novice, mid-career and veteran. These experiential cohorts formed the new bounded cases, and the findings of these bound cases are reported separately in chapter four, followed by cross-case analysis.

Table 10

\section{Initial Subject Codes}

\begin{tabular}{|l|l|l|l|l|}
\hline School Code & Subject Code & Name Code & Gender/Grade & Experience \\
\hline Cedar Elementary & 1 & $\mathrm{M}$ & F1 & 31 \\
\hline & 2 & $\mathrm{D}$ & $\mathrm{F} 1$ & 11 \\
\hline & 3 & $\mathrm{~J}$ & $\mathrm{~F} 3$ & 1 \\
\hline $\begin{array}{l}\text { Dogwood } \\
\text { Elementary }\end{array}$ & & & \\
\hline & 4 & $\mathrm{~L}$ & $\mathrm{~F} 4$ & 4 \\
\hline & 5 & $\mathrm{R}$ & $\mathrm{F} 1$ & 1 \\
\hline & 6 & $\mathrm{E}$ & $\mathrm{F} 1$ & 6 \\
\hline & 7 & $\mathrm{~K}$ & $\mathrm{~F} 2$ & 2 \\
\hline & & & & \\
\hline & 8 & $\mathrm{~T}$ & $\mathrm{~F} 5$ & 4 \\
\hline & 9 & $\mathrm{~N}$ & $\mathrm{FK}$ & 18 \\
\hline & 10 & $\mathrm{~L}$ & $\mathrm{~F} 1$ & 19 \\
\hline $\begin{array}{l}\text { Teak Elementary } \\
\text { School Middle }\end{array}$ & 11 & & & \\
\hline & 12 & $\mathrm{D}$ & F6 & 4 \\
\hline & 13 & $\mathrm{E}$ & M6 & 1 \\
\hline & 14 & $\mathrm{H}$ & M8 & 1 \\
\hline & 15 & $\mathrm{~B}$ & M678 & 2 \\
\hline & & $\mathrm{K}$ & F78 & 2 \\
\hline
\end{tabular}


Binding cases together (e.g., the experiential cohort) is an acceptable qualitative practice to give the group a more clear voice (Miles \& Huberman, 1994). Cross-case analysis is typical of a multiple case study (Creswell, 1998; Miles \& Huberman, 1994). Binding teacher groups by experience is supported by other researchers (Evans, 1996; Glickman, 2002; Glickman, et al., 1998)

\section{Research and Study Questions}

This proposed study is naturalist research of multiple case studies utilizing ethnographic techniques. The primary research and study question was:

1. Does participation in the Powerful Learning Lab influence the practice of regular classroom teachers? (Practice is defined as teacher planning, teaching, assessing and reflecting.) Since the data collection methods and data resources favored self-report (teachers wrote lesson plans and then reflected on those plans, and teachers were interviewed about their perception of their practice), much of the research gathered was teacher perception and beliefs about their practice. However, since I also observed these teachers, and I reviewed student work samples, which provided additional evidence to triangulate the teacher self-reports. This triangulation of data suggested there was actual influence as opposed to merely perceived influence on teacher practice.

The secondary research and study questions were:

1. What are the factors that teachers perceive support learning in a district-wide comprehensive reform effort? 
2. What factors do teachers perceive contribute to student achievement?

3. What are the implications for teacher education programs, so that teachers would be better prepared to be successful in teaching poor, urban, and diverse children?

4. What are the teachers' perceptions of the benefits and limitations of the Powerful Learning Lab experience?

\section{$\underline{\text { Role of Researcher }}$}

The role of the research was that of participant observer. In many ways, the researcher had an insider perspective (Bullough \& Baughman, 1997; Spindler, 1982), in that I had been involved with the district for three years at the time of the study. My role in the district had been one of a technical service provider for the district's school improvement model, the Accelerated Schools Project. I also developed and wrote most of the Powerful Learning Lab curriculum and materials. I co-facilitated the lab with Dr. Tom Chenoweth throughout its eighth-month life cycle. While my participation level is considerable, there is significant benefit to this "insider" view as supported by Spindler (1982).

Some of the socio cultural knowledge affecting behavior and communication in any particular setting being studies is implicit or tacit, not known to some participants and known only ambiguously to others. A significant task of ethnography is therefore to make explicit what is implicit and tacit to informants and participants in the social settings being studied. (p.7) 
In order to understand the familiar, tacit thoughts, beliefs, and actions of teachers, it is more likely that a participant-observer would be able to probe these areas than a complete outsider. My familiarity with some of the participants and our established positive relationship lead to increased access to information and high comfort level for participants.

The limitations of the participant observer are most directly related to objectivity. I found myself being very skeptical of positive results, wondering if the participants didn't want to hurt my feelings. Granted, some participants were likely hesitant to report something unfavorable about the lab out of courtesy to my feelings. I viewed the results as a bit rose colored because of this tendency for teachers to avoid conflict, and even their lack of experience in providing critical feedback. However, feedback was submitted anonymously during each of the lab's face-to-face sessions, (which included a period of time prior to formal data collection) and the group didn't appear to hold back criticism, at times they were brutally honest.

Since this study was a phase I research project, as it was the study of an early model for PLL, the next step would be to develop a more objective methodology either employing survey, or third party investigators to further determine the affect of the professional development provided through the Accelerated Schools Project. Never the less, in such a small sample, and in preliminary phase I research, the benefits of rich description and insider view of regular teacher practice outweigh the limitations. This study will inform further development of ASP Powerful Learning 
Labs, further research and other aspects of professional development that ASP offers to its schools.

\section{Selection of Sample}

The sample identified for study were those participating teachers who work in Hazelton's three elementary and one middle school, who were also participating in the Accelerated Schools Project Powerful Learning Lab. So they were a purposive (sometimes called purposeful) sample, representing both elementary and middle school teachers. The sample included all of the participants rather than a random sample, as the entire group of fifteen was still a small sample. Purposive sampling is typical of qualitative research as it lends to rich description and is research that teachers believe (Putnam \& Borko, 2000). Patton (1987) states, "The power of purposeful sampling lies in selecting information-rich cases for study in depth." (p. $52)$.

Fifteen teachers were selected for the sample, and fifteen teachers completed the study. All of these teachers participated in the Powerful Learning Lab held between August 2000 and March 2001. Teachers continued to submit written reflections and lesson plans through June of 2001. Each teacher participant was from a CSR or Schoolwide Title I school. The district was totally immersed in comprehensive school reform, both federally and locally funded. 


\section{$\underline{\text { Data Collection }}$}

The data collection included two rounds of individual interviews of each participant, a formal observation of each participant at work, and analysis of each participant's powerful learning lab portfolio, which includes lesson plans, reflections and student work samples. More informal observations (brief walk-throughs) took place two additional times, as part of the ASP site visits that are scheduled for February and March 2001. Second round interviews took place between August and December 2001. Observations took place between January and March, 2001. Interviews were audio taped and then transcribed ${ }^{3}$. Classroom observations were written using the Accelerated School's Classroom Observation protocol (Appendix G), which emphasized powerful learning. Teacher reflections were part of the Powerful Learning Lab Portfolio, and a final written reflection on the lab experience. Teachers submitted final lesson plans and written reflections through June, 2001. I kept a journal of notes and emerging themes throughout the data collection phase. I was the sole researcher for data collection. Each of the data collection methods is discussed in the following sections.

\section{Interview Protocol}

Each participant was formally interviewed twice by the researcher. The first round of interviews took place immediately following the final (March) PLL session. Each participant was interviewed at his/her choice of location either at school or at a local coffee shop. Two first round interviews were completed by phone, as the 
participants were unavailable during the days I spent in Hazelton. I asked the questions from the protocol, while taking notes, and each interview was audio taped.

The purpose of the interview was to probe a bit deeper into the thinking of the sample teachers. I had reviewed their portfolios that included lesson plans, peer debriefing notes, and written reflections of the lessons planned and taught. The interviews were semi-structured with ample prompting and opportunity for sample participants to expound about their perceptions of their own teaching practice. My field notes reflect interviewees appeared relaxed, willing to talk. I transcribed each audio tape and returned an electronic or hard copy of the transcription to each participant for further reflection and an opportunity to append any comments. The final interview took place after the PLL concluded, throughout the summer and fall of 2001. Second interviews were done by telephone, transcribed and sent through electronic mail to each participant.

The purpose of the second interview was to be able to verify patterns and themes that had emerged in the first round of interviews and examination of the lab portfolios. I was trying to determine if over time, several months the sample participant's perceptions had changed. There were no clear indicators that their perceptions had changed, and there was almost no variation or additional information gleaned. The participants were invited to review the transcript in order to comment, and amend its accuracy and clarity (see Appendix F for the complete interview protocol). Although the written protocol was done in table format, each question's 
response was lengthy, often filling numerous lines of text, not the few illustrated in the blank protocol sheet.

The interviews were the main source of data for the secondary research questions. The secondary research questions were asked and answers were recorded without prompts.

Utilizing a standard interview protocol, and using a sole researcher provided better reliability to the study, as all participants experience the same interview protocol administered by the same researcher, this eliminated the need for an interrater reliability check.

\section{Observation Protocol}

I observed each participant teacher for at least one lesson of thirty to eighty minutes in length. This observation was chronologically linked to one of the written lessons that had been planned during or immediately after the PLL lab. The purpose of the observation was to determine if I could observe anything out of the ordinary to dispute the teachers' self- reporting in their portfolios. I was triangulating the selfreports of the interviews and the written reflections in the portfolio to add a verification or reality check that teachers were reporting their teaching practice in a way that rang true. During the observation, I made notes using the classroom observation tool developed by the National Center for Accelerated Schools for the Tools for Assessing School Progress (TASP), an ASP internal assessment of school 
implementation. The classroom observation tool is included in Appendix G; the complete TASP is available on the ASP website at: www.acceleratedschools.net My purpose in making a scheduled observation was two-fold; first, to inform this study. I was curious about a match between what the participants of this study were reporting in their written lesson plans and reflections and what I might see during one of these lessons. I was looking for patterns that were consistent or inconsistent with their self-reporting. I followed up the observation with a close examination of the teachers' portfolio about the lesson that I had observed. I observed no inconsistencies with the teacher's self-reporting in the lab portfolio. These teachers were describing what I observed.

The second purpose of using the classroom observation tool was not directly related to the study. I was helping to pilot the tool for the inclusion in the TASP, a necessary task related to my work for the ASP movement. Unfortunately, the tool was a bit cumbersome, the observation tool was definitely targeting the evidence of the powerful learning components in a lesson, but there was not a clear match between the observation tool and the PLL portfolio language. Also, in the portfolio the teachers were responding to their own thinking, and I couldn't observe their thinking. However, I could observe how they interacted with students, student actions and student work products. The observations provided some anecdotal references to the interviews and written reflections which were reported, and the observations verified that the teachers' self-reporting was accurate at least for the one lesson that I observed. 
In addition to this formal observational component of the study, since it was my third year working for the district, for some of the teachers in this study, I'd had the opportunity to visit them several times during previous site visits to their schools. So, while the design of the study called for a single observation, my work had provided me access to observing the participants prior to the data collection timeline.

\section{Portfolios and Written Reflection Protocol}

Each participant's portfolio was reviewed as part of his/her participation in the lab. I developed a portfolio field note form (Appendix $\mathrm{H}$ ) for making notes while reviewing the portfolios. I made photocopies of the participants written reflections and debriefing statements (see Appendix C), and then transcribed each of the written documents into the QSR NUD*IST 5.0 software program. Each transcription was coded to identify the author and bound to the individual teacher case. Since each participant retained the portfolio and written reflections; I did not make copies for the participants.

The purpose of including the portfolio in the data collection process was this contained the most objective pieces of data, the student work samples. Without the inclusion of student work as evidence of a lesson, the data would be exclusively teacher perception. I'd have no way of verifying that a lesson was even taught, and not just planned. Because the portfolio included student work, there was accountability for accuracy on the part of the teacher. A teacher couldn't claim that all students had met an objective when their work samples indicated that some 
students had struggled. The triangulation of the interviews, my observation of one lesson, and the lab portfolio which included both teacher written plans and reflections, and student work samples support that the evidence went beyond mere perception of teaching practice.

\section{Data Analysis}

Initially, a description of each individual participant case was completed along with a within-case analysis using the QSR NUD*IST 5.0 software analysis program for the transcribed interviews and transcribed written reflections. After data reduction, data display and initial analysis the individual participant cases were stratified in several demographic groupings. I ran preliminary analysis by gender, age, and grade level. I chose not to conduct an analysis based on ethnicity, because my sample was predominately white. Early analysis yielded little patterning of results, the gender of the group was very skewed with only 4 men, all whom taught at the middle school level. Grade level grouping was also problematic, since I had very few intermediate grade teachers. So, I grouped the individual cases in experiential cohorts (novice, mid-career and veteran) for further and final analysis. The similarity of experience that the experiential cohorts were reporting was actually an early finding of the study. The literature on both adult development and teacher career development support the decision to bind the cases by experience. Teachers who are at a similar experience level tend to report similar experiences. 
The experiential cohort case findings are reported in chapter four. The merging of individual cases into small groups rendering a newly defined case is common in qualitative research, and especially in multiple case research (Miles \& Huberman, 1999). Additionally a thematic analysis or cross-case analysis was performed utilizing the software. Emerging themes were identified and then evidence of those themes is discussed in both chapters four and five. The data collection methods, purpose, benefits and limitations are summarized in Table 11. It is through the triangulation of data and data collection methods that I developed a complex and rich description of these teachers in the center of school reform. Examining spoken and written documents balanced an "interview" only protocol. Also, there were times when the participants' writing was more focused than their interviews. The observations provided anecdotal information and supported the teacher self-reports. In qualitative research it is important to adhere to the genre's standards and to explicitly address verification. Both of these issues are addressed in the next section. 
Table 11

Types of Data Collection, Method, Purpose, Benefits and Limitations

\begin{tabular}{|c|c|c|c|}
\hline $\begin{array}{l}\text { Type of } \\
\text { Data } \\
\text { Collection }\end{array}$ & Method & Purpose & $\begin{array}{l}\text { Benefits and } \\
\text { Limitations }\end{array}$ \\
\hline $\begin{array}{l}\text { Preliminary } \\
\text { Interview }\end{array}$ & $\begin{array}{l}\text { Face-to-face (audio taped) } \\
\text { transcribed then analyzed; } \\
\text { Telephone interviews } \\
\text { were transcribed over the } \\
\text { phone, and then analyzed. }\end{array}$ & $\begin{array}{l}\text { Document participant's } \\
\text { voice; determine } \\
\text { participants thinking in } \\
\text { terms of planning, } \\
\text { teaching, assessment of } \\
\text { student work, and } \\
\text { reflection relating to CSR } \\
\text { and the Powerful Learning } \\
\text { Lab }\end{array}$ & $\begin{array}{l}\text { B: allowed teachers to } \\
\text { explain thoughts and } \\
\text { actions that may not be } \\
\text { explicit in other types } \\
\text { of data collection } \\
\text { L: relied on language } \\
\text { ability }\end{array}$ \\
\hline $\begin{array}{l}\text { Classroom } \\
\text { observation }\end{array}$ & $\begin{array}{l}\text { researcher took field notes } \\
\text { on the TASP classroom } \\
\text { observation tool, semi- } \\
\text { verbatim }\end{array}$ & $\begin{array}{l}\text { Observation of teacher } \\
\text { behaviors, sought } \\
\text { confirmation and/or } \\
\text { discrepancy of interview } \\
\text { data and portfolio self- } \\
\text { reporting }\end{array}$ & $\begin{array}{l}\text { B: observations } \\
\text { portray a richer more } \\
\text { complex description of } \\
\text { teacher behavior than } \\
\text { words alone } \\
\text { L: can't observe } \\
\text { teachers' thinking }\end{array}$ \\
\hline $\begin{array}{l}\text { Examination } \\
\text { of Teacher } \\
\text { Portfolio }\end{array}$ & $\begin{array}{l}\text { Researcher read \& made } \\
\text { notes on teacher lesson } \\
\text { plans, student work } \\
\text { samples, and written } \\
\text { teacher reflections; } \\
\text { written reflections } \\
\text { transcribed }\end{array}$ & $\begin{array}{l}\text { Written verification and } \\
\text { clarification of interviews, } \\
\text { portfolio self-reports and } \\
\text { lesson plans and } \\
\text { observations. Student } \\
\text { work samples were } \\
\text { evidence of teaching } \\
\text { practice }\end{array}$ & $\begin{array}{l}\text { B: student work } \\
\text { samples verify (or not) } \\
\text { teacher's planning \& } \\
\text { reflection, may elicit } \\
\text { new patterns \& themes } \\
\text { L: small sample, } 6 \\
\text { students, possible } \\
\text { problems with mobility } \\
\text { of students }\end{array}$ \\
\hline $\begin{array}{l}\text { Teacher } \\
\text { verification of } \\
\text { interview } \\
\text { transcription }\end{array}$ & $\begin{array}{l}\text { Teacher participants received } \\
\text { electronic and/or written } \\
\text { copy of their own interview } \\
\text { transcription }\end{array}$ & $\begin{array}{l}\text { Allowed teacher participants } \\
\text { to clarify any information and } \\
\text { refute misperceptions and or } \\
\text { inaccuracies }\end{array}$ & $\begin{array}{l}\text { B: more accurate data } \\
\text { collection }\end{array}$ \\
\hline $\begin{array}{l}\text { Final } \\
\text { Interview }\end{array}$ & $\begin{array}{l}\text { telephone; } \\
\text { transcribed then analyzed }\end{array}$ & $\begin{array}{l}\text { Documented any new } \\
\text { learning, or change in } \\
\text { participant's voice, planning, } \\
\text { teaching, assessment of } \\
\text { student work, and reflection. } \\
\text { Help clarify \& document } \\
\text { emerging themes }\end{array}$ & $\begin{array}{l}\text { B: allowed researcher to } \\
\text { verify themes \& trends } \\
\text { L: relied on language } \\
\text { ability }\end{array}$ \\
\hline
\end{tabular}


Standards of Qualitative Research

Addressing the standards of qualitative research (Creswell, 1998) was an important aspect of this study. The following standards were met in the design of this study:

1. The Standard of Positionality: the bias of the researcher was explicit in that I stated my biases: a) teachers are the ultimate purveyors of education and school improvement, and b) I addressed my participant-observer status and my contributions to the design of the powerful learning lab. In many ways this study was a study of a project I developed.

2. The Standard of Community: This study was conducted in twin communities: the immediate geographic community of Hazelton, and the more nebulous community of the national Accelerated Schools Project. The study addressed both communities and served the purpose of sharing findings with both communities.

3. The Standard of Voice: The study was a vehicle for teachers to be heard as individuals and as a cohort. Multiple, alternative, collective and dissonant voices were shared.

4. The Standard of Reciprocity: The relationship between researcher and participant is contingent upon high quality sharing, trust and 
mutual respect. I was able to access the participants' viewpoint because of an existing trusting relationship.

5. The Standard of Sacredness of Relationships: Every participant voice was heard; yet identities remained strictly confidential. No sharing of individual interview text or observations was shared with school administration. Participant's findings were not identified by gender, teaching assignment, ethnicity, or age that might pinpoint any one participant's identity. A cohort profile was provided, but no data linking individual responses to identifying demographics was shared.

\section{Verification}

While qualitative inquiry is sometimes criticized by quantitative researchers for insufficient verification methods, qualitative verification methods increase the ability of researchers to make assertions about qualitative studies. The following verification methods were employed in this study:

1. Prolonged Engagement and Persistent Observations: The data collection for this study encompassed ten months and involved in-depth interviews, observations, and analysis of teacher portfolios. Additionally, the sample teachers had been working in the Powerful Learning Lab with me since August 2000. Therefore the early establishment of relationships, the building of trust between participants and me had already occurred. I was readily accessible by telephone, and electronic 
mail, which increased the participants' ability to confirm and clarify data. In terms of understanding the context of the study, this is the third year I has been conducting work in this school district and the second qualitative study related to comprehensive school reform (Chenoweth \& Petti, 2000).

2. Triangulation: The study utilized multiple and different sources, methods, and theories to provide corroborating evidence. The use of multiple and different sources to illuminate emerging themes is consistent with other ethnographic research (Spindler, 1982; Lincoln \& Guba, 1985: Miles \& Huberman, 1994; Creswell, 1998). The study's foundation was teacher self-reporting through interviews, written lesson plans and written reflections on their teaching. These self-reports were triangulated by my observations of their teaching a lesson and the evidence in the lab portfolio, especially the student work samples.

3. Peer Review or Debriefing: My doctoral advisor and dissertation committee acted as external reviewers of the research process. Lincoln and Guba (1985) define the role of the peer reviewer as a "devil's advocate" or as Creswell (1998) states, an individual who keeps the researcher honest; asks hard questions about methods, meanings, and interpretations; and provides the researcher with the opportunity for catharsis by sympathetically listening to the researcher's feelings (p. 202). 
4. Negative Case Analysis: As themes and patterns emerge in the data collection and analysis process, was the possibility that single or outlier cases will be identified. These cases that do not fit an emerging pattern are termed negative cases (Lincoln \& Guba, 1985; Patton, 1987; Miles \& Huberman, 1994). While no obvious negative cases appeared to disconfirm emerging themes; the mid-career cohort emerged in some themes as the dissonant voice.

5. Member checks: I solicited participant's views of the credibility of the findings by taking the transcriptions of the individual cases back to the participants for review and comment. This allowed the participants to examine data and provide alternative language, critical observations or interpretations of the data that I might have missed. While most participants had little to offer during this process, one provided more insight and all were given the opportunity. The member check process has been well documented in qualitative research (Lincoln \& Guba, 1985; Miles \& Huberman, 1994; Stake, 1995; Creswell, 1998).

\section{Summary}

The significance of this study was to determine if the effort, resources, and organizational change required in Comprehensive School Reform (CSR) is making a difference to what others (Bodilly, 1998; Calhoun \& Joyce, 1998; Hill et al., 2000) describe as the core technology of schools, that of teaching and learning. 
Listening at the teacher level enabled me to describe the practices of those at the front line of school reform, i.e. regular teachers. The teaching practices examined in the study were teacher planning, teaching, assessing, and reflecting.

The sample of this study was a group of fifteen regular classroom teachers who participated in a year-long professional development program, the Powerful Learning Lab associated with the Accelerated Schools Project. These teachers were from three elementary schools and one middle school that were in its third year of the Accelerated Schools Project, a comprehensive school reform model.

Data collection involved structure interviews, classroom observations and the review of teacher portfolios. The teacher portfolio consisted of written lesson plans, samples of student work, and written teacher reflections of those lessons. Most of the data was teacher self-report, however the portfolio and classroom observations balanced the self-reports of the interviews and reflections in order to triangulate the data and data collection methods.

Qualitative data is sometimes ambiguous. Some participants were more verbal and eloquent than others. Some participants wrote detailed lesson plans and others didn't. Participant writing skills and passion varied. They didn't always answer interview questions directly, they talked about other subjects, and they sometimes strayed from the point. Classroom observations were somewhat problematic; it was impossible for one observer to see everything. Writing about one's teaching is a proven method of thinking aloud and reflecting, but can also wandering from the point. Any one of these data sources is insufficient and 
inherently flawed. However, utilizing multiple and various sources of data and data collection methods provided much stronger methodology, and stronger evidence and findings.

Much of this study was the recording of the stories of the participant teachers' perceptions and experiences. At times the data was murky or incomplete. Yet, using all these data collection methods and varied sources of data, I was able to determine patterns and uncover some clarity to provide a rich picture of the experiences of these novice, mid-career and veteran teachers. Their story unfolds in the findings of the next chapter. 


\section{End Notes}

1. For example: U.S. Department of Education studies related to the assessment of Title 1 (1996), Kirst (1990), and Passow (1990), Olson \& Rothman (1993).

2. See for example: U.S. Department of Education (1999, November) CSRD in the Field: Fall 1999 Update. [On-line] Available: http://www.ed.gov/offices/OESE/compreform/csrd99report.html or University of Texas at Austin, Charles A. Dana Center. (1999). Hope for Urban Education: A Study of Nine High-Performing, High-Poverty, Urban Elementary Schools. Washington, DC: U.S. Department of Education, Planning and Evaluation Service.

3. Participants may decline audio, which would result in principal investigator making field notes and taking verbatim quotes manually. 


\section{CHAPTER IV}

\section{RESEARCH FINDINGS}

Effective teachers think about what they are currently doing, assess the results of their practice, explore with each other new possibilities for teaching students, and are able to consider student's perspectives. (Glickman, et al., 1998, pp. 76-7)

\section{Introduction}

The research findings for this study are reported first as bounded cases.

Each case is referred to as an experiential cohort. The decision to bind the cases by experience was made after individual teacher's cases were analyzed, and through a series of base data (demographic) analyses, the experience cohort emerged as the logical and most unified voice. This pattern of similar responses by experience level was one of the early findings of the study. There were clear and repetitive sources of evidence that the individuals within the experiential cohorts were reporting similar perceptions and experiences of teaching and participation in the Powerful Learning Lab (PLL). Others have reported that teachers experience similar work related phenomena at experiential benchmarks (Evans, 1996; Glickman, 2002; Glickman, et al., 1998; Levine, 1989). Each case (experiential cohort) was analyzed around the four components of teaching practice (planning, teaching, assessing and reflecting). All data collected were stratified into the 
experiential cohort, and reported collectively. Therefore, the case report for each experiential cohort includes data that were collected in interviews, written reflections, and classroom observations. This holistic review of the data led to a clearer portrait of the experiential cohort, rather than separately reporting on the findings of the interviews, the written reflections and the classroom observations. The reporting of the separate experiential cases focuses on the primary research question:

1. Does participation in the Powerful Learning Lab influence practice of regular classroom teachers? (Practice is defined as teacher planning, teaching, assessing and reflecting)

Following each experiential cohort analysis, there is cross-case analysis (actually a cross-cohort analysis) of the four components of teaching practice (planning, teaching, assessing and reflecting). Subsequently after the cross-case analysis report, there is a report of the emergent themes from the research (collaboration, critical thinking and writing to learn), leading to further discussion of these themes in chapter five. Finally the last section of the chapter analyzes findings of the remaining secondary research questions:

1. What are the factors that teachers perceive support learning in a districtwide comprehensive reform effort?

2. What factors do teachers perceive contribute to student achievement? 
3. What are the implications for teacher education programs, so that teachers would be better prepared to be successful in teaching poor, urban, and diverse children?

4. What are the benefits and limitations of the Powerful Learning Lab experience?

\section{Case Reports}

The case reports are stratified into three experiential cohorts or cases, novice, mid-career and veteran. This experiential stratification is supported in the literature review that discussed the teacher career cycle, as teachers experience similar phenomena at distinct career benchmarks.

\section{Case One: Novice Cohort}

Case description. The Novice Cohort consisted of a total of seven teachers. All had less than three years experience; four were first year teachers and three were in their second year of teaching. This cohort contained two primary grade teachers, one intermediate grade teacher and four middle school teachers. There were three men and four women. The base data table displays more of their case profile (see Table 12). As a group they were young, six of them in their 20 s, and they all volunteered to attend the Powerful Learning Lab. None expressed any feelings of coercion toward participating in the lab. All seven were still teaching a year after the study, and six remained in the Hazelton district. Collectively, this cohort began to 
bond even though, they did not necessarily work together in their respective schools, nor were they assigned teamwork in the lab. It was if they went to the lab and gleaned from their more experienced peers, but then often informally grouped to share ideas, strategies and (at times) comfort and support. During the PPL the movement between working in mixed experiential groups and then smaller novice groups was a natural group dynamic that ebbed and flowed throughout the lab experience. One year after the lab, the novices report that they still communicate with lab participants in each experiential group.

Table 12

Base Data of Case One: Novice Cohort

\begin{tabular}{|l|l|l|l|}
\hline Age in years & Years experience & Gender & Grade level \\
\hline 23 & 1 & Female & primary \\
\hline 24 & 1 & Female & Intermediate \\
\hline 25 & 2 & Female & Primary \\
\hline 25 & 1 & Male & Middle School \\
\hline 26 & 1 & Male & Middle School \\
\hline 26 & 2 & Female & Middle School \\
\hline 30 & 2 & Male & Middle School \\
\hline
\end{tabular}


Key findings from the novice cohort include:

Planning: Novice teachers spent most of their time planning for instruction (compared to mid-career or veteran teachers) and felt the lab influenced their planning more than other practices.

Teaching: Novice teachers displayed confidence: they weren't afraid to try many teaching strategies and assessment method Assessment: Novice teachers didn't focus on assessment as much or as deeply as mid-career teachers, and used assessment to modify their planning. Reflection: Novice teachers increased their frequency of reflection as the year progressed, reflections provided a gateway to meaning.

Planning and the novice cohort. Teacher Planning is often considered a "pre-active" phase in teaching practice (Costa \& Garmston, 1994). "Planning may well include the most important decisions teacher make because it is the phase upon which all other decisions rest" (p. 90).

Planning is one of the more time-consuming aspects of teaching for beginners (Featherstone, Munby \& Russell, 1997; Freiberg \& Driscoll, 1992). An analysis of the lab portfolio reflections supports that the novice group struggled with planning, especially during the first few months of the school year. Novice teachers reported feeling "overwhelmed", "uncertain", and "unprepared” to plan effectively, as they were learning how to teach and what to teach simultaneously. Every novice reported on the five components of powerful learning, that the words associated with the components became a professional vocabulary for them, a way 
to frame their planning and a way to communicate about teaching to colleagues.

For some the powerful learning vocabulary opened the door to speak to other colleagues as this beginning teacher explains,

The PL lab has given me a mind-frame for planning. The teaching program I was in [a University Master's degree program] used a lot of the same ideas, but [the] powerful learning [lab] has given me the vocabulary to use it. We talked about instruction that was authentic, learner centered, but we didn't call it that. Now that I have a vocabulary to use these ideas; it has really affected my planning in that I am more reflective when I plan, like I want to have the components of powerful learning in my teaching. Like if I look at my plans and if I don't have it. Powerful learning also gives me a vocabulary to talk with other teachers, especially the coach, she can tell me, "Oh that is so authentic or learner-centered". (novice teacher, interview)

This cohort tended to comment specifically and repeatedly on the powerful learning components and often used them as a barometer to measure their planning, carefully scanning lessons for inclusion of one or more. The following quote illustrates the internal measuring of planning with the five components that more than half of the novices reported:

I find a lesson to not be well planned if I do not include one or more [powerful learning] components in each of my lessons. I find that there are some components I feel more comfortable with planning than others. (novice teacher, interview)

Many reported out that some components were "easier" or more "fun" to plan for, as the following quotation illustrates:

I really love planning for the authentic component. I find it very easy to ask myself questions such as: 'Does this lesson relate to the real world? Are students able to see how the concept related to their daily 
lives? Do students understand and see a valid reason for learning the concept at hand?' (novice teacher, interview)

Others reported that the five components allowed them to examine their

teaching for weak areas, and they were able to use the lab experience as a way to

practice and improve teaching strategies that had not been previously tried.

I try to make my teaching more authentic, I think I was in the dark on this [component] before the lab, but I keep trying to search for more authentic reasons; it is one that I got more out of the lab. It [planning for the authentic component] helps me when kids get stuck. (novice teacher, interview)

I have a harder time planning for the continuous component. I think this is because I am fairly inexperienced and I often have a hard time making different disciplines connect, as I am frantically trying to cover a large variety of curriculum. Also as I proceed through the school year, I feel so behind that I hardly am able to revisit concepts covered earlier in the year. Planning for the continuous component is harder for me, and I think this is the one component I am least prepared to teach adequately. (novice teacher, interview)

For these novice teachers the planning phase was where most mentioned a connection to other aspects of teaching, such as assessment or reflection. The overlap of the teaching practice components became apparent to some of the novices àfter the mid point of the year. In a spring interview, a novice teacher reported a more holistic approach to teaching, with comments about thinking simultaneously about the actions associated with teaching practice. Prior to late spring, the novice teachers expressed a cyclical, sequential view of the teaching practice (see Figure 4). For many novices the separateness of the components of teaching practice remained throughout the year. 


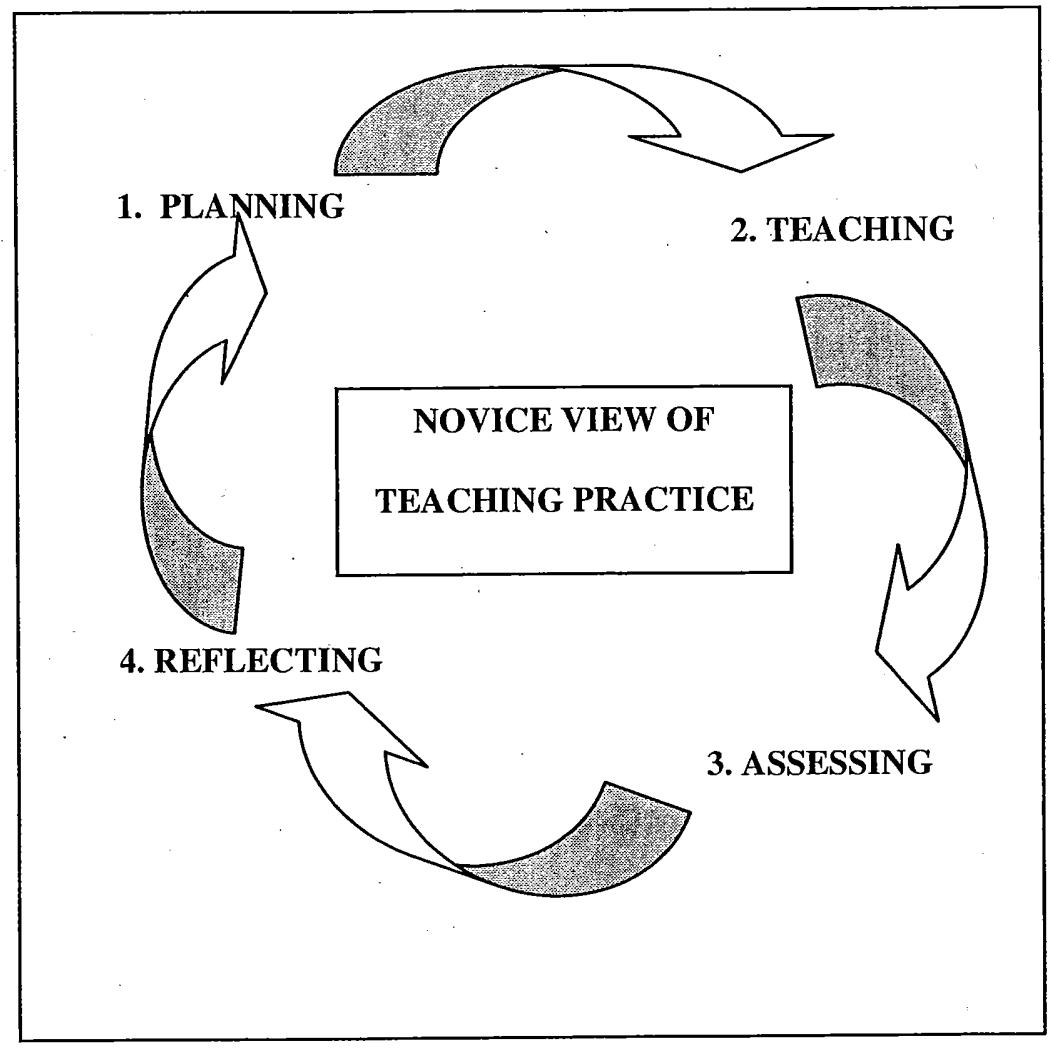

Figure 4. Novice cohort's cyclical view of teaching practice.

Teaching and the novice cohort. The novice cohort's voice in the area of teaching was one of confidence, especially at the end of the school year. Many expressed in writing and through their interviews and classroom observations a sense of confidence that they could be effective and that they were willing to continue to learn to improve their craft. Perhaps one of the more pragmatic sources of evidence of this confidence is that all of these novice teachers are still at it, still working, most in the Hazelton district. Novice teachers reported their stress level in the spring of 2001 was considerably less than it was in August of 2000, when 
many of them were facing their first teaching assignment ever! The August and September reflections on their teaching voiced concern about their ability to do the work, they often reported feeling overwhelmed.

I'm not sure I can make a difference, my students are all trying but there are so many and I'm just rushing through lessons to get curriculum covered, I think I'm leaving them in the dust. I hope I will get better at balancing the kids' needs and my ability to teach. (novice teacher, September 2000, written reflection)

Being a part of the year long cohort contributed to the feelings of confidence reported by the novices during spring and summer of 2001. They enjoyed the lab organization that included peer teaching, and an opportunity to both practice new strategies on each other and collaborate about teaching ideas. One novice captures these thoughts,

The teaching strategies that were shared were really great. I liked the way that we did the peer teaching,[ at the Powerful Learning Lab] it made us become powerful teachers of teachers, it was way better than a lecture. It gave us a good visual for a powerful lesson. (novice teacher, interview)

Another novice teacher explained that powerful learning training gave her ${ }^{1}$ the courage to take risks to challenge her students more.

[Powerful learning influenced my teaching] by definitely trying to challenge my kids more. Like in a lesson I did yesterday, I used the word "homophone" rather than "pairs", I want them to be challenged, so they will know more. Some of the words I used yesterday, I thought the kids wouldn't be able to read, but they could read it, and their partner sometimes knows one word. It also helps with English language learners to partner with a child. (novice, primary grade teacher, interview)

I have noticed that the lab has effected my instruction in some critical ways. To begin with I find my role to be more of a facilitator in the 
class, and less of a dispenser of information. Although I don't do this as much as I would like to, I often make a very conscious effort to not be a talking head in front of the classroom. (novice teacher, interview)

By late spring 2001, the novices were able to demonstrate an ability to translate what was studied, written and discussed into action. The classroom observations indicated evidence of the powerful learning components, and student work products indicated students had attained concepts. The novices collectively reported improvement from summer 2000 to spring 2001 in their ability to understand and translate powerful learning into their everyday teaching repertoire.

The Powerful Learning Lab has helped me to see how I can take these [powerful learning] components and translate them from an idea on paper to a working and active view of instruction in my own classroom. (novice teacher, written reflection)

Assessing and the novice cohort. The contextual diversity of the Hazelton School District was mentioned more often in the context of assessment than in any other teaching context. These novice teachers were well aware of the pressures, and the difficulty of assessment in the state and the added challenge of so many English Speakers of Other Languages (ESOL) and English Language Learners (ELL). I observed one novice teacher whose entire math class was composed of non-native English speakers, I overheard at least eight languages during the observation and there were two new students who had been in the United States less than a month. The teacher allowed students to process information in any language, but was strapped to find a speaker to partner with a new Somali student. The teacher tried nobly to translate most of the directions for the lesson into Spanish (even though the 
teacher was not fluent in Spanish), and used excellent picture clues and a sort of signing/miming set of directions. Nevertheless, students were able to form groups and complete the assignment.

Observing this lesson, I noticed students were processing the task in many native languages. The reality of the complexity of a school district where there are forty world languages was truly evident. Several novice teachers commented that powerful learning assessments would be more appropriate than traditional paper and pencil assessment for their diverse students.

I'm not afraid of various types of assessment. I find myself more accepting of a greater variety of responses than before [the Powerful Learning Lab], which goes along with trying to be more inclusive. For example I think of ways my non English speakers can respond that might be different from my English speakers. Pictures, native language responses, I don't know, I think I'm more flexible about how kids respond. I think I accept a wider variety of assessment, even though my PL standards are higher. (novice teacher, interview)

Intuitively I've noticed that I've had to change my assessments, to make accommodations for kids, because they [ESOL and ELL students] weren't strong enough in a test format, but they could perform orally, or do a project. I try to assess differently throughout my teaching. (novice teacher, interview)

Some of the novices made a connection between student performance assessments and their own teaching. They described a constant questioning of their actions as they formally and informally assessed their students' progress.

It [the Powerful Learning Lab experience] made me look at assessment in a deeper way. When we did the [assigned, Powerful Learning Lab] lessons, we looked at kids at 3 different levels, I looked at the lesson in a different way, I asked myself, 'Why didn't this kid get it?' It made me modify my instruction based on what I saw on the assessment, and it pointed out some weaknesses in my 
lessons; It made me look at assessment at a deeper, wider level, more than just, 'Did they get it?' (novice teacher, interview)

One novice made a connection between the teacher's powerful learning portfolio, which was a form of assessment and assessment methods with students. While it was the intent of the Powerful Learning Lab design to model and mimic effective powerful learning strategies, only one novice teacher commented on this event.

Because my portfolio has forced me to be very objective and goal driven, I now focus assessment not on one specific answer, yet rather how closely my students address the objective at hand. Although I already saw the value of rubrics though my Master's work at the university, I have seen through the lab that using a rubric is often more powerful than creating a key. I like the freedom I feel that powerful learning has brought to assessment. I am excited about the large variety of assessment opportunities that are now available through the philosophy of powerful learning. (novice teacher, written reflection)

Assessment did not seem to trouble the novice cohort, and they reported that assessment is on their minds throughout the teaching process. By spring many mentioned that their planning actually began with thinking about assessment.

In going along with planning, part of assessment, is part of what I think of first, so I ask myself, how am I going to find out whether or not they've learned what I wanted them to, whether I use paper and pencil, a test, or a project. (novice teacher, interview)

Eighty six percent of the novices reported the connectedness of planning and assessment. Throughout the year's participation in the lab they moved away from separate acts of planning, teaching, and then assessing, more toward an iterative or cyclical view of the practice of teaching. However, the novice group 
maintained a more sequential view of teaching (see Figure 3) than their more experienced peers. The novices reported and demonstrated during their observations an ability to "think on their feet" and make adjustments to their teaching using the powerful learning components.

Planning, assessment and teaching are related, I'm more conscious[since the lab] of how I'm affecting my kids, I'll change in the middle of a lesson that isn't going well, I'll make an adjustment, I'll try something new and improve the lesson. I had been teaching with a real solid pictorial emphasis, and I wasn't using kinesthetic, or symbolic, so I changed modes, to make the lesson more challenging, ; utilizing more elements of powerful learning and to build on the pictorial, when I added the other two[components], the kids were getting it better because I wasn't hitting all of their needs. [before] (novice teacher, interview)

Reflecting and the novice cohort. Teacher reflection has been reported as one of the actions of effective teaching (Schon, 1983; Costa \& Garmston, 1994;

Glickman, 2002; Goodlad, 1994; Hargreaves, 1994).

Both Mezirow (1981, 1990) and Brookfield's (1986) work on adult learning indicates that in order to learn and grow, teachers need to participate in a continuous cycle of collaborative activity and reflection on that activity, and need to develop the powers of critical thinking. ${ }^{2}$

Since the novice cohort had recently completed a college licensure program reflection was not new to this group. In fact, they reported that reflection was expected in their university programs. However, the Powerful Learning Lab gave them an anchor for structuring their reflections on their practice.

Fortunately I come from an MAT program that highly emphasized reflective thinking. In fact my entire Master's project was based on reflection. I don't really think the Powerful Learning Lab changed my view on reflection, but helped to reinforce what I 
was already doing (which is always very reassuring). (novice teacher, written reflection)

While early reflection exercises in the Powerful Learning Lab were a bit forced for some novice teachers, especially the men, who wrote less (quantity) in their lab portfolios than the women, the incidence of reflection for all the novices increased, and they began to see reflection as a natural part of their work.

Yeah, that [reflection] was a big part of it [the Powerful Learning $\mathrm{Lab}$. We were also adopting a math text, and we needed to reflect on the materials, what we were doing, why we doing [something], was it beneficial? Did it [the new math program] do better, or accomplish what the lesson was supposed to. The labs supported this, for me, now I do it [reflect] all of the time. (novice teacher, interview)

This transition from little reflection and analytical thought to frequent, almost second nature reflection is echoed throughout the novice artifacts as the school year progressed.

I didn't really analyze [or reflect on] what I was doing [in the fall]. Now [spring], I'm more critical, I'm checking to see if all kids are included. (novice teacher, interview)

The Powerful Learning Lab portfolio required lab participants to follow six students throughout the school year, collecting student work samples and using that small sample of work for reflection on lessons taught and for planning for instruction. This tracking of student work throughout the year assisted novice teachers in their reflection, and for some raised their level of awareness of selfevaluation. "The lesson write-up of looking at six kids, made me more aware that kids weren't engaged." (novice teacher, interview) 
By late spring, the novice cohort had integrated reflection into frequent if not daily practice.

Everyday, after every class, I'm reflecting now, after my first block, I look at my lesson, then make changes, and it's better the next block. I always critique myself, and change my lessons to make it better. I can make modifications because I teach the same subjects all day. (novice teacher, interview)

For most, the reflection process is what brought meaning to their practice. When these novices stepped back to reflect on their teaching or their student performance, no matter how complimentary or critical those reflections were, they reported that reflection was the gateway to meaning.

Through reflecting on the five components, I find my planning to be very focused and meaningful. (novice teacher, written reflection)

My reflection is so focused now, from planning instruction to instruction in process, to evaluating the success of instruction. Each powerful learning component opens a whole world of reflection and a unique slant to view instruction in the classroom. It is great to reflect on a lesson from an authentic perspective, and then view the same lesson from a learner-centered perspective. The combination of perspectives makes my reflection so much deeper and more meaningful. (novice teacher, interview)

I think more than anything, the Powerful Learning Lab has been an engine to promote my own ideas and reflection about what good teachers do and what makes instruction powerful.(novice teacher, interview)

Whether as a result of participation in the Powerful Learning Lab, or as a natural outcome of navigating through their first year or two of teaching, the novice group engaged in critical thought about their practice. The emergence of critical thinking theme began with the evidence from the novice cohort, but is present in 
the other two cases. A more complete discussion of critical thinking follows in the cross-case analysis.

In response to the primary research question, did participation in the Powerful Learning Lab influence novice teacher practice? , the findings indicate, yes. The burning second question, "to what extent?" remains unanswered in the study. The following passage offers a glimpse into the level of influence.

Overall, I believe that I have changed some of my teaching practices in a way that is more powerful for my students. I have learned a lot of ideas on how to engage my students, how to involve all of my students, and how to weave everything together. I believe that I have grown as a teacher this past year. I have reflected upon some of my lessons to see what worked and what didn't work. I have adjusted lessons so that $I$ hold the interest of all of my students and all can participate. ... The Powerful learning Lab was a wonderful. Addition to my first year of teaching. It has allowed me to look at teaching in an effective way. (novice teacher, written reflection)

\section{Case Two: Mid-Career Cohort}

Case description. Mid-career is defined in the literature (Evans, 1996) as, “ a period when one has learned the ropes, is established in one's position, and exercises regularly the competence one learned during entry [to a career]" (p. 103). For the sample of this study mid-career included teachers beyond their third year of teaching through their tenth year. The Mid-career Cohort consisted of a total of four teachers. All had less than ten years experience with an experiential range of four through six years; three were in their fourth year, and one in her sixth, so they were collectively on the younger end of the mid-career cohort. This cohort contained one primary grade teacher, two intermediate grade teachers and one middle school 
teacher. All four were women. As a group they were young, three of them in their 20 's, and they all volunteered to attend the Powerful Learning Lab. None expressed any feelings of coercion toward participating in the lab. All four were new to the Hazelton district, working there only one or two years. All four were still teaching a year after the study, and remained in the Hazelton district. While two of these teachers taught at the same school, their collaborative work in the PLL was with other teachers both within and outside of the sample group. Figure 7 illustrates the base demographics of the mid-career cohort.

Key findings from the mid-career cohort included:

Planning: Mid-career teachers reported they enjoyed planning for powerful learning Teaching: Mid-career teachers connected all the practices of teaching, and reported that planning, teaching assessment and reflection were all interconnected.

Assessment: Mid-career teachers focused more on assessment than the novice or veteran teachers: they used assessment effectively to reflect on their practice and planning and to develop new assessment, Reflection: Mid-career teachers reflected more in their writing about their than novice or veteran teachers and, they were most critical of themselves of all the cohorts. 
Table 13

Base Data Case Two: Mid-Career Cohort

\begin{tabular}{|l|l|l|l|}
\hline Age in years & Years experience & Gender & Grade level \\
\hline 26 & 4 & Female & Intermediate \\
\hline 28 & 6 & Female & Primary \\
\hline 29 & 4 & Female & Intermediate \\
\hline 34 & 4 & Female & Middle School \\
\hline
\end{tabular}

Planning and the mid-career cohort. For three of the four mid-career

teachers, planning was an anticipated and even enjoyable part of teaching. They

expressed interest, invested time, and seemed to benefit from writing powerful

learning lesson plans. They were optimistic that the planning would help them be

better teachers.

The introductory lesson that was presented on the first day of class [Powerful Learning Lab] was a powerful insight to the type of learning that I wanted to occur in my classroom back at [my school]. The interest was high, the participants were enthusiastic and the lesson covered a majority of the Powerful Learning Teaching Benchmarks. I knew from that first day that I had a lot of work to do in order to get to the level of planning I needed to present such wonderfully powerful lessons. (mid-career teacher, written reflection)

I would begin to plan my lessons around the Powerful Learning benchmarks along with the Washington Essential Academic Learning Requirements [state standards]. The two sets of benchmarks work so well together and provide me with the guidelines needed to produce well-rounded, informative lessons. Lesson planning also began to take less and less time as I became familiar with the benchmarks. I started to become more organized and relaxed in my lesson planning 
knowing that I had Powerful Learning guidelines to follow. (midcareer teacher, written reflection)

The mid-career teachers appreciated the powerful learning lesson planning forms that were part of their portfolio and used them to organize their planning.

They dove in to the planning process without much hesitation.

Having authentic, interactive, learner-centered, continuous and inclusive components interwoven throughout lessons has been a good framework in which to plan. (mid-career teacher, written reflection)

The lesson planning organizer with the components written down in the boxes has been a very helpful tool for me this year in planning lessons and in setting goals for my classroom. (mid-career teacher, written reflection)

I used to think about Multiple Intelligence when I plan, but now I think about Multiple Intelligence and the PL components, they go together. (mid-career teacher, interview)

Throughout the course of the lab, one mid-career teacher reported a change in her view of the Powerful Learning Lab and her planning. In the fall she was reticent to view the lab as influential, but her opinion changed during the course of the year. The following three excerpts, fall, winter, spring reflect her change in perception.

It [Powerful Learning Lab] hasn't changed what I teach or how I teach, but it does change what I call it. I know what it means more; I have the vocabulary to describe what I'm doing when I teach. (midcareer teacher, fall written reflection)

As I planned these lessons [required lessons for Powerful Learning Lab] they were a lot more difficult. I had to refer back to our notebook [Powerful Learning Lab Portfolio] to make sure it fit. I already did this lesson in my class but $I$ had not thought of it as a powerful lesson. (mid-career teacher, winter written reflection) 
As I look back on the Powerful Learning Lab experience I think I have grown as a teacher and think differently as I plan lessons. The language I use when I talk about lessons always goes back to Powerful Learning. I think about all of the aspects or how a lesson could improve if it had all of the parts included. (mid-career teacher, late spring written reflection)

The mid-career cohort viewed planning as the cornerstone to effective teaching. This was evident in their interviews, written reflections and lengthy discussions following classroom observations. Each mid-career participant was able to articulate specific planning elements following a classroom observation. A final, reflective comment sums up their collective voice in regard to planning.

Overall, this Powerful Learning Lab has provided a strong framework in which to create [plan] better lessons to help increase student achievement. (mid-career teacher, written reflection)

Teaching and the mid-career cohort. Mid-career and veteran teachers perceived the practice of teaching more holistically than novice teachers. Most comments and written reflections integrated the practices of planning, teaching, assessing and reflecting. Experienced teachers view the functions as consistently interwoven, much like the center point in a Venn Diagram (see Figure 5). 


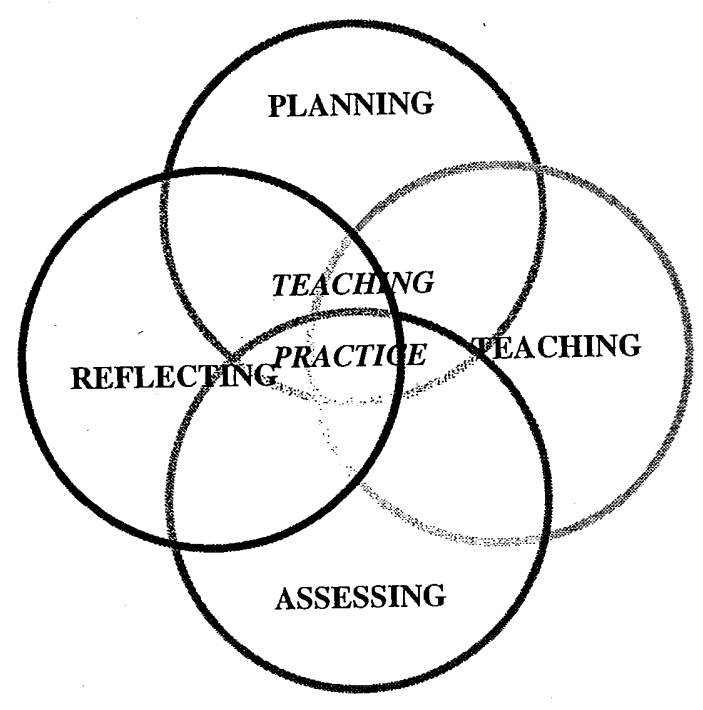

Figure 5. Mid-career and veteran teachers' overlapping and holistic view of teaching practice.

The planning and the teaching feed each other, because of the planning, the teaching was better. The PL components were more real, we had to think more about them, the lesson planning sheet really helped. I thought about the components much more during my teaching. (mid-career teacher, interview) Specific teaching strategies were mentioned throughout the artifacts of the mid-career cohort. They valued working in groups at the lab to discuss and learn about teaching strategies, and seemed to apply what they were studying in their classrooms. During classroom observations there was clear evidence that the midcareer teachers were incorporating many powerful learning strategies into their 
teaching. The following vignette illustrates the depth of powerful learning integration of the mid-career teacher cohort.

My classroom produced a solar system play. This started as a little project and evolved into this huge project. We were studying the solar system and the Science Kit and lessons needed something more to get the kids involved. The music teacher and I found a script and we started from there. We liked the script but we wanted the kids to add a lot to it.

We were also doing research for our Young Writer's Day Books. Students worked in teams and then shared out to the rest of the class their findings. Each student took notes. We used these notes to write each themed page of our books as well as got (sic) information to write the speaking parts. Students used [the] researched information to write their books and decide on speaking parts [for our play]. The [students'] books themselves took about 6 weeks. We went through the writing process...Students tried out for parts [for our play]. Some students did not want speaking parts so they took on roles of prop and costume managers. The lines were written [by students $\}$ and ... we voted on the most important lines.

Students also worked in teams to create the costumes. They made them out of butcher paper. They had to be to scale. We did a lot of math to get them this way. The prop and costume managers made sure that teams were on task. As it grew closer we practiced and made background props. We presented the play to our school and it was great.

As an assessment lesson I had students work in teams to create a poster that showed everything they knew about the solar system.... The posters turned out great. I think the kids were surprised when they started talking about what they knew.

This unit really matched the continuous and interactive components of Powerful Learning. It also matched with all of the other components. It was authentic because students were creating something that they were going to present. The information had meaning to them. It was interactive because at almost every point of this project students were asked to work in teams and partners. It was learner-centered because students could choose their roles in the play. They made choices on a daily basis about our final production. It was 
inclusive because all students participated in many different heterogeneous groups. ... It was continuous because many subjects were integrated into this unit. Students had to use what they learned or knew to apply to the project they were working on. (mid-career teacher, written reflection, describing the integration of powerful learning in planning, teaching, assessing, and reflecting)

While as a group, the mid-career teachers displayed confidence in their ability before attending the Powerful Learning Lab, they each reflected that they improved their teaching performance through the experience of attending the lab.

This dilemma of mid-career teachers who at times report they were confident in their teaching, yet juxtaposed those feelings with ambivalence, or a receptiveness to new knowledge can be described,

Middle adulthood is ushered in by a loss of such feelings of omnipotence, with the realization of one's limitations. It occasions a period of reexamination of self and a revision of plans. The mentor relationship becomes less important as the young adult continues to move toward his or her goals and the middle-aged mentor no longer appears so exalted or wise. On the one hand, the middle-aged adult becomes more autonomous in deciding his or her priorities; on the other hand, he or she confronts the limits to what he or she can ultimately hope to accomplish. (Glickman, Gordon and Ross-Gordon, 1998, p. 65)

This ability to accept new knowledge through a lens of experience differs

slightly from the wide-eyed, accepting novice. The mid-career teachers were less lavish in praise and more critical of how their time was spent in the lab activities.

It [participating in the Powerful Learning Lab] hasn't changed what I teach or how I teach, but it does change what I call it. ....I am more aware of what I've done. I've learned a lot more strategies; I take into consideration more things, more strategies. (mid-career teacher, interview) 
The mid-career cohort wanted the teaching strategies of the lab to be more specific toward their individual needs. Comments from both middle school and primary school teachers in this cohort suggest the mid-career teacher wanted specific techniques tailored to their teaching assignments. Although the mid-career teachers completed all the components of the lab, and were the group who wrote prolific written reflections compared to their novice and veteran counterparts, this was a group that mentioned the most division of their focus. The mid-career teacher interviews often "bird-walked" into areas of their personal lives. This shift of focus from career to the balancing act of personal life and career is typical of mid-career teachers (Evans, 1996).

Assessing and the mid-career cohort. The mid-career teachers spoke and wrote at length on assessment. For many mid-career teachers, student assessment was an area of concern, and they often related assessment of student performance as one of the pressures of teaching. This group consistently mentioned assessment and the Washington State Standards (Essential Academic Learning Requirements, or EALRs) in the same context. Their voice articulated slightly different purposes of assessment, and each of these are explored in the findings. Some mid-career teachers yiewed the assessment of student work as a gauge for their own planning and a way to modify and adjust their teaching.

The portfolio I have kept for the learning labs has definitely strengthened my use of student work as an ongoing assessment of my practice. I really found that looking at my students' work for evidence of meeting the Washington State Essential Academic Learning Requirements (EALR's) and the five components of 
Powerful Learning has made me aware of the strengths and weaknesses in my teaching. (mid-career teacher, written reflection)

The Powerful Learning Lab required participant teachers to follow six students throughout the school year, keeping samples of their work following every lesson that was written, taught, assessed, and reflected on for the lab. This monitoring and assessing of the student's work exposed teachers to the power of using assessment to inform their practice.

Being forced to look at my student work in a really critical way, to gauge if they were really learning, to take the student sample, and then really examine it. It really made me think about what I was doing, whether or not I should revisit it. (mid-career teacher, interview)

The assessment really made me reflect and think about what I could have done better. (mid-career teacher, interview)

I have always been a reflective teacher, but the portfolio is a usable tool that helps keep my reflections relevant. (mid-career teacher, written reflection)

I intend to continue to reflect on student work to determine whether I am including these components at a more intense level. (mid-career teacher, written reflection)

In addition to using the student work samples as a vehicle for assessing their practice, mid-career teachers worked on improving their creation and use of assessment tools for their students. The lab exposed them to a variety of assessment tools and methods, which were previously untried for some of the participants.

I now believe my assessment to be authentic and standards-based, because of this tool [differentiated instruction planning and assessment form]. (mid-career teacher, written reflection) 
Thanks to [the assessment] ideas presented in the Powerful Learning Lab, not only have I expanded my assessment styles, but I have also been able to create methods of truer, more accurate assessment. I feel that these changes have allowed me to be more fair and concise with my grading procedures. (mid-career teacher, written reflection)

One teacher described her assessment procedure in a vignette, as she explained that her students are now more engaged in assessment, and her awareness of the need to share with students the assessment of their work, prior to instruction.

Students receive a personal copy of the rubrics for each major project. Having the standards written out on a sheet of paper that students receive alleviates many questions and allows students to make choices about the level of effort they choose to exert. The use of rubrics has been very successful with my class this year. There is no hidden agenda. (mid-career teacher, written reflection)

This same teacher continues with her classroom vignette, explaining that at times students were involved in the assessment process, completing both self and peer evaluations of work.

Allowing my students to self-assess on projects and assignments has also proven successful. I have noticed that even when students miss points they still learn when they are given the chance to self assess. The whole assessment process is a learning experience.

In addition to self-assessment, I also allow my students to make corrections on most everything. Again, having the opportunity to go back and look at a problem or question a second time allows the students to acknowledge their error and correct. Therefore another learning experience occurs. When students are not given the chance to correct mistakes, they often don't take the time to go back and figure out the correct answers. This has been a very valuable use of our time this year. (mid-career teacher, written reflection)

The mid-career teachers reported an acceptance of a wider range of assessments through some of the practice lessons at the PLL. Examining authentic 
and varied assessments that were demonstrated at the lab encouraged these teachers to use them in their classrooms.

The lab helped me realize I can assess more than just a test. I look at projects and my observations of kids, [I think,] 'What can they demonstrate? What have they learned?' I talk more to the kids; get their feedback more during the teaching, rather than just at the end of a unit. (mid-career teacher, interview)

The use of writing to assess was consistently applied by the mid-career teachers.

We write in math, not a formal math journal, but what do we know. I use KWL, I used this in math, I provide more language arts support, I feel supported in this decision because of going to the PL lab. (midcareer teacher, interview)

One teacher explained that the lab's use of assessment put pressure on her to think more deeply about assessment and its purpose.

The accountability that someone was going to check on my assessment was huge, especially in first grade. I had to create some rubrics that made me think about my assessment, and not make it so subjective. I think it was helpful to pull student work and look at it more carefully, more critically. (mid-career teacher, interview)

The theme that emerged from the mid-career teachers was connectedness, that the practices of teaching are all connected and interrelated. Assessment was a topic that was definitely important to these mid-career teachers, and they selfreported a willingness to take risks in terms of trying out different and new assessment tools and methods.

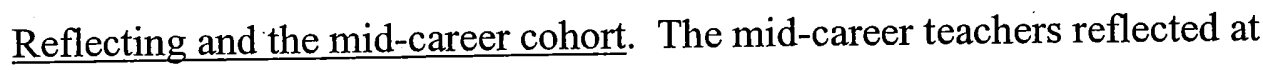
length on their lab lessons and on their teaching throughout the year. They were collectively a bit hard on themselves, at times more critical of their own work than 
the other two cohorts, and they used the reflection times built into the lab as time for career and sometimes life introspection. They reported "enjoying" the reflection process and using the formal reflection pages provided in the lab portfolio frequently.

In the past, I would question my practice, and essentially beat myself up over gaps in lessons, or I would question whether my teaching was standards-based. Using the reflection sheets, I have found that I can critically look at what I am doing in the classroom, where my students are in the learning process, and where we need to go next. I intend to continue this process with a rubric I will create over the summer. I want to be able to check myself on the level of comprehension, components of Powerful Learning, and the EALR's. (mid-career teacher, written reflection)

The mid-career teachers attributed reflection as a way to improve practice, much like assessment, but linked reflection on their practice to improved student performance more often than any other experiential group.

I think that being in the lab has made me think about my teaching a lot more. I'm thinking more about what the kids are learning. I'm thinking about more of my kids, and trying to make learning more real life and integrated. (mid-career teacher, interview)

Its [reflecting as a lab assignment] definitely influenced how much I use reflection in planning to guide my planning. I'm looking at student work more in mind of the standards, looking for understanding. I'm having kids do a lot of writing so that I can determine if they understand it. I never would have gotten kids to higher levels with out planning with reflecting on student work. (mid-career teacher, interview)

Although the mid-career group displayed actions and attitudes that were typical to mid-career professionals, not really apathy, but a more tentative 
cynicism, they reported their teaching was influenced by the Powerful Learning

Lab experience.

This experience has changed me as a teacher. The real difference for me was the ability to revisit. This was so much more useful than oneday seminars, or conferences with separate sessions. I will continue to reflect, and refine, and gauge my students' progress - daily. (midcareer teacher, written reflection)

Even the most reluctant teacher of the four, the one who didn't value formal planning as much as the others was influenced by her experiences at the lab.

Overall, I think that the Powerful Learning Lab has made me a better teacher. I think more about all the components in everything I do. I am not really changing what or how I'm teaching, but I am changing how I think about learning and teaching. (mid-career teacher, final written reflection)

All of the mid-career teachers reported about "thinking" about the practices of teaching more often, more deeply, and with more awareness. The theme of thinking or critical thinking was prevalent in the artifacts for the mid career teacher. “...successful teachers are thoughtful teachers" (Porter \& Brophy, 1988, reported in Glickman, et al., 1998, p. 53). So given the emphasis of mid-career teacher's artifacts indicating the lab influenced their thinking, especially planning, assessing, and reflecting, the answer to the first research question, does participation in the Powerful Learning Lab influence regular teacher practice, the answer is yes.

\section{Case Three: Veteran Cohort}

Case description. Veteran teachers are sometimes characterized in the literature by negative connotations: complacent or bored (Glickman, et al., 1998), 
or even "stagnant" and "deadwood" (Evans, 1996). There are few descriptors of the veteran group that are positive. This group is generally represented by characteristics of career stability, they've been teaching either at the same school or same grade/subject level for years, and there is little or no motivation to move or change. While individual committed, dedicated veterans exist, they appear to be rarely described. Yet, veteran teachers are the majority of the teaching force nationwide. While Hazelton's demographics differ slightly from the nation's 20 percent of Hazelton's teachers have over ten years of experience); the application of the veteran teacher's case is appropriate for most school districts.

The teaching force is now composed mainly of people in middle age and mid-to-late career who have been teaching in their current school for twenty years or more. Teacher's average age is nearly forty-five (in 1973 it was thirty four) ${ }^{3}$

This study's veteran cohort included teachers beyond their tenth year of teaching through their twenty first year. The specific characteristics of the veteran teachers are a bit skewed, all are female, in their forties or fifties, and all are primary grade teachers. Their story is reported as one "veteran case", the demogràphic they all share is that of being primary grade teachers, three teach first grade and one teaches kindergarten students. (See Table 14 for further demographic information on the veteran cohort.) 
Table 14

Base Data Case Three: Veteran Cohort

\begin{tabular}{|l|l|l|l|}
\hline Age in years & Years experience & Gender & Grade level \\
\hline 44 & 18 & Female & primary \\
\hline 46 & 11 & Female & primary \\
\hline 47 & 19 & Female & primary \\
\hline 53 & 21 & Female & primary \\
\hline
\end{tabular}

Each veteran teacher reported they volunteered to participate in the Powerful Learning Lab, none expressed feelings of coercion. They have been with the Hazelton district for a range of three to eleven years, so they do not necessarily reflect the non-mobile descriptors of the veteran described in educational literature.

Key findings from the veteran cohort include:

- Planning: Veteran teachers engaged in planning with a new focus on the PL components.

- Teaching: Veteran teachers reported they were willing to take risks and try new teaching strategies and that the PLL experience was their first opportunity to critically examine their practice in years.

- Assessment: Veteran teachers were perplexed and least cohesive about assessment than the other two cohorts. Veteran teachers viewed assessment \% as an opportunity to communicate with parents when others didn't. 
- Reflection: Veteran teachers reported the benefits of reflecting on their practice as an opportunity to be introspective about their teaching. The recognized the benefit of building in time for reflection.

Planning and the veteran cohort. When I was developing the Powerful Learning Lab and its teacher portfolio, I was concerned about the veteran group of teacher's reaction to writing detailed lesson plans. My experience as a school administrator had taught me that teachers were resistant to writing detailed plans, and the most resistant were teachers with several years experience. So, I expected reluctance. This small cohort of veteran teachers surprised me. Not only were they willing to write lesson plans using the powerful learning framework, but they did so with great detail and only one veteran suggested they should write one lesson plan per powerful learning component, instead of two. For some of these veteran teachers, the experience of writing those plans helped them construct meaning for the powerful learning components. Through the writing of the plans (each emphasizing a powerful learning component) the veterans understood the complexity of the framework, and how the components were inevitably intertwined.

The five PL components all work together to form a completed program of learning for the students in a classroom. I started writing lesson plans to reach one of the five components such as "authentic". As I continued to write lesson plans throughout I was seeing I was including more and more of the components and oftentimes had all five in many of the lessons I was teaching. I think this is one of the ways my teaching and lessons have changed this year. (veteran teacher, written reflection) 
The lab has totally changed how I look at my lessons, I don't just look at my goals, I look at the avenues, the process, how do I get to this goal, by getting the different PL components, how do I reach all of the children? It gets easier, and easier. I go through my plan with my little sheet [of Powerful Learning components] and make sure they are there. Now, I find I put many PL components in my lessons, not just one, they are blending together. (veteran teacher, interview)

A veteran teacher who described herself as very traditional, explained how planning with the Powerful Learning framework has influenced her to look beyond the teacher's guide, if at first only in the margins.

I used to think that coming up with a lesson that is powerful was too much work, too much prep. I found that I could take a lesson and tweak it just a little to make it more powerful. (veteran teacher, interview)

One thing that changed me, instead of looking at the main lesson, I look at the margins and read about how to teach this lesson for ESL or TAG, and these strategies are really powerful learning, so I look more at the activities that are more powerful or extensions, and do those, then go back to the basic worksheet for guided practice. (same veteran teacher, interview)

The seriousness and thoroughness that the veteran cohort attributed to planning may be a result of a tendency of primary teachers to plan extensively. My experience as a school administrator supports that primary teachers spend more time in planning and write more detailed lesson plans than their upper elementary and secondary colleagues.

I think for me, I take planning very seriously, I put in all the five components of PL now, the authentic, etc. (veteran teacher, interview) 
There was a persistent pattern in the veterans' artifacts describing themselves as life long learners. Often their reflections indicated passages about learning, recent applications of the lab's content, and sharing their lab "learning" with other colleagues. This finding disputes the some of the more negative descriptions of the veteran teachers as "deadwood", "bored", or "unchallenged" (Evans, 1996; Glickman, et al., 1998). This cohort of veterans was willing and able to participate, learn and share their experience with others.

The Powerful Learning Lab gave me the knowledge and skills that greatly impacted my lesson planning process. I am in the process of learning how to make lesson plans that teach essential skills and information in a creative and engaging way that challenges all students and helps them develop a richer understanding of the material being taught/learned. (veteran teacher, written reflection).

The lab has provided me with insights on all areas; being sure that everyone is involved. I keep the 5 components of PL at the forefront. (veteran teacher, interview)

Teaching and the veteran cohort. The idea that veteran teachers will actually change or improve their teaching practice is quite controversial. Many researchers (Evans, 1996; Glickman, et al., 1998) would describe veteran teachers similarly to the following vignette:

Many of the [veteran] teachers are old-timers as well. A few began their careers in this school and plan to retire from here. The teachers have not grown much and are fixed in teaching patterns 20 or more years old. Their enthusiasm peaked many years ago; and without the stimulus of new challenges, their interests turned elsewhere. These interests are most often the subject of faculty conversations: the repertory season, the perils of small business, summer travel, gardening, and grandchildren. The social committee is a serious assignment, and birthdays and other holidays get important attention. Rarely do the teachers talk about teaching, and 
when they do, it is about a specific problem student or an unsupportive parent. If asked, they would say they are not unhappy as teachers at Arabesque [Elementary School]. ${ }^{4}$

Plagued with negative descriptors, or marginal descriptors, this veteran cohort again defied much of the research about this most experienced cohort. This cohort continually presented examples within their interviews, reflections, observations, and through their high level of participation during the lab sessions, that they were willing to examine and possibly change their teaching practice. They epitomized risk taking for the rest of the sample.

Now I'm able more easily to take a risk and stretch to try a different teaching model in my classroom because it makes sense. I'm able to see the five components within the teaching models and decide which would be most effective for the students and the particular learning process, for instance a group investigation or paired-sharing for learning a rhyming lesson. (veteran teacher, written reflection)

Their willingness to both share their experiences and explore a new or newly remembered strategy was consistently documented.

One of the things I'm really trying to do is to make the activities less teacher-directed, this is hard for me, especially with first grade. It is hard for me to let go, and stand back, but these kids are ready to go, they can do a lot more learner-centered things, because we work so much on cooperative learning. I guess, my main goal is to make things more learner-centered and less teacher-directed, less direct instruction. I do a lot of direct instruction, and I realize I can do less. (veteran teacher, interview)

The propensity to rely on direct instruction was common in this cohort.

Some reported that this was the most "comfortable or familiar" teaching strategy, while others attributed the need for more direct instruction to be more developmental. These kindergarten and first grade teachers perceived direct 
instruction as a required precursor to more hands on or powerful learning. They reported they frequently relied on the Powerful Learning lesson planning tools as a way to move away from so much direct instruction. Another veteran teacher argued that by focusing on powerful learning components she was able to construct more meaning for her lessons, more attention to the essential elements of her curriculum.

Being aware of the 5 components of PL; Making learning more real (authentic), Sharpening my computer, my mind, to get rid of the fluff. I focused on what was really necessary. I kept aiming for what we want to get in terms of student achievement. (veteran teacher, interview)

All of the veteran teachers reported the Powerful Learning Lab was the first comprehensive opportunity to examine their teaching in quite a few years. They each described other one day workshops, and some summer course taken in the past few years, but for most, this was the first opportunity they had to examine teaching methods since their original teacher licensure program. For most, it had been nearly twenty years since they had engaged their thinking for a sustained period of time on their practice. Their willingness to candidly share their learning was inconsistent with the more negative descriptions of veteran teachers in the literature (Evans, 1996; Glickman, et al., 1998; Fried, 1995).

The pair-sharing of lessons, jigsaw of text materials and collaborative planning were only vaguely familiar to me before the powerful learning lab. I now have a stronger understanding of these techniques and strategies. (veteran teacher, written reflection). 
Assessing and the veteran teacher. As a group, the veteran cohort was least cohesive about assessment. They expressed a range of attitudes about assessment, from lack of confidence and skill in assessing student work, to a renewed commitment to use a variety of assessment tools to examine their student's work. One veteran introspectively associated her students' work samples as an assessment of her teaching. It was difficult to report themes or patterns on the topic of assessment, as each of the four veterans approached the topic quite divergently.

The veteran who expressed the least confidence in her ability to assess student work stated,

I'm not exactly sure if this class has helped me with assessment. I think I need more, personally. I guess I feel that I can assess on my feet better, I might come up with a few questions where kids might raise their hands. I might assess prior experience now; I might try to see if they can connect the lesson to prior learning. ... I do a lot of curriculum based assessment, which is more traditional, which is less around Powerful Learning. I do have to say, that assessment was my least area of growth. I feel that is still my area to learn more about. (veteran teacher, interview)

Again, this passage reflects the veteran teachers' cohort willingness to be introspective, to be critical of her practice, and to commit to learning more. Instead of turning an impassioned ear, or giving up in frustration, this veteran saw that learning was the solution to her problem with assessment. Two veteran teachers reported they were using more variety in their assessment techniques as a result of their experiences in the Powerful Learning Lab.

I feel this year I really looked at assessment and how many ways there are to assess knowledge of students. I have used students working together in pairs, working on the floor making a graph about 
results, showing me their own problem which they made up and teach to the classroom, even using toothpick pictures to show addition and number facts. (veteran teacher, written reflection)

I think one thing is that I have more a variety of things to assess. I think that before I would see things, but I wasn't sure if it was validated, if I observed it. Now, I know I can journal that activityor observation and see whether or not my kids are meeting my target. I used to think that I had to have pencil and paper for everything. It is so nice now, that I realize that my students who have no language, still have some skills, because I can witness them doing the clapping or whatever the indicator happens to be. I think that has been a real benefit. (veteran teacher, interview)

Another purpose for assessment made by the veteran teachers was that of assessment as communication to parents. The veteran teachers communicated with parents not only about their child's progress, but also as a way to inform parents about powerful learning. No other experiential cohort made this observation.

I think I've always done portfolios, but I think that they are better now, they are thicker ( 3 inches thick), and I also sit down with parents and the child and go through the portfolio and the report card. I think this is better. I also believe that all of my assessments are based on the 5 components of powerful learning now. I share the PL components with parents now; I use the PL components in the planning, teaching and assessment. (veteran teacher, interview)

The assessment assignment in the powerful learning portfolio required teachers to keep work samples, track, and record six students throughout the school year. This opportunity was reported as rewarding and beneficial for the teacher and for the six students, but impractical in terms of application to a regular teaching load of more than 25 students.

The lab helped me to look at individual kids. Really looking at 6 kids, following them, really focusing on their work and my teaching. Without examining those $6 \mathrm{kids}$, it would have been like herding, I 
have 28 kids, lots with high needs (9 ESOL [English Speakers of Other Languages], 6 IEPs [Individual Education Plans], 2 medically fragile). The lab pulled out the specifics ... [but] my class size really hindered any kind of acceleration [and] the opportunity to follow all my students so closely. (veteran teacher, interview)

Finally, the veterans did associate assessment with the Washington State Standards similarly to the mid-career teachers. Their awareness of the standards was high, and there was continual reference to the Washington EALRs in their lesson plans.

It's [the Powerful Learning Lab] made me more aware of what am I doing? Why am I doing what I am? Are they [my lessons] aligned to the EALRs, the benchmarks? That book [the Washington Essential Academic Learning Requirements] that used to sit there, now I have a copy of it at my home, so I always have it [EALRs] with me, I am so much more conscious now, [ I ask myself, ] 'Is this meeting the state requirements? And if not, do I need it in there?' Then take it out, put things in that do (meet the requirements). It's made me a much more powerful teacher. I now look at all curriculum more critically, asking myself, 'Is it aligned with the state curriculum?' I have the freedom to put something in or take it out and know why. I could actually sell that to the superintendent, with confidence, if I had to. I think it is really important. Before, I don't think I had that background. I use multiple resources now, instead of one or two, and I'm able to sell that to the principal or superintendent without any problem, as to why this piece needs to go in. (veteran teacher, interview)

Reflecting and the veteran cohort. According to adult development theories, the veteran teacher who is in midlife, and continues to learn should be experiencing a combination of reflection and action, called praxis by Freire (1970). Praxis implies that adult learners are reflecting while they practice their art (in this case teaching) as a way to learn and improve their profession. Praxis implies that reflection and action are more than just sequential components in a path toward understanding. The term means there is forethought, purpose and situational 
elements to reflection that is intertwined with action. These include a commitment to human well being and the search for truth, and respect for others. It is the action of people who are free, who are able to act for themselves. Moreover, praxis is always risky. It requires that a person "makes a wise and prudent practical judgment about how to act in this situation" (Carr \& Kemmis, 1986, p.190). Glickman, Gordon, and Ross-Gordon (1998) discuss the importance of critical reflection relating to adult learning.

The educator, in order to develop the meaning perspective of being an educator would: increase self awareness through consciousnessraising activities, make his or her assumptions about beliefs about practice explicit, engage in critical reflection on those assumptions and beliefs, engage in dialogue with others, and develop an informed theory of practice. ${ }^{5}$

The veteran cohort valued the reflection exercises within the lab, and reflecting on their teaching back at school.

The teacher reflection time after each lesson proved to be insightful. Sometimes this reflection was by myself and sometimes with a fellow teacher. (veteran teacher, written reflection)

The most consistent theme related to reflection and the Powerful Learning Lab was time. Veteran teachers consistently reported that the lab experience gave them time to reflect and think, the gift of "think time" was reported as a tremendous benefit. "Time, the lab gave us time to apply what we've learned, think time!" (veteran teacher, interview) The veteran teachers viewed reflection almost exclusively in terms of self assessment of their teaching practice.

In terms of reflecting, I feel like I think more about, 'did they get 
it?', I sort of think about, 'How did I make this powerful? Which [powerful learning] components did I use?' Then I get excited that I realize I've used more than one component. I do more internal self assessment about my teaching. I also, ask [myself] 'Did I lose the focus? Did the learning occur, did I focus on the objective, or did I go off on a tangent?' (veteran teacher, interview)

Unlike the mid-career cohorts who commented on reflecting on their students' work, the veteran cohort consistently interpreted reflection as an introspective act to assess their own teaching.

Overall, the veteran cohort was a study of contrasts to the salient literature of veteran teachers. They did not categorize themselves as overly burned out, and neither did they present themselves as a case of bored or unchallenged workers "just putting in their time", instead they consistently described themselves as "still learning", which was a bit unusual. These veterans were more closely aligned with Glickman's descriptions of the professional educators who have high levels of knowledge and commitment about teaching (Glickman, 2002, p. 89). So in terms of this limited cohort of veterans, there was evidence that the Powerful Learning Lab did influence their teaching.

The lab revitalized me; I can do so much more. I feel less burned out. I can make learning fun. Turning the learning over to the kids and making it powerful, it more energizing to me; I'm not as exhausted at the end of the day. (veteran teacher, interview)

\section{Cross-Case Analysis}

This portion of the chapter focuses on the cross case analysis which includes a cross case analysis between cohort cases in the four areas of teaching 
(planning, teaching, assessing, and reflecting). The findings of the comparisons and contrasts between the cohorts are presented. Emergent themes from the primary research question are presented. Additionally, further findings of the remaining research questions are reported.

Cross-Case Analysis of Teaching Practice Between Experiential Cohorts

A cross-case analysis of the experiential cohorts in each of the four areas of teaching practice produced interesting results, with more similarities between the novice and veteran cohorts than expected. This key finding, that the two ends of the spectrum, novice and veteran were more similar than the mid-career cohort was surprising. Other key findings include: 1) planning was valued by all, but most by the novices, 2) mid-career teachers reported learning the least new strategies, 3) mid-career teachers were most focused about assessment, and 4) all groups demonstrated and reported more reflecting on their practice as a result of the PLL.

Cross-case analysis of planning. The novice cohort was most prolific in their verbal and written artifacts about the planning phase. This was a very real, demanding, and time consuming task for them. Beginning teachers spend a huge amount of time planning, often caught in the unenviable position of teaching content that has been barely mastered themselves, so they are caught in the classic beginning career dilemma of learning to teach, learning to plan, and trying to determine what to teach all simultaneously. The mid-career teacher is often characterized as an "expert" or "master" (Steffy, 1989), or "maturing" (Gregorc, 
1973) at this phase of her career. She is able to perform the basics, has moved beyond survival. She is often depicted having a strong commitment to education and is honing in on the technical aspects of her position, planning being one of those tasks. While the veteran typically, has the advantage of familiarity of curriculum content, stability of position, and the benefit of years of planning experience. What was interesting about this particular veteran cohort was their willingness to embrace written lesson planning with energy and thoughtfulness. Figure 6 further illustrates the comparison between the experiential cohorts and the teaching action of planning.

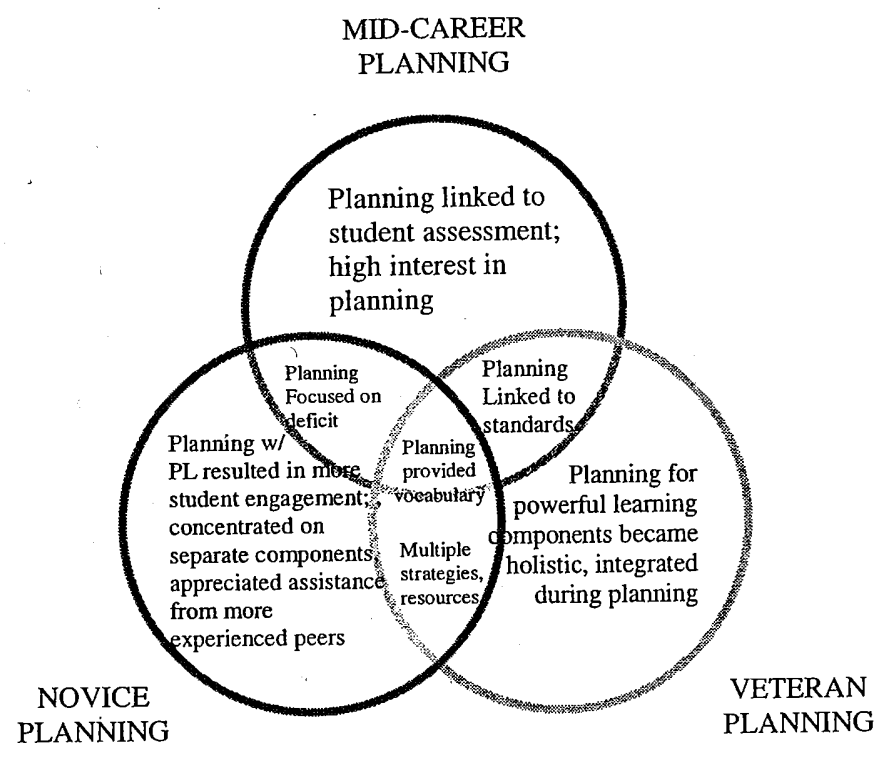

Figure 6. Comparison of planning between novice, mid-career and veteran cohorts 
The similarities that intersected all cases were: vocabulary, ease, and an ability to take a student's perspective. All groups reported that using the powerful learning framework provided a consistent vocabulary for talking about their teaching with colleagues. This was especially helpful during peer coaching and peer debriefing sessions. A unified, specific and technical vocabulary about effective teaching is a cornerstone for establishing a collegial community of learners. Judith Little describes the importance of a professional vocabulary “...teachers in successful schools used precise, technical language in discussing instructional concerns" (as cited in Glickman, et al., 1998, p. 77).

Each case reported that planning became "easier" and less time consuming as the year progressed. The familiarity with the powerful learning components, practice and observation of their peers, all contributed to greater familiarity with planning for the framework, and translating those plans into teaching. One teacher explains,

Lesson planning also began to take less and less time as I became familiar with the benchmarks. I started to become more organized and relaxed in my lesson planning knowing that I had Powerful Learning guidelines to follow. (mid-career teacher, interview)

It [planning] gets easier, and easier. (veteran teacher, interview)

I am very.conscious and aware that powerful learning can make my planning more effective and easier. (novice teacher, written reflection) 
The final similarity between all of the cases, was the reporting of the teacher taking a student's perspective or view of their lesson planning. Each case cohort reported looking at their lesson planning phase from a student's view.

I'm thinking [when I'm planning], 'Am I engaging all the kids? Are they interested, and will they remember it? Is it authentic? Is it interactive, am I doing group work?' Now, I think, 'How am I going to engage kids so they will remember? What will this lesson be like for a first grader?' (novice teacher, interview)

Another technique I frequently use when planning and instructing is imagining myself as a fifth grade student. I try to keep in mind how a fifth grader would feel about the lessons being presented. If I am bored and not interested in the subject as an adult it must be 100 times worse for a ten year old. (mid-career teacher, written reflection)

Now I think [plan] like I'm one of my students. I realize that my students, who have no language, still have some skills, because I can witness them doing the clapping or whatever the indicator happens to be. I think that has been a real benefit, planning through the eyes of my students. (veteran teacher, interview)

Analyzing the contrasting data between the cohorts has important implications for the future planning of the lab. Examining the outlying differences between the cases, the novice's appreciation of being able to plan with experienced peers, their more compartmentalized thinking about the framework, and their selfreported growth in planning, indicates a strong need to keep their planning experiences fairly consistent with the Powerful Learning Lab design.

However, there are clear indicators that there is a need for more differentiation in the planning phase for the groups. For example, the novices did not mention the connection of planning to meet state standards (Washington's 
EALRs), while both the mid-career and veteran teachers did. This indicates there is a greater need to explicitly link planning and state standards for the novice group, but not necessarily a strategy that is needed for more experienced teachers. Another interesting distinction that will be discussed further in chapter five is the veteran's ability to view the powerful learning framework holistically, and the novice and mid-career cohort's tendency to segment the components, taking a more analytical strategy to planning, while the veteran's ability to synthesize the components into a framework was more aligned to the Powerful Learning framework's intent. It may be adult development phenomena, which novices move from a stratified, compartmental thinking of the powerful learning components, and through experience and practice, they move toward a more synthesized, holistic view of planning.

Another novice and mid-career theme was their tendency to take a deficit view of planning relating to the five components. They selected specific components that were difficult, or in which they felt they personally struggled, and approached planning from a deficit viewpoint, spending much time and energy on their perceived weaker component.

I have a harder time planning for the continuous component. I think this is because I am fairly inexperienced and I often have a hard time making different disciplines connect, as I am frantically trying to cover a large variety of curriculum. Also as I proceed through the school year, I feel so behind that I hardly am able to revisit concepts covered earlier in the year. Planning for the continuous component is harder for me, and I think this is the one component I am least prepared to teach adequately. (novice teacher, written reflection) 
As I planned these lessons [emphasizing the inclusive component] they were a lot more difficult.. I had to refer back to our notebook to make sure it fit. (mid-career teacher, written reflection)

Examining the cross-case patterns of planning will be tremendously helpful in further development of the Powerful Learning Lab, and help the Accelerated Schools Project determine what further support in lesson planning should be developed.

Cross-case analysis of teaching. In looking at a comparative analysis of the cases in teaching (see Figure 7), the novice group reported the most "gain", their interviews and reflections were excited utterances of how many strategies they learned and were able to practice with peer teaching. They reported many benefits from working with experienced peers and appreciated their feedback. They were willing to try new ideas provided through the lab or through informal alliances with the mid-career and veteran teachers. The novice teachers were gathers of information, strategies, and ideas. They tried everything. The mid-career teachers tended to focus their discussion of teaching on highly specialized areas; all drew a correlation between powerful learning strategies, and higher level student thinking and products. The mid-career teachers did not attribute learning many new strategies, but rather, a new way of organizing effective teaching practices. The veterans were similar to the novices, expressing they learned new ideas and strategies. Figure 7 illustrates the findings in the cross-case analysis of teaching. 


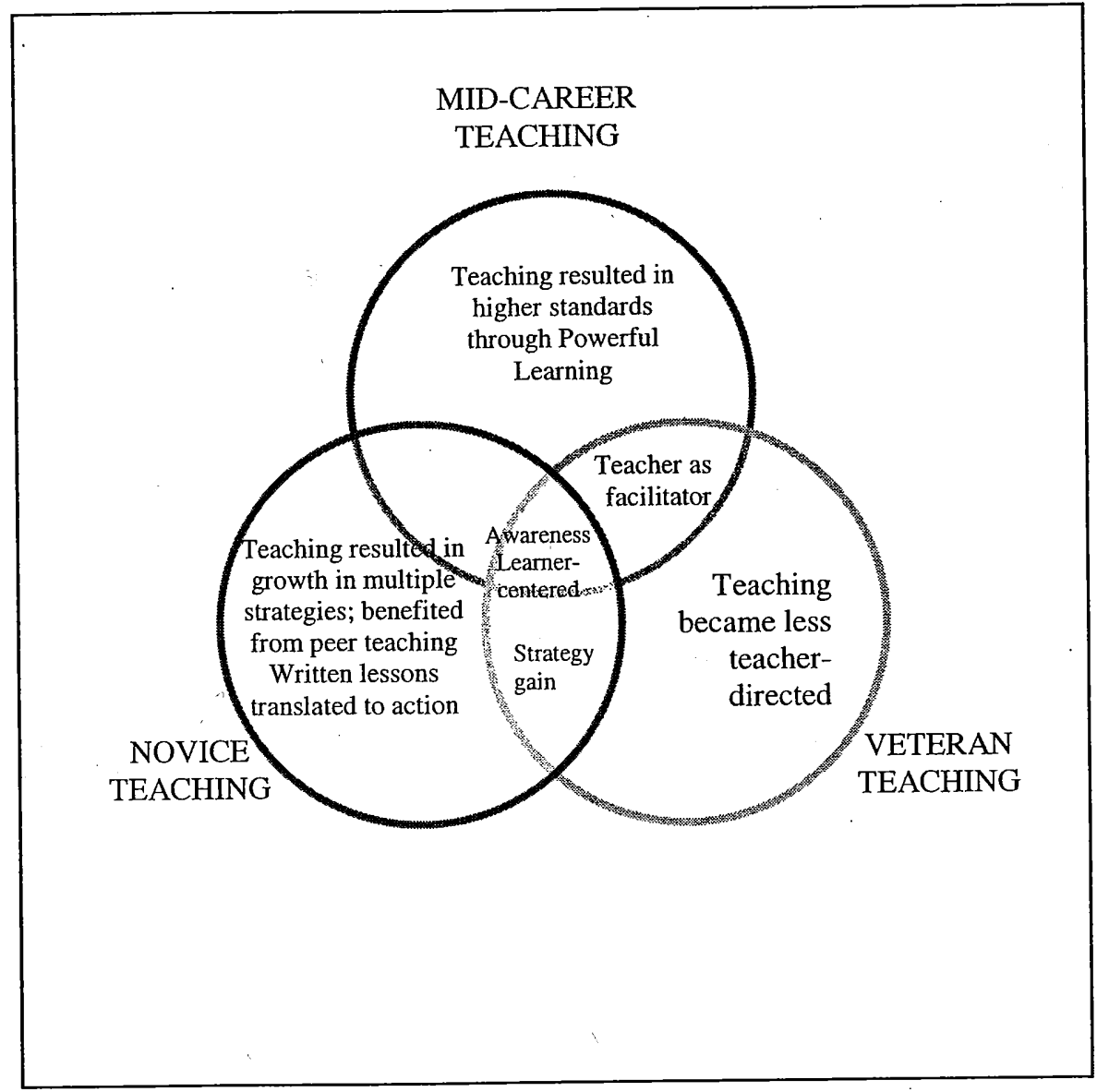

Figure 7. Comparison of teaching between novice, mid-career and veteran cohorts.

Each cohort used the term "awareness" to describe one of the characteristics of influence on their teaching. Each group, through increased awareness of powerful learning components and terms reported they were better able to practice more eclectic teaching strategies. One mid-career teacher summarized, "I am more aware of how I deliver information."

I'm more aware of what I've done. I've learned a lot more strategies; I take into consideration more things, more strategies. (mid-career teacher, interview) 
Planning and teaching are related, I'm more conscious of how I'm affecting my kids, I'll change in the middle of a lesson that isn't going well; I'll make an adjustment, I'1l try something new and improve the lesson. (novice teacher, interview)

For the veteran teachers, the awareness raised a consciousness of some previously tried strategies, that might have been abandoned, or in some cases an affirmation of strategies that their experience using successful strategies was still valid.

I also found I went back to some of the things I'd been doing before, and was able to determine that, 'Oh, this is PL', but I wasn't as aware before... (veteran teacher, interview)

Another similarity across cases was the recognition of the role shift for students when working within the powerful learning framework. They consistently reported (with glee!) that their students were becoming more empowered as learners and researchers. As teachers, they were experiencing a role shift as their lessons were moving from teacher directed teaching to student-directed learning, and in some cases, students were stepping into the teaching role.

...I catch myself and say, 'I want this to be more learner-centered', so I try to make the kids do the work. Like when kids come up and say, 'how do you spell...'. Now I say, 'Hmmm, how can we solve that problem'. It is really effective, I don't give out as much information now; I want the kids to think. When kids come up to me and say, 'This is really hard,' then I think, 'Wow, I've done my job!' (novice teacher, interview)

Instead of handing the information to my students, I am engaging them in self-discovery of the information. My students are placed in the position to become the experts on a topic and teach what they learn to their peers. Students are also having the opportunity to work 
in a variety of groups, different sizes, dynamics, and methods of selection. They are taking more ownership of their education. (midcareer teacher, written reflection)

One of the things I'm really trying to do, is to make the activities less teacher-directed....but these kids are ready to go, they can do a lot more learner centered things... (veteran teacher, interview)

Mid-career teachers talked more about results in terms of student achievement and student outcomes throughout their artifacts. As a group, the midcareer teachers tended to focus on tangibles like student performance, student work samples, and student assessment. They are the group that reported that integrating powerful learning framework resulted in higher levels of student thinking and higher levels of student achievement related to assessment tasks. I observed mid career teachers doing both formal and informal assessments during their observations.

...students are taking on the challenges of stepping into roles they are unfamiliar with and experiencing success. It is amazing to witness what ten and eleven-year-old students are capable of doing. The higher I raise the standard, the harder they work to meet it. (Midcareer teacher, written reflection)

Novice teachers and veteran teachers both commented on the quantity of ideas and teaching strategies gained through their experience in the lab. Both groups reported in quantitative terms that they learned more new or revisited instructional strategies.

I got so many ideas [from attending the lab].... For doing jigsaws, the name game would be really useful at the beginning of a term.

Different teaching strategies, like the one where you helped us with the stamp act, the hook to lure people into lessons. I use hooks to get 
my kids intrigued. The teaching strategies that were shared were really great. (novice teacher, interview)

I have learned a lot of ideas on how to engage my students, how to involve all of my students, and how to weave everything together. (novice teacher, written reflection)

The significant learning for me in the Powerful Learning Lab came in part from the instructional strategies in our text, Models of Teaching. I had not realized there are 25 teaching strategies in the world that fit into four models: the social family, the information-processing family, the personal family, the behavioral systems family. (Veteran teacher, written reflection)

The novice group reported that they benefited from translating written lesson plans into action, and the realization that the writing helped them make sense of the content, strategies, and framework of powerful learning. Since the novice group was inexperienced, their perceived benefit of writing lesson plans and trying out various strategies was expected and consistent with novice teacher behavior (Barth, 2001; Evans, 1996; Glickman, 2002). However the veteran cohort's reporting of similar eagerness to try a variety of strategies may be a result of missed opportunities since they participated in teacher education programs ten to twenty years ago.

The Powerful Learning Lab has helped me to see how I can take these components and translate them from an idea on paper to a working and active view of instruction in my own classroom. (novice teacher, written reflection)

It's allowed me to become more aware, taking what I've written down and really doing it. (novice teacher, interview)

The striking similarity in responses between novice and veteran cases was surprising. I did not expect the two groups to get along so well, or express so many 
similarities in terms of positives. The mid-career cohort indicated less influence on their teaching than the other two cohort cases, yet that is consistent with teacher fourth stage of teacher development that was discussed earlier in chapter two, which describes enthusiastic and growing teachers have "reached high levels of competence" (Burke \& McDonnell, 1992, p. 90).

Cross-case analysis of assessing. The mid-career teachers were most concerned with assessment and were most prolific in their reporting of assessment throughout their artifacts. The mid-career cohort's level of dialogue and written reflections indicated that this component of teaching was a priority. They emphasized the connectivity of assessment to all other teaching action more consistently throughout their data.

The novices were just learning how to assess students, so while they were very open to trying a variety of assessment tools and investigated various assessment purposes, they did not reflect as much as the mid-career cohort on assessment, nor did they consistently link it to the other teacher practices (planning, teaching and reflection).

The veteran cohort was similar to the novices, in reporting on a paradigm shift away from pencil and paper assessment to other forms of assessment (anecdotal records, observations, project and problem based learning), but they didn't necessarily relate their student assessment as a way to evaluate their teaching. They weren't as articulate about assessment as the mid-career teachers, 
perhaps because of familiarity of purpose. A summary of the three cases findings of assessment is presented in Figure 8 .

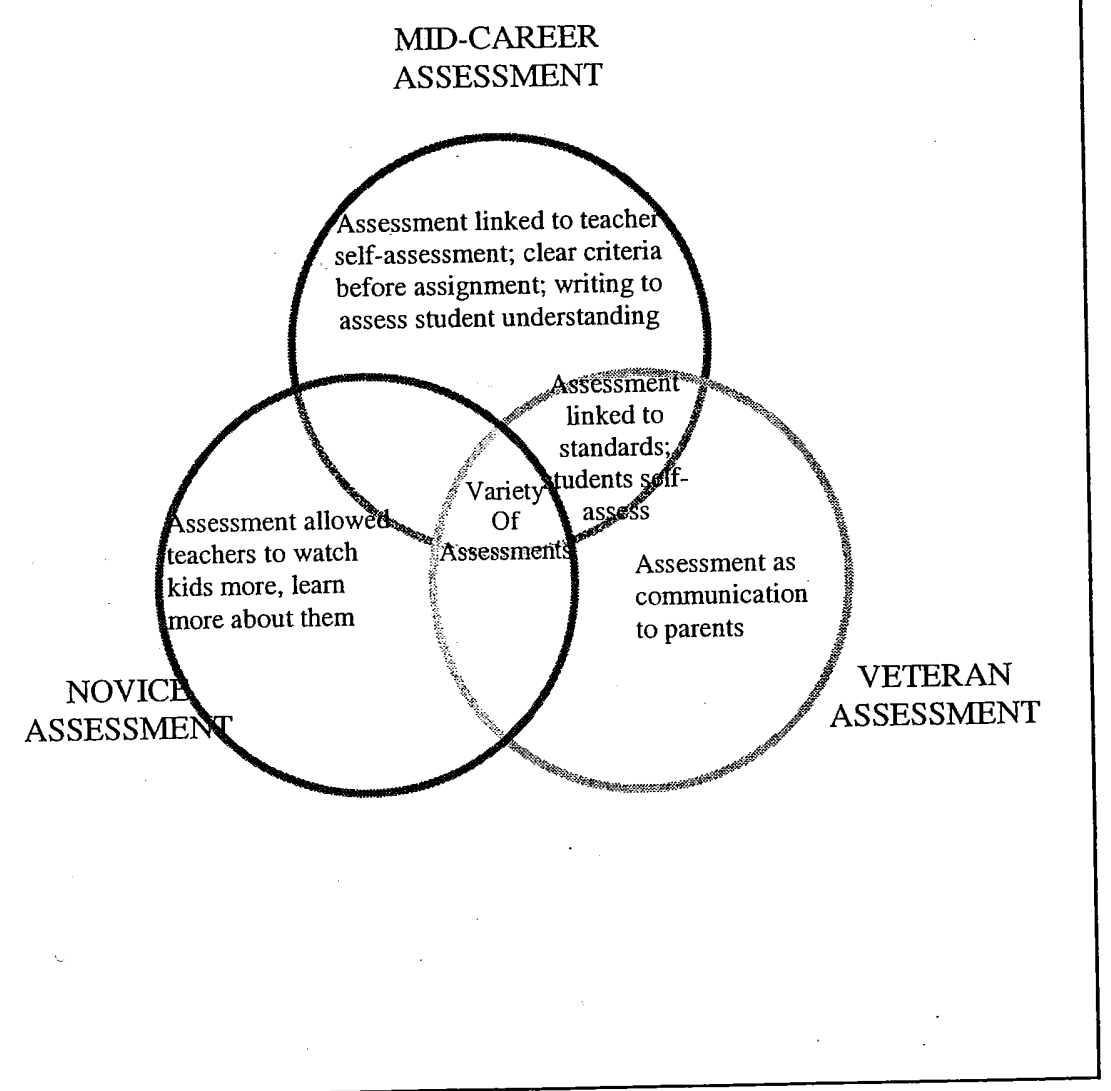

Figure 8. Comparison of assessment between novice, mid-career and veteran cohorts.

The most consistent similarity across all cases was that of variety. Each group commented that a variety of assessments were tried, and by expanding the number of different types of assessments, teachers in each cohort gained more information about their students' understanding of content. The theme of variety 
persisted throughout all cases, but was most frequently reported by the novice and veteran cohort.

I think one thing is that I have more a variety of things to assess. I think that before I would see things, but I wasn't sure if it was validated, if I observed it. Now, I know I can journal [document] that activity or observation and see whether or not my kids are meeting my target. I used to think that I had to have pencil and paper for everything. (veteran teacher, interview)

...part of assessment, is part of what I think of first, so I ask myself, how am I going to find out whether or not they've learned what I wanted them to, whether I use paper and pencil, observation, a test, or a project. (novice teacher, interview)

The lab helped me realize I can assess more than just a test. I look at projects and my observations of kids. What can they demonstrate, what have they learned? I talk more to the kids; get their feedback more during the teaching, rather than just at the end. (mid-career teacher, interview)

Mid-career teachers clearly viewed assessment of student work products as a way to evaluate their teaching. Through the careful examination of student work, mid-career teachers monitored their effectiveness as teachers, making adjustments to planning, teaching, and curriculum emphasis based on their findings.

... not only have I expanded my assessment styles, but I have also been able to create methods of truer, more accurate assessment. I feel that these changes have allowed me to be more fair and concise with my grading procedures. (mid-career teacher, written reflection)

Mid career teachers also reported that using student writing as a means for assessing student understanding was a newly explored strategy. They transferred their writing as teachers (as part of the lab assignments) to having students write. It 
was almost as they needed to experience writing as gateway to understanding and meaning themselves, before incorporating writing to understand in their teaching.

I use their writing to determine if the kids really got the concept. It's a more interesting way to assess their thinking than just a test. (mid-career teacher, interview)

The mid-career teachers and the veteran teachers utilized student involvement in assessment. They both involved students in the creation of assessment rubrics and they involved students in both self-assessment and peer assessment.

Creating rubrics has also allowed the students to have more ownership of the grade that they earn for projects. When students are aware of what is expected ahead of time there are fewer questions and more consistency in the work produced. Students know where the standard is set and they can rise to meet the expectations. There is no guessing about what will be accepted and what will not be accepted. (mid-career teacher, written reflection).

Students have become part of the assessment process with games and hands on teams. I often times have three students work together with a problem allowing them to work out the details to reach the goals. (veteran teacher, written reflection)

Veteran teachers were the only group that viewed assessment as a method of communicating student progress to parents. They also communicated to parents about the powerful learning framework, helping to educate parents that their assessment might be more inclusive than just end of unit paper pencil tests.

The novice teachers viewed a variety of assessment tools and strategies as a path for enabling them to better understand their students; and get to know their learning styles, strengths, and challenges. They reported watching their kids more, 
using observation of their students to inform their teaching and planning. The natural orientation for a beginning teacher is to focus more on curriculum, and less on their students (Featherstone, et al., 1997).

It's [powerful learning assessment] helped me understand some of my kids a little better, like give better directions, it's allowed me to assess whether or not they can follow directions, complete the directions correctly. I've observed them more. (novice teacher, interview)

The most influential part [of using powerful learning assessments], was that I needed to learn about each student individually. For example, I used to assume that all the kids came in at the same level, now I realize they don't. I'm looking at them more, (more critically), to really help them learn. (novice teacher, interview)

Cross-case analysis of reflecting. The consistent finding across all cases was that the teachers used reflection as an opportunity to gauge incorporation of the five components of powerful learning in their teaching, at every phase: planning, teaching and assessing. This reflection occurred throughout the teaching cycle and was reported by all cases (see Figure 9).

I compare my lessons now to the 5 components and try to make the lesson include those [components]. (novice teacher, interview)

Overall, I think that the Powerful Learning Lab has made me a better teacher. I think more about all the components in everything I do. (Mid-career teacher, written reflection) 


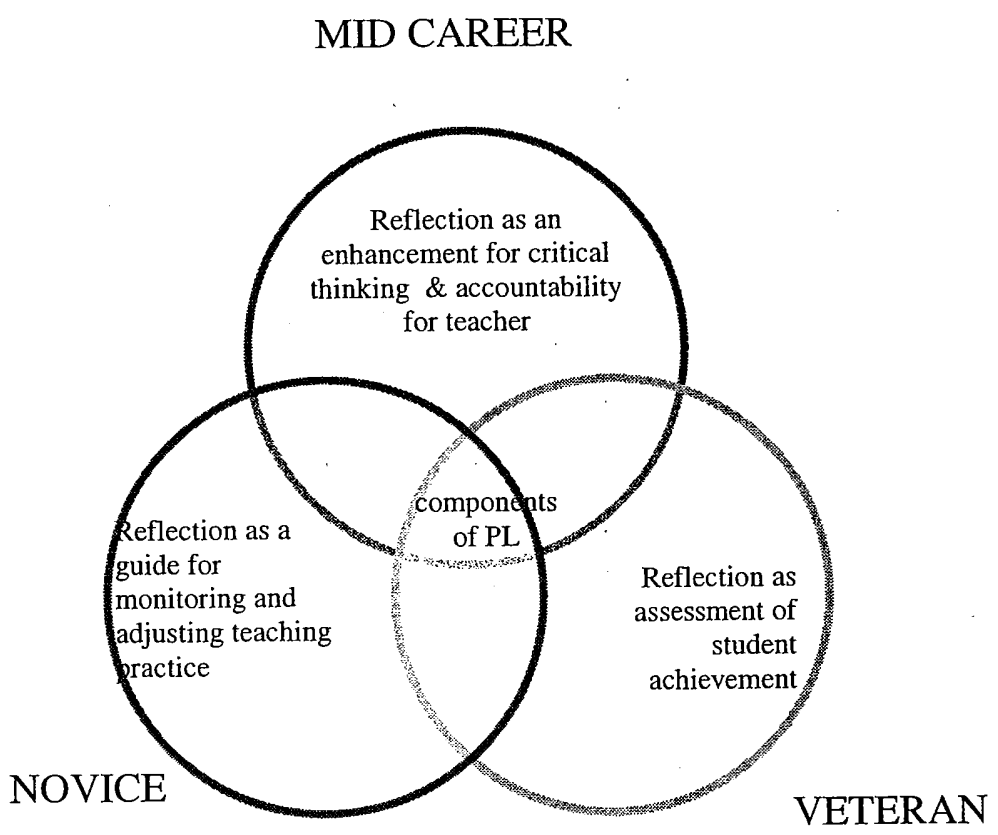

Figure 9. Comparison of reflection between novice, mid-career and veteran cohorts.

A novice teacher commented,

My reflection is so focused now, from planning instruction to instruction in process, to evaluating the success of instruction. Each powerful learning component opens a whole world of reflection and a unique slant to view instruction in the classroom. It is great to reflect on a lesson from an authentic perspective, and then view the same lesson from a learner-centered perspective. The combination of perspectives makes my reflection so much deeper and more meaningful. (Novice teacher, written reflection) 
Mid-career teachers connected reflection to critical thinking and accountability. They reported that taking the time to reflect on their teaching and writing or discussing those reflections made them think more critically about their teaching, their planning, their delivery of instruction, their choice of curriculum, and their assessments.

Using the reflection sheets, I have found that I can critically look at what I am doing in the classroom, where my students are in the learning process and where we need to go next. (mid-career teacher, written reflection)

The assessment really made me reflect and think about what I could have done better. We will do such a better job if we take the time to say what is good and what needed improvement. (mid-career teacher, interview)

For mid-career teachers, purposeful, regular reflection provided more challenge to their work environment and emphasized accountability.

It definitely has, made me more challenged to do better, if something didn't work, I'm more likely to go back and figure out why, and make it work. I'm getting better, it is becoming more reflective in a natural way, and it is more automatic. (mid-career teacher, interview)

The accountability of writing and reflecting upon the lessons has been a very good exercise in my teaching. (Mid-career teacher, written reflection)

The novice cohort also indicated they became more critical of their teaching through reflection, but they consistently reported the reflection prompted actions of monitoring student behavior and performance and adjusting their teaching practice (which included planning, teaching and assessing). They reported being able to "think and respond on their feet," by reflecting during instruction. 
I have reflected upon some of my lessons to see what worked and what didn't work. Have adjusted lessons so that I hold the interest of all of my students and all can participate. (novice teacher, written reflection)

For the novice group, reflection became an automatic function. Even though, they had recently completed college programs that incorporated reflection, the lab requirements of reflection became part of their normal daily functions as teachers.

Reflections was a very big part of my college program, but the PL framework gives me the vocabulary to be more specific, and get at what I need to improve on, now I can take bits and pieces and improve it. (novice teacher, interview)

The veteran cohort reported using reflection as a link to assessment of student achievement, their reporting of internal reflections tended more toward whether or not students were obtaining their lesson objectives. This group also reported a higher frequency of reflection throughout the day, before, during and after instruction.

In terms of reflecting, I feel like I think more about, "did they get it?" I sort of think about, "how did I make this powerful?" which components did I use, then I get excited that I realize I've used more than one component. (veteran teacher, interview)

Well the lab has allowed me to have frameworks to reflect on if I have met my goals. We have rubrics, we can write a rubrics, so I can see, what I look for if they have mastered a skill. (veteran teacher, interview)

In summary, the findings related to the primary research question, (Does participation in the Powerful Learning Lab influence regular teacher practice?) indicate that all cases were influenced by their participation in the lab in a positive 
way. Each cohort's perception of what aspect of teaching practice was most

influenced varied somewhat, but all cases reported their planning, teaching, assessing and reflecting did generally improve. Further investigation of the themes of the cases and answers to the remaining research questions follow.

\section{Characteristics of Cases and Emerging Themes}

Cross-case analysis yielded interesting characteristics of the cases. There were distinct patterns in terms of quantity of data and preference of learning styles, data reporting and data collection. These characteristics are consistent throughout the artifacts and are related to the emerging themes. (See Table 15.)

\section{Table 15}

Cross-Case Analysis of Data Characteristics and Learning Preference

\begin{tabular}{|l|l|l|l|}
\hline Case & Quantity of Response & $\begin{array}{l}\text { Observational Data } \\
\text { characteristics }\end{array}$ & $\begin{array}{l}\text { Learning Preference } \\
\text { Characteristic }\end{array}$ \\
\hline Novice & $\begin{array}{l}\text { Shortest interviews; } \\
\text { enritten reflection at } \\
\text { end of year written } \\
\text { reflections brief }\end{array}$ & $\begin{array}{l}\text { Focused on 1-2 components } \\
\text { at a high level; comfortable } \\
\text { with cooperative learning; } \\
\text { began/ended lessons with } \\
\text { teacher directed talk }\end{array}$ & $\begin{array}{l}\text { Equal preference for } \\
\text { talking and writing } \\
\text { Disliked Models of } \\
\text { Teaching Textbook } \\
\text { Invited Feedback } \\
\text { Liked Peer teaching }\end{array}$ \\
\hline $\begin{array}{l}\text { Mid- } \\
\text { career }\end{array}$ & $\begin{array}{l}\text { Long written } \\
\text { reflections throughout } \\
\text { the year, interviews } \\
\text { were longer than } \\
\text { novice, shorter than } \\
\text { veterans }\end{array}$ & $\begin{array}{l}\text { Clearer criteria for student } \\
\text { work/outcomes; least teacher } \\
\text { directed of all cohorts; more } \\
\text { student-student interaction; } \\
\text { lessons demonstrated multiple } \\
\text { components, lots of student } \\
\text { work displayed }\end{array}$ & $\begin{array}{l}\text { Preferred writing } \\
\text { Disliked Models of } \\
\text { Teaching Textbook } \\
\text { Invited Feedback } \\
\text { Liked Peer Teaching }\end{array}$ \\
\hline $\begin{array}{l}\text { Veteran } \\
\text { written reflections at } \\
\text { of year written } \\
\text { reflection }\end{array}$ & $\begin{array}{l}\text { Lessons demonstrated } \\
\text { multiple PL components; } \\
\text { began lesson as teacher } \\
\text { directed, most of lesson } \\
\text { emphasized student } \\
\text { interaction and student } \\
\text { discovery }\end{array}$ & $\begin{array}{l}\text { Preferred talking } \\
\text { Liked Models of } \\
\text { Teaching Textbook } \\
\text { Provided Feedback } \\
\text { Liked Peer Teaching } \\
\text { Liked Lecture }\end{array}$ \\
\hline
\end{tabular}


The characteristics are consistent with adult and teacher development patterns discussed in chapter two. The veterans (and older teachers) preferred talking to writing (although they engaged in writing tasks) and enjoyed the lecture aspects of the lab; while the novice and mid-career (younger) teachers preferred a more active learning style, enjoyed writing, and peer teaching. They were at ease with a constructivist learning approach, while the veterans preferred a more traditional teacher at the head of the class approach. The orientation of the cases also contributed to how they responded in the interviews

The subtle differences between cases in orientation toward their work are reflected in Table 16. The novice group phrased their conversations more often around curriculum and planning issues. Whereas the mid-career group was clearly results oriented with constant reference to student performance, student work, and student outcomes. They addressed assessment with more interest and depth than the other areas of teaching practice. The veteran group was more people oriented, referring to people, peers, kids much more frequently and with more detail than curriculum or student work products. Veterans reported even responses to the four components of teaching practices, with only a slight emphasis on reflection. 
Table 16

Case Orientation and Teaching Practice Emphasis

\begin{tabular}{|l|l|l|}
\hline Cohort & Orientation & $\begin{array}{l}\text { Teaching Practice } \\
\text { emphasis }\end{array}$ \\
\hline Novice & Curriculum oriented & planning \\
\hline Mid-career & Results oriented & Assessment \\
\hline Veteran & People oriented & reflection \\
\hline
\end{tabular}

Three emergent themes were gleaned from the data: collaboration, critical

thinking and writing to learn (see Table 17).

\section{Table 17}

\section{Emerging Themes of Research Findings}

\begin{tabular}{|l|l|l|l|}
\hline Case & Collaboration Theme & $\begin{array}{l}\text { Critical Thinking } \\
\text { Theme }\end{array}$ & $\begin{array}{l}\text { Writing To Learn } \\
\text { Theme }\end{array}$ \\
\hline Novice & $\begin{array}{l}\text { Profoundly grateful to } \\
\text { plan and interact with } \\
\text { experienced peers, } \\
\text { benefited from } \\
\text { feedback, and at } \\
\text { end of year, sought } \\
\text { each other. }\end{array}$ & $\begin{array}{l}\text { Reported critical } \\
\text { thinking at } \\
\text { planning phase and } \\
\text { assessing phase. }\end{array}$ & $\begin{array}{l}\text { Writing helped clarify } \\
\text { components; writing } \\
\text { reflections helped organize } \\
\text { thinking. }\end{array}$ \\
\hline Mid-career & $\begin{array}{l}\text { Reported collaboration } \\
\text { as a benefit, but very } \\
\text { focused, task oriented, } \\
\text { more interested on } \\
\text { planning and assessing, } \\
\text { less interested in } \\
\text { feedback. }\end{array}$ & $\begin{array}{l}\text { Reported critical } \\
\text { thinking at all } \\
\text { phases of teaching, } \\
\text { especially at } \\
\text { assessment, } \\
\text { reflection and } \\
\text { planning. }\end{array}$ & $\begin{array}{l}\text { Writing to learn and writing } \\
\text { reflections caused them to } \\
\text { "think", "question" and } \\
\text { "improve practice". Written } \\
\text { planning brought } \\
\text { accountability. Transferred } \\
\text { to more student writing } \\
\text { across curriculum. }\end{array}$ \\
\hline Veteran & $\begin{array}{l}\text { Looked forward to } \\
\text { collaboration time, } \\
\text { mentioned social and } \\
\text { outside of lab } \\
\text { collaboration, enjoyed } \\
\text { peer feedback; } \\
\text { anticipated it. }\end{array}$ & $\begin{array}{l}\text { Reported critical } \\
\text { thinking at } \\
\text { planning/especially } \\
\text { making curriculum } \\
\text { decisions; during } \\
\text { assessment, and } \\
\text { while reflecting. }\end{array}$ & $\begin{array}{l}\text { Writing to learn, more about } \\
\text { PL components, and more } \\
\text { about their students. } \\
\text { Written reflection allowed } \\
\text { them to revisit past } \\
\text { practices. }\end{array}$ \\
\hline
\end{tabular}


Collaboration. Collaboration was consistently reported as a benefit of the Powerful Learning Lab. Each cohort appreciated the opportunity to collaborate with other teachers from around the region.

During the lab, the entire group of 42 lab participants met in three consistent groups. First they met in cross-region age-level groups, (primary, intermediate, and middle school teacher groups for peer feedback, and to "pairshare" their lessons developed, taught, and reflected upon). Then the entire participants group (42) met in "interest groups" to learn and study about the teaching strategies related to one or more powerful learning components. The final consistent group was grade level and/or school level teams for planning for the lessons. The group also sat in school level teams during whole group instructions, such as during the lecture on the culture of poverty.

So, there were multiple opportunities for this sample group to interact with teachers beyond their immediate school or grade level. In addition to these formal groups, informal groups formed. Accelerated Schools coaches roved from group to group, participating in many groups. During these various groupings, collaboration was the norm. Every individual teacher case in the sample population reported about the benefits of collaboration. It was the most prevalent benefit, reported by 100 percent of the sample.

The lab was planned with intentional and multiple opportunities for collaboration; however the influence of collaboration on teaching practices was 
consistently reported. Every teacher, across every demographic criteria reported collaboration as a benefit.

Collaboration is well documented as an effective strategy for improving teaching (Barth, 2001; Brookfield, 1986; Glickman, 2002; Glickman et.al., 1998; Lambert, 1998; Schon, 1983; Sergiovanni, 1994; Smylie, 1995). Through the faceto-face teacher talk, teachers clarified understanding, tossed out ideas for further development, and bantered in their own technical language the large and small dilemmas of teaching. Teacher collaboration is a characteristic of teacher learning, and teaching is an "intensive technology" (Hawley \& Valli, 1999, p. 130). By intensive they mean that teaching is fraught with ambiguity, due to the multiple circumstances that teachers encounter in the act of teaching, task performance in teaching is varied, and outcomes of teaching are multiple, diffuse, and difficult to measure. Hawley and Valli continue,

Because teaching is an intensive technology, teacher learning is essential to improved student learning. A school that fosters teacher learning will be one that 1) minimizes bureaucratic constraints and rules; 2) is clear about its multiple goals and the priorities it assigns to them; 3)provides teachers, students and administrators valid and accurate measures of student performance and of the process associate with differences in student performance; and 4) provides educators opportunities to learn collaboratively, practice what they learn, and evaluate the consequences in light of established goals. (p. 131)

The depth of appreciation and passion of the benefits of collaboration intersected each case, novice, mid-career and veteran, as the following findings illustrate.

Being around people from all over the place, from all the spectrum of education, it was really cool, very helpful for getting ideas from other 
teachers. It was really easy to get a whole bunch of peer help. That helped me plan for lessons in a better way. (novice teacher, interview)

...the collaboration [at the Powerful Learning Lab] with other teachers really helped my practice; it validated what I've been doing, but let me go out of my comfort level too. It was OK to explore new ways to teach. It's helped me to take risks. I think the kids learn more when I'm out of my comfort zone, when I take risks. I've learned to ask more questions of myself and my kids. (mid-career teacher, interview)

My past year of training and working with the other teachers in the PL lab has been the most valuable educational experienced for me in my teaching career. We felt comfortable around each other and because of it we all grew through each other's knowledge. ...I so enjoyed sharing our lessons, which we had written and taught prior to coming to class with other teachers for a pat on the back for hard work and ways to improve it. When we grouped by like grade levels I always came away with new ideas and feeling of teamwork. After working with such a powerful group of teachers I can see how "powerful" education can be for students and how we can reach our goal of education for ALL students. (veteran teacher, written reflection).

At the one year follow up interview, "collaboration" was most frequent response as to "what stuck" with participants a year later. Being able to collaborate at all phases of teaching practice and to receive feedback from peers was a critical learning for Powerful Learning Lab participants. They viewed collaboration as a gain, even though the collaboration went both ways, participants offered ideas, suggestions and feedback as often as they received it.

Critical thinking. The critical thinking theme was intertwined in many of the aspects of teaching, often at the planning, assessing and or reflection phase. The frequent references to "think time", "thinking critically about practice," and 
"re-thinking" were prevalent in all cases, and across cases. Critical thinking is often referred to as reflection, but the findings of this study produced a critical thinking element that goes beyond reflecting on practice, to making critical observations and those critical observations led to a change in teacher practice. This change was often reported as risk taking, trying new things, or trying strategies that had failed before, but working through times of frustration with the strategy. Reflection and critical thinking are most inextricably linked; the findings related to critical thinking were always followed by a description of an action. So the critical thinking became the catalyst for change in teaching practice.

Most of the teachers attributed the critical thinking to structural elements of the lab, the year-long commitment, meeting every few months, the required written reflections, and the reflections on student work. The "thinking" staff is another well documented description of successful schools (Barth, 2001; Boyer, 1995; Evans, 1996 Glickman, 2002; Goodlad, 1983; Little, 1999; Schlechty, 1997; Schon, 1983). A learning community has become the panacea of recent school reform, but a true learning community must be inhabited by teachers who think critically, who question, struggle, read, write, and wonder about their practice. Barth (2001) describes the necessity of continued teacher learning in simple prose,

Children are not dumb. They look at the most important role models in their lives, their parents, teachers, principals and ministers and say, 'I want to be like that.' I f they see adult models who are done, baked, cooked, finished as learners, they too want to be done, bake, cooked, finished as learners - ' I'm outta here!' If they see about them adults who ask questions, read, write, pose and solve problems, work together, and struggle with important learning, they 
want to ask questions, read, write, pose and solve problems, and engage in and struggle with important learning. (p. 24)

Writing to learn. Writing to learn is well documented in best practice literature (Barth, 2001; Marzano, Pickering \& Pollock, 2001; Routman, 1988; Routman, 2002; Zemelman, Daniels \& Hyde, 1998). Typically, this body of literature is formulated around the teaching of writing, and using writing to improve student understanding. Well, the same best practice was applicable to the teachers involved in the Powerful Learning Labs. Their assigned writing tasks, were often reported as the learning point for teacher participants in the lab. Even though the writing may have become tedious at times, the cohorts consistently reported across cases that writing helped deepen their understanding, as on midcareer teacher states,

Writing the reflections does seem sort of monotonous, but it makes me think, and makes me learn from it, and determine where the kids came from in the beginning. (mid-career teacher, interview)

Teacher participants in the lab kept a portfolio of their written lesson plans, student work samples from those lessons, written reflections on their teaching, peer debriefing notes from peer observations of their teaching, and a final (longer) written reflection of the overall lab experience. It was often through writing, that teachers reported being able to revisit their own thinking, and challenge some of their previous assumptions about teaching and learning. Using writing as a way to unlock meaning and influence practice has been successfully demonstrated in professional development such as the National Writing Project (Lieberman and 
Wood, 2002). Throughout the year, the cohorts writing became more thoughtful, longer, and more focused. At the end of the year, teachers were able to look back at their year long record of their teaching journey and reflect and plan for the next year. One novice wrote,

The portfolio has promoted my reflection, and given me a great repertoire of lessons to use in the future. I am glad it was used as a learning tool, and would like to see that kept in the future.[ future Powerful Learning Labs] (novice teacher, written reflection)

Teachers wrote ten formal lesson plans, two plans for each component.

Only one veteran teacher suggested the written lesson plan number be decreased from ten to five. Yet, the veteran cohort did value writing to learn and understand their own practice.

When I think all I have learned about powerful learning I feel I need to continue to write powerful lessons, which I can share with others. (veteran teacher, written reflection).

Writing about one's practice forces teachers to think and reflect just by the action of writing. Barth (2001) summarizes these benefits,

For most of us, writing comes with great difficulty. Yet part of what it means to be a professional is to learn how to write about practice and to disclose one's thoughts in writing to others. When we write we become responsible for our words and ultimately we become more thoughtful human beings. Writing (and reading) about practices is closely related to improving practice, for with written words come the innermost secrets of schools and of their schoolmasters. (p. 67)

During follow up interviews a year after the Powerful Learning Lab, writing to learn persisted as a theme. All participants were asked, "What has stuck with 
you about your lab experience, one year later?" The power of writing to learn was reported as the third most frequent response.

The three emergent themes of collaboration, critical thinking, and writing, are all related, and are organized in the following radial diagram (see Figure 10 ). When one teacher collaborates with another teacher or teachers, the experience should produce critical thinking, which then prompts further collaboration or a change in teaching practice. If writing about teaching creates clearer understanding, more critical thinking occurs, and if that writing and thinking occurs in conjunction with collaboration, even more influence on teacher practice is likely. So, in many ways the three themes are interwoven around teaching practice, and all influence teaching practice. 


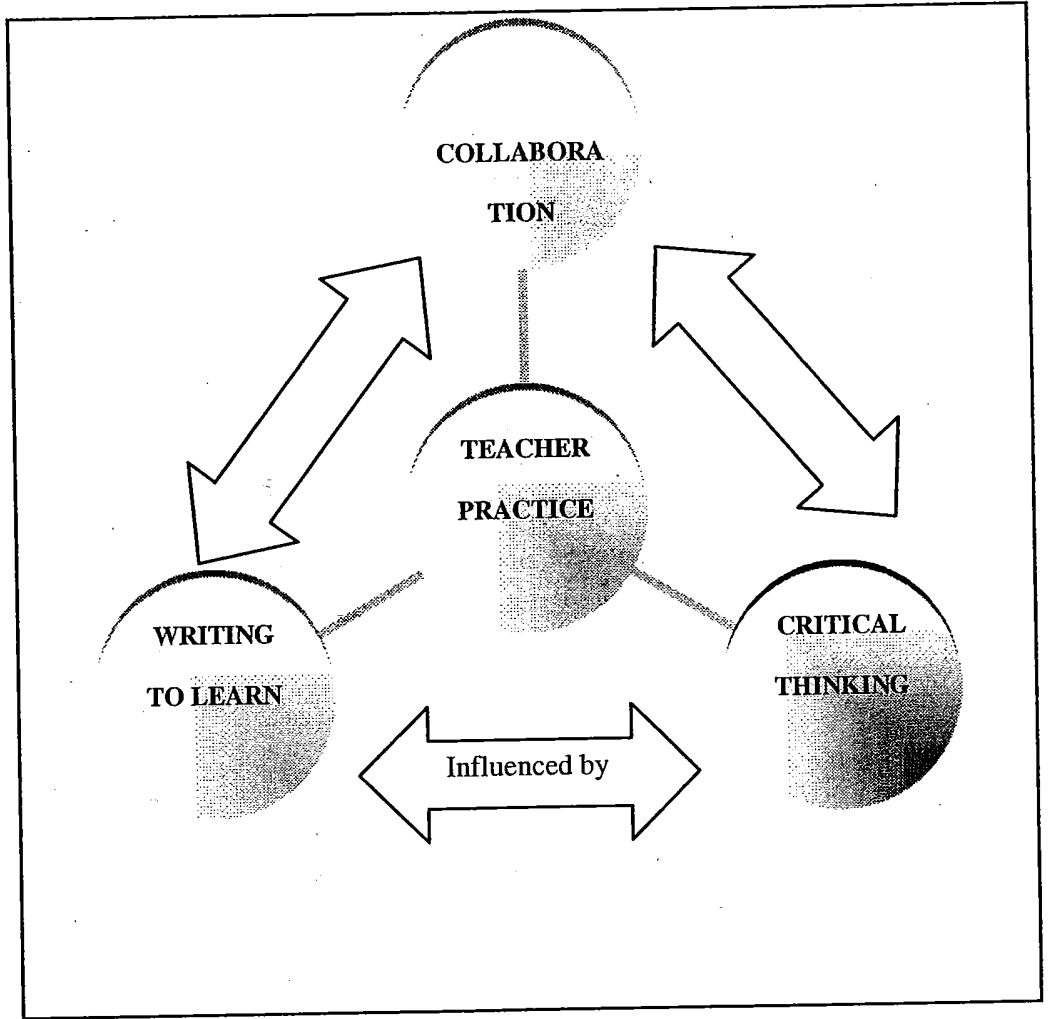

Figure 10. Diagram of collaboration, critical thinking and writing to learn and their influence on teaching practice.

\section{Secondary Research Question Findings}

The remaining secondary research questions were more concrete than the primary question about teacher practice. The primary source of data collection for the secondary research questions were the interviews. Each question was asked and answers recorded, unprompted. This open ended response allowed participants to make their own decisions about the secondary research questions and not be guided 
by a set of answers. There were clear indicators in the data about these. Those findings are presented in Tables 18, 19, 20, 21 and 22.

Question: What are the district factors that support teacher learning? Table 14 summarizes the findings about teacher's perception of the district factors that support teacher learning in a comprehensive school improvement environment.

\section{Table 18}

Teachers' Perception of District Support Factors for Teacher Learning by Percent

\begin{tabular}{|c|c|c|c|c|c|}
\hline cohort & $\begin{array}{c}\text { Staff } \\
\text { development w/ } \\
\text { release time }\end{array}$ & $\begin{array}{c}\text { ASP Coach } \\
\text { mentor } \\
\text { Teacher }\end{array}$ & Principal & $\begin{array}{c}\text { Superin- } \\
\text { tendent }\end{array}$ & $\begin{array}{c}\text { ASP meeting } \\
\text { structures } \\
\text { (Cadre, SAW, team } \\
\text { meetings) }\end{array}$ \\
\hline $\begin{array}{c}\text { Novice } \mathrm{n} \\
=7\end{array}$ & $71 \%$ & $57 \%$ & $43 \%$ & $14 \%$ & $43 \%$ \\
\hline $\begin{array}{c}\text { Mid } \\
\text { career } \\
\mathrm{n}=4\end{array}$ & $50 \%$ & $50 \%$ & $0 \%$ & $0 \%$ & $25 \%$ \\
\hline $\begin{array}{c}\text { Veteran } \\
\mathrm{n}=4\end{array}$ & $50 \%$ & $0 \%$ & $25 \%$ & $50 \%$ & $25 \%$ \\
\hline $\begin{array}{c}\text { Total } \\
\mathrm{n}=15\end{array}$ & $60 \%$ & $40 \%$ & $33 \%$ & $20 \%$ & $33 \%$ \\
\hline
\end{tabular}

The findings report all responses in percentages related to the cohort size, then the total percentage of responses for the entire sample are reported at the bottom of the table.

What is clear is that teachers perceive support through staff development opportunities, such as the Powerful Learning Lab, and other staff development options with release time.

The district made a long term commitment to this class [Powerful Learning Lab]. I was worried that they wouldn't be able to get the substitutes. I was really worried; I wouldn't be able to do this. The 
fact that the district pulled it off, and made that commitment, was great. (veteran teacher, interview)

The Accelerated Schools coach and/or mentor teachers were most valued by the less experienced cohorts, with $57 \%$ of the novice teachers indicating the coach helped them, and $50 \%$ of the mid-career teachers reporting the coach as a district factor supporting teacher learning. No veteran teachers named the coach as a factor. This importance of the coach was articulated in the following comment, Having a coach at our school [was a support factor for teacher learning]. I was so shocked last year when our coach said she'd come in and teach a lesson. It was so helpful to have a coach come in and model the lesson. Things that you do everyday, like a read aloud, having her model some question strategies. She was able to model reading strategies that I could use. (mid-career teacher, interview)

Support of building and district administrators was important to the novice and veteran cohorts. The middle school principal was mentioned most frequently as a supporter for teacher learning. "[My principal] is great at supporting staff development. Administrative support is great" (novice teacher, interview). The support of the superintendent was perceived as both inspirational and financial support.

I think that [the superintendent] is supportive, he is visible on campus, it is very nice, both financial and verbal support. (veteran teacher, interview)

Each cohort valued the Accelerated Schools meeting structures as supports for teacher learning, this was expressed in terms of time commitment and an opportunity to collaborate with peers about teaching. 
Question: What factors do teachers perceive contribute to student

achievement? The complete display of the findings are in Table 19, but there is no question teachers perceive themselves to be the greatest factor affecting student achievement.

\section{Table 19}

Teachers' Perception of Factors Contributing to Student Achievement by Percent

\begin{tabular}{|c|c|c|c|c|c|}
\hline Cohort & Teacher & $\begin{array}{c}\text { Student } \\
\text { motivation }\end{array}$ & $\begin{array}{c}\text { Parent/ community } \\
\text { involvement }\end{array}$ & $\begin{array}{c}\text { Success in } \\
\text { school }\end{array}$ & $\begin{array}{c}\text { PL } \\
\text { Components }\end{array}$ \\
\hline $\begin{array}{c}\text { Novice } \\
\mathrm{n}=7\end{array}$ & $86 \%$ & $14 \%$ & $29 \%$ & $0 \%$ & $29 \%$ \\
\hline $\begin{array}{c}\text { Mid } \\
\text { career } \\
\mathrm{N}=4\end{array}$ & $75 \%$ & $25 \%$ & $0 \%$ & $0 \%$ & $50 \%$ \\
\hline $\begin{array}{c}\text { Veteran } \\
\mathrm{N}=4\end{array}$ & $100 \%$ & $50 \%$ & $50 \%$ & $25 \%$ & $25 \%$ \\
\hline $\begin{array}{c}\text { Total } \\
\text { sample } \\
\mathrm{N}=15\end{array}$ & $87 \%$ & $27 \%$ & $27 \%$ & $6 \%$ & $33 \%$ \\
\hline
\end{tabular}

There was almost unanimous agreement by teachers, that teachers are the most significant factor contributing to student achievement. Some explained this perception as teacher-student rapport, others just answered the question with a resounding "TEACHERS!" This is consistent with Wang, Haertel, and Walberg's (1993-1994) meta-analysis of student achievement.

From novice to veteran, the participants consistently reported that the quality, dedication, and ability of the teacher were the most important factor contributing to student achievement.

Dedicated professionals, obviously [is the factor that most affects student achievement]. We have teachers here who are just counting 
the days until retirement. If everyone would be dedicated and make an effort to communicate, we could really help (kids). (novice teacher, interview)

One mid-career teacher was so convinced that the teacher was paramount to student learning, she was willing to express her own vulnerability.

I think a huge factor is the teacher. I know that in my first year of teaching I didn't want to admit that. I had a tough first year, and I didn't want to admit that the students' performance reflected on my teaching. I think that it is really true, and the kids' performance is really related to the teacher, the curriculum, and how she integrates those two factors [teaching and curriculum]. (mid-career teacher, interview)

The remaining factors that teachers perceive contributed to student achievement were less than $50 \%$ but included: the powerful learning components, which the participants perceived as good teaching methods, student motivation, parent and/or community involvement and success in school.

Question: What recommendations do you have for teacher preparation programs? The sample had many suggestions for teacher preparation programs; most expressed they did not receive enough or correct training. All participants described themselves as being unprepared to teach in a district where diversity and poverty was the norm. Many were touched by the Powerful Learning Lab's discussion and lecture on the culture of poverty, building on Ruby Payne's work (Payne, 1998). The lecture and discussion on the culture of poverty was part of the January, 2002 Powerful Learning Lab content strand. This topic was scheduled for fifty minutes, but the participants refused to end it; they demanded more discussion 
and more information! The findings for this research question are summarized in Table 20.

Table 20

Recommendations for Teacher Preparation Programs by Percent

\begin{tabular}{|c|c|c|c|c|c|c|c|}
\hline Cohort & $\begin{array}{c}\text { Pov- } \\
\text { erty }\end{array}$ & Diversity & $\begin{array}{c}\text { Classroom } \\
\text { Management }\end{array}$ & $\begin{array}{c}\text { Language } \\
\text { acquisition }\end{array}$ & $\begin{array}{c}\text { State } \\
\text { standards }\end{array}$ & $\begin{array}{c}\text { More } \\
\text { Field } \\
\text { Experi- } \\
\text { ences }\end{array}$ & $\begin{array}{c}\text { Reflection } \\
\text { \& } \\
\text { Collabora } \\
\text {-tion }\end{array}$ \\
\hline $\begin{array}{c}\text { Novice } \\
\mathrm{n}=7\end{array}$ & $86 \%$ & $86 \%$ & $14 \%$ & $14 \%$ & $14 \%$ & $71 \%$ & $0 \%$ \\
\hline $\begin{array}{c}\text { Mid } \\
\text { career } \\
\mathrm{n}=4\end{array}$ & $25 \%$ & & $25 \%$ & $25 \%$ & $25 \%$ & $0 \%$ & $50 \%$ \\
\hline $\begin{array}{c}\text { Vetera } \\
\mathrm{n} \\
\mathrm{n}=4\end{array}$ & $75 \%$ & $50 \%$ & $25 \%$ & $0 \%$ & $0 \%$ & $50 \%$ & $25 \%$ \\
\hline $\begin{array}{c}\text { Total } \\
\text { sample } \\
\mathrm{n}=15\end{array}$ & $67 \%$ & $53 \%$ & $20 \%$ & $13 \%$ & $13 \%$ & $47 \%$ & $20 \%$ \\
\hline
\end{tabular}

With the exception of the last two columns (field experiences, and reflection and collaboration), the teacher's suggestions for teacher preparation program improvement involved having more coursework, especially in the area of poverty and diversity. Teachers explained they received little or no information about either poverty or diversity in their teacher preparation programs. One particularly interesting report was from the first year teachers, who had completed their teacher training within the last year, and yet they unanimously reported, there were no provisions, courses or even discussions in their teacher licensure programs about poverty or diversity. 
They [pre-service teachers] need to read the Ruby Payne book, $A$ Framework for Understanding Poverty, which is about the culture of poverty. There needs to be more course work and more "walking the talk" of multi cultural education. ...I don't know how much more I can stress sensitivity. I still hear a lot of ignorance about other cultures. (novice teacher interview)

The one thing that I would have benefited from was more [coursework] on diversity, some way of letting people know that your kids will come from really broken homes, extreme poverty, I had no idea. Nothing prepared me for this setting. My student teaching experience was in a white middle class school. If we had had something on the "culture of poverty" it would have helped me. (novice teacher interview)

The recommendations for more field work, included recommendations for doing home visits, volunteer work with youth, community volunteer work in diverse communities, and more classroom experiences and visitations of diverse and poor schools. The recommendation for more collaboration, and more opportunities for students to reflect on their practice teaching was suggested. On particular suggestion was to incorporate pre-service teacher collaboration of the problems of beginning teaching, especially planning and classroom management and diagnosing difficulties.

My program tried to have reflection, but it was inadequate, weighted too heavily on the planning side. The reflection wasn't based on what the kids were learning, and what did I need to do. I think that being able to determine if kids are grasping the learning comes from working in the field. Perhaps using more diagnostic reflection would be helpful. (mid-career teacher, interview)

Question: What were the benefits and limitations of the powerful learning lab? The participants were eager to discuss the benefits and limitations of the lab, 
offering suggestions for content as well as process. The findings for this research question are displayed in Table 21 and 22.

Table 21

Teachers' Perception of Benefits of Powerful Learning Lab by Percent

\begin{tabular}{|c|c|c|c|c|c|c|c|}
\hline Cohort & Reflection & $\begin{array}{c}\text { Improved } \\
\text { teaching }\end{array}$ & $\begin{array}{c}\text { Time } \\
\text { to } \\
\text { plan }\end{array}$ & Collaboration & $\begin{array}{c}\text { Best } \\
\text { Practice } \\
\text { Seminars }\end{array}$ & $\begin{array}{c}\text { Guided } \\
\text { Practice } \\
\text { w/Feedback }\end{array}$ & $\begin{array}{c}\text { Year } \\
\text { long }\end{array}$ \\
\hline $\begin{array}{c}\text { Novice } \\
\mathrm{n}=7\end{array}$ & $29 \%$ & $100 \%$ & $29 \%$ & $86 \%$ & $43 \%$ & $57 \%$ & $57 \%$ \\
\hline $\begin{array}{c}\text { Mid career } \\
\mathrm{n}=4\end{array}$ & $50 \%$ & $100 \%$ & $50 \%$ & $50 \%$ & $25 \%$ & $25 \%$ & $50 \%$ \\
\hline $\begin{array}{c}\text { Veteran } \\
\mathrm{n}=4\end{array}$ & $25 \%$ & $100 \%$ & $25 \%$ & $75 \%$ & $50 \%$ & $50 \%$ & $25 \%$ \\
\hline $\begin{array}{c}\text { Total } \\
\text { sample } \\
\mathrm{n}=15\end{array}$ & $33 \%$ & $100 \%$ & $33 \%$ & $73 \%$ & $40 \%$ & $47 \%$ & $47 \%$ \\
\hline
\end{tabular}

The most significant perceived benefit of the Powerful Learning Lab, was that all of the participants reported they became better teachers. Some even mentioned personal growth as well. Personal growth and personal change is part of professional growth.

Being a part of the Powerful Learning Lab at Portland State University has been a very valuable experience. Not only have I learned a lot about my teaching styles and methods, but I have learned a lot about my personal abilities and challenges as well. Since August of 2000, I have strengthened my teaching ability, finetuned many skills and developed a new confidence in my career. (mid-career teacher, written reflection)

Stated more succinctly a novice reported in an interview, "I'm really glad I went down there every time, I really did learn and grow a lot from the labs. I grew as a professional and as a human." 
The year-long structure proved a successful strategy. There was a palatable turning point in January, 2002, during the third session of the PLL, the large group of 42 participants really began to come together as a community. I kept anecdotal notes about the PLL; in January I noted the majority of the group arrived very early, thirty minutes before the session, to share, meet and greet each other. They stayed beyond the allocated time to work and plan together. They were totally absorbed during work times and took shorter lunch breaks. They began to have lunch with other peers than those from their home school. This social bonding would not have happened in a one or two day seminar. Participants valued the guided practice that the lab structured provided, shared planning, going back to teach, peer review, then feedback and sharing from the larger group upon return to Portland State University.

Being able to spread it[the Powerful Learning Lab] out over a year, have time to reflect on the different components, practice them, reflect on them, and bring it back, and evaluate it. It helped to ingrain it, helped me to soak it in. It really helped not to think about the regular work day, get isolated, get away. Time to work during the week, getting to isolate the experience, and the supportive group. Built some great friendships with other teachers, sharing rooms, etc. It was such a good experience for me; I'd like to get more involved with ASP. (novice teacher, interview)

This experience has changed me as a teacher. The real difference for me was the ability to revisit. This was so much more useful than oneday seminars, or conferences with separate sessions. I will continue to reflect, and refine, and gauge my students' progress - daily. (midcareer teacher, interview)

Both peer and instructor feedback was very important to the participants.

They invited comments on their ideas, plans, and student results. They weren't just 
seeking praise. They appreciated being able to share when they were struggling, and getting ideas and advise from peers, instructors, or Portland State University staff who participated in the best practice seminars.

The significant learning from the actual Lab for me was the interaction and sharing of the models of teaching and learning by peer teachers. Through the groups in the Lab I found myself pulling together many classes, readings, conferences, in-services, methods, philosophies, strategies, etc. from twenty years of teaching experience in an organized manner. A teaching repertoire of models of learning was not only within our text, but began emerging from the "best practices" I'd read, seen, taught, put aside for further consideration or use. Now I'm able more easily to take a risk and stretch to try a different teaching model in my classroom because it makes sense. I'm able to see the five components within the teaching models and decide which would be most effective for the students and the particular learning process, for instance a group investigation or paired-sharing for learning a rhyming lesson. (veteran teacher, written reflection)

The participant sample was generous with explanations of benefits of the lab, but didn't offer as many suggestions for improvement or limitations. The group was satisfied with their experience, and might have been a bit tired by the time the limitations question was asked. They were also a very positive group, and might not have been easily inclined to make suggestions. 
Table 22

Teachers' Perception of Limitations of Powerful Learning Labs by Percent

\begin{tabular}{|c|c|c|c|c|c|c|}
\hline Cohort & $\begin{array}{c}\text { Needed } \\
\text { Differentiation }\end{array}$ & Textbook & $\begin{array}{c}\text { Write Fewer } \\
\text { Lesson Plans }\end{array}$ & Fatigue & $\begin{array}{c}\text { More } \\
\text { Lecture }\end{array}$ & $\begin{array}{c}\text { Meet } \\
\text { More } \\
\text { Often }\end{array}$ \\
\hline $\begin{array}{c}\text { Novice } \\
\mathrm{n}=7\end{array}$ & $29 \%$ & $57 \%$ & $0 \%$ & $0 \%$ & $0 \%$ & $14 \%$ \\
\hline $\begin{array}{c}\text { Mid } \\
\text { career } \\
\mathrm{n}=4\end{array}$ & $50 \%$ & $25 \%$ & $0 \%$ & $25 \%$ & $0 \%$ & $0 \%$ \\
\hline $\begin{array}{c}\text { Veteran } \\
\mathrm{n}=4\end{array}$ & $0 \%$ & $0 \%$ & $25 \%$ & $25 \%$ & $25 \%$ & $0 \%$ \\
\hline $\begin{array}{c}\text { Total } \\
\text { sample } \\
\mathrm{n}=15\end{array}$ & $27 \%$ & $33 \%$ & $7 \%$ & $13 \%$ & $7 \%$ & $7 \%$ \\
\hline
\end{tabular}

From the few comments about limitations, there were some key areas for consideration of improving future Powerful Learning Labs. The entire lab sample was quite large, 42 teachers from first year through thirty years of experience was quite a challenge. The sample group made suggestions for more differentiation. Differentiation can be of product, process and content (Tomlinson, 1999). The study's cohorts' suggestions included differentiating product in areas of planning. Veterans didn't need to write ten lessons, but perhaps five would be sufficient (suggested by one veteran). An opportunity to differentiate content and focus on some primary teaching strategies apart from intermediate or middle school strategies was also suggested.

The largest percentage of comments about the lab's limitations was around the textbook. The younger teachers disliked the text, Models for Teaching (Joyce, et al., 2000). The ones who commented negatively about the text thought it was 
too wordy or difficult to read. Conversely, the veteran cohort liked the textbook. Perhaps a more judicious selection of readings from the text would have been a better balance.

\section{Summary}

In summary, the study answered the primary research question quite substantially, and provided important data for the research goals. The Powerful Learning Lab did indeed influence teacher practice. This influence was supported by triangulated data (interviews, written reflections, student work samples, and classroom observations). Each experiential cohort reported their practice improved. All areas of practice (planning, teaching, assessment and reflection) were influenced. The classroom observations indicated that the powerful learning components were executed and that students were engaged in learning.

The novice cohort was most influenced in the planning phase. They spent the most time planning and felt the Powerful Learning Lab influenced their planning by providing a framework for planning and a professional technical vocabulary for planning lessons within the constructivist framework. The most observable characteristic of the novice group's teaching practice was confidence. This group felt competent and confident in their teaching repertoire and reported that the Powerful Learning Lab gave them confidence through a variety of teaching strategies practiced during the lab. Observations of the novice cohort indicated that these beginning teachers were indeed competent and able to demonstrate a variety of teaching 
strategies that were consistent with those studied and practiced in the Powerful Learning Lab. Novice teachers didn't focus on assessment as much or as deeply as mid-career or veteran teachers. They did use their assessment of student work to make adjustments to their lesson planning. Novice teachers increased their frequency of reflection as the year progressed, reflections provided a gateway to meaning.

The mid-career cohort reported they enjoyed planning for powerful learning. They used the five components of powerful learning to organize their lesson plans and to improve areas of weakness. Mid-career teachers didn't report many new teaching strategies, but commented that their awareness of the connectedness of planning, teaching, assessing and reflecting increased. Observations of this cohort indicated that mid-career teachers were competent, at ease in the classroom, and able to demonstrate many teaching strategies that embodied powerful learning. Midcareer teachers connected all the practices of teaching, and reported that planning, teaching assessment and reflection were all interconnected. Mid-career teachers focused more on assessment than the novice or veteran teachers. They used assessment effectively to reflect on their practice and planning and to develop new assessment methods and tools. Mid-career teachers reflected more in their writing than novice or veteran teachers, and they were most critical of themselves of all the cohorts.

Veteran teachers engaged in lesson planning to my surprise. They reported using the powerful learning framework to plan for more complete and integrated lessons. Veteran teachers engaged in planning with a new focus on the Powerful 
Learning components. Veteran teachers reported they were willing to take risks and try new teaching strategies and that the Powerful Learning Lab experience was their first opportunity to critically examine their practice in years. My observations indicated that the veteran teachers were able to demonstrate a variety of teaching strategies, but that they also used the most direct instruction, most often at the beginning and end of lessons.

Veteran teachers were least cohesive about assessment than the other two cohorts. Some reported their assessment options improved during the course of the lab, and that they had more variety in their assessment methods as a result of trying various assessment strategies demonstrated in the lab. One veteran was perplexed by assessment and reported that the lab did not help her with assessment, but rather assessment was an area that needed more work. Veteran teachers viewed assessment as an opportunity to communicate with parents about powerful learning when the other cohorts did not. Veteran teachers reported the benefits of reflecting on their practice as an opportunity to be introspective about their teaching. They recognized the benefit of building in time for reflection. Their implication was that without specific time set aside for reflection, they would not have engaged in reflection on their own.

The emerging themes of collaboration, critical thinking and writing to learn will definitely influence and inform further planning for professional development by the Accelerated Schools Project. The most significant and clear evidence of the importance of collaboration was that it was the sole theme that each participant 
reported as the most significant benefit of the lab. Their interviews, and written reflections consistently revealed that collaboration was influencing their practice. They valued collaboration with colleagues and with the Powerful Learning Lab instructors.

The theme of critical thinking was expressed in interviews and written reflections most frequently during the reflection aspects of the lab and when referring to writing lesson plans and reflections. Both the act of writing caused participants to think critically about their practice which in turn caused them to act differently. This critical thinking theme is related to reflection, but extends beyond reflection because it influenced action. Teachers across all experiential cohorts reported their teaching was changed because of their critical thinking about their practice!

The final theme of writing to learn is well documented in the literature and in the findings, especially the interviews and written reflections which were part of the unit portfolio. Teachers reported that the act of writing caused them to be clearer in their thinking, think critically about their practice and generate meaning about their practice through writing. These reports are consistent with research and educational literature about the benefits of writing on student learning as well (Little, 1999; Marzano, et al., 2001; Routman, 1998).

The secondary research questions were determined through interview data. Teachers perceived the most significant district factor that contributed to teacher learning was professional development with release time. This finding supports 
continuation of the lab experience during the teacher work day. This finding is discussed in further detail in chapter five. This finding was in response to the first secondary research question

Other secondary research question findings include: 1) teachers perceived themselves to be the most influential factor on student achievement. These teachers reported that the quality of the teacher-student relationship is the most important factor affecting student achievement. 2) Teachers in the study believed that teacher preparation programs could improve in providing teachers more coursework in the culture of poverty and multi-cultural diversity, and more high quality field experiences.

The final secondary research question pertained to the teachers' perceptions of the benefits and limitations of the Powerful Learning Lab. Teachers perceived the Powerful Learning Lab was a benefit to improving their practice. The benefits of the lab reinforced the emergent themes; participants valued the benefits of collaboration, critical thinking, writing, and time to plan, collaborate and reflect. The interview data was sparse in terms of feedback on the limitations of the lab; however, the need to differentiate lab content and process to allow for the range of experience and teacher interests was the most important finding. Other suggestions and benefits conclude that ASP needs to continue to refine this important professional development opportunity.

The four purposes of the study: 1) to contribute to the development of future powerful learning labs and the Accelerated Schools Project; 2) to consider 
the importance of context, 3) to inform teacher preparation programs, and 4) to inform school leadership were informed by the findings. Further discussion, speculation and recommendations of the findings, and these four purposes are discussed in Chapter V. 


\section{End Notes}

${ }^{1}$ Her does not necessary reflect the gender of the speaker, but will be used throughout the chapter for all pronoun text as females represent the largest population in the study. She/ her will be the personal pronoun default.

${ }^{2}$ Mezirow and Brookfield's research reported in Glickman, Gordon, Ross-Gordon (1998) Supervision of Instruction A Developmental Approach, $4^{\text {th }}$ ed. Needham Heights, MA: Allyn \& Bacon, p. 75.

${ }^{3}$ Evans, R. (1996) The Human Side of School Change: Reform, Resistance, and the Real-Life Problems of Innovation, p. 93. San Francisco: Jossey-Bass.

${ }^{4}$ Vignette part of a description of the fictional Arabesque Elementary School depicted in: Lambert, L. (1998) Building Leadership Capacity in Schools, p. 30. Alexandria, VA: Association for Supervision and Curriculum Development.

${ }^{5}$ Cranton, $\mathrm{P}$ (1994) Understanding And Promoting Transformative Learning. (p.294). San Francisco: Jossey-Bass. cited in Glickman, et al. (1998), p. 55. 


\section{CHAPTER V}

\section{DISCUSSION, SPECULATIONS, IMPLICATIONS AND FURTHER RESEARCH}

You would have to be a stone to not have the learning labs influence your practice. I was very skeptical when I first came to the lab in August, but I have become much more analytical about my practice in a quantifiable way. There were two very clear things that I really appreciated about the learning labs. The first was the opportunity to work with so many teachers from so many places. Not often do middle school and elementary school teachers get to collaborate. It is important for us to know where our students have come from, and where they are going. It makes our lessons more learner centered when we know, for sure, what they need to be successful beyond our room. We can adjust how we expect them to learn, and so then, change what we present them, to better prepare them. ...This experience has changed me as a teacher. The real difference for me was the ability to revisit. . This was so much more useful than oneday seminars, or conferences with separate sessions. (mid-career teacher, written reflection)

\section{Introduction}

The final chapter of this dissertation discusses the findings of the study from the salient literature on adult and teacher development. Further comment is provided related to research and theory in the professional development area in comparison to another study on teacher learning. Speculations are made about the 
Accelerated Schools Project, teacher preparation programs, and school and district leadership are further discussed. Finally suggestions for further research are presented.

Discussion and Speculations of Findings from a Perspective of Adult and Teacher Development

\section{Adult Development}

Michael Knowles and andragogy theory. The case findings of the study support most of Michael Knowles' assumptions about adult development. Knowles' (1984) assumptions were:

1. Adults have an independent self-concept and who can direct their own learning.

2. Adults have accumulated a reservoir of experience that is a rich resource for learning.

3. Adults have learning needs closely related to changing social roles.

4. Adults are problem-centered and interested in immediate application of knowledge.

5. Adults are motivated to learn by internal rather than external factors (refer to p.61 for further discussion).

The participants in the study became more independent and self-directed (first assumption) as the lab progressed, especially the novice cohort. Their reporting that the powerful learning framework became more "natural", more "automatic" supported this idea. Novice teachers focused on planning. The midcareer and the veterans quickly were able to integrate all of the components in their 
planning, and began to adjust teaching through the lens of powerful learning, both case groups sought out the aspect of teaching they most wanted to influence. MidCareer teachers began by focusing on assessment and moved into deeper reflection. Veteran teachers balanced all teaching areas but concentrated more on reflection for improving their practice.

All of the participants in the PLL came with a reservoir of skills, talents, knowledge and experience (second assumption) and they readily shared these experiences with others. The veteran group became natural mentors for the novices, and many times they were observed sharing their knowledge of curriculum or classroom management with another less-experienced teacher.

The mid-career cohort was the most demonstrative of Knowles' third assumption, they were at mid life, some just beginning marriages, or considering having children, and they often spoke of the demands of their changing social and personal lives. They even speculated if teaching would be too much for them as they expanded their personal responsibilities.

Knowles' fourth assumption (adults are problem-centered and interested in immediate application of knowledge.) was evident in all of the experiential cohorts. The novices tended to focus on their most immediate need, planning, whereas the mid-career teachers tended to emphasize assessment and reflection in their work. Veteran teachers saw special validity in the best practice seminars that immediately followed the Powerful Learning Labs. As one veteran comments, 
After (each) of these sessions [content area seminars] I went back to the classroom with lots of new teaching strategies, games and activities. ...Dr. M's lecture on ADHD pupils/children was my ultimate 'life saver' this year. Dr. $M$ had tons of insights and suggestions, all but one of his suggestions worked with my ADHD pupil, creating success in the class-room for this pupil and survival for myself. (veteran teacher, interview)

Each cohort determined which aspect of teaching was most critical and sought out solutions within the powerful learning framework.

The fifth assumption of Knowles work (adults are intrinsically motivated), was more obvious in the reflection evidence of the cohorts. Each experiential cohort made commitment for further and future learning (including during the summer!).

Using the reflection sheets, I have found that I can critically look at what I am doing in the classroom, where my students are in the learning process, and where we need to go next. I intend to continue this process with a rubric $I$ will create over the summer.(mid-career teacher, written reflection)

Self-directed learning. Grow's table of stages of self-directed learning was particularly pertinent to the cohorts at mid-year (see Chapter II). As explained in chapter II, Grow developed a matrix for learning which depicts adult learners as progressing from dependent learners who rely on the instructor to provide explicit instruction such as lecture to very independent learners who pursue independent projects and the instructor role shifts to more facilitation. More independent learners have acquired base knowledge and seek to develop projects and research that addresses their personal learning needs and learning profiles. Looking back, I tried to control too much of the agenda, content and process; I think the lab would 
have been stronger if at mid-year we re-negotiated content, process and product, to allow for better differentiation. The entire PLL cohort size of 42 was a challenge for me to balance needs of the participants. Employing Grow's matrix at the mid point of the PLL would have been wise and would have addressed the reoccurring finding that participants wanted more differentiation in the Powerful Learning Labs.

The findings support Grow's model as the participants moved away from being dependent on the lab instructors and the guest speakers, toward more selfdirected learning. The findings indicate that the younger participants were far more comfortable with the instructors in the facilitator and consultant role (see Table 15). In contrast, as the veteran teachers preferred a more dependent role as learners. The implication for future labs is that a more coordinated movement of learners from dependent toward self-directed might be proposed. For example, if, part way through the year, teachers who indicated and demonstrated self-directed learning behaviors might be given a more self-directed assignment, rather than completing the lab assignments as originally designed. The suggestion to offer multiple projects for lab participants will be further explored in the implications for Accelerated Schools section of this chapter.

Transformative learning theory. Another observation from the findings was that participants' frames of reference were altered. Mezirow (1997) explained that our frames of reference are the associations, concepts, values, feelings and conditioned responses that adults acquire. These structures or assumptions that 
make up our frames of reference determine, shape and limit adult expectations, perceptions, cognition, feelings and emotions. When transformative learning occurs, there is a shift in one's frame of reference. The shift typically results in a "more inclusive, discriminating, self- reflective and integrative experience" (Mezirow, 1997, p. 5). An example of one teacher's shift in frame of reference is explained,

Last August, when I first was introduced to Powerful Learning, I thought "Oh great, yet another program. I'll bet everything is just a new name for all of the same, old stuff." I was very wrong. Through the Powerful Learning Labs, I have learned that many methods can be interwoven with the concepts of powerful learning. I feel as though Accelerated Schools has given me the best of wools with which I can weave a tapestry that will include the needs of all of my students. The strands of the strong wool easily spin into the design the Washington State EALR's.[Essential Academic Learning Requirement]. (mid-career teacher, written reflection)

The findings of all cases support that participant's frames of reference were altered. These findings were most often reported in the reflection phase of teaching, and to some extent after completing a few rounds of the teaching cycle.

The following responses illustrate a change of frame of reference.

A lot of time I have to catch myself, for example, I catch myself, when kids, especially when I'm teaching math, they come up to me and say what is the answer; I catch myself and say "I want this to be more learner-centered", so I try to make the kids do the work. (novice, interview)

The second major component of transformative learning relates to an adult's point of view. Mezirow (1997) asserts that learning occurs when an adult's 
point of view is changed. The findings suggest that participants were able to change their point of view.

I try to keep in mind how a fifth grader would feel about the lessons being presented. If I am bored and not interested in the subject as an adult it must be 100 times worse for a ten year old. Keeping their interest in mind has improved my instruction tremendously. (midcareer teacher, written reflection)

The paradigm shifts that occur either by expanding or elaborating on one's existing point of view, or through establishing a new point of view, or through transforming one's point of view through the creation of misconceptions, or finally by becoming more aware and critically reflective of our generalized biases, do not necessarily come easily. "We do not make transformative changes in the way we learn as long as what we learn fits comfortably in our existing frames of reference." (Mezirow, 1997, p. 7). This problematic shift in point of view and the challenging of one's assumptions was consistently reported in the findings.

I really found the session on "Understanding Poverty" to be helpful in my assessment. I have the advantage, and disadvantage, of having a 6th grader at home. I do not mean to say that I assume my students all have the same supports at home, but I do find myself assuming that all parents put their child's education as their fist priority. And, if they do not, then I slip into thinking that they should - judging their values. During the "Poverty" session, I found that I had no right whatsoever to judge the priorities of the parents of my students. I went back to school after that session and changed my expectations of homework. (mid-career teacher, written reflection).

I have no doubt the PLL was transformative for participants, it certainly was for me. Working with such a wide range of adults was a considerable challenge. Meeting frequently with participants throughout the lab experience affected my 
frame of reference. I was able to deconstruct much of what I thought I knew about teaching and learning by observing the participants teach and listening to their personal reflections about their teaching. I discovered that learning was far more personal than I had earlier surmised.

Postmodernist perspectives. The consideration of postmodernist perspectives is important as the Accelerated Schools Project continues to refine its services to adult learner. Since most of our schools remain elementary schools and most elementary teachers are women, keeping current on feminist learning theories is a responsible action for ASP. This particular student had two cohorts of all women, the mid-career and novice cohorts. While the mid-career cohort did not demonstrate characteristics that were compatible to feminist learning theories, the veteran cohort did. All of the case cohorts reported making connections in their learning, but the all women cohorts of mid-career and veteran teachers consistently reported making connections to other aspects of teaching and/or prior knowledge. These veteran women steadily related their learning in terms of "connectedness".

I also found I went back to some of the things I'd been doing before, and was able to determine that "oh, this is PL", but I wasn't as aware before, or had forgotten some methods. So, it kind of verified all of those other.[methods] (veteran teacher, interview)

The women participants of the mid-career and veteran cohorts were definitely influenced and looked forward to the interaction with their peers. By the January meeting of the lab, female participants were interacting like old friends, 
asking questions about their children and grandchildren. They connected on a personal, relationship level with other participants.

We had so much interaction beyond planned activities; being able to compare notes with other teachers and Title 1 specialists was really beneficial. I saw that there was hope out there! I saw people really trying, trying to do home school visits, being able to talk things over with other teachers is so importation, and being able to hear what they tried. ... I looked forward to meeting [my partner] for the pair-share; I wanted to hear about her kids. (veteran teacher, interview)

None of the men participants reported making friends with other participants, but all reported that they valued the professional collaboration opportunities. So, the subtle difference between the men and women self-reports, is the women, especially the veteran women connected on a relational level that exceeded professional collaboration, and reported making friends. Building on participant's relationships with their peers is an example of how Accelerated Schools Project guiding principals work. Our participants did build on strengths and showed unity of purpose often through establishing and maintaining a solid relationship with their peers. My first concern about the lab's composition was the large number of female participants. Both the study's experiential cohorts and the complete PLL cohort consisted of mostly women. Our decision to keep a two person instruction team, Dr. Chenoweth and me, was sound. I tended to be pretty task oriented during planning for the PLL, but Dr. Chenoweth made sure we took care of the relationships we were cultivating in the lab, suggesting a celebration evening, which was a huge success and extremely well attended. His awareness of 
feminist theory proved extremely helpful, and it was very important to the veteran women of this study that relationships be cultivated. Given that women comprise the majority of teachers in our schools, following feminist theory is an important and responsible action for further development of the Powerful Learning Labs.

There was a discernable difference in the PLL session in January 2002. At that point, the group became much more engaged, more involved, and more committed to the collective pursuit of improving teacher practice. The participants arrived early and stayed late. They wrote more, and posed more questions and dialogue to each other, rather than to the instructors. Thirty participants stayed the extra day for a seminar on special needs and differentiating instruction. There was a definite shift in the emotion in the room. They had become a community, there was more interaction, more humor, teasing, and a genuine eagerness to be there, that had not been present before. The participants even expressed a "sadness" that the labs would be ending.

It [the lab experience] was great because it started last summer, we got together as a group, and planned, then taught the lesson, then reviewed those lessons and then went on to another. It's been a real growing process. I was really good that it was a whole year. It was kind of sad to think we wouldn't be together anymore. (veteran teacher, interview)

In developing the lab, and now analyzing and reflecting about the participants' story, it is very tempting to find faults in the content, organization, instruction of the PLL, but in terms of adult learning, I'm confident that the 
participants did learn, and I certainly learned much and could redesign a stronger PLL at the next opportunity.

\section{Teacher Development}

Considering teacher development theory the findings of the study are a bit skewed. Reviewing Figure 2, the findings suggest that the case cohorts were operating in the middle and upper levels of the concepts depicted. The novice case findings definitely indicate those teachers were finding their niche. While the midcareer case and veteran case findings indicate those teachers were demonstrating an ability to go beyond competence. They reported challenging themselves and their students to achieve at higher levels. Much of the success of the lab can be illustrated using the Hertzberg and Mazlow diagram (see Figure 2). Key to the findings that support the lab participants were functioning at high levels lies in the intersection of the Venn diagram: choice. All participants had a tremendous degree of choice. They were voluntary participants. They had chosen to be there, and they chose to remain. I think that if PLL participants had been required to attend the outcomes of the lab would have been far less successful. This is a definite challenge for the Accelerated Schools Project as we are frequently finding our project in schools that have had little courtship or buy-in process, and more and more ASP schools are pressured to adopt any CSR model without adequate preparation in the change process. In many respects this study's cohort represented Hazelton's employees who were most able and willing to change. 
Hertzberg (in Glickman, et al. 1998) describes work hygiene factors as the minimal conditions required to accomplish work, these "basics" are related to Mazlow's lower levels of need, or physical needs (see Figure 2). Hertzberg contended that unions often organize their lobbying efforts around work hygiene issues rather than the substance of the actual work. ( In terms of work hygiene factors, none of the participants were active in the local teacher's union or district leadership groups. They were selected for their regular status, so none reported any issues relating to work hygiene factors that affected their participation.) The absence of the distraction of work hygiene factors, allowed the participants to be more available and receptive to the motivation factors described in Hertzberg's theory. The findings supported "growth" as the most frequently mentioned motivation factor related to their lab experience.

The case findings aligned with the existing literature on phase and stage theories of teacher development. The novice group displayed all of the characteristics typically associate with first and second year teachers. They were idealistic, enthusiastic, and growth oriented (Fessler \& Christensen, 1992; Glickman, 2002; Steffy, 1989). A closer examination of the case cohorts through the lens of Fessler and Christensen's Teacher Career Cycle (see Figure 3) revealed the novice cohort straddled the phases of induction and competency building. While four were in their very first year of teaching, technically the induction phase, by spring all of the first year had move into competency building. The findings imply that the survival phase of induction was brief or non-existent. 
Only one first year teacher expressed concerns early in the lab about "adequacy" which is the issue that most often permeates the survival phase of induction. Instead, the novice cohort moved to the "recovery" part of survival which is where beginning teachers "are frequently able to see the amusing side of things and are able to respond more objectively to situations and demands of teaching." (Letven, 1992, p. 61). Perhaps the most significant difference between the novice case and the typical novice teacher is they were not alone, the lab experience allowed them access to experienced peers prior to the start of the school year. This type of new teacher support is unusual and could account for a smoother and quicker transition to the competency building phase of the teacher career cycle.

Both members of the novice group and the mid-career group reported feelings and actions associated with competency building. The excitement and willingness to learn that accompanies the competency building phase was consistent with the findings.

The lab has also created a thirst for me to learn more about differentiated learning. I can really see now how this can make a classroom more powerful. I need to learn a lot more, but at least the spark is started. (novice teacher, written reflection)

A critical aspect of the competency building phase is the teacher's search for a mentor (Glickman, 2002; Krupp, 1981, Steffy, 1989). The findings suggest that the lab experience allowed novice and mid-career teachers to find and relate to one or more mentors. Consistent evidence supports that the participants enjoyed 
and benefited from talking, planning, and working with more experienced teachers, the lab instructors, and the guest speakers.

Having a mentor teacher [from the lab] was really great. At the beginning of the year it was tough, because she was busy and I was busy, but it has been really helpful. (novice teacher, interview)

The findings also support that both the mid-career and veteran teachers were still searching for new ways to enrich their teaching.

The career frustration period of teacher development had either missed or not yet hit the participants of the study. Granted the participants were too young for the typical teacher who meets career frustration, and the veteran teachers may have already experienced this phenomenon and passed through it. There were no findings in the data that concur with Fessler and Christensen's (1992) career frustration phase. The remaining phases (stability, wind-down and exit) of the teacher career cycle carry negative connotations, or at minimum are less positive. Only one veteran showed these signs of the characteristics of stability, but the lab experience rejuvenated her.

The class [the Powerful Learning Lab] wasn't as hard as I thought; [it had] a lot of benefits, it was really good for me. The lab revitalized me; I can do so much more. I feel less burned out. I can make learning fun. Turning the learning over to the kids and making it powerful, is more energizing to me, I'm not as exhausted at the end of the day.... I'd take it [the lab] again if I could. (veteran teacher, interview)

This revitalization or renewal is well documented in the literature (Barth, 2001; Darling-Hammond \& Sykes, 1999; Fried, 1995; Glickman, et al., 1998;

Goodlad, 1994). The findings of the study supported that the veteran teachers 
experienced renewal, rather than stability or wind-down. Career exit is the period in a teacher's career after she/he leaves the profession. All of the participants were still teaching a year after the study, so none belong in the exit phase of the career cycle.

\section{Discussion and Speculations of Findings From a Perspective of Professional Development}

The Powerful Learning Lab is a key professional development component of the Basic Partnership Agreement (BPA) for technical support that schools make with the Accelerated Schools Project. PLL is a cornerstone to the year two and beyond service ASP offers schools. As a reform model, ASP is all about professional development. That is the primary service ASP offers its participant schools. Discussing the findings as they relate to high quality professional development is pertinent to the process of continuously improving the Accelerated Schools Project's service to schools. This particular discussion will compare the findings of this small, local study, with a large national study. The two studies are almost polar opposites in terms of methodology, yet the findings bear some remarkable similarities.

\section{National Study: The Eisenhower Study}

Designing Effective Professional Development: Lessons from the

Eisenhower Program $^{1}$ was a longitudinal study seeking to determine effective professional development characteristics as they relate to teacher change. The 
unique aspect of looking at the effects of professional development set this study apart from others. The Eisenhower study used a national probability sample of 1,027 mathematics and science teachers to provide the first large-scale empirical comparison of effects of different characteristics of professional development on teacher's learning (Garet, Porter, Desimone, Birman \& Suk Yoon, 2001).

The Eisenhower study surveyed teachers from spring through fall of 1998, with the survey pertaining to professional development activities these teachers engaged in from July through December 1997. A total of 1027 survey responses were returned or approximately 72 percent of the total surveyed. All responses were self reports of teacher experiences and behavior. While the Eisenhower study used a survey sampling procedure in the methodology and a much larger sample, the similarities in teacher participation in professional development and the comparison that the responses were self-reports of teacher experiences and behavior were similar to the Hazelton study.

On the basis of research of high-quality professional development, the Eisenhower study results focused on two sets of features, "structural and core" features. The structural features included the form of the professional activity, the duration of the activity, and the degree to which the activity emphasize collective participation. The Eisenhower study concluded that teachers reported higher levels of learning when the form of the professional development was from a reform type, such as teacher learning labs, teacher networks, or teacher study groups, particularly when the activity was situated within the teacher workday. The study 
also concluded that activities that were of longer duration and sustained over time were more effective. The time was calculated in both hours of contact time, and duration (span in days, weeks, months) of the activity, with the correlate of hours and span being $r=.41$. The final structural finding was that professional development designed to involve collective groups of teachers (from the same school, grade level or department) were more effective in affecting teacher learning than professional development activities that engaged single teachers from separate schools or grade levels.

\section{Local Study: The Hazelton Study}

These findings from the Eisenhower study were very similar to the design elements of the PLL for the Hazelton study. The PLL form was reform type. The PLL was situated in the third year of professional development within the Accelerated Schools Project's commitment for technical service to the Hazelton district. Therefore the PLL was already embedded in school reform, and employed a teacher learning lab which proved to be significant in the Eisenhower study. The duration of the PLL was also consistent with the positive impact from the Eisenhower study, and the PLL cohorts commented that the duration of the lab (over the course of a year) was a benefit. With the exception of the first two days in August, the PLL face-to-face and follow up teaching assignments took place during the regular workday. The Powerful Learning Lab also depicted the condition of 
collective participation, as the Hazelton School District was a large team, and each school within Hazelton sent smaller school teams of three to eight participants.

The core features that the Eisenhower findings indicated were significant for teacher learning were: content focus (teachers reported learning more from professional development activities that emphasized deepening or improving teacher's content knowledge), active learning (teachers reported more learning when they were actively engaged in meaningful analysis of teaching and learning such as reviewing student work or obtaining feedback on their teaching), and coherence to teacher professional development (teachers reported learning more when the professional development was aligned with state standards and assessments). These aspects were met in the PLL design and demonstrated in the findings. The optional third day of each two-day session of the PLL had a content focus. We called these days "Powerful Learning Best Practice Seminars." Each of the four days had a specific content focus with subject experts conducting the seminar. The four seminars involved the following topics: classroom management, literacy (with separate sessions for primary and intermediate teachers), special needs and differentiated instruction, and math (with separate sessions for primary and intermediate teachers). PLL teachers were definitely active learners as they were required to teach and analyze their teaching, participate in peer coaching, and analyze student work products as part of the lab. One of the less successful matches to the Eisenhower study was the clear coherence of professional development, although the PLL portfolio planning process began with 
state standards, there was inconsistent application of the lessons to clear state standards. In the future, providing a more systematic check of alignment of planning and assessment to state standards would strengthen the PLL.

While the Eisenhower study has the markings of an important, large-scale, quantitative study, the findings were remarkably similar to the design of the PLL and the small, qualitative Hazelton study. The teachers in the Eisenhower study valued the same things that the Hazelton study teachers valued. Both groups reported learning more or better because of: the duration of the professional development, the active learning involved with analyzing their teaching and student work, and the benefit of working with colleagues (or collaboration) from either the same grade level or school. The core findings were also similar, with the exception of the content strand of the Eisenhower study. That study was specifically designed around math and science professional development. The Hazelton study was designed around the more generic teaching methods and strategies that define the Powerful Learning Framework. However, the Hazelton findings that the participant teachers really engaged in the third day powerful learning seminars that did focus on content was similar to the Eisenhower results. The other core findings from the Eisenhower study, the benefit of active learning such as peer observation and coaching, and examining student work, were consistent with the Hazelton findings. The absence of content specific strategies as part of ASP is one of the movement's challenges, especially in this era of 
accountability, and legislation, such as California that mandates two options for state adopted curriculum in reading.

The final core findings of the Eisenhower study was the fostering coherence with other priorities such as the alignment of professional development activities with state standards was consistent with the Hazelton findings. The mid-career and veteran cohorts reported this "coherence" more than the novice cohort as they began to view the teaching process as holistic and integrated. Some participants connected the Accelerated Schools process to the integrated organization of the school, teaching and curriculum. In conclusion, while the type of research conducted in the two studies (Eisenhower and Hazelton) was quite different, the findings were remarkably similar. The Eisenhower study supported the current design of the 2000-01 PLL.

\section{Writing for Professional Development and Learning}

Writing for professional development involves critical thinking, critical assumptions, actions, behavior and beliefs. Writing evokes much of the inner soul, thinking, and imagination of practitioners. Barth (2001) writes,

When we write we become responsible for our words and ultimately we become more thoughtful human beings. Writing (and reading) about practice is closely related to improving practice, for with written words come the innermost secrets of schools and their school masters. (p. 67)

The writing to learn theme emerged from the findings. Teacher participants expressed that writing their lesson plans and their reflections increased their 
awareness of powerful learning, their understanding of their teaching practice and their accountability for their practice. There is considerable agreement in the literature that writing improves adult and teacher learning (Barth, 2001; Cranton, 1997; Levine, 1989; Little, 1999). Little (1999) illustrates,

A school organized for teacher learning would promote the systematic study of teaching and learning in at least two ways. First the schools would support teachers in investigating questions, problems and curiosities that arise in teaching. A writing workshop formed by teachers in one elementary school met weekly after school to 'get smarter' about helping children become good writers. .. These inquires exemplify a burgeoning teacher research movement made increasingly visible through conferences, journals, and published collections of teachers' research. Their [the teacher's writing project] principal significance, however, lies in their power to inform teachers' own practice. ( p. 236)

Revisiting writing as an adult (and writing to learn) is expressed by Clark (1997), "I specially look forward to writing. As an undergraduate student, I wrote easily and found it a pleasure. It was through writing that I generally discovered my way."(p.14). The findings of the study indicate that the participants agreed, through writing they found their way, by solidifying ideas and concepts. Even though the writing was sometimes a chore for participants, they appreciated the benefits of writing as a way of unlocking their thinking.

Writing the reflections does seem sort of monotonous, but it makes me think, and makes me learn from it, and determine where the kids came from in the beginning. (mid-career teacher, interview).

Levine (1989) described writing for professional development as a standard procedure in the Principal's Center at Harvard University. At the Principal's Center, school principals participate in writing groups for a variety of purposes, 
they use free writing as a transition activity, to "unload" the issues of the day when they arrive in their writing groups, they write about topics of interest to the group, and they receive feedback on their writing. Some groups pursue publishing their writing as a way to contribute to the professional literature. The practice of writing to learn as part of the Principal's Center at Harvard has been part of the project's leadership curriculum for over twenty years and continues.

Writing is by nature a reflective process that evokes critical thinking. Teachers who write about their practice will be forced into decisions about word choice, about organization, about clarity of ideas; in short they are thinking and learning through the writing process. Teachers who are thinking and learning are teachers who will effect student achievement. Barth (2001) agrees,

Writing about our experiences in schools is one way to ensure that we reflect on and learn from experience. By writing about practice, each of us comes to know more about what we do and about what we know. Because the written word has a shelf life that the spoken word does not enjoy, those who write about their lives in schools discover that other members of the school community are highly interested in their ideas. ... The pen still wields power. (p. 68)

Considering the evidence of writing to learn in the literature and in the findings of the Hazelton study, it's imperative that ASP continue to include writing as a learning method for teachers and school community members. I'd speculate that ASP should increase its use of writing and facilitate and mentor writing groups in our professional development services to schools. The principals of ASP may benefit the most from a principals writing group, as it is often the principal who has 
the least time in his/her day for reflection, writing and critical thinking, yet the principal stands to benefit greatly from writing for professional growth.

\section{Implications for Accelerated Schools Project}

The Powerful Learning Lab was truly an experiment in delivering the Basic Partnership Agreement (BPA) to affiliated Accelerated Schools in their second year and beyond. While the findings from the Hazelton study indicate the overall experience was successful for teachers in terms of teacher learning and even toward influencing teacher practice; there remain aspects of the lab design that should be improved, and redesigned. Structurally the labs were a success. The longitudinal format working collaboratively with a teaching cohort for almost an entire school year proved to be effective and was consistent with high quality professional development programs (Ball \& Cohen, 1999; Barth, 2001; Cannella \& Reiff, 1994; Darling-Hammond et al., 1999; Little, 1999; U. S. Department of Education, 1999; Zemke \& Zemke, 1996).

Some key implications are:

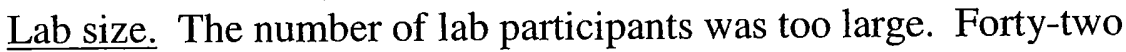
participants with two instructors were too many and too diverse for optimal teacher learning. The unwieldy size of the entire group required many compromises in terms of meeting facility, format, and content. There were times when the meeting facilities were too crowded for comfort, and ensuring equal participation was impossible. While the large whole group provided an appropriate format for some 
content topics and formats, such as the lecture on the culture of poverty, the ability to read the crowd, and adjust for a longer time frame with smaller groups proved remained a challenge with such a large number of participants. I was constantly trying to find the balance of presenting new content effectively and efficiently, and balancing process and application time for new ideas. Future labs should be smaller, or smaller cohorts of teachers should meet separately more often with more instructors or facilitators to maximize teacher learning.

Lab location. There were benefits and limitations for conducting the PLL at Portland State University. The travel required for schools to attend was considerable and added expenses, especially for large teams. While many participants enjoyed the complete removal from the school and home setting, this organization limited participation from teachers unable or unwilling to leave (such as those with small children at home). Ideally, ASP has to find a way to bring the PLL to school sites, we need to build more internal capacity so that our staff is able to take longitudinal training to our schools. This is another perplexing dilemma for the many schools in our network that are single-school sites and or very remote. Perhaps we should investigate a way to "hybrid" the PLL concept so that part of it can be done face-to-face, but perhaps part could be done remotely through interactive technology such as WebEx ${ }^{\circledR}$, egenda ${ }^{\mathrm{TM}}$ or other distance learning strategies.

Need for differentiation. A key theme from the findings of the Hazelton study was the need for more frequent differentiation. The lab adequately addressed 
differentiation on process, with multiple grouping and task strategies for teachers to select. There was not adequate differentiation of content. Part of this was due to the mixed cohort composition of the lab participants. There were participants in their second and third year of ASP, and many, many brand new teachers, who were just beginning their first teaching position. The benefit of new and experienced teachers collaborating should remain in the lab as designed, but differentiation of content for part of the lab experience would be a better benefit to the participants. For example, a group of teachers might self select to examine aspects of emergent literacy through the lens of the powerful learning framework, while a different group might select classroom management, or writing across the curriculum. I'd like to experiment with a teaching strategies survey and provide more teacher led inquiry into more advanced strategies such as higher-end learning, student led inquiry and more sophisticated aspects of differentiation.

Differentiating the product that lab participants produce is also a valid recommendation. A veteran teacher really doesn't need to write ten lesson plans to internalize the powerful learning framework, she might be more engaged in producing a product that addresses a learning priority for her, or an identified school priority, such as a curriculum alignment project. Another huge implication for the findings was that the participants did not connect powerful learning as a part of ASP.

I learned a lot, I didn't know that PL and ASP were part of the same 
thing. I thought ASP was this whole other thing. (Cadre meetings and stuff) I think that PL makes you more aware of what is going on in the school. (mid-career teacher, interview)

Even though this was only articulated in one participant's documentation, the absence of this connection in all the data, speaks loudly to the need for the Accelerated Schools Project to do a better job enculturating teachers in their first year that the project is about improving teaching and learning. ASP is still too process and governance oriented. The structure of our BPA is around training a leadership team. I'm beginning to question the effectiveness of this. Perhaps, we'd be better off returning to whole-school training in many areas, and working earlier with teacher teams on curriculum and instruction, rather than relying on newly trained school teams to lead the way.

Collaboration. Finally, the consistent finding that all of the participants valued the collaborative nature of the lab. Their acknowledgement that collaboration emerged as the most significant theme is tremendously important to future labs. Retaining the "critical friend" aspect of the lab, where teachers have an opportunity to come together, talk and write about their work, receive feedback and observe each other teaching is paramount to teacher learning. Little (1999) further explains this important idea,

...teacher learning arises out of close involvement with students and their work, shared responsibility for student progress, sensibly organize time and space, access to the expertise of colleagues inside and outside of the school, focused and timely feedback on one's own work, and an overall ethos in which teacher learning is valued. (p. 233) 
Implications for Teacher Preparation

Poverty and diversity. The implication of the findings for teacher preparation programs is most poignantly directed to the omission of sufficient required study of diverse cultures and poverty. As the teacher shortage in the United States continues to grow, there will be large numbers of new teachers entering the work force. Many universities have prepared for this by offering degree completion and teacher licensure programs that market to and target potential teachers. These teacher preparation programs must move quickly to address the growing diversity and increased poverty of our nation's most challenging schools. Only one recent college graduate participant mentioned that a course was even available on diversity, but it was an elective.

Even though Portland State University includes course on multicultural education in their current program for teacher training, none of the PLL cohort attended Portland State University. Also, this course is a recent addition and it is obyious, that the majority of the PLL participants never had the opportunity to take such a course. Since ASP schools identify their community's challenges as part of taking stock, it makes sense that the ASP satellite center staff, should be reviewing those findings more closely and tailoring service to districts to address such a gap in critical issues. ASP satellite centers could easily facilitate workshops, seminars and or graduate work which involved study of diverse populations and the impacts of poverty on learning. 
Across all cases, novice, mid-career, veteran, female, male, young, old every participant felt unprepared to address the issues of race, cultural diversity and poverty that are inherent in the Hazelton district. The dramatic shift in cultural paradigm is expressed by this participant,

During the "Poverty" session, I found that I had no right whatsoever to judge the priorities of the parents of my students. I went back to school after that session and changed my expectations of homework. I still assign it, because many parents expect it. But, I do not give it much weight in grades. I used to believe that homework "proved" that students could regurgitate what they had learned in a different setting. I have believed for some time that homework is preparing them for higher education. I now believe that homework might frustrate some of those fragile beings that visit my room daily. Inclusive needs to not just impact my lessons, but what I grade. Homework is inherently not inclusive. (mid-career teacher, written reflection)

Field experience. Additionally, the participants' recommendation for teacher preparation programs to include more field experience was fairly consistent. Feeling unprepared to do the real work of teaching is consistent with earlier studies of teacher preparation programs (Fessler \& Christensen, 1992; Lambert \& Ball, 1999; Steffy, 1989). Yet, listening, to the voices of the newly induced teachers, such as the novice cohort, is important for teacher preparation institutions. These teachers still want more field experiences. Quality field experiences that parallel the tenets of high quality professional development with aspects of collaboration with experienced teachers, and receiving skilled feedback on their teaching, examining and discussing student work, would greatly improve the type and quality of field experiences these recent graduates received. Quality 
field experiences should also include access to mentors, written reflection, and opportunities for collaboration with content area experts. I've often commented to pre-service teachers, that the observation requirements of early field experience are backwards. It is only after pre-service teachers get some experience teaching that they are really able to "see" and observe the nuances and art of effective teachers.

\section{Implications for School Leaders}

\section{Collaboration and supervision and evaluation. School leaders assume a} variety of titles; a school leader could be a teacher, a principal, a superintendent, or a paraprofessional. The implication of the findings for school leaders lies in the emergent themes and the cross analysis of teaching practice of this study. The theme of collaboration is undeniable: teachers want and need to collaborate with each other, to talk about practice, to observe each other teach, to discuss and analyze student work for teacher learning to occur. Much of teacher support mechanisms are shrouded under the term teacher supervision. Supervision typically elicits some anxiety from teachers, as the act of being observed and evaluated by a school administrator is so hierarchal in nature. Supervisors observe and evaluate subordinates. Teachers are often nervous during formal observations from school principals. School principals can feel burdened by the bureaucratic nature of the clinical supervision cycle.

Considering alternate forms of teacher evaluation and supervision is a critical need and a critical fit with the Accelerated Schools project. Using multiple 
sources of data such as student and parent reports, peer review, and teacher portfolios are a few strategies that promote more effective teacher learning (Peterson, 1995). Placing the teacher at the center of the evaluation activities provides more opportunity for more meaningful teacher learning. Peterson (1995) explains,

The teacher should be responsible for data assembly, adequacy of judgments, and the use of evaluation results. In addition, have teachers become involved in the evaluation of their colleagues. The teacher should be a monitor of his or her own evaluation, own practice and the practice of others. The teacher needs to be engaged in the production of more credible external information about his or her work, and a more public judgment about the quality of that work. (p. 5)

Glickman et al., (1998) and Glickman (2002) support Peterson's ideas of influencing teacher learning and teacher behavior.

Glickman, et al. (1998, p. 81), developed a model of influences on teacher development ( see Figure 11). In Glickman's model, developed to address teacher supervision, the teacher's development toward altruistic and abstract thinking is paramount to teacher development, growth and efficacy. His model puts the teacher in the center of ever widening concentric circles of context (adult learning, work environment, and the teaching profession). 


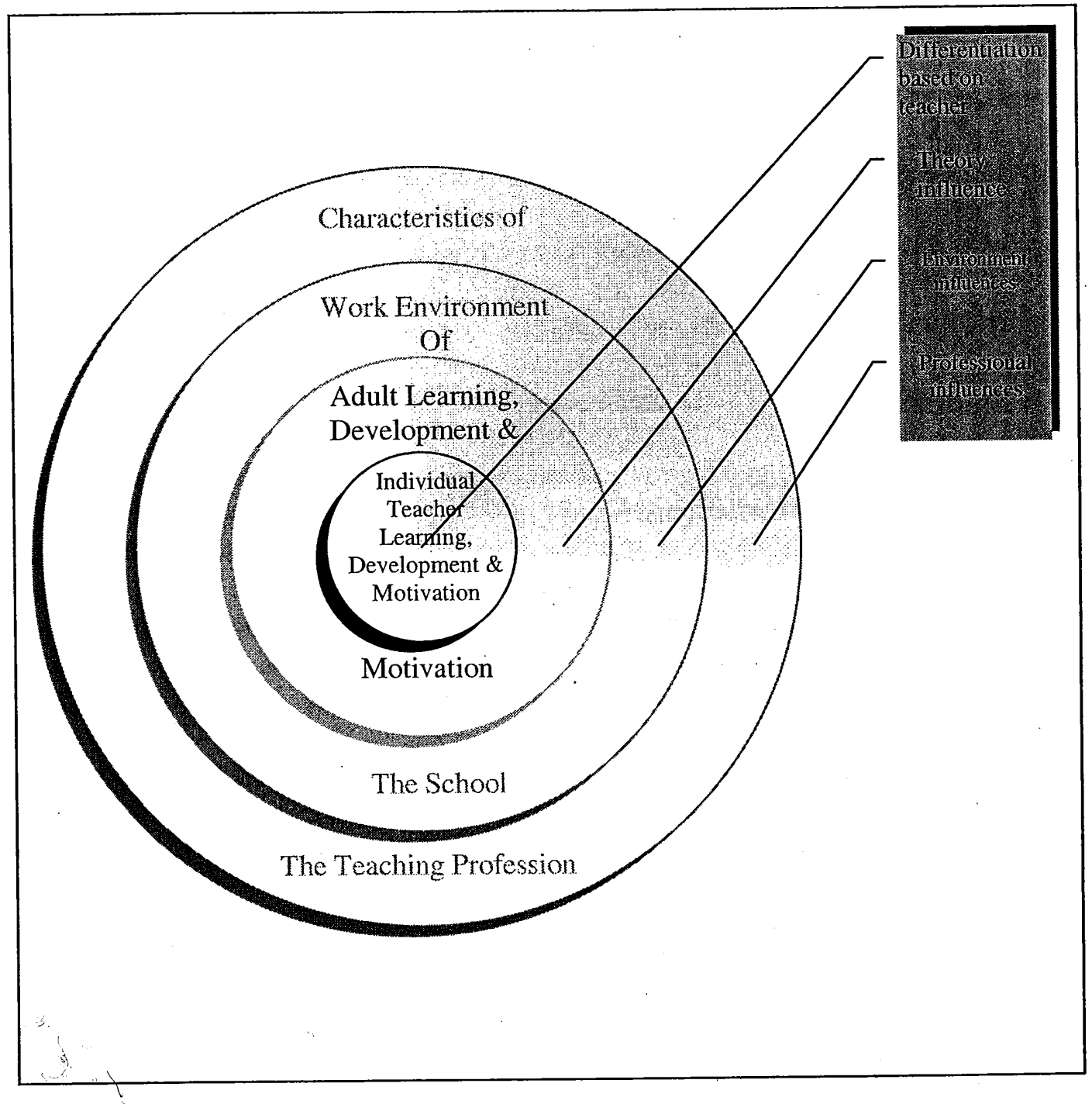

Figure 11. Glickman's influences on teacher development.

Glickman's model honors differentiation of supervision based on individual teacher characteristics such as learning and motivation. The model also recognizes that individual teachers learning or motivation may not be fixed, but function as a perception of the teacher's role in the ever-widening environments of school and the teaching profession. Glickman (2002) offers a wide range of supervisory 
experiences for the equally wide range of teachers who inhabit schools. An example of how Glickman's perception of teacher supervision might be expanded to include some of the teachers who participated in the Hazelton study are the range of feedback experiences that a teacher might encounter.

For example, the direct, clinical supervision model might be appropriate for a beginning or struggling teacher. Whereas, a teacher who is in a competency building phase of his/her career might select a peer coaching experience with another skilled teacher. While, a highly motivated teacher might lead a teacher study group or critical friends group to inquire about a specific teaching strategy or content area. School leadership would benefit from exploring more individualized methods of influencing teacher learning. The benefits of these alternative forms of feedback are consistently reported in the literature (Barth, 2001; Garet, et al., 2001; Glickman, 2002; Goodlad, 1994; Little, 1999). Little (1999) elaborates, Perhaps one of the most powerful and least costly occasions of teacher learning is the systematic, sustained study of student work, coupled with individual and collective efforts to figure out how that work results from practices and choice of teaching. (p. 235)

The consistent move away from teacher isolationism is prevalent in highly affective teacher learning or professional development programs. Lortie (1975) was one of the first to document the loneliness and isolation that teachers feel in traditionally organized schools. Huberman (1995) coined the "lone wolf" metaphor as the common practice of teachers who "labor on their own to decide what instruction works, what standard of student work is good enough, and what 
additional knowledge, skill, or insights would best serve them and their students." (Little,1999, p. 234).

Benefits of writing. Another important implication for school leaders is the importance and benefit of writing about practice, writing to learn, and building time into the teacher work day for thoughtful critical reflection. An example of this might be beginning school faculty meetings ( or ASP School-as-a-whole meetings), with free-writing about the day, or a specific teaching incident, teacher practice, or topic related to the school's vision or improvement plan. Leaders should recognize the importance of the commitment of words to paper as an effective learning activity.

Combining differentiated supervision options, more opportunities for teachers to collaborate, focused teacher writing and study groups all contribute to an environment for teacher learning. School leaders (principals) need to lay the infrastructure for these activities to occur. Little (1999) concurs with this eclectic approach to teacher learning, as she recommends that teacher learning opportunities must be complex and varied.

Schools most conducive to teacher learning supply as rich a soup as possible of information, consultation, and materials both inside and outside the school. Insularity - from useful information, stimulating alternatives, competing ideas, or productive criticism constitutes the major threat to productive professional learning. (p. 242)

In many ways, the Accelerated Schools Project has left school principals hanging. When the ASP movement moved to a trainer of trainers model, we 
included the principal in the training, but didn't offer enough support for the unique role a building principal plays in an ASP school. During the summer of 2001, ASP piloted a summer institute for principals, called "Leadership for Learning". The institute was very well received by principals. ASP needs to involve principals more thoroughly in ASP trainings. While the PLL was designed for teachers, we should have been meeting with principals to explain what we were doing, and to engage them in dialogue about some of the issues of support and ways to institutionalize powerful learning in their schools. Ideally ASP schools would have indicators and evidence that powerful learning was part of the teacher evaluation and supervision process. We would see evidence of teacher led inquiry in schools, where principals were supporting teachers learning more about effective teaching. Too often our ASP principals become managers instead of instructional leaders.

\section{Suggestions for Further Research}

Building on the findings of this study, a productive next step would be to determine if there is a connection to student achievement. This study was basically a phase one research project to gather evidence of teacher learning in the lab setting, and to provide formative feedback for future lab development and design. Yet, the remaining and burning questions of "So What? Did participation in the powerful learning lab affect student achievement?" remain unanswered. A follow up study that would follow participant teachers' student achievement results would be extremely beneficial to the Accelerated Schools Project. Qualitative research is 
a start, but the next step would be to conduct some data analysis of student learning as an effect of perceived teacher learning.

Another interesting study would be to administer the Teacher Activity Survey (used in the Eisenhower study) to the complete and subsequent cohorts of participants in Powerful Learning Labs. This would help ASP determine what elements of the Powerful Learning Lab had the most lasting effects on teacher behavior.

\section{Lessons Learned}

It is essential for the Accelerated Schools Project to continue to build on the lessons of adult development as we further strive to improve the professional development menu that we offer our schools. Meeting the needs of the divergent teachers that typically occupy our ASP schools is a considerable challenge. We must continue to listen to their experience, perception, and work collaboratively with them in designing professional development that will ultimately improve student achievement.

Further development of content area professional development is warranted based on the findings of this study. Teachers in diverse and poor schools are asking for specific content and strategies that will improve key student learning areas such as literacy. The Accelerated Schools Project is currently working with a literacy consultant to determine how to best integrate powerful learning with the qualities of a high quality literacy program. ASP can no longer survive in the 
organizational and governance of reorganizing schools, the project must better address specific issues of teaching and learning, curriculum content and teaching strategies in order to grow in an era of state standards and accountability.

Much of the positive influence on teacher practice suggested in the study hinges on the key concept of choice. Participation in this PLL was determined by teacher willingness and choice. We will however, encounter schools and district that will mandate participation in the ASP professional development opportunities, and indeed, much of the CSR policy dictates that school personnel engage in high quality professional development. Future labs must consider the possibility that participants will be less willing to participate in such a long commitment of time as the PLL demands. Unwilling or uncommitted participants are a very real challenge for future lab development.

The three emerging themes of collaboration, critical thinking and writing to learn are crucial to continue to embed in our professional development offerings to schools $\_$ASP must always design professional development that will include these critical themes.

Since the Accelerated Schools Project is organized around regional satellite centers that most often are affiliated with universities that prepare future teachers it is critical that we share the findings of this study with those partners. We must work with our teacher preparation programs to help them listen to the experiences of the teachers who work in our schools, so that teacher preparation programs can continue to improve. 
Until the last few years, the Accelerated Schools Project has neglected its support of building principals. When we shifted the school training model from whole school to a trainer of trainers model, we cast our school principals adrift. Our recent inclusion of a principal's leadership institute has begun to revive our support to school principals. We need to continue to engage our school principals in the teacher learning process. The school principal must be able to be a strong instructional leader in our ASP schools. We need to have our principals more engaged in leading for teacher learning.

Finally, the ability to influence teacher practice is the first evidence of influencing teacher learning. This study took a very small step toward determining whether or not the Accelerated Schools Project is able to influence teacher practice. The findings suggest it can. The remaining and continuing work of affecting teacher learning and ultimately student achievement are larger goals still on the horizon. 
End Notes

${ }^{1}$ U. S. Department of Education, Office of the Under Secretary, Planning and Evaluation Service. (1999). Designing effective professional development: Lessons from the Eisenhower program. [On-line]. Available: http://www.ed.gov/inits/teachers/eisenhower/ 


\section{REFERENCES}

Abdal-Haqq, I. (1998). Constructivism in teach education: considerations for those who would link practice to theory. (ERIC Document Reproduction Service No. ED 426986).

Archer, J. (1999, March 17). New Teachers Abandon Field at High Rate. Education Week,18 (27). [On-line]. Available http://edweek.org/ew/vol18/27retain.h18.

Ball, D.L. \& Cohen, D. (1999). Developing practice, developing practitioners. In L. Darling-Hammond \& G. Sykes (Eds.), Teaching as the learning profession: Handbook of policy and practice (pp. 3-32). San Francisco: Jossey-Bass.

Bambino, D. (2002). Critical friends. Educational Leadershi,. 59 (6), 25-27.

Barth, R. (2000). Learning to Lead. In The Jossey-Bass reader on educational leadership (pp. 146-255). San Francisco: Jossey-Bass.

Barth, R. (2001). Learning by heart. San Francisco: Jossey-Bass.

Bass, B. (1998). Transformational leadership: Industrial, military, and educational impact. Mahwah, NJ: Lawrence Erlbaum Assoc.

Bauer, S., \& Mesa, J. (1999, April). Building a conceptual model for shared accountability in an accelerated school district. Paper presented at the Annual Meeting of the American Educational Research Association, Montreal, Canada.

Belenky, M., Clinchy, B., Goldberger, N. \& Tarule, J. (1986). Women's ways of knowing: The development of self, voice and mind. New York: Basic.

Bergeson, T. (2000, Fall). State of education address. Office of Superintendent of Public Instruction. [On-line]. Available: http://www.k12.wa.us/supt/stateofed/default.asp

Berliner, D., \& Biddle, B. (1995). The manufactured crisis: Myths, fraud, and the attack on America's public schools. New York: Longman. 
Bigge, L., \& Shermis S. (1999).Learning theories for teachers, $6^{\text {th }}$ ed. New York: Longman.

Blair, J. (2000, October 26). Citing author, Harold H. Wenglinsky in "How Teaching Matters: Bring the Classroom Back Into Discussions of Teacher Quality" in ETS study link effective teaching methods to test-score gains. Education Week, 20 (8), 24.

Bodilly, S. (1998). Lessons from new American schools' scale-up phase: Prospects for bringing designs to multiple schools. Santa Monica, CA: RAND

Bolman, L., \& Deal, T. (1997). Reframing organizations: Artistry, choice, and leadership, ( $2^{\text {nd }}$ ed.). San Francisco: Jossey-Bass.

Boyer, E. (1995). The basic school: A community for learning. Princeton, NJ: Carnegie Foundation for the Advancement of Teaching.

Bradley, A. (1999, March 10). States' uneven teacher supply complicates staffing of schools. Education Week, 18 (26) [On-line]. Available http://edweek.org/ew/vol-18/26supply.h18

Bradley, A. \& Olson, L. (1993). The balance of power. In From risk to renewal: charting a course for reform (pp. 43-60). Washington D.C.: Education Week

Bridges, E. M. \& Hallinger, P. (1995). Implementing problem based learning in leadership development. Eugene, OR: ERIC Clearinghouse on Educational Management.

Brockett, R.B., \& Hiemstra, R. (1991).Self-Direction in adult learning: Perspectives on theory, research, and practice. London: Routeledge.

Brookfield, S. (1986). Understanding and facilitating adult learning. San Francisco: Jossey-Bass.

Brooks, J. G., \& Brooks, M. G. (1993). In search of understanding: The case for constructivist classrooms. Arlington, VA: Association for Supervision \& Curriculum Development.

Brooks, M., \& Brooks, J (1999). The courage to be constructivist. Educational Leadership, 57 (3), 18-24. 
Bruner, J. (1962). The process of education. Cambridge, MA: Harvard University Press.

Building strengths through powerful learning laboratories. (1999, Fall). Accelerated Schools, 8, (2), 1, 4-7.

Bullough, Jr. R. V., \& Baughman, K. (1997). 'First-year' teacher eight years later: An inquiry into teacher development. New York: Teachers College Press.

Burke, P. J., McDonnell, J. H. (1992). Competency building. In R. Fessler \& J.C. Christensen (Eds.), The teacher career cycle: Understanding and guiding the professional development of teachers (pp. 87-117). Boston: Allyn \& Bacon

Burke, P. J., \& McDonnell, J.H. (1992). Enthusiastic and growing. In R. Fessler \& J.C. Christensen (Eds.), The teacher career cycle: Understanding and guiding the professional development of teachers (pp. 119-151). Boston: Allyn \& Bacon

Burns. M. (1978). Leadership. New York: Harper \& Row

Calhoun, E. (2002). Action research for school improvement. Educational Leadership, 59, (6), 18-24.

Calhoun, E., \& Joyce, B. (1998). "Inside-out" and "outside-in": Learning from past and present school improvement paradigms. In A. Hargreaves et al. (Eds.), International handbook of educational change,(pp. 1286-1298). Great Britain: Kluwer Academic Publishers.

Cannella, G.S., \& Reiff, J.C. (1994). Individual constructivist teacher education: Teachers as empowered learners. Teacher Education Quarterly,21(3), 2738.

Carr, W. \& Kemmis, S. (1986) Becoming critical: Education, knowledge and action research. Lewes', England: Falmer.

Chaika, G. (2000) The teacher shortage: Please apply. Education World [On-line]. Available: http://www.education-world.com/a admin/admin155.shtml

Chenoweth, T., \& Kushman, J. (1996). Building initial commitment to accelerate. In Accelerated schools in action: Lessons from the field, (pp.145-168). Thousand Oaks, CA: Corwin Press. 
Chenoweth, T.G. \& Petti, A. (2000). Implementing district-wide comprehensive school reform. Published paper \& presented at AERA (American Educational Research Association), New Orleans, LA

Consortium for Policy Research in Education. (1996; March). Public policy and school reform: A research summary (No. RR-036). Philadelphia, PA: University of Pennsylvania. Graduate School of Education.

Cooper, J. E. (1995). The role of narrative and dialogue in constructivist leadership. In L. Lambert et al., Constructivist leadership, (pp. 36-48). New York: Teachers College Press.

Costa, A. \& Garmston, R. (1994). Cognitive coaching: A foundation for renaissance schools. Norwood, MA: Christopher-Gordon Publishers, Inc.

Cranton, P. (Ed.). (1997, Summer). Transformative learning in action: Insights from practice: New directions for adult and continuing education, 74, San Francisco: Jossey-Bass.

Creswell, J. (1998). Qualitative inquiry and research design: Choosing among five traditions. Thousand Oaks, CA: Sage Publications.

Damasio, A. (1999). The feeling of what happens: body and emotion in the making of consciousness. New York: Harcourt Brace.

Darling-Hammond L., \& McLaughlin, M.W. (1999). Investing in teaching as a learning profession. In L. Darling-Hammond \& G. Sykes (Eds.), Teaching as the learning profession: Handbook of policy and practice (pp. 376-411). San Francisco: Jossey-Bass.

Darling-Hammond, L., \& Sykes, G. (Eds.) (1999). Teaching as the learning profession: Handbook of policy and practice. (pp. 376-411). San Francisco: Jossey-Bass.

Deal, T. \& Peterson, K. (1999). Shaping school culture: The heart of leadership. San Francisco: Jossey-Bass.

Delaker, J. (2001). Poverty in the United States, 2000.ed States, 2000. U.S. Census Bureau, Current Populations Reports, (Series P-60-214). Washington, DC: U.S. Government Printing Office. 
DeVries, R., \& Kohlberg, L. (1990). Constructivist early education: Overview and comparison with other programs. Washington, DC: National Association for the Education of Young Children.

Dewey, J. (1902). The child and the curriculum. Chicago: University of Chicago.

Dewey, J. (1915). The school and society (Rev. ed.). Chicago: University of Chicago.

Dewey, J. (1916). Democracy and education. New York: Macmillan

Dewey, J (1938). Experience and education. New York: Kappa Delta Pi.

Dirkx, J.M. (2001, Spring). The power of feelings: emotion, imagination, and the construction of meaning in adult learning. In S.B. Merriam, (Ed.) The new update on adult learning theory: New directions for adult and continuing education, (vol. 89, pp. 63-72). San Francisco: Jossey-Bass.

Eisner, E. (1991). The enlightened eye: Qualitative inquiry and the enhancement of educational practice. New York: Macmillan.

Eisner, E. (1994). Cognition and curriculum reconsidered ( $2^{\text {nd }}$ ed.). New York: Teachers College Press.

Evans, R. (1996). The human side of school change: Reform resistance, and the real -life problems of innovation. San Francisco: Jossey-Bass.

Featherstone, D., Munby, H., \& Russell, T. (Eds.). (1997). Finding a voice while learning to teach. London: Falmer.

Fessler, R., Christensen, J. C. (Eds.). (1992). The Teacher Career Cycle: Understanding and Guiding the Professional Development of Teachers. Boston: Allyn \& Bacon.

Fogarty, R. (1999). Architects of intellect. Educational Leadership, 57, (3) p. 7678.

Freiberg, H.J. \& Driscoll, A. (1992). Universal teaching strategies. Boston: Allyn \& Bacon.

Freire, P. (1970). Pedagogy of the oppressed. New York: Herder \& Herder. 
Fried, R. L. (1995). The passionate teacher. Boston: Beacon.

From risk to renewal: Charting a course for reform. (1993). Washington D.C.: Education Week.

Fullan, M. (1993). Change forces: Probing the depths of educational reform. London: Falmer Press.

Gardner, H. (1991). The unschooled mind: How children think and how schools should teach. New York: Basic Books.

Garet, M. S., Porter, A. C., Desimone, L, Birman, B. F. \& Suk Yoon, K. (2001, Winter). What makes professional development effective? Results from a national sample of teachers. American Educational Research Journal, 38 (4) 915-945.

Garmston, R., \& Wellman, B. (1999). The adaptive school: A sourcebook for developing collaborative groups. Norwood, MA: Christopher-Gordon.

Glickman, C. (2002). Leadership for learning. Alexandria, VA: Association for Supervision and Curriculum Development.

Glickman, C., Gordon, S., \& Ross-Gordon, J. (1998). Supervision of instruction A developmental approach $\left(4^{\text {th }}\right.$ ed.). Needham Heights, MA: Allyn \& Bacon.

Glines, D., \& Long K. (1992, March). Transitioning toward educational futures. Phi Delta Kappan ,73 (7) 557-560.

Gôleman, D. (1995). Emotional intelligence. New York: Bantam Books.

Goodlad, J. (1983, April). A study of schooling: Some implications for school improvement. Phi Delta Kappan, 64, (6 ) 557.

Goodlad, J. (1994). Educational renewal: Better teachers, better schools. San Francisco: Jossey-Bass.

Gregorc, A. F. (1973, December.). Developing plans for professional growth. NASSP Bulletin, 21 (4) 1-8.

Grow, G. (1991). Teaching learners to be self-directed: A stage approach. Adult Education Quarterly, 41 (3) 125-149. 
Grow, G. (1994). Teaching Learners to be Self-Directed [On-line]. Available: www.longleaf.net/ggrow/SSDL/Model.html.

Haberman, M. (1995). Star teachers of children in poverty. West Lafayette, IN: Kappa Delta Pi.

Hansman, C. A. (2001, Spring) Context-based adult learning. In S. B. Merriam. (Ed.) The new update on adult learning theory: New directions for adult and continuing education, (pp. 43-51). San Francisco: Jossey-Bass.

Hargreaves, A. (1994). Changing teachers, changing times: Teachers' work and culture in the postmodern age. New York: Teachers College Press.

Hargreaves, A., \& Fullan, M. (1998). What's worth fighting for out there? New York: Teachers College Press.

Hart, A. W. (1993). Principal succession: Establishing leadership in schools. Albany, NY: SUNY Press.

Hawley, W. D., \& Rosenholtz, S. (1984). Good Schools: A Synthesis of Research on How Schools Influence Student achievement. Special issue, Peabody Journal of Education, 4, 1-178.

Hawley, W. D. \& Valli, L. (1999). The essentials of effective professional development. In L. Darling-Hammond, \& G. Sykes (Eds.), Teaching as the learning profession: Handbook of policy and practice. San Francisco: Jossey-Bass.

Hayes, E. (2001, Spring). A new look at women's learning. In Merriam, S. B. - (Ed.). The new update on adult learning theory: New directions for adult and continuing education. (pp. 35-42). San Francisco: Jossey-Bass.

Hess, F. (1999). Spinning wheels: The politics of urban school reform. Washington D C: Brookings Institution Press.

Hill, L. H. (2001, Spring). The brain and consciousness; sources of information for understanding adult learning theory. In S. B. Merriam. (Ed.), The new update on adult learning theory: New directions for adult and continuing education, (pp. 73-81). San Francisco: Jossey-Bass.

Hill, P., Cambell, C. \& Harvey, J. (2000). It takes a city: Getting serious about urban school reform. Washington, D C: Brookings Institution. 
Hopfenberg, W. S. \& Levin, H. M. (1993). The accelerated schools resource guide. San Francisco: Jossey-Bass.

Huberman, M. (1995). Professional careers and professional development: Some intersections. In T. Guskey \& M Huberman (Eds.), Professional development in education. New York: Teachers College Press.

Idol, L., \& Jones, B. (Eds.). (1991). Educational values and cognitive instruction: Implications for reform. Hillsdale, NJ: Lawrence Erlbaum Associates.

Jensen, E. (1996). Brain-based learning. Del Mar, CA: Turning Point.

Jensen, E. (1998). Teaching with the brain in mind. Alexandria, VA: Association for Supervision and Curriculum Development.

Johnson, S. M. \& Kardos, S. M. (2002). Keeping new teachers in mind. Educational Leadership, 59 (6) 12-16.

Joyce, B., Weil, M. \& Calhoun, E. (2000). Models of teaching ${ }_{2} 6^{\text {th }}$ ed.). Boston: Allyn \& Bacon.

Kirst, M. (1990). The crash of the first wave. In S. B. Bacharach (Ed.), Education reform: Making sense of it all. Boston: Allyn \& Bacon.

Knowles, M. S. (1984). The adult learner: A neglected species ( $3^{\text {rd }}$ ed.) (p. 13). Houston, TX: Gulf.

Krupp, J. A. (1981). Adult development: Implications for staff development. Manchester, CT: Adult Development \& Learning.

Ladson-Billings, G. (1994). The dreamkeepers: Successful teacher of African American children. San Francisco: Jossey-Bass

Lambert, L. (1998). Building leadership capacity in schools. Alexandria, VA: Association for Supervision \& Curriculum Development.

Lambert, L. et al. (1995). The constructivist leader. New York: Teachers College Press.

Lambert, M., \& Ball, D. L. (1999). Aligning teacher education with contemporary k-12 reform visions. In L. Darling-Hammond, \& G. Sykes (Eds.), Teaching as the learning profession: Handbook of policy and practice. San Francisco: Jossey-Bass. 
Lawrence-Lightfoot, S., \& Davis, J. H. (1997). The art and science of portraiture. San Francisco: Jossey-Bass

LeCompte, M.D., \& Goetz; J. P. (1982). Problems of reliability and validity in ethnographic research. Review of Educational Research, 51 31-60.

Leithwood, K., Jantzi, D., \& Steinbach, R. (1999). Changing leadership for changing times. Buckingham, UK: Open University Press.

Lester, J. P., \& Stewart, J. (1996). Public policy: An evolutionary approach. Minneapolis: West Publishing

Letven, E. (1992). Induction. In R. Fessler \& J. C. Christensen (Eds.). The teacher career cycle: Understanding and guiding the professional development of teachers (pp. 59-86). Boston: Allyn \& Bacon.

Levin, H. M. (1985). The educationally disadvantaged: A national crisis. Philadelphia: Public/Private Ventures.

Levin, H. M. (1986). Educational reform for disadvantaged students: An emerging crisis. Washington, DC: National Education Association.

Levin, H. M. (1997, Fall/Winter). The dilemma of principal succession. Accelerated Schools, 6 (3)1-3.

Levin, H. M. (1999, Fall). Accelerated visions: The evolution of powerful learning. Accelerated Schools, 8 (2) 2-3.

Levine, S. L. (1989). Promoting adult growth in schools: The promise of professional development. Boston: Allyn \& Bacon.

Levinson, D. (1978). The seasons of a man's life. New York: Knopf.

Lewis, A., \& Paik, S. (2001). Add it up: Using research to improve education for low-income and minority students. Washington, DC: Poverty and Race

- Research Action Council.

Lieberman. A.. \& Wood, D. R. (2002). The national writing project. Educational Leadership, 59 (6) 40-43.

Lincoln, Y. S. \& Guba, E.G. (1985). Naturalistic inquiry. Beverly Hills, CA: Sage. 
Lippman, L., Burns, S., \& McArthur, E. (1996). Urban schools: The challenge of location and poverty. National Center for Education Statistics. U.S. Department of Education Office of Educational Research and Improvement NCES 96-184.

Little, J. W. (1999). Organizing schools for teacher learning. In L. DarlingHammond \& G. Sykes (Eds.) Teaching as the learning profession: Handbook of policy and practice (pp. 233-262). San Francisco: JosseyBass.

Lortie, D. (1975). Schoolteacher: A sociological study. Chicago: IL: University of Chicago Press.

Maggio, R. (comp.) (1997) Quotations on Education. Paramus: NJ: Prentice Hall.

Marsh, D. (2000). Educational leadership for the twenty-first century: Integrating three essential perspectives. In The Jossey-Bass Reader on Educational Leadership (pp. 126-145) San Francisco: Jossey-Bass.

Marzano, R., Pickering, D., \& Pollock, J. (2001). Classroom instruction that works: Research-based strategies for increasing student achievement. Alexandria, VA: Association for Supervision and Curriculum Development.

McKeown, M. G., \& Beck, I.L. (1999). Getting the discussion started. Educational Leadership, 57 (3) 25-28.

Merriam, S. B. (Ed.). (1993). An update on adult learning theory: New directions for adult an continuing education. San Francisco: Jossey-Bass.

Merriam, S. B. (2001, Spring). Androgogy and self-directed learning: pillars of adult learning theory. In S.B. Merriam. (Ed.), The new update on adult learning theory: New directions for adult and continuing education. (pp. 313). San Francisco: Jossey-Bass.

Merriam, S. B. (Ed.). (2001, Spring). The new update on adult learning theory: New directions for adult and continuing education. San Francisco: JosseyBass.

Mezirow, J. (1997, Spring) Transformative learning: Theory to practice. In Cranton, P. (Ed.). Transformative learning in action: Insights from practice: new directions for adult and continuing education. (pp. 5-12). San Francisco: Jossey-Bass. 
Miles, M. B., \& Huberman, A. M. (1994). Qualitative data analysis: An expanded sourcebook. Thousand Oaks, CA: Sage.

National Center for Policy Analysis. (2001). Teacher Shortage Emerging [On-line]. Available: http://www.ncpa.org/pi/edu/pdedu/pdedu162.html

National Commission on Excellence in Education. (1983) A nation at risk: The imperative for educational reform (GPA 065-000-00177-2). Washington, DC: U.S. Government Printing Office.

Olson, L. (1999, April 14). Following the plan. Education Week.

Olson, L. (2002, January 16). States gear up for new federal law. Education Week.

Olson, L., \& Rothman, R. (1993). The road map to reform. In From risk to renewal: Charting a course for reform. Washington, DC: Education Week.

Owens, R. (1991). Organizational behavior in education $\left(4^{\text {th }}\right.$ ed.). Needham Heights, MA: Allyn \& Bacon.

Palmer, P. (1998). The courage to teach: Exploring the inner landscape of a teacher's life. San Francisco: Jossey-Bass.

Passow, A. H. (1990). How it happened, wave by wave. In S. B. Bacharach (Ed.), Education reform: Making sense of it all. Boston: Allyn \& Bacon.

Patton, M. Q. (1987). How to use qualitative methods in education. Thousand Oaks, CA: Sage.

Payne, R. K. (1998). A framework for understanding poverty. Baytown, TX: RFT Publishing, Co.

Perkins, D. (1992). Smart schools: From training memories to educating minds. New York: Free Press.

Perkins, D. (1999). The many faces of constructivism. Educational Leadership, 57 (3) 6-11.

Peterson, K. (1995). Teacher evaluation: A comprehensive guide to new directions and practices. Thousand Oaks, CA: Corwin Press. 
Piaget, J. $(1929,1951)$. The child's conception of the world. (J. Tomlinson \& A. Tomlinson, Trans.) Savage, MD: Littlefield Adams.

Poplin, M., \& Weeres, J. (1992). Voices from inside: A report on schooling from inside the classroom. Claremont, CA: Claremont Graduate School, The Institute for Education in Transformation.

Powerful learning in action. (1994, Spring). Accelerated Schools, 3, (3) 1-5.

Putnam, R. T., \& Borko, H. (2000). What do new views of knowledge and thinking have to say about research on teacher learning? Educational Researcher, 29 (3) 4-15.

Richardson, L. (1990). Writing strategies: Reaching diverse audiences. Newbury Park, CA: Sage.

Richardson. V. (1997). Constructivist teaching and teacher education: Theory and practice. In V. Richardson (Ed.) Constructivist teacher education: Building new understandings (pp. 3-14). Washington DC: Falmer Press.

Riordan, C. (1997). Equality and achievement: An introduction to the sociology of education. New York: Longman

Rosenshine, B. \& Meister, C. (1992). The use of scaffolds for teaching higher-level cognitive strategies. Educational Leadership. 49 (2), 26-33.

Routman, R. (1988). Transitions from literature to literacy. Portsmouth, NH: Heinemann.

Routman, R. (2002). Teacher talk. Educational Leadership, 59 (6) 32-35.

Scherer, M. (1999). The C word. Educational Leadership, 57 (3) 5.

Scherer, M. (2002). Job one. Educational Leadership, 59 (6) 5.

Schlechty, P. (1997). Inventing better schools: An action plan for educational reform. San Francisco: Jossey-Bass.

Schon, D. (1983). The reflective practitioner. New York: Basic Books.

Schwann, C., \& Spady, W. (1998). Total leaders: Applying the best future-focused change strategies to education. Arlington, VA: ASCD 
Senge, P. (1990). The fifth discipline. New York: Doubleday.

Sergiovanni, T. (1994). Building community in schools. San Francisco: JosseyBass.

Sergiovanni, T., \& Carver, F. (1973). The new school executive. New York: Harper \& Row.

Shepard, L. (2000). The role of assessment in a learning culture. Educational Researcher, 29 (7) 4-14.

Slavin, R. (1998). Sand, bricks, and seeds: School change strategies and readiness for reform.). In A. Hargreaves. et al. (Eds.), International handbook of educational change (pp. 1299-1313). Great Britain: Kluwer Academic Publishers.

Slavin, R., \& Fashola, O. S. (1998). Show me the evidence! Proven and promising programs for America's schools. Thousand Oaks, CA: Corwin Press.

Slovacek, S. (1996). The changing role of principals in accelerated schools. In Accelerated schools in action: Lessons from the field, (pp.169-180). Thousand Oaks, CA: Corwin Press.

Smylie, M.A. (1995). Teacher learning in the workplace: Implications for school Reform. In T.R. Guskey \& M. Huberman (Eds.). Professional development in education: New paradigms and practices (pp.112-124). New York: Teachers College, Columbia University.

Spindler, G. (1982). Doing the ethnography of schooling: Educational anthropology in action. New York: Holt, Rinehart \& Winston.

Stake, R. (1995). The art of case study research. Thousand Oaks, CA: Sage.

Steffy, B. E. (1989). Career stages of classroom teachers. Lancaster, PA: Technomic.

Sykes, G. (1999). Teacher and student learning: Strengthening their connection. In L. Darling-Hammond \& G. Sykes (Eds.), Teaching as the learning profession: Handbook of policy and practice (pp. 151-180). San Francisco: Jossey-Bass.

Tennant, M. (1986). An evaluation of Knowles' theory of adult learning. International Journal of Lifelong Education, 5 (2) 113-122. 
Tomlinson, C.A. (1999). The differentiated classroom: Responding to the needs of all learners. Alexandria, VA: Association for Supervision \& Curriculum Development.

Tough, A. (1971). The adult's learning projects; A fresh approach to theory and practice in adult learning. Toronto: Ontario Institute for Studies in Education.

Tyack, D., \& Cuban, L. (1997). Tinkering toward utopia: A century of public school reform. Boston: Harvard University Press.

U.S. Department of Education. (1999). Comprehensive school reform demonstration program 84.332A [On-line]. Available: http://web99.ed.gov/GTEP/Prgram2.nsf/b39cd123fd4a045b8525644400514 $\underline{\mathrm{f} 2 \mathrm{~b} /}$

U.S. Department of Education. (1999). Cross-cutting guidance for the Elementary and Secondary Education Act September 1996. Washington, D.C. [ Online]. Available: Http://www.ed.gov/legislation/ESEA/Guidance.

U.S. Department of Education (November, 1999). CSRD in the field: Fall 1999 update. [On-line]. Available: http://www.ed.gov/offices/OESE/compreform/csrd99report.html

U.S. Department of Education. (1995). The Improving America's Schools Act of 1994: reauthorization of the Elementary and Secondary Education Act.[On-line]. Available: http://www.ed.gov/legislation/ESEA/brochure/iasa-bro.html

U.S. Department of Education (1996). Mapping out the national assessment of Title I: The interim report - 1996. [On-line]. Available: http://www.éd.gov/pubs/NatAssess/sec.1.html

U. S. Department of Education (2000). Promising results continuing challeges: Final report of the national assessment of Title I. [On-line]. Available: http://www.ed.gov/office/OUS/eval/exsum.html.

U. S. Department of Education, Office of the Under Secretary, Planning and Evaluation Service. (1999). Designing effective professional development: Lessons from the Eisenhower program. [On-line]. Available: http://www.ed.gov/inits/teachers/eisenhower/ 
Vygotsky, L.S. (1962). Thought and language. Cambridge, MA: MIT Press.

Wang, M., Haertel, G., \& Walberg H. (1993-1994). What helps students learn? Educational Leadership, 51 (5) 74-79.

Wheatley, M. (1999). Leadership and the new science: Discovering order in a chaotic world. San Francisco: Berret-Koehler, Publishers.

Wilcox, K. (1982). Ethnography as a methodology and its application to the study of schooling: A review. In G. Spinder (Ed.), Doing the ethnography of schooling. New York: Holt, Rinehart \& Winston.

Willis, S. (2002). Creating a knowledge base for teaching: A conversation with James Stigler. Educational Leadership, 59 (6) 6-11.

Wilson, A. L. (1993). The promise of situated cognition. In S. B. Merriam. (Ed.), An update on adult learning theory: New directions for adult an continuing education. San Francisco: Jossey-Bass.

Wolcott, H. (1973). The man in the principal's office: An ethnography. New York: Holt, Rinehart \& Winston.

Wolcott, H. (1994). Transforming qualitative data: description, analysis, and interpretation. Thousand Oaks, CA: Sage.

Zemelman, S., Daniels, H., \& Hyde, A. (1998). Best practice: New standards for teaching and learning in America's schools. $\left(2^{\text {nd }}\right.$ ed.). Portsmouth, NH: Heinemann.

Zemke, R., \& Zemke, S. (1996). Adult learning: What we know for sure? In D. Zielinski (Ed.), Adult learning in your classroom. Minneapolis, $\mathrm{MN}$ : Lakewood Books. 
APPENDIX A

POWERFUL LEARNING FRAMEWORK

ACCELERATED SCHOOLS PROJECT 


\section{Accelerated Schools Project}

Powerful Learning Framework

The ASP Powerful Learning Framework embeds the ASP structure (curriculum, instruction and context with the guiding principles and the 5 components of powerful learning.

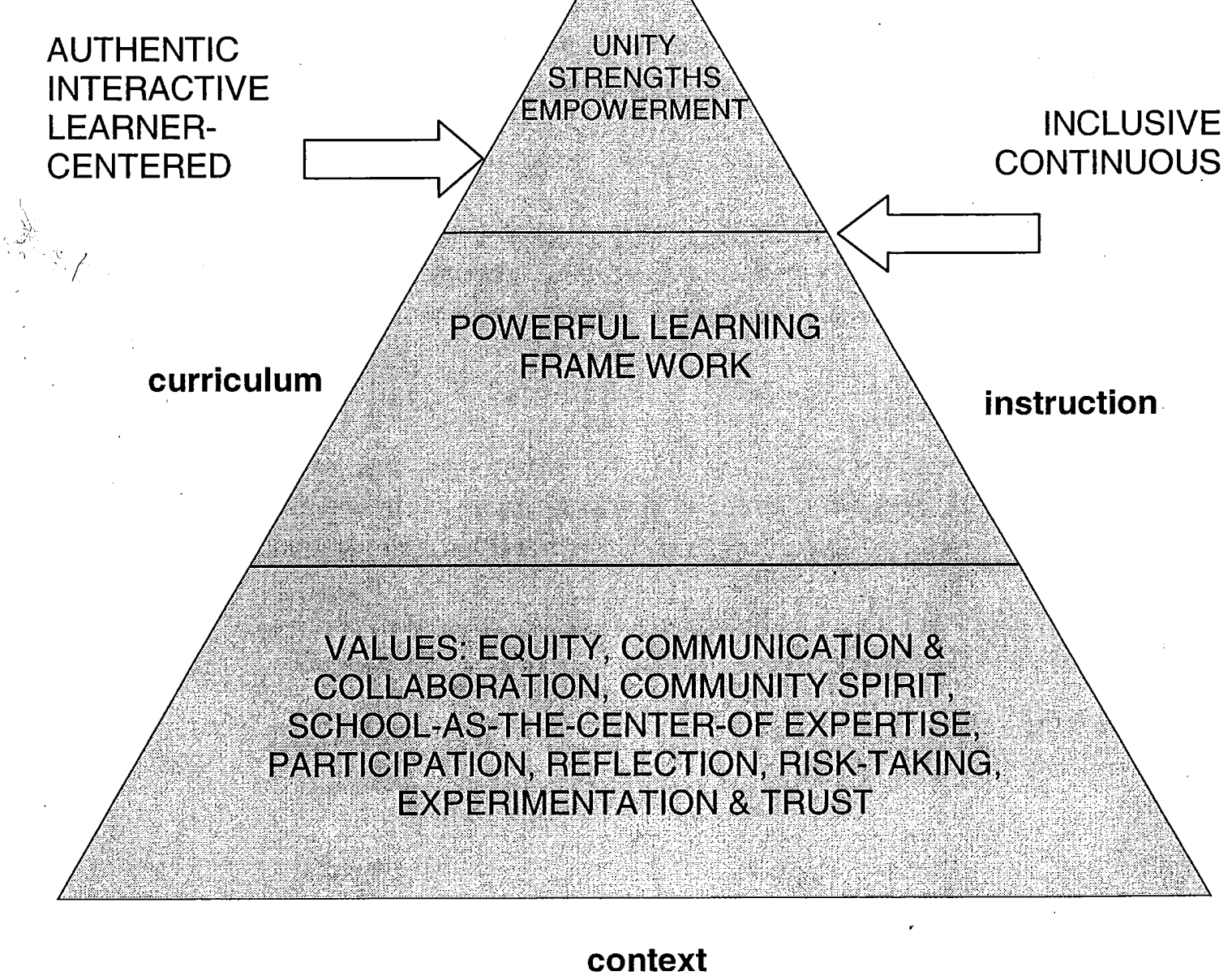




\section{DESCRIPTION OF THE FIVE COMPONENTS OF POWERFUL LEARNING:}

Authentic:

Students can relate what they are experiencing in the classroom to real issues and situations. Lessons are relevant to the learner, have recognizable goals, and build connections.

Interactive:

Students participate in interactive opportunities. Individuals collaborate with others in the learning process and work together toward a common purpose. Through this interaction, students are able to share their expertise.

Learner Centered:

Student exploration and continual discovery are essential in the powerful learning process. The learners' experiences and interests help shape the direction and content of the lessons. Students become enabled to take charge of their own learning.

Continuous:

Students perceive knowledge in a more holistic manner to strengthen connections between different learning contexts. Students can apply existing knowledge to what they have already learned and make connections between different subject areas.

Inclusive:

Powerful learning focuses on giving all students equal access to learning opportunities. Challenges are structured which encourage the class to draw on the expertise of students who may not be as vocal or perceived of as smart. 


\section{APPENDIX B}

\section{POWERFUL LEARNING LAB SUMMARY}




\section{Powerful Learning Lab Summary Page}

The Powerful Learning Lab is a series of workshops and classroom clinics designed to further the implementation of school-wide powerful learning. One of the persistent challenges facing Accelerated Schools is how to increase the focus on teaching and learning while a school works toward realization of its vision. The Powerful Learning Lab systematically presents information on the components of powerful learning and provides opportunities for practice and reflection on all sides of the powerful learning triangle. The lab builds a peer support system, which boosts the ability of teachers to risk trying innovative approaches in planning, teaching, and assessing learning.

Participants in the Powerful Learning Lab are encouraged to work in pairs or teams from their home school. These teams can be at grade level or cross grade level and cross-discipline.

\section{Powerful Learning Lab Timeline}

Labs 1-2 August 14, 15, 2000

Content: PL Overview, Interactive

Component \& Social Family from Models of Teaching

Optional Powerful Learning Best Practice Seminar: Classroom

Management and Powerful Learning:

featured guest: Dr. Kenneth Peterson date: August 16, 2001

Labs 3-4 October 16,17 2000

Content: Continuous \& Inclusive Components \& Information-Processing Family from Models of Teaching: Peer Coaching

Optional Powerful Learning Best Practice Seminar: Literacy and Powerful Learning:

featured guests: Shirley Murata \& Cherie McGrew date: October 18, 2001

Labs 5-6 January 8, 92001

Content: Learner-Centered Component \& Personal Family from

Models of Teaching: Culture of Poverty

Optional Powerful Learning Best Practice Seminar: Special Needs \& Powerful Learning

featured guests: Dr. Nancy Benson \& Dr. Tom Moran date: January, 10 2002

Labs 7-8 March 5, 62001 
Content: Authentic Components \& Behaviorist

Family from Models of Teaching: Differentiated Instruction

Optional Powerful Learning Best Practice Seminar: Math \& Powerful Learning

featured guests: Cathy Reed \& Sandy Krilovec date: March 72002

\section{Powerful Learning Graduate Credit Option}

Graduate Credit through PSU is available for participants. Grades are recorded for spring term, 2001, although the lab runs for the school year. WA clock hours and Oregon PDC is also available. Graduate credit, clock hours, and PDC are for an additional charge.

Powerful Learning Labs connect standards, curriculum, best practice, assessment, and teaching \& learning, one teacher at a time! 


\section{APPENDIX C}

POWERFUL LEARNING LAB PORTFOLIO 


\section{Powerful Learning Lab Portfolio}

\section{The Powerful Learning Lab Portfolio}

The goal of the Powerful Learning Lab Portfolio is to guide, support and document the learning of teachers and students through examining and implementing Accelerated Schools' principles, values and powerful learning.

The Powerful Learning Lab Portfolio is a purposeful collection of student work, teacher plans, reflection and analysis that demonstrates progress in the development of powerful learning and student achievement of standards. Teachers, professional colleagues and students participate in the selection of materials so the portfolio provides valuable data from multiple perspectives.

This portfolio is a working document and a work of art. It should be at your side as you plan and create powerful learning for students and yourself. It will also contain examples of student work for your own reflection and evolve into a professional documentation of teaching and learning.

In the Powerful Learning Lab teachers work with learning standards, performance criteria and rubrics*, which guide the evaluation of teacher development, the design of lessons and ongoing assessment of student work. Teachers will also explore strategies from the text, Models of Teaching, $6^{\text {th }}$ Ed. by Bruce Joyce et al.

Each component of powerful learning is described as a standard. Criteria for each of the component standards are listed. The powerful learning rubric defines the levels of teacher development in powerful learning. The rubric, reflection questions and a debriefing format for peer support team promote continuous assessment of teacher progress in the development of the powerful learning standards.

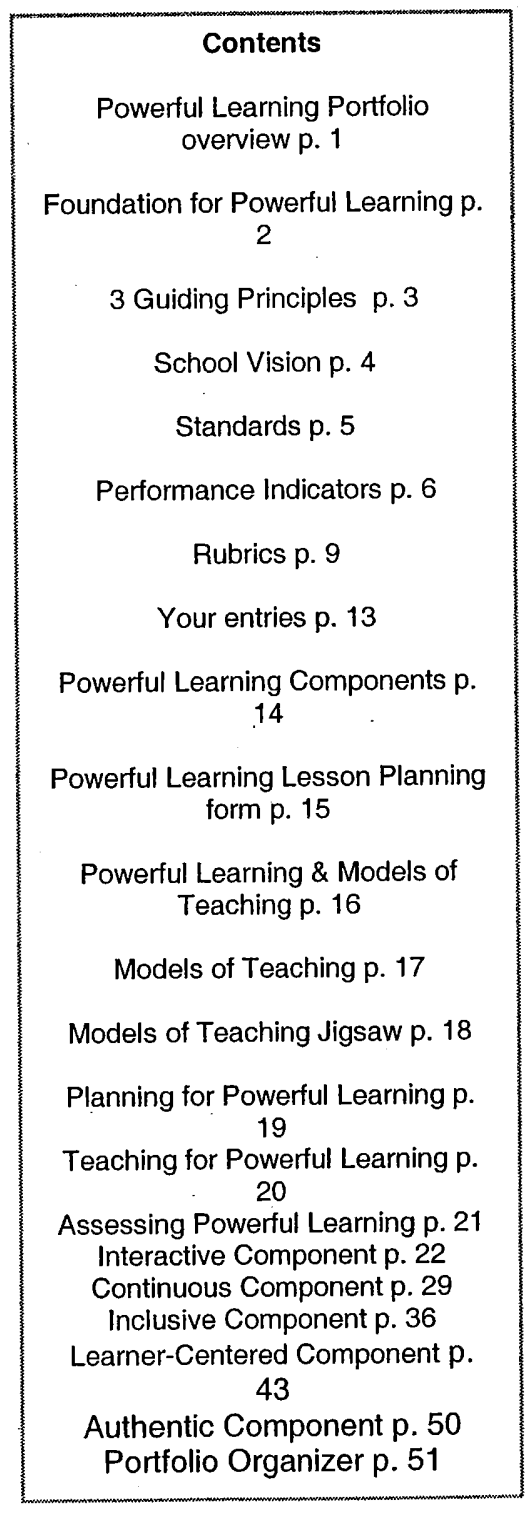

\section{* Rubric and scoring guide are used synonymously.}




\title{
Powerful Learning Lab
}

\author{
All children achieve \\ All children are treated as gifted \\ Teachers \& students work together to develop a vision of the ideal classroom \\ Teachers and students collaborate in learning \\ Ideas count
}

July 5, 2000 Powerful Learning Lab Portfolio

Adapted from National Center by NW Regional Center for Accelerated

Schools at Portland State University

\section{Foundation for Powerful Learning}

Learning is powerful when the student can use what was learned in effective ways and when the learning changes the learner. A major challenge in developing powerful learning is in teaching essential skills and information in a creative and engaging way that challenges all students and helps them develop a richer understanding. The Accelerated Schools Project has developed a process that integrates the principles and values of Accelerated Schools and constructivist-based learning theory.

The Powerful Learning framework is illustrated by a triangle that represents the essential elements of curriculum, instruction and organization. Teachers use these elements to create powerful learning for all students. These elements are what is taught, how teaching and learning take place and the learning context, which encompasses all perceptions, expectations and resources of the school community.

The five components of powerful learning describe a variety of instructional methods and practices that are grounded in research about effective learning and focused on student achievement of high standards.

Examining the $\mathbf{3}$ guiding principles of Accelerated Schools and identifying how they are incorporated into teaching and learning is an important aspect of developing powerful learning. Purpose is determined by standards, the school's vision, the learners' dreams and the conviction that all children can learn. Unity is built through open communication, positive feedback, trust and equity of opportunity. Empowerment means that all members of the learning community have a role in high impact decision-making. Asking questions, experimentation and taking risks are encouraged. Responsibility means that everyone is involved in uncovering answers to the questions, which were asked and accountable for the outcomes of the choices that were made. Building on strengths happens when educators make time to learn about and understand the attitudes, perceptions and expectations of all members of the learning community and when everyone has an authentic role that contributes to the success of the community. 


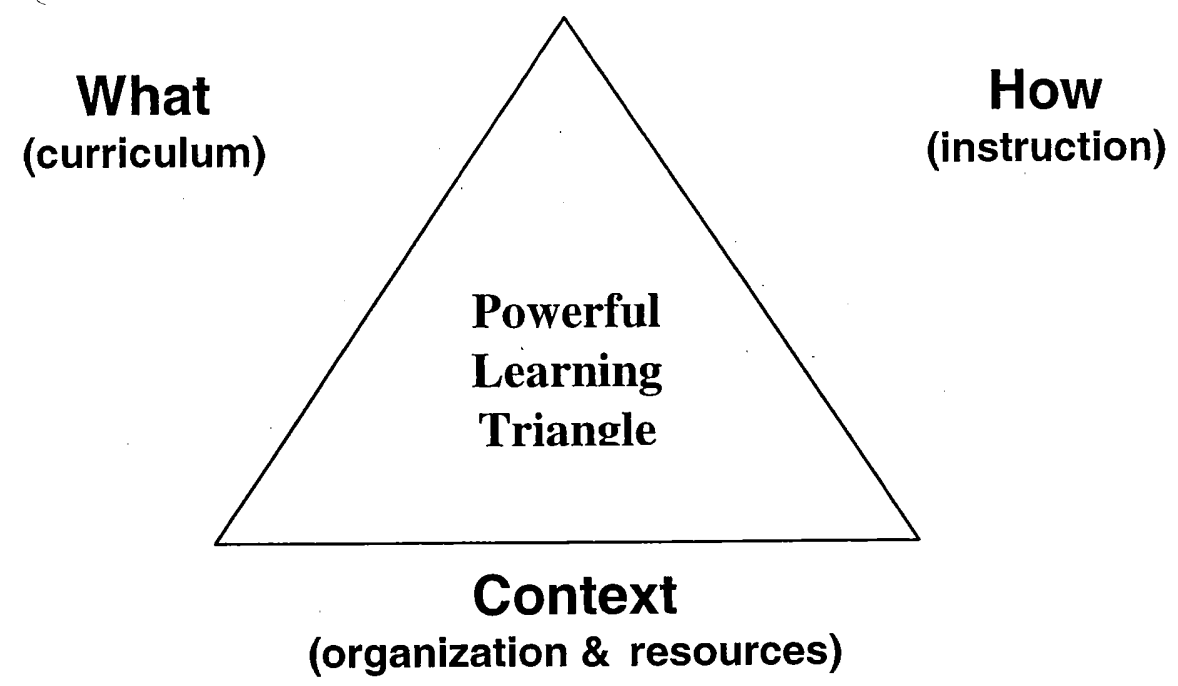

\section{Guiding Principles}

These entries might include samples of student work and reflection from journals, videos or interviews. Descriptions of definitions, activities, procedures and guidelines for interactions will also provide helpful information.

How do you guide your students to understand unity of purpose, empowerment coupled with responsibility and building on strengths?

Unity of Purpose:

Empowerment with Responsibility:

Building on Strengths:

How are these principles embedded nito daily classroom activities, procedures and interactions?

Unity of Purpose:

Empowerment with Responsibility:

Building on Strengths:

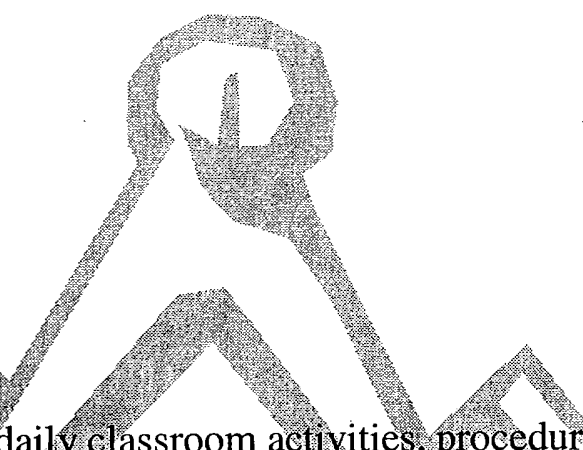




\section{$\underline{\text { School Vision }}$}

What does your school's vision say about what learners should know and be able to do?

What is your vision for students?

How do you work toward your personal and your school vision...?

In daily procedures?

In planning?

In instruction?

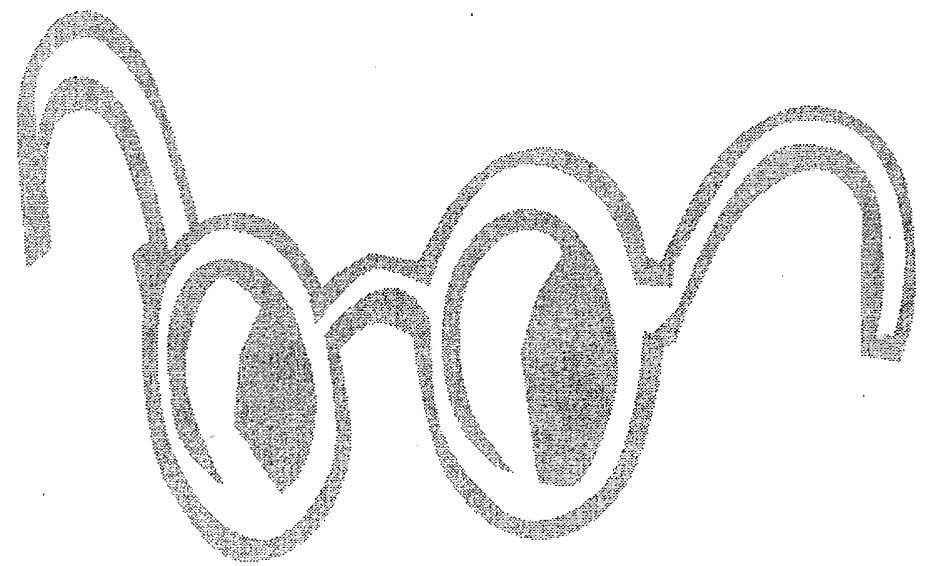

In assessment?

In communicating with parents?

In celebrating your and your students' success? 
$\underline{\text { Standards }}$

Standards: Describe exemplary model of performance in general terms.

Examples:

Oregon: Students will comprehend a variety of printed materials (English)

Washington: Students read different materials for a variety of purposes (EALR 3)

Your Standards

What subject areas or subject area strands will you focus on in the powerful learning portfolio?

What broad concepts related to this subject area or this strand of subjects do you want your students to learn?

(continued on next page)

What standard(s) will be addressed? Please include the source of the standard, the grade level, the name of the subject area from which the standard is drawn, the subsubject area, if any, and identifying numbers or codes. Examples:

Oregon Content Standards: Grade 3: English: Students will comprehend a variety of printed materials

Washington EALR 3: Grade 4: The student reads different materials for a variety of purposes

If all or some of the students achieve all of the selected standards before the end of the lab select additional standards. 
Performance Indicators/Criteria/Benchmarks

Performance Indicators, Criteria or Benchmarks: Point out concretely what the standards mean. Examples:

Oregon Content Standards: Grade 3: English: Students will comprehend a variety of printed materials

- Use context clues to choose the correct meaning for given words on the stare assessment

- Use knowledge of common words in their compound or plural forms to help determine the meaning of words in the passage

- Use illustrations such as pictures, charts, graphs, or diagrams to help determine the meaning of words in the passage

Washington: Students read different materials for a variety of purposes (EALR 3)

- Read to learn new information such as reading science \& mathematics texts, technical documents, and for personal interest

- Read to perform a task such as using schedules, following directions, filling out job applications, and solving problems

- Read for literary experience in a variety of forms such as novel, short stories, poems, plays and essays to understand self and others

- Read for career applications 
Your Standards \& Performance Indicator Entries

Include performance criteria for each standard. You may need to make copies of this table.

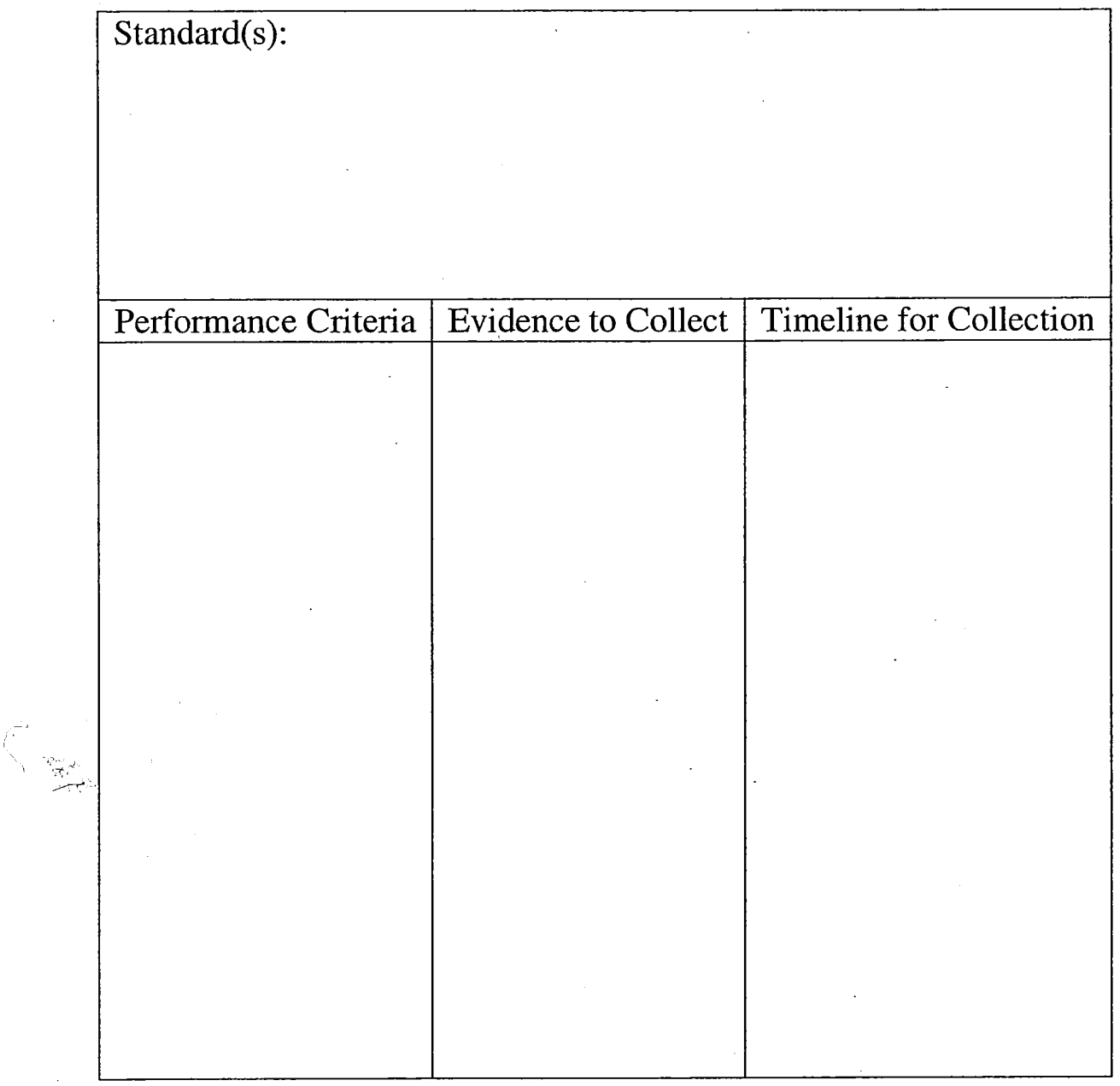


Your Standards \& Performance Indicator Entries

Include performance criteria for each standard. You may need to make copies of this table.

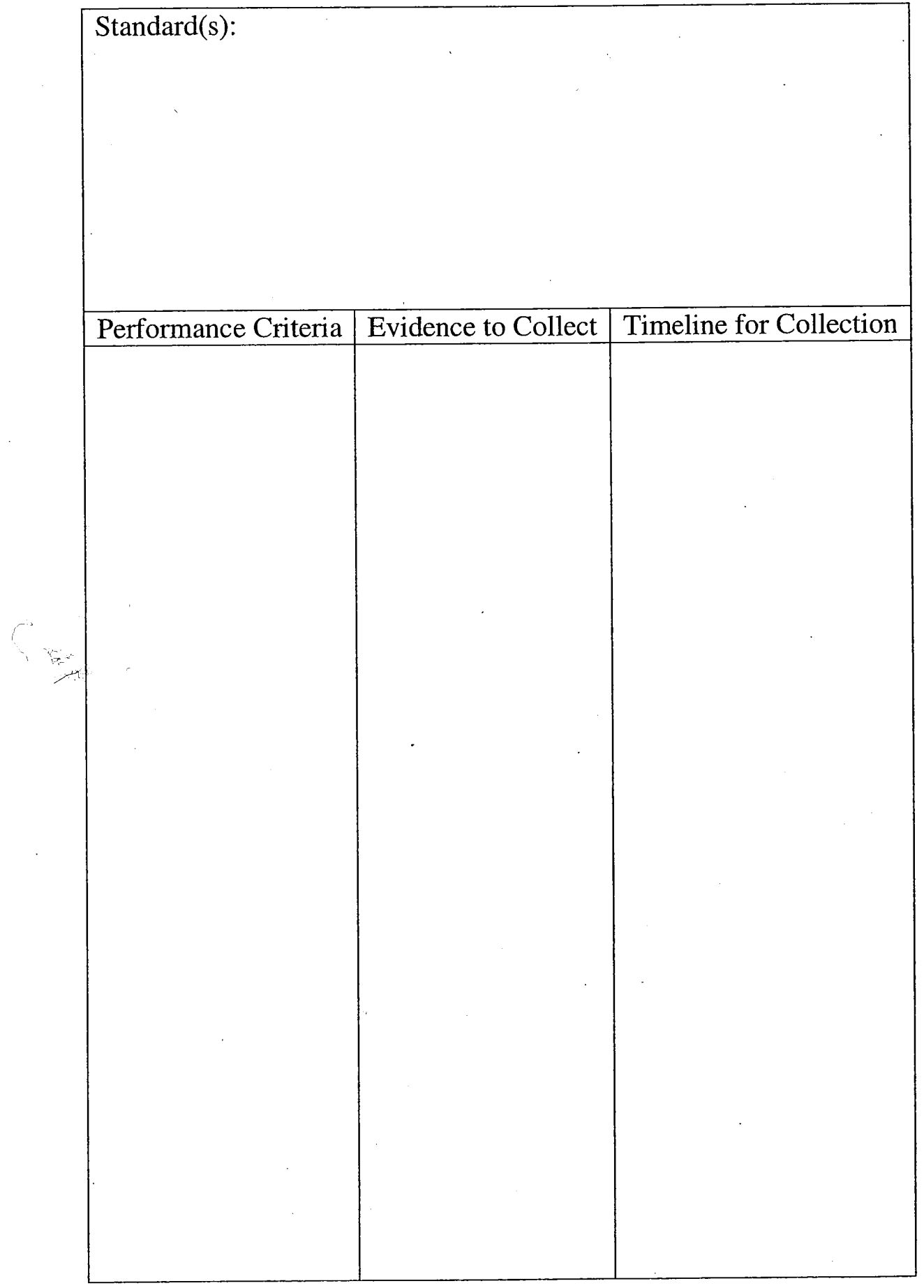




\section{Rubrics or Scoring Guides}

Rubrics: Scales of performance descriptors specific to each development level.

Analytical scales assign point values to each criterion and total the points to arrive at a general level of development. Holistic scales assign a score based on the overall performance. Anchor pieces or examples of student work, which demonstrate each level are necessary when using holistic scales.

Example from the New Standards-Language Arts (This is a holistic scale.)

Levels of Performance

L-little evidence of achievement

B-below the standard

$\mathrm{N}$-nearly achieved the standard

S-achieved the standard

$\mathrm{H}$-achieved the standard with honors

This holistic scale can be transformed into an analytical scale by developing rating scales for each of the criteria and determining score ranges for each of the developmental levels:

For example the range of scores might be: $\mathrm{H}=20-17, \mathrm{~S}=16-13, \mathrm{~N}=12-9, \mathrm{~B}=8-5$, $\mathrm{L}=4-0$.

A teacher-designed example of a rating scale for criteria 3 from the New Standards Language Arts is:

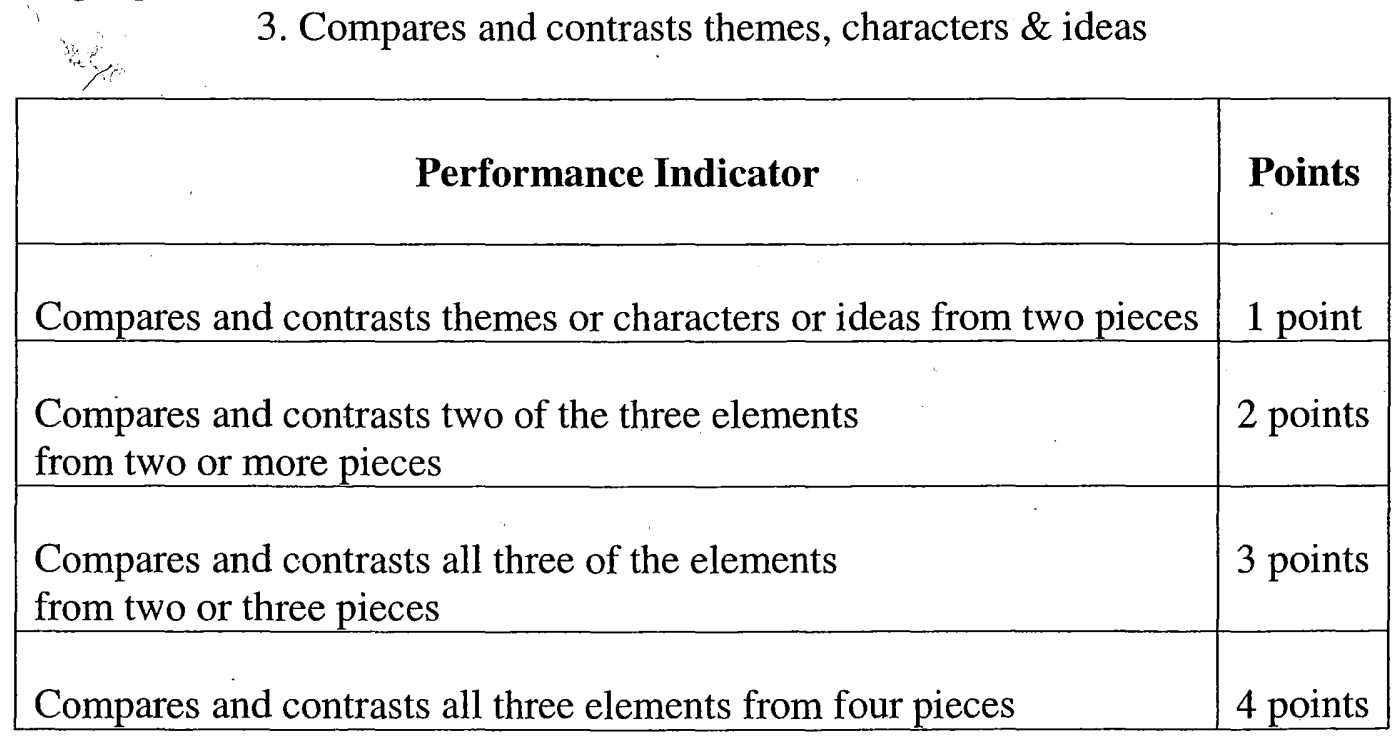




\section{$\underline{\text { Your Rubrics }}$}

Develop or select rubrics for each criteria of every standard or set of standards you are addressing in the portfolio. The following rubric is easy to use, can be applied to many types of standards; can be used in a holistic or analytical manner.

$+\quad$ Has demonstrated proficiency

$\uparrow$

Developing proficiency

- $\quad$ Has not developed proficiency

Rubric scores are not labels or grades. Rubrics are a consistent and organized form of feedback about how the learner is using the knowledge, skills and procedures addressed in the standard. Teachers and learners can use the feedback to guide decisions for the next cycle of teaching and learning.

\section{Select Representative Students:}

Your rubrics will be applied to student artifacts created by all members of the class. Your portfolio entries will use the rubrics to demonstrate progress of six learners from your class. Prior to the pre-assessment select six students from the class. Select two students who generally are quick to understand and use new information, select two students who with practice and continuing feedback usually are able to understand and use new information and select two students who often struggle to complete tasks that demonstrate understanding of new information. Rather than using your students' names identify them as S1, S2, S3, S4, S5, S6.

\section{Samples of Student Work:}

Ten portfolio entries will be samples of student work from each of the six students. Entries can take a variety of different forms such as written reports, oral presentations, graphic displays, performance tasks, tests, descriptions of observed behavior, videos or audiotapes. Five of the entries will be collected during demonstration lessons taught in the lab. The other five entries will be collected between lab sessions. All entries should be connected to work on the selected standards. 


\section{Rubric Record Keeping}

The following table organizes records of student progress. You may make copies of it to use with every standard or set of standards you are addressing. You may also modify it to meet you needs.

Standard(s)

$+\quad$ Has demonstrated proficiency

$\uparrow \quad$ Developing proficiency

- Has not developed proficiency

$\quad$ Performance Indicators
$P=$ performance
assessment
$R=$ written report
$O=$ oral presentation
$D=$ description of
observation
$G=$ graphic presentation
$\%=$ Percentage correct/test

\begin{tabular}{|l|l|l|l|l|l|l|}
\hline Performance Indicators & S1 & S2 & S3 & S4 & S5 & S6 \\
\hline & & & & & & \\
\hline & & & & & & \\
\hline & & & & & & \\
\hline & & & & & & \\
\hline & & & & & & \\
\hline & & & & & & \\
\hline & & & & & & \\
\hline & & & & & & \\
\hline
\end{tabular}




\section{Your Entries}

The next section of the portfolio focuses on the How Of Powerful Learning. Each component is described by standards and benchmarks. Rubrics for each of the five components will guide your self-assessment before the lab sessions and at the conclusion of the lab.

The lesson organizer and powerful learning planning forms are designed to guide planning, individual reflection and observation of demonstration lessons by peer support team members. A debriefing format is also included.

\section{Lesson Plan Entries}

Include ten lessons, using the lesson organizer. Include a lesson plan for each demonstration lesson. Between lab sessions enter a second lesson organizer for the powerful learning component addressed in the most recent lab. Include samples of student work collected during the lesson. All lesson plans should be focused on some part of the standards you selected to include in the portfolio.

Prior to each demonstration lesson distribute copies of the lesson plan organizer to each member of your peer support team.

When you complete each of the lessons use the lesson organizer to guide your reflection.

Review the student work collected, the student performance criteria, the component standard and benchmarks. Use rubric record keeper to record student performance on criteria. Insert samples of student work. If the samples of student work are oversized and will not fit in the portfolio, please write a description of the work and state where it can be found.

On the back of the lesson organizer answer the following questions:

What serendipitous events added value to the lesson?

What went well?

What goal(s) did you reach?

What goals didn't you reach?

What would you do differently if you teach this lesson again?

What should be addressed in the next lesson?

Go back to the lesson plan.

Place a check by each of the planned activities you completed during the lesson.

Circle the check if you feel the activity was successful. 


\section{Peer Support Team Debriefing}

Appoint a recorder each time the peer support team debriefs your demonstration lesson. Include the recorders' debriefing notes in you portfolio. 


\section{POWERFUL LEARNING COMPONENTS}

\section{AUTHENTIC}

Students can relate what they are experiencing in the classroom to real issues and situations. Lessons are relevant to the learner, have recognizable goals, and build connections.

\section{INTERACTIVE}

Students participate in interactive opportunities. Individuals collaborate with others in the learning process and work together toward a common purpose. Through this interaction, students are able to share their expertise.

\section{LEARNER-CENTERED}

Student exploration and continual discovery are essential in the powerful learning process. The learners' experiences and interests help shape the direction and content of the lessons. Students become enabled to take charge of their own learning. CONTINUOUS

Students perceive knowledge in a more holistic manner to strengthen connections between different learning contexts. Students can apply existing knowledge to what they have already learned and make connections between different subject areas.

\section{INCLUSIVE}

Powerful learning focuses on giving all students equal access to learning opportunities. Challenges are structured which encourage the class to draw on the expertise of students who may not be as vocal or perceived of as smart. 


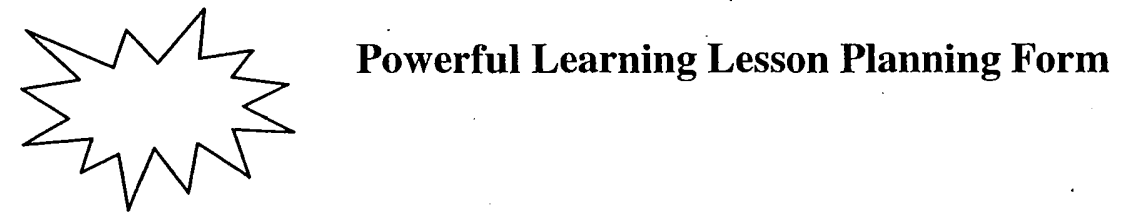

How this relates to the school vision:

Standard:

\section{Content/curriculum:}

\section{Lesson Design Components}

\section{Authentic}

Real-world projects * relevant * recognizable goals * build connections * hands-on

\section{Interactive}

Collaboration * cooperative learning * pairing * sharing

\section{Learner-Centered}

Learner's prior experiences/ background knowledge * interest-based* student selected

\section{Inclusive}

All students * heterogeneous groups* outside experts * buddy classes * community resources

\section{Continuous}

Holistic * integrated * applies existing knowledge * connections to different subjects

Assessment:

a Performance

口 Project

a Journal/writing

ㅁ. Illustration/art
口 Written test

口 Observation/anecdotal records

口 Interview/conference

- Multi-media project 
Layering Powerful Learning and Models of Teaching

The powerful learning framework includes specific vocabulary that is related to years of educational research that is often referred to as "best practice", or practices in the art of teaching and learning that yield positive results in terms of student learning and student achievement. During this yearlong lab you will be integrating the vocabulary of the powerful learning components and triangle, the guiding principles of the Accelerated Schools philosophy, and strategies from Models of Teaching by Bruce Joyce et al. This portfolio will depict your planning, your instructional strategies, your students' work products, and reflections about your teaching. While this may seem a bit overwhelming at first to keep all the language pieces straight, there is exponential benefit to you and your students to combine many teaching strategies and many research proven best practices. Remember, learning is a journey not a destination!

"Complex growth often requires a multidimensional approach. One model or dimension of content is accompanied by another model or dimension of content and so on, until the rich and necessary growth takes place. ... successful programs deal with the need to grow on several fronts at once." - Models of Teaching p. 417. 
Models of Teaching Families:

Labs 1-2 The Social Family of Models

Chapters 3-7

Powerful Learning Focus: Interactive

Labs 3-4 The Information-Processing Family of Models Chapters 8-15

Powerful Learning Focus: Continuous \&

Inclusive

Labs 5-6 The Personal Family of Models

Chapter 16-18

Powerful Learning Focus: Learner-Centered

Labs 7-8 The Behavior Systems Family of Models

Chapters 19-22

Powerful Learning Focus: Authentic

It is extremely important to understand that the powerful learning framework is a holistic framework, even though we are analyzing by separating the components, truly powerful learning occurs when ALL components are present, and multiple models of teaching are employed to meet the needs of diverse learners! 
Models of Teaching Jigsaw

Each participant is expected to become familiar with a variety of models of teaching. Some of you will enjoy reading every chapter of the book. However, you will be working in groups to study deeply one chapter at a time and present that information to the group in a POWERFUL way that demonstrates the model you are learning about. During these micro teaching sessions you are employing many Accelerated Schools principles and values:

Building on strengths (of your group's talent \& expertise)

Unity of Purpose (we are all here to learn from each other)

- Empowerment with responsibility (every participant is expected to participate and contribute ideas)

a Equity (there is equal opportunity for all to learn, share, grow)

- Communication \& collaboration (you will collaborate with others and communicate your expanded collective insights to the group)

a Community spirit (we will become a community of learners)

a School-as-the-center-of expertise (we will look with in the group's expertise, as well as share the expertise of PSU staff)

- Participation (everyone!)

- Reflection (upon your own understanding, teaching, and that of others)

․ Risk taking (teaching other teachers....no explanation needed)

口 Trust (of course, we all work on this!)

Basic Jigsaw directions:

1. Read and discuss your chapter with your group (read independently, aloud, in pairs, you choose!)

2. Organize the main ideas in some way

3. Plan a lesson that conveys the content in a way that is consistent with your chapter's message an/or the powerful learning component: i.e. jurisprudential inquiry analyzes cases, so your group will create a case and lead the group through inquiry about this strategy

4. Teach a mini lesson 15-30 minutes

5. Debrief (led by instructors) 


\section{Planning Phase:}

Creating Powerful Learning for Students (adapted from National Center for Accelerated Schools Project, 1995)

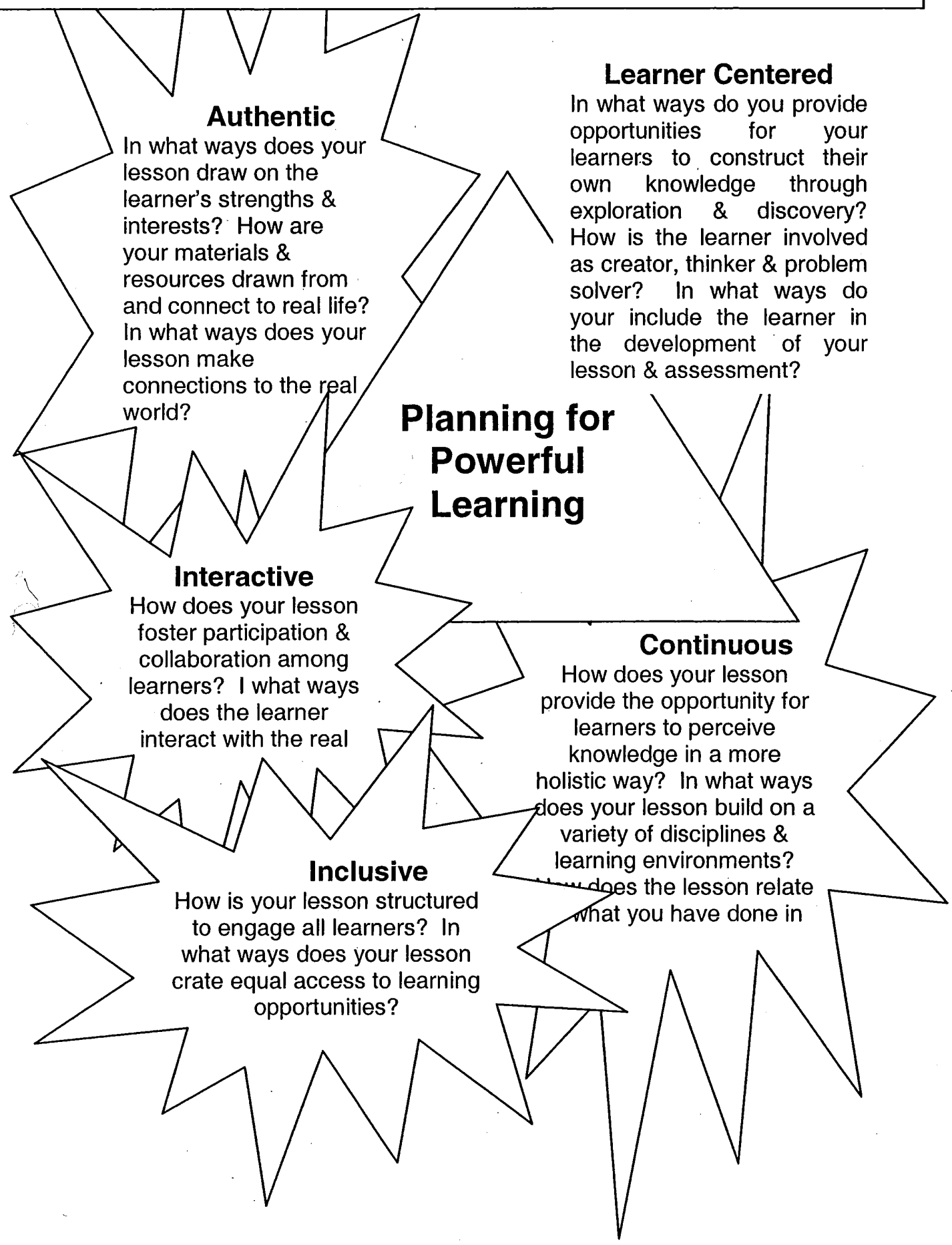




\section{Implementation Phase:}

Teaching for Powerful Learning (created by Amy Petti, NW Satellite Center, 6/99)

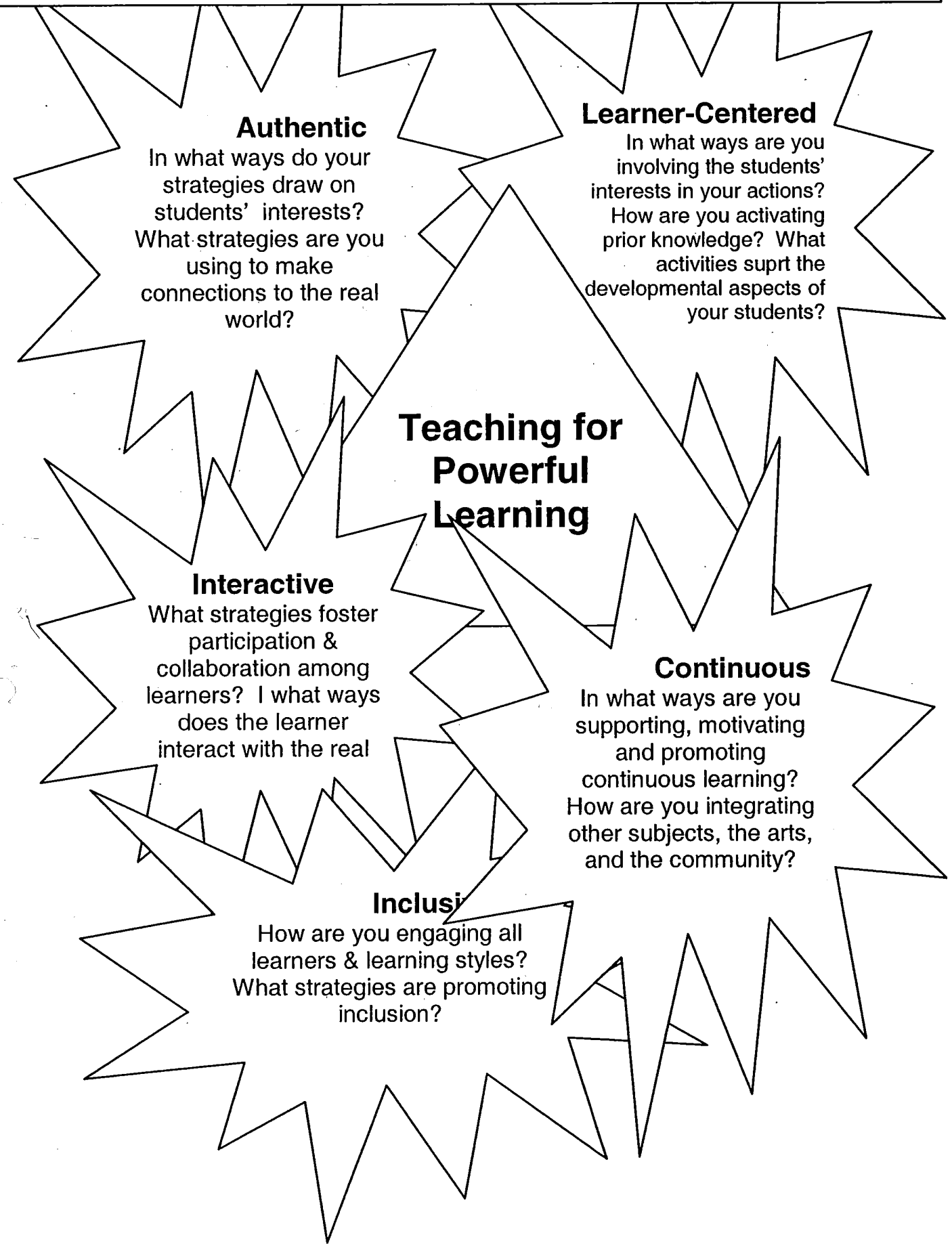


Assessment Phase:

Assessing for Powerful Learning (created by Amy Petti, NW Satellite Center, 6/99)

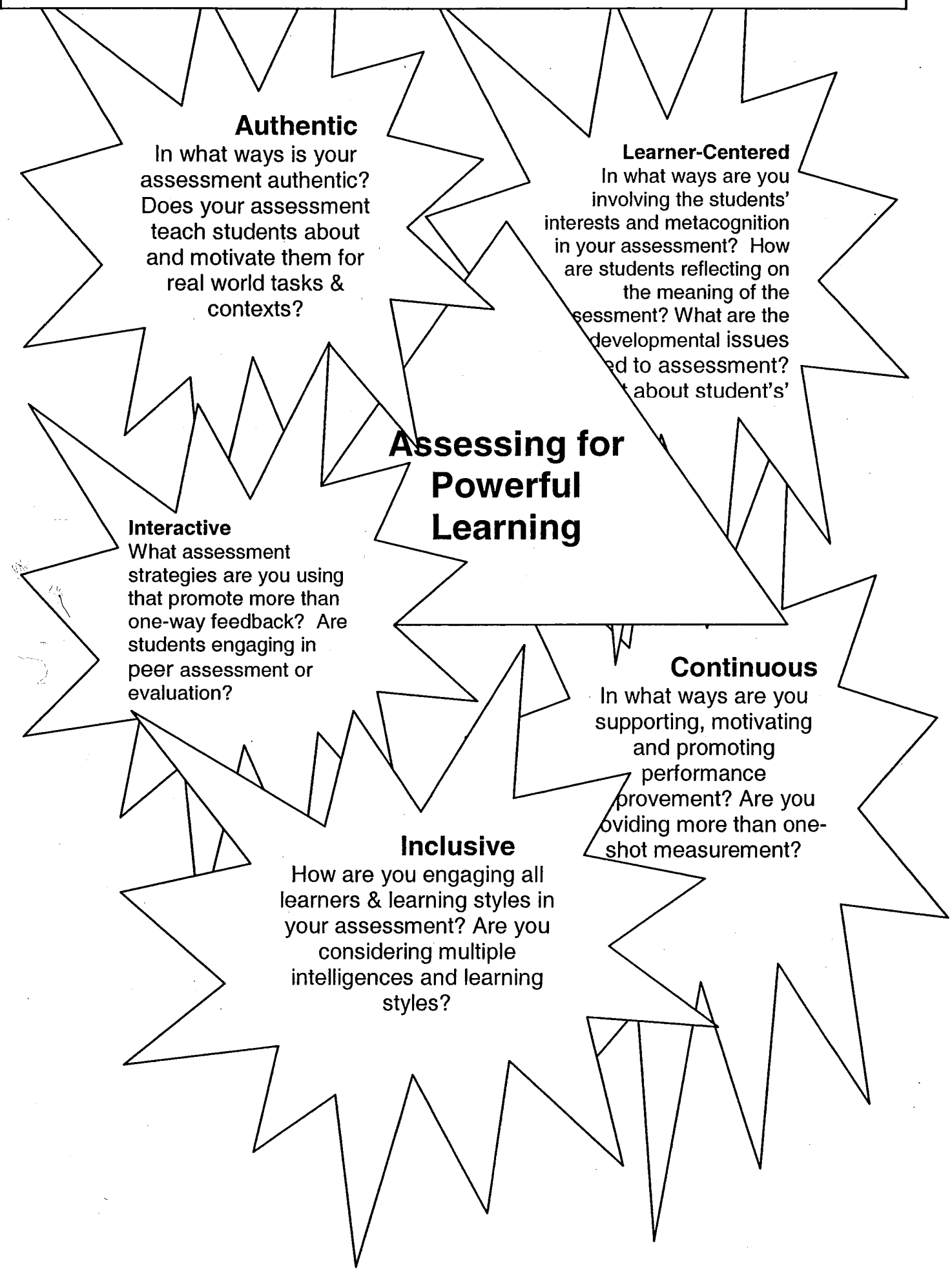




\section{Interactive Component of Powerful Learning}

Standard: Teachers and learners are members of the learning community. Powerful learning includes interactive opportunities for individuals to collaborate with others in the learning process and to work together towards a common purpose. Through this interaction, students are able to share their expertise and knowledge with one another.

\section{Criteria:}

口 Responsiveness to students needs during lessons: The teacher builds on student response and questions to guide lessons.

- Opportunities for collaboration: The teacher provides learners with opportunities to participate and demonstrate learning through collaboration with their peers in the learning process [examples, coop. Groups, pairs...]

- High Expectations: The teacher sets high expectations for learners. These expectations are conveyed during lessons, in one-to-one interactions and in group work.

- Assessment of collaborative work: The teacher collects information relating to peer collaboration to determine who is uncomfortable with collaborative work and which roles are suited best to the individual learners. This information guides the teacher in designing collaborative work.

Powerful Learning Rubric - The Interactive Component

Rate yourself on each of the component criteria. Use a B to label your selfassessment before the lab session that focuses on this component. Use an A to label your self-assessment at the end of the final lab session.

Developmental Levels

Level 1 - I do not acknowledge or understand how to plan for and implement this element.

Level 2 - I acknowledge and understand how to plan and implement this element but $I$ have not begun to plan for or implement this element. Level 3 - I am just beginning to plan for implementation of this element. Level 4 - I am planning and beginning to implement this element. Level 5 - I plan and proficiently implement this element on a regular basis.

\begin{tabular}{|l|l|l|l|l|l|}
\hline Benchmarks & Level 1 & Level 2 & Level 3 & Level 4 & Level 5 \\
\hline Responsiveness & & & & & \\
\hline Collaboration & & & & & \\
\hline High Expectations & & & & & \\
\hline Assessment & & & & & \\
\hline
\end{tabular}


$\underline{\text { Lesson Organizer for The Interactive Component }}$

Teacher name, class \& grade:

Date:

Performance Criteria focus:

Student work to collect/observe:

Capturing Learner Attention

Activity/Resources/Materials Teacher Behaviors Observed Learner Behaviors

Maintaining Continuous Engagement

Activity/Resources/Materials Teacher Behaviors Observed Learner Behaviors

Closure

Activity/Resources/Materials Teacher Behaviors Observed Learner Behaviors 


\section{After the Lesson}

Review the student work collected, the student performance criteria, the component standard and benchmarks. Use rubric record keeper to record student performance on criteria. Insert samples of student work. If the samples of student work are oversized and will not fit in the portfolio please write a description of the work and state where it can be found, and/or take a photo.

Answer the following questions:

What serendipitous events added value to the lesson?

What went well?

What goal(s) did you reach?

What goals did you not reach?

What will you do differently if you teach this lesson again?

What will you address in the next lesson?

Place a check by each of the planned activities you completed during the lesson.

Circle the check if you feel the activity was successful. 
Peer Support Team Debriefing for the Interactive Component Part One: Summary of Lesson

This lesson was related to the following standard(s) and performance criteria:

How did this lesson demonstrate the interactive powerful learning component?

What model of teaching was used?

Part Two: Demonstrating Teacher Observation

What worked?

What did not work?

Part Three: Peer Support Team Observations (optional)

What effective teacher behaviors were observed?

What effective learner behaviors were observed?

Part Four: Assessment of Student Work

The student work collected/observed demonstrates the following:

Demonstrating Teacher: What would you do differently if you teach this lesson again?

What will be addressed in the next lesson? 
Lesson Organizer for The Interactive Component

Teacher name, class \& grade:

Date:

Performance Criteria focus:

Student work to collect/observe:

\section{Capturing Learner Attention}

Activity/Resources/Materials Teacher Behaviors Observed Learner Behaviors

Maintaining Continuous Engagement

Activity/Resources/Materials Teacher Behaviors Observed Learner Behaviors

\section{Closure}

Activity/Resources/Materials Teacher Behaviors Observed Learner Behaviors 


\section{After the Lesson}

Review the student work collected, the student performance criteria, the component standard and benchmarks. Use rubric record keeper to record student performance on criteria. Insert samples of student work. If the samples of student work are oversized and will not fit in the portfolio please write a description of the work and state where it can be found, and/or take a photo.

Answer the following questions:

What serendipitous events added value to the lesson?

What went well?

What goal(s) did you reach?

What goals did you not reach?

What will you do differently if you teach this lesson again?

What will you address in the next lesson?

Place a check by each of the planned activities you completed during the lesson.

Circle the check if you feel the activity was successful. 


\section{Peer Support Team Debriefing for the Interactive Component}

Part One: Summary of Lesson

This lesson was related to the following standard(s) and performance criteria:

How did this lesson demonstrate the interactive powerful learning component?

What model of teaching was used?

Part Two: Demonstrating Teacher Observation

What worked?

What did not work?

Part Three: Peer Support Team Observations (optional)

What effective teacher behaviors were observed?

What effective learner behaviors were observed?

Part Four: Assessment of Student Work

The student work collected/observed demonstrates the following:

Demonstrating Teacher: What would you do differently if you teach this lesson again?

What will be addressed in the next lesson? 


\section{CONTINUOUS Component of Powerful Learning}

Standard: Powerful learning strengthens connections between different learning contexts so that students perceive knowledge in a more holistic manner. Students can apply existing knowledge to what they have already learned and make connections between different subject areas. Content is integrated into many subject areas.

\section{Criteria:}

. Prior Knowledge: The teacher activates students' prior knowledge, making connections to past learning.

- Integrated: Content integrates multiple subject areas.

- New Strategies: Learners are guided to build on strengths and various strategies are modeled for the students as tools for improving their work.

- Transfer: Learners practice and use learning in more than one subject area.

- Reflection: Learners are guided to reflect on their work and learn from their mistakes.

- Assessment: The teacher collects information from multiple sources to assess learner understanding of concepts and skills before and after instruction. This information informs daily instruction.

Powerful Learning Rubric-The Continuous Component

Rate yourself on each of the component criteria. Use a B to label your selfassessment before the lab session, which focuses on this component. Use an A to label your self-assessment at the end of the final lab session.

\section{Developmental Levels}

Level 1 - I do not acknowledge or understand how to plan for and implement this element.

Level 2 - I acknowledge and understand how to plan and implement this element but $I$ have not begun to plan for or implement this element. Level 3 - I am just beginning to plan for implementation of this element. Level 4 - I am planning and beginning to implement this element. Level 5 - I plan and proficiently implement this element on a regular basis.

\begin{tabular}{|l|l|l|l|l|l|}
\hline Benchmarks & Level 1 & Level 2 & Level 3 & Level 4 & Level 5 \\
\hline Prior Knowledge & & & & & \\
\hline Integrated & & & & & \\
\hline New strategies & & & & & \\
\hline Transfer & & & & & \\
\hline Reflection & & & & & \\
\hline Assessment & & & & & \\
\hline
\end{tabular}


Lesson Organizer for The Continuous Component

Teacher name, class \& grade: Date:

Performance Criteria focus:

Student work to collect/observe:

Capturing Learner Attention

Activity/Resources/Materials Teacher Behaviors Observed Learner Behaviors

Maintaining Continuous Engagement

Activity/Resources/Materials Teacher Behaviors Observed Learner Behaviors

Closure

Activity/Resources/Materials Teacher Behaviors Observed Learner Behaviors 


\section{After the Lesson}

Review the student work collected, the student performance criteria, the component standard and benchmarks. Use rubric record keeper to record student performance on criteria. Insert samples of student work. If the samples of student work are oversized and will not fit in the portfolio please.write a description of the work and state where it can be found, and/or take a photo.

Answer the following questions:

What serendipitous events added value to the lesson?

What went well?

What goal(s) did you reach?

What goals did you not reach?

What will you do differently if you teach this lesson again?

What will you address in the next lesson?

Place a check by each of the planned activities you completed during the lesson.

Circle the check if you feel the activity was successful. 


\section{Peer Support Team Debriefing for The Continuous Component}

Part One: Summary of Lesson

This lesson was related to the following standard(s) and performance criteria:

How did this lesson demonstrate the continuous powerful learning component?

What model of teaching was used?

Part Two: Demonstrating Teacher Observation

What worked?

What did not work?

Part Three: Peer Support Team Observations (optional)

What effective teacher behaviors were observed?

What effective learner behaviors were observed?

\&.

$$
\text { Part Four: Assessment of Student Work }
$$

The student work collected/observed demonstrates the following:

Demonstrating Teacher: What would you do differently if you teach this lesson again?

What will be addressed in the next lesson? 
Lesson Organizer for The Continuous Component

Teacher name, class \& grade:

Date:

Performance Criteria focus:

Student work to collect/observe:

\section{Capturing Learner Attention}

Activity/Resources/Materials Teacher Behaviors Observed Learner Behaviors

\section{Maintaining Continuous Engagement}

Activity/Resources/Materials Teacher Behaviors Observed Learner Behaviors

\section{Closure}

Activity/Resources/Materials Teacher Behaviors Observed Learner Behaviors 


\section{After the Lesson}

Review the student work collected, the student performance criteria, the component standard and benchmarks. Use rubric record keeper to record student performance on criteria. Insert samples of student work. If the samples of student work are oversized and will not fit in the portfolio please write a description of the work and state where it can be found, and/or take a photo.

Answer the following questions:

What serendipitous events added value to the lesson?

What went well?

What goal(s) did you reach?

What goals did you not reach?

What will you do differently if you teach this lesson again?

What will you address in the next lesson?

Place a check by each of the planned activities you completed during the lesson.

Circle the check if you feel the activity was successful. 


\title{
Peer Support Team Debriefing for The Continuous Component
}

\author{
Part One: Summary of Lesson
}

This lesson was related to the following standard(s) and performance criteria:

How did this lesson demonstrate the continuous powerful learning component?

What model of teaching was used?

Part Two: Demonstrating Teacher Observation

What worked?

What did not work?

Part Three: Peer Support Team Observations (optional)

What effective teacher behaviors were observed?

What effective learner behaviors were observed?

Part Four: Assessment of Student Work

The student work collected/observed demonstrates the following:

Demonstrating Teacher: What would you do differently if you teach this lesson again?

What will be addressed in the next lesson? 


\section{Inclusive Component of Powerful Learning}

Standard: Powerful learning focuses on giving all students equal access to learning opportunities. Challenges are structured which encourage the class to draw on the expertise of students who may not be as vocal or perceived of as smart. Criteria:

口 Differential instruction: The teacher offers activities that allow learners to explore and communicate learning in a variety of ways, at various paces.

- Removing obstacles: The teacher notices obstacles that prevent all students from participating in learning activities and adjusts instruction to remove them in the planning and/or implementation phases.

Designing activities for learners who need more practice: The teacher designs activities for learners who need additional background information and experience.

ㅁ Designing activities for faster learners: The teacher designs activities that compact basic skills, procedures and definitions for learners who master the material quickly.

- Heterogeneous groups: Allow for students of various abilities \& talents to work together to build on each other's strengths.

- Assessment: The teacher collects information to determine which concepts and skills are unclear to some learners, who have mastered the material quickly, who eagerly participate in learning activities and who needs encouragement to explore and use the material. This information guides the teacher in designing differential instruction.

\section{Powerful Learning Rubric - The Inclusive Component}

Rate yourself on each of the component criteria. Use a B to label your selfassessment before the lab session that focuses on this component. Use an A to label your self-assessment at the end of the final lab session.

\section{Developmental Levels}

\section{Level 1 - I do not acknowledge or understand how to plan for and implement} this element.

Level 2 - I acknowledge and understand how to plan and implement this element but $I$ have not begun to plan for or implement this element.

Level 3 - I am just beginning to plan for implementation of this element. Level 4 - I am planning and beginning to implement this element. Level 5 - I plan and proficiently implement this element on a regular basis.

\begin{tabular}{|l|l|l|l|l|l|}
\hline Benchmarks & Level 1 & Level 2 & Level 3 & Level 4 & Level 5 \\
\hline Differential Instruction & & & & & \\
\hline Removing Obstacles & & & & & \\
\hline More Background or Practice & & & & & \\
\hline More Enrichment & & & & & \\
\hline Heterogeneous Groups & & & & & \\
\hline Assessment & & & & & \\
\hline
\end{tabular}


Lesson Organizer for The Inclusive Component

Teacher name, class $\&$ grade:

Date:

Performance Criteria focus:

Student work to collect/observe:

Capturing Learner Attention

Activity/Resources/Materials Teacher Behaviors Observed Learner Behaviors

Maintaining Continuous Engagement

Activity/Resources/Materials Teacher Behaviors Observed Learner Behaviors

Closure

Activity/Resources/Materials Teacher Behaviors Observed Learner Behaviors 


\section{After the Lesson}

Review the student work collected, the student performance criteria, the component standard and benchmarks. Use rubric record keeper to record student performance on criteria. Insert samples of student work. If the samples of student work are oversized and will not fit in the portfolio please write a description of the work and state where it can be found, and/or take a photo.

Answer the following questions:

What serendipitous events added value to the lesson?

What went well?

What goal(s) did you reach?

What goals did you not reach?

What will you do differently if you teach this lesson again?

What will you address in the next lesson?

Place a check by each of the planned activities you completed during the lesson.

Circle the check if you feel the activity was successful. 


\title{
Peer Support Team Debriefing for the Inclusive Component
}

\author{
Part One: Summary of Lesson
}

This lesson was related to the following standard(s) and performance criteria:

How did this lesson demonstrate the inclusive powerful learning component?

What model of teaching was used?

Part Two: Demonstrating Teacher Observation

What worked?

What did not work?

Part Three: Peer Support Team Observations (optional)

What effective teacher behaviors were observed?

What effective learner behaviors were observed?

$$
\text { Part Four: Assessment of Student Work }
$$

The student work collected/observed demonstrates the following:

Demonstrating Teacher: What would you do differently if you teach this lesson again?

What will be addressed in the next lesson? 
Lesson Organizer for The Inclusive Component

Teacher name, class \& grade:

Date:

Performance Criteria focus:

Student work to collect/observe:

\section{Capturing Learner Attention}

Activity/Resources/Materials Teacher Behaviors Observed Learner Behaviors

Maintaining Continuous Engagement

Activity/Resources/Materials Teacher Behaviors Observed Learner Behaviors

\section{Closure}

Activity/Resources/Materials Teacher Behaviors Observed Learner Behaviors 


\section{After the Lesson}

Review the student work collected, the student performance criteria, the component standard and benchmarks. Use rubric record keeper to record student performance on criteria. Insert samples of student work. If the samples of student work are oversized and will not fit in the portfolio please write a description of the work and state where it can be found, and/or take a photo.

Answer the following questions:

What serendipitous events added value to the lesson?

What went well?

What goal(s) did you reach?

What goals did you not reach?

What will you do differently if you teach this lesson again?

What will you address in the next lesson?

Place a check by each of the planned activities you completed during the lesson.

Circle the check if you feel the activity was successful. 
Peer Support Team Debriefing for the Inclusive Component

Part One: Summary of Lesson

This lesson was related to the following standard(s) and performance criteria:

How did this lesson demonstrate the inclusive powerful learning component?

What model of teaching was used?

Part Two: Demonstrating Teacher Observation

What worked?

What did not work?

Part Three: Peer Support Team Observations (optional)

What effective teacher behaviors were observed?

What effective learner behaviors were observed?

Part Four: Assessment of Student Work

The student work collected/observed demonstrates the following:

Demonstrating Teacher: What would you do differently if you teach this lesson again?

What will be addressed in the next lesson? 


\section{Learner Centered Component of Powerful Learning}

Standard: Student exploration and continual discovery are essential in the powerful learning process. The learners' experiences and interests help shape the direction and content of the lessons. Students become enabled to take charge of their own learning.

\section{Criteria:}

- Learners' motivation: The teacher presents activities and/or problems which capture the learners' interest by inspiring curiosity, a sense of wonder or a desire to solve a problem.

- Managing time and resources: Learners are guided to develop and use strategies for managing time and materials effectively.

- Choice: Learners make choices related to their learning. Using different channels of communication. Learners explore new material or problems using a variety of senses and different learning strategies.

- Demonstrating learning: Learners have the opportunity to restate, explain and describe their learning in a variety of ways.

- Assessment: The teacher gathers information about student interests and preferred styles of learning in order to differentiate their instruction accordingly. This information is gathered from various sources, such as student and parent reports and teacher observations. The teacher incorporates assessment activities into the lesson, which allows learners to demonstrate their understanding using a variety of learning styles and intelligences.

Powerful Learning Rubric - The Learner Centered Component

Rate yourself on each of the component criteria. Use a B to label your selfassessment before the lab session that focuses on this component. Use an A to label your self-assessment at the end of the final lab session.

\section{Developmental Levels}

Level 1 - I do not acknowledge or understand how to plan for and implement this element.

Level 2 - I acknowledge and understand how to plan and implement this element but $I$ have not begun to plan for or implement this element.

Level 3 - I am just beginning to plan for implementation of this element. Level 4 - I am planning and beginning to implement this element.

Level 5 - I plan and proficiently implement this element on a regular basis.

\begin{tabular}{|l|l|l|l|l|l|}
\hline Benchmarks & Level 1 & Level 2 & Level 3 & Level 4 & Level 5 \\
\hline Learners' Motivation & & & & & \\
\hline Managing Time \& Resources & & & & & \\
\hline Choice & & & & & \\
\hline Demonstrating Learning & & & & & \\
\hline Assessment & & & & & \\
\hline
\end{tabular}


Lesson Organizer for

The Learner Centered Component

Teacher name, class \& grade: $\quad$ Date:

Performance Criteria focus:

Student work to collect/observe:

Capturing Learner Attention

Activity/Resources/Materials Teacher Behaviors Observed Learner Behaviors

Maintaining Continuous Engagement

Activity/Resources/Materials Teacher Behaviors Observed Learner Behaviors

\section{Closure}

Activity/Resources/Materials Teacher Behaviors Observed Learner Behaviors 


\section{After the Lesson}

Review the student work collected, the student performance criteria, the component standard and benchmarks. Use rubric record keeper to record student performance on criteria. Insert samples of student work. If the samples of student work are oversized and will not fit in the portfolio please write a description of the work and state where it can be found, and/or take a photo.

Answer the following questions:

What serendipitous events added value to the lesson?

What went well?

What goal(s) did you reach?

What goals did you not reach?

What will you do differently if you teach this lesson again?

What will you address in the next lesson?

Place a check by each of the planned activities you completed during the lesson.

Circle the check if you feel the activity was successful. 


\title{
Peer Support Team Debriefing for the Learner Centered Component
}

\author{
Part One: Summary of Lesson
}

This lesson was related to the following standard(s) and performance criteria:

How did this lesson demonstrate the learner-centered powerful learning component?

What model of teaching was used?

Part Two: Demonstrating Teacher Observation

What worked?

What did not work?

Part Three: Peer Support Team Observations (optional)

What effective teacher behaviors were observed?

What effective learner behaviors were observed?

Part Four: Assessment of Student Work

The student work collected/observed demonstrates the following:

Demonstrating Teacher: What would you do differently if you teach this lesson again?

What will be addressed in the next lesson? 


\section{Lesson Organizer for}

The Learner Centered Component

Teacher name, class \& grade:

Date:

Performance Criteria focus:

Student work to collect/observe:

\section{Capturing Learner Attention}

Activity/Resources/Materials Teacher Behaviors Observed Learner Behaviors

\section{Maintaining Continuous Engagement}

Activity/Resources/Materials Teacher Behaviors Observed Learner Behaviors

\section{Closure}

Activity/Resources/Materials Teacher Behaviors Observed Learner Behaviors 


\section{After the Lesson}

Review the student work collected, the student performance criteria, the component standard and benchmarks. Use rubric record keeper to record student performance on criteria. Insert samples of student work. If the samples of student work are oversized and will not fit in the portfolio please write a description of the work and state where it can be found, and/or take a photo.

Answer the following questions:

What serendipitous events added value to the lesson?

What went well?

What goal(s) did you reach?

What goals did you not reach?

What will you do differently if you teach this lesson again?

What will you address in the next lesson?

Place a check by each of the planned activities you completed during the lesson.

Circle the check if you feel the activity was successful. 
Peer Support Team Debriefing for the Learner Centered Component

Part One: Summary of Lesson

This lesson was related to the following standard(s) and performance criteria:

How did this lesson demonstrate the learner-centered powerful learning component?

What model of teaching was used?

Part Two: Demonstrating Teacher Observation

What worked?

What did not work?

Part Three: Peer Support Team Observations (optional)

What effective teacher behaviors were observed?

What effective learner behaviors were observed?

Part Four: Assessment of Student Work

The student work collected/observed demonstrates the following:

Demonstrating Teacher: What would you do differently if you teach this lesson again?

What will be addressed in the next lesson? 


\section{Authentic Component of Powerful Learning}

Standard: Students can relate what they are experiencing in the classroom to real issues and situations. Lessons are relevant to the learner, have recognizable goals, use hands-on authentic materials and build connections to the real world.

\section{Criteria:}

․ Connection to real life: The teacher uses materials and resources drawn from and connected to real life.

- Serendipity: The teacher takes advantage of unplanned events or circumstances, such as news events or topics that the students bring up to enhance student learning.

- Cultural traditions: The teacher draws on the cultural traditions of parents, students and school community to enrich learning experiences and the environment.

- Use of community resources: The teacher designs curriculum and instruction drawing upon the human and material resources of the school and larger community.

ㅁ Goals: Goals relevant to real"world situations.

- Celebrating learning: The learners demonstrate and celebrate their learning with the community.

口 Assessment of learner experiences and interests: The teacher obtains information about learners' life experiences, goals and interests. This information guides the design of learning activities, such as field trips, reports, projects, guest speakers, journal assignments, literature and problem-solving activities.

\section{Powerful Learning Rubric - The Authentic Component}

Rate yourself on each of the component criteria. Use a B to label your selfassessment before the lab session that focuses on this component. Use an A to label you self-assessment at the end of the final lab session.

\section{Developmental Levels}

Level 1 - I do not acknowledge or understand how to plan for and implement this element.

Level 2 - I acknowledge and understand how to plan and implement this element but I have not begun to plan for or implement this element.

Level 3 - I am just beginning to plan for implementation of this element. Level 4 - I am planning and beginning to implement this element. Level 5 - I plan and proficiently implement this element on a regular basis.

\begin{tabular}{|l|l|l|l|l|l|}
\hline Benchmarks & Level 1 & Level 2 & Level 3 & Level 4 & Level 5 \\
\hline Connection to Real Life & & & & & \\
\hline Serendipity & & & & & \\
\hline Cultural Traditions & & & & & \\
\hline Goals & & & & & \\
\hline Celebrating Learning & & & & & \\
\hline Assessment & & & & & \\
\hline
\end{tabular}


Lesson Organizer for The Authentic Component

Teacher name, class \& grade: Date:

Performance Criteria focus:

Student work to collect/observe:

\section{Capturing Learner Attention}

Activity/Resources/Materials Teacher Behaviors Observed Learner Behaviors

Maintaining Continuous Engagement

Activity/Resources/Materials Teacher Behaviors Observed Learner Behaviors

\section{Closure}

Activity/Resources/Materials Teacher Behaviors Observed Learner Behaviors 


\section{After the Lesson}

Review the student work collected, the student performance criteria, the component standard and benchmarks. Use rubric record keeper to record student performance on criteria. Insert samples of student work. If the samples of student work are oversized and will not fit in the portfolio please write a description of the work and state where it can be found, and/or take a photo.

Answer the following questions:

What serendipitous events added value to the lesson?

What went well?

What goal(s) did you reach?

What goals did you not reach?

What will you do differently if you teach this lesson again?

\section{What will you address in the next lesson?}

Place a check by each of the planned activities you completed during the lesson.

Circle the check if you feel the activity was successful. 


\section{Peer Support Team Debriefing for the Authentic Component}

Part One: Summary of Lesson

This lesson was related to the following standard(s) and performance criteria:

How did this lesson demonstrate the authentic powerful learning component?

What model of teaching was used?

Part Two: Demonstrating Teacher Observation

What worked?

What did not work?

Part Three: Peer Support Team Observations (optional)

What effective teacher behaviors were observed?

What effective learner behaviors were observed?

Part Four: Assessment of Student Work

The student work collected/observed demonstrates the following:

Demonstrating Teacher: What would you do differently if you teach this lesson again?

What will be addressed in the next lesson? 
Lesson Organizer for The Authentic Component

Teacher name, class \& grade: $\quad$ Date:

Performance Criteria focus:

Student work to collect/observe:

\section{Capturing Learner Attention}

Activity/Resources/Materials Teacher Behaviors Observed Learner Behaviors

Maintaining Continuous Engagement

Activity/Resources/Materials Teacher Behaviors Observed Learner Behaviors

\section{Closure}

Activity/Resources/Materials Teacher Behaviors Observed Learner Behaviors 


\section{After the Lesson}

Review the student work collected, the student performance criteria, the component standard and benchmarks. Use rubric record keeper to record student performance on criteria. Insert samples of student work. If the samples of student work are oversized and will not fit in the portfolio please write a description of the work and state where it can be found, and/or take a photo.

Answer the following questions:

What serendipitous events added value to the lesson?

What went well?

What goal(s) did you reach?

What goals did you not reach?

What will you do differently if you teach this lesson again?

\section{What will you address in the next lesson?}

Place a check by each of the planned activities you completed during the lesson.

Circle the check if you feel the activity was successful. 


\section{Peer Support Team Debriefing for the Authentic Component}

Part One: Summary of Lesson

This lesson was related to the following standard(s) and performance criteria:

How did this lesson demonstrate the authentic powerful learning component?

What model of teaching was used?

Part Two: Demonstrating Teacher Observation

What worked?

What did not work?

Part Three: Peer Support Team Observations (optional)

What effective teacher behaviors were observed?

What effective learner behaviors were observed?

Part Four: Assessment of Student Work

The student work collected/observed demonstrates the following:

Demonstrating Teacher: What would you do differently if you teach this lesson again?

What will be addressed in the next lesson? 


\section{Final Portfolio Reflection}

Facilitating powerful learning is an ongoing process. Through systematic examination of what is taught, how teaching and learning take place and the learning context, which encompasses all perceptions, expectations and resources of the school community educators will continue to refine and strengthen powerful learning.

Following are suggestions for final reflections on the powerful learning lab and portfolio process.

How have you strengthened you understanding of the context of your classroom? How has this affected you practice?

What features of the lab's focus on assessment have strengthened your ability to use ongoing assessment to inform daily practice?

What significant understandings related to the five components of powerful learning have occurred during the lab/portfolio process? How have these understanding affected your practice?

What insights have you gained from your peers? How will you continue to build on their strengths in the future?

What areas of powerful learning do you want to investigate further? How can you do so?

How would you like to collaborate with and mentor peers as they learn about powerful learning? 
Portfolio \& Presentation OrganizerThis is a checklist to help you organize the portfolio and prepare for each of the eight lab sessions.

\begin{tabular}{|c|c|c|}
\hline Session \& Date & Discuss \& Present & Complete Entry \\
\hline $\begin{array}{l}\text { Session 1: August 14, } \\
2000 \\
\text { Session 2: August 15, } \\
2000\end{array}$ & $\begin{array}{l}3 \text { guiding principles } \\
\text { Vision } \\
\text { Standards \& performance indicators } \\
\text { Rubrics } \\
\text { Social Family of Models } \\
\text { Interactive component }\end{array}$ & Portfolio pp. $3,4,5,7,11,23$ \\
\hline Before Session 3-4 & & $\begin{array}{l}\text { Lesson organizer or Lesson } \\
\text { planning form } \\
\text { After the Lesson reflection } \\
\text { Student work samples } \\
\text { Peer support team debriefing } \\
\text { form }\end{array}$ \\
\hline $\begin{array}{l}\text { Session } 3: \text { October } 16, \\
2000 \\
\text { Session } 4: \text { October } 17 \\
2000\end{array}$ & $\begin{array}{l}\text { Feedback from Lessons } 1 \& 2 \\
\text { Information-Processing family of } \\
\text { Models } \\
\text { Continuous \& Inclusive components }\end{array}$ & $\begin{array}{l}\text { Lesson organizers } \\
\text { Student work samples } \\
\text { Teacher reflections } \\
\text { Peer support debriefs }\end{array}$ \\
\hline Before Session 5-6 & & $\begin{array}{l}\text { Lesson organizer or Lesson } \\
\text { planning form } \\
\text { After the Lesson reflection } \\
\text { Student work samples } \\
\text { Peer support team debriefing } \\
\text { form }\end{array}$ \\
\hline $\begin{array}{l}\text { Session 5: January 8, } \\
2001 \\
\text { Session 6: January 9, } \\
2001\end{array}$ & $\begin{array}{l}\text { Feedback from Lessons } 3 \& 4 \\
\text { Personal Family of Models } \\
\text { Learner-Centered component }\end{array}$ & $\begin{array}{l}\text { Lesson organizers } \\
\text { Student work samples } \\
\text { Teacher reflections } \\
\text { Peer support debriefs }\end{array}$ \\
\hline Before Session 7-8 & & $\begin{array}{l}\text { Lesson organizer or Lesson } \\
\text { planning form } \\
\text { After the Lesson reflection } \\
\text { Student work samples } \\
\text { Peer support team debriefing } \\
\text { form }\end{array}$ \\
\hline $\begin{array}{l}\text { Session 7: March 5, } \\
\text { 2001 } \\
\text { Session 8: March 6, } \\
2001\end{array}$ & $\begin{array}{l}\text { Feedback from lessons 5-6 } \\
\text { Behavior Systems Family of Models } \\
\text { Authentic component }\end{array}$ & $\begin{array}{l}\text { Lesson organizers } \\
\text { Student work samples } \\
\text { Teacher reflections } \\
\text { Peer support debriefs } \\
\end{array}$ \\
\hline $\begin{array}{l}\text { Session Eight - } \\
\text { Celebration }\end{array}$ & $\begin{array}{l}\text { Personal overview \& reflection } \\
\text { Display of student work and } \\
\text { reflection }\end{array}$ & $\begin{array}{l}\text { Final Portfolio Reflection } \\
\text { Final Portfolio entries due by } \\
\text { end of term }\end{array}$ \\
\hline
\end{tabular}




\section{APPENDIX D}

\section{ACCELERATED SCHOOLS PROCESS}




\section{Accelerated Schools Project}

1. Philosophy

- The schools we want for children in at-risk situations should be the same schools we want for our own children.

- Powerful learning experiences are provided for all children through the integration of curriculum, instruction. and organization

- Accelerated School communities share a set of values, beliefs and attitudes: equity, communication \& collaboration, community spirit, school-as-the-center-of expertise, participation, reflection, risk-taking, experimentation \& trust

2. Three Guiding Principles

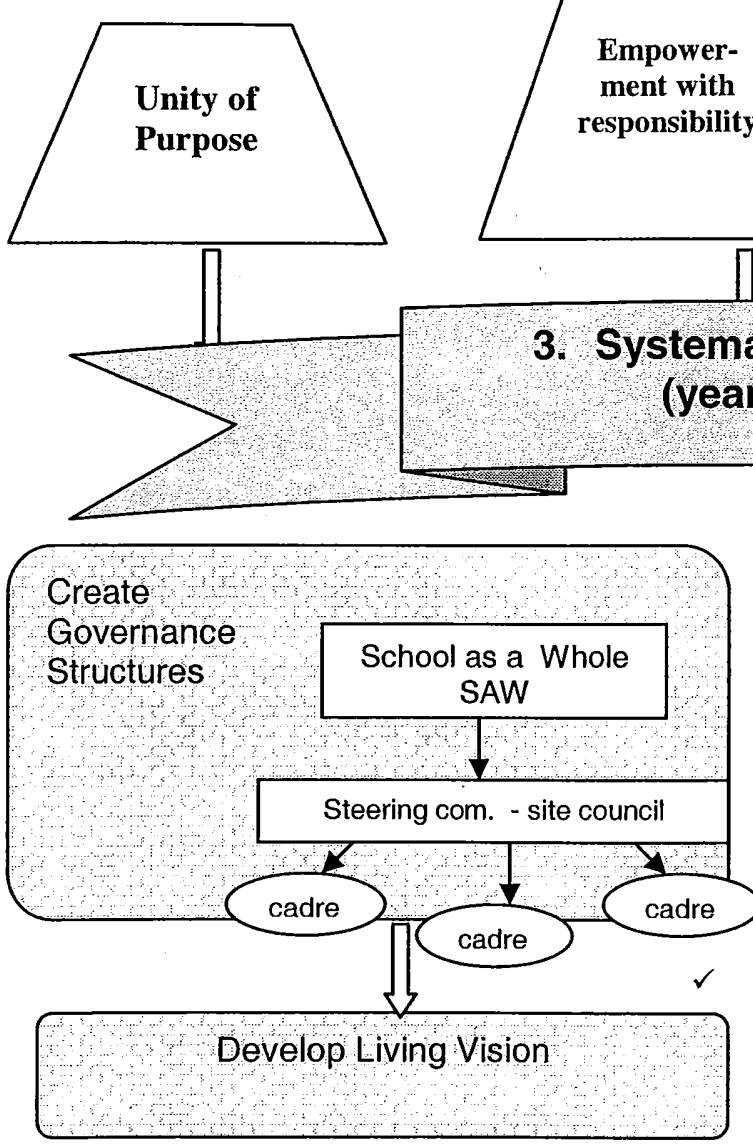

- Include members of entire school community on all cadres through a selfselection process

- Build a steering committee or site council of cadre representatives, administrators, parents, students, and community

- Empower SAW to act as the decisionmaking body

Take Stock

\section{Set Priorities}

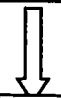

Follow Inquiry Process for

Relentless \& Continuous Improvement of the "there"

Imagine what kind of school you would want for your own child

Determine student outcomes aligned with standards

Celebrate your shared vision!

\section{chailenges}

- Develop a data driven picture of the here and now of student performance

$\checkmark \quad$ Prioritize the differences between taking stock and vision

Focus on priority area

Brainstorm solutions

- Synthesize solutions and investigate best practice

- Develop action plans

- Pilot test/implement the plan

- Evaluate and reassess 
APPENDIX E

ACCELERATED SCHOOLS PROJECT

BASIC PARTNERSHP AGREEMENT 


\section{NW Satellite Center for \\ Accelerated Schools at \\ Portland State University \\ Basic Partnership Agreement*}

The Northwest Satellite Center for Accelerated Schools at Portland State University assesses schools a fee of $\$ 45,000^{*}$ ( ${ }^{*}$ Portland metro area schools at $\$ 25,000$ ) a year for each implementation site that includes the following services:

\section{YEAR 1}

- Training of a coach, principal and 1-3 school staff member(s) (excluding travel expenses), consisting of three sessions (5 days of initial training, 2 days of powerful learning training, and 2 days of inquiry training)

- $2+2$ days mentioned above are recommended for the entire school

- 2-day launch assistance by NW Satellite Staff

- Opportunity to attend 4 Powerful Learning Best Practice Seminars

- Training materials

- Technical assistance by electronic mail, fax and phone;

- Two site visits by an ASP center staff member

- 8 monthly networking/training meetings at Portland State University or agreed upon location

- Assistance with evaluation of implementation

- A subscription to newsletters and an electronic ASP network;

- Three copies of the Accelerated Schools Resource Guide.

Years 2 and 3 (see attached year 2 contract)

Targeted professional development in key components of the ASP model (e.g. Powerful Learning, the Inquiry Process, evaluation, governance, collaborative decision-making, and revitalization)

- 8 days of staff development options to support ongoing technical assistance (situation-specific assistance may include: helping schools align with state and district policies and mandates, building effective internal and external communication, reinforcing district support, planning for training of new staff, addressing the role of leadership in a restructuring school, analyzing data, and sharing new research findings)

- 4 days of Powerful Learning Best practice seminars

- Opportunity to participate in Intel Teach to the Future training (40 hour equivalent)

- Opportunity to send staff to any year 1 training options

- Technical assistance by electronic mail, fax and phone;

- Three site visits by an ASP center staff member 
- Bi-monthly networking and training opportunities including year end reflection and planning meeting

- Assistance with on-going, in-depth evaluation of project implementation

- A subscription to newsletters and an electronic ASP network.

* The Basic Partnership Agreement requires a minimum three-year commitment. Our experience shows that while changes occur in the first year, full transformation of a school takes approximately five years (assuming no change in site administrator occurs). During this time, it is crucial to maintain active coaching at the school site and regular meeting times.

In addition to the Basic Partnership Agreement, schools and/or districts must:

- Provide release time for two days of initial training for the entire teaching staff

- Provide release time during the first year for the equivalent of four full days of additional training

- Be responsible for releasing the designated coach from at least $25 \%$ of his/her district assignment for each school served (estimated at about \$12-20,000 for .25 FTE salary/benefits coach). We strongly recommend a .50 FTE coach for schools with student populations over 300 students and a 1.0 FTE coach for schools with student populations over 500 .

- Schedule weekly meeting time at each school, amounting to about 36 hours per year, for whole school engagement in the restructuring process

- Provide funds for coaches to attend the National Accelerated Schools annual conference

Accelerated schools participating in Title I often use these funds to cover the expenses associated with release time and staff development. Districts may absorb the cost of the coach by providing release time for a district staff member to serve as coach.

Optional District Support:

- Funds for staff members and parents to attend the National Accelerated Schools annual conference

- Materials for school Accelerated Schools Professional Development and Research Library

- Stipends for teachers and staff members who participate in leadership team training and act as internal facilitators

- Stipends for staff members for additional professional development. This is particularly beneficial during years two and three as schools begin to implement the results of the inquiry process. 


\section{APPENDIX F}

INTERVIEW PROTOCOL 
Amy Daggett Petti

Portland State University

Date:

Interview number $12 \quad 3$

Participant code

\section{Research Problem: Do Comprehensive School Reform Efforts Influence Regular Teacher Practice?}

\section{Interview Protocol Sheet (first round)}

Subject Profile:

grade level:

experience:

age: gender:

years of teaching ethnicity teacher

preparation program years in the district

Research Questions: (ask each question, and record both answers and reflections/notes in the appropriate column)

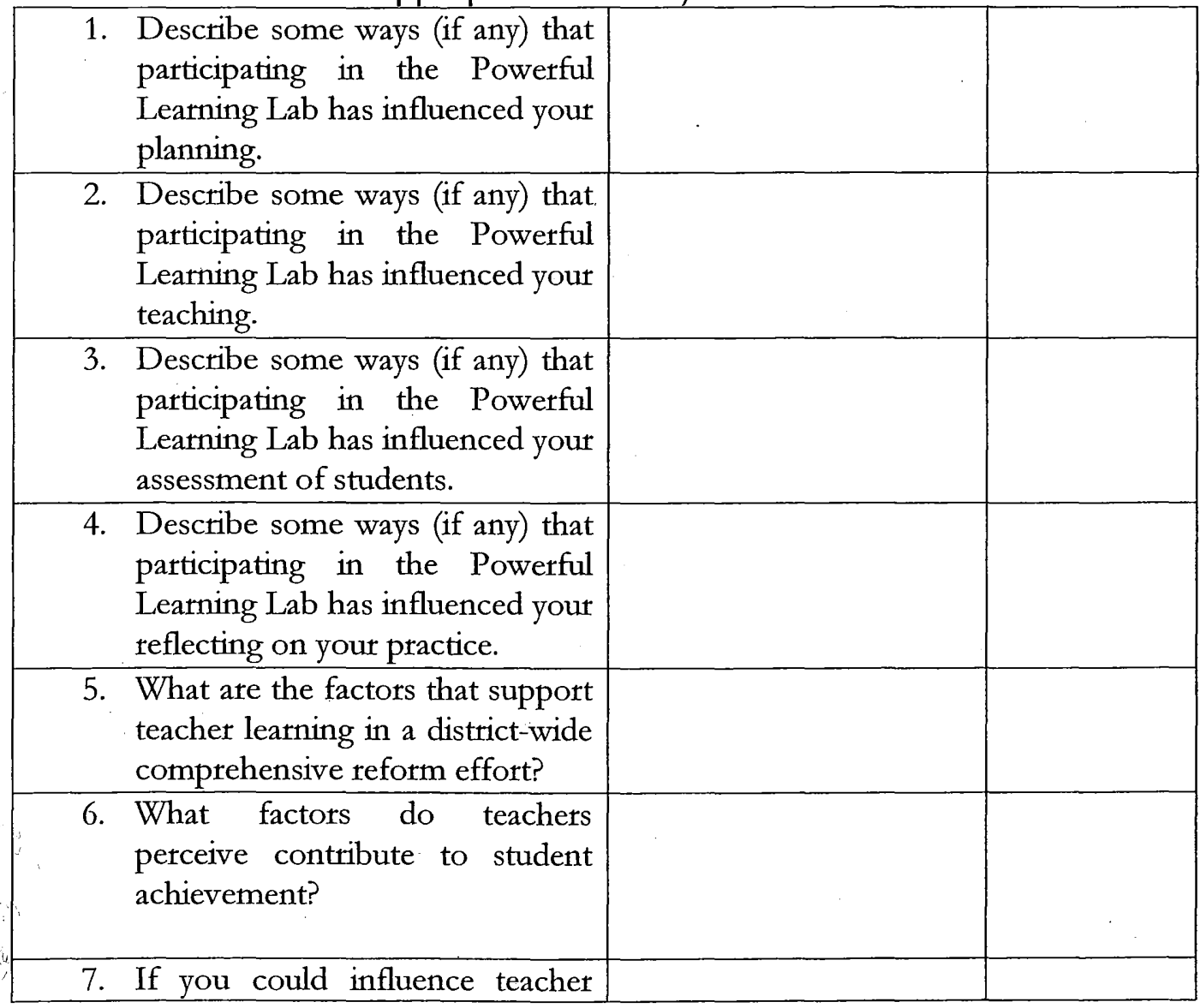




\begin{tabular}{|c|c|}
\hline \multicolumn{2}{|l|}{$\begin{array}{l}\text { education programs, so that } \\
\text { teachers would be better } \\
\text { prepared to be successful in } \\
\text { teaching poor, urban, and diverse } \\
\text { children, how would you do it? } \\
\text { What changes would you make? }\end{array}$} \\
\hline $\begin{array}{l}\text { 8. What are the benefits and } \\
\text { limitations of the Powerful } \\
\text { Learning Lab experience? }\end{array}$ & \\
\hline $\begin{array}{l}\text { 9. What types of support could } \\
\text { your building or district } \\
\text { administrators offer to further } \\
\text { enhance teaching and learning? }\end{array}$ & \\
\hline $\begin{array}{l}\text { 10. How is the framework for } \\
\text { Powerful Learning and the } \\
\text { Models of Teaching influencing } \\
\text { your classroom practice? }\end{array}$ & \\
\hline
\end{tabular}


Amy Daggett Petti Portland State University Date:

Interview number $12 \cdot 3$

Participant code

\section{Research Problem: Do Comprehensive School Reform Efforts Influence Regular Teacher Practice?}

\section{Interview Protocol Sheet (second round)}

Subject Profile:

grade level:

experience:

age:

years of teaching

preparation program

gender: ethnicity teacher years in the district

Research Questions: (ask each question, and record both answers and reflections/notes in the appropriate column)

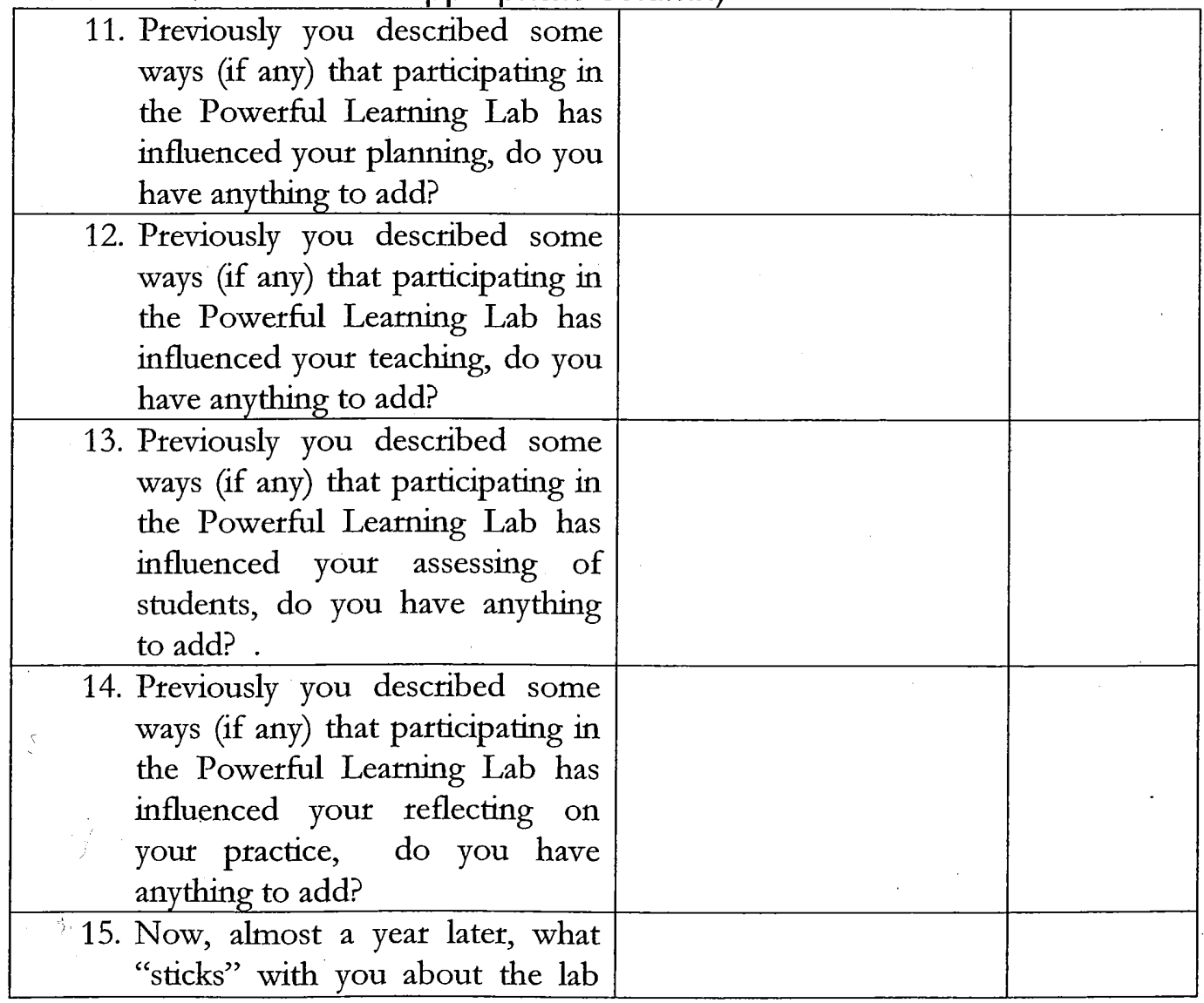




\begin{tabular}{|l|l|l|}
\hline experience? & & \\
\hline $\begin{array}{l}\text { 16. Do you have any comments or } \\
\text { stories to tell? }\end{array}$ & & \\
\hline
\end{tabular}


APPENDIX G

CLASSROOM OBSERVATION PROTOCOL 


\section{Accelerated Schools Project \\ Classroom Observation Notes}

Classroom

Grade/Subject Date

Observer Pre-Conf. Date

Directions: It is highly advisable to meet with the teacher being observed in a pre-conference to find out about the instruction leading up to the observation, the goals of the instruction, and any other information that will make the observation more meaningful. Use a copy of this form to summarize each of the three classroom visits. Check off any of the aspects of Powerful Learning that were observed and make notes about specifics below each section and/or at the end.

PART I. Organizing Instruction with the PL Triangle: How, What, and Context

$\square$ The purpose of the lesson is well defined.

$\square \quad$ A variety of instructional approaches are employed in the lesson.

$\square \quad$ Resources are used to support student learning. (Time, materials, classroom

management, flexible classroom organization)

$\square \quad$ Student strengths are identified and built upon.

$\square \quad$ Students are empowered and held responsible for extending their learning and following up on interests.

$\square \quad$ The class is unified in focus upon growth in their learning.

$\square \quad$ Instructional methods are a productive match for the instructional goals and context of the class.

$\square \quad$ Instructional goals are linked to state, district, and/or school standards.

Comments:

PART II. THE FIVE COMPONENTS 


\section{A. AUTHENTIC}

$\square \quad$ Instruction is based upon and/or includes application to real life situations

or

issues.

$\square$ Students are taught to use the vocabulary, methods, and/or activities of adults in

the work world or in the discipline.

$\square$. Students demonstrate knowledge through authentic performances and the creation of authentic products.

$\square$ The curriculum and instruction draws upon varied cultural traditions, including

those of the members of the school community.

$\square \quad$ Instruction utilizes the resources available in the community, including people,

Comments:

organizations, sites, and special events.

\section{B. INTERACTIVE}

Students collaborate in pairs and small groups sharing knowledge and expertise, completing projects, and critiquing each other's work.

$\square$ Students and teachers engage in dialogue one-on-one, in small groups, and in large

groups. (This includes LEP students, whose language development is nurtured through use.)

$\square$ Students' and teachers' dialogue builds knowledge, develops critical thinking, and

assists students' reflection upon and assessment of their work.

$\square \quad$ Students interact with the world outside the school through field-based experiences and/or technology.

$\square$ Students interact with ideas through text, film, art, and dialogue.

$\square$ Students demonstrate their learning to others and seek critical feedback as part of

the learning and assessment process.

$\square$ Students interact with their parents in the learning and assessment process.

\section{Comments:}




\section{LEARNER-CENTERED}

$\square \quad$ Curriculum is built upon genuine student interests and strengths.

$\square$ Students are involved in the planning of instruction, (with the choice of exhibition

and assessment within criteria established by teacher or school.)

$\square$ Students have opportunities to be creators, thinkers, and problem-solvers.

$\square$ The classroom has appropriate materials, books, equipment, and references that

students can access easily.

$\square \quad$ Students demonstrate their learning through unique authentic products and performances.

$\square \quad$ The classrooms and areas around the school have displays of student work that

show student originality, individual creativity, and thinking.

\section{Comments:}

\section{INCLUSIVE}

$\square \quad$ All students, (including children who are LEP or have special needs) are actively moving.

involved by exploring, reading, collaborating, listening, touching, and

$\square \quad$ Instruction is differentiated so that each student has meaningful and challenging instruction.

$\square \quad$ Students' strengths are identified and tapped so that each can make valuable

contributions.

$\square \quad$ The classroom and routines are structured to assure access for all students.

$\square \quad$ Appropriate supports are in place to assure equal access to the curriculum; there

are no obstacles to full participation.

\section{Comments:}




\section{E. CONTINUOUS}

$\square \quad$ Connections are made in lessons to previous learning; prior knowledge is accessed

and built upon.

$\square$ Students construct meaning through discovery, experimentation, writing, speaking, and art.

$\square$ Students are encouraged and supported to continue learning more about a topic

that interests them by carrying out independent investigations/research.

$\square$ Connections to other disciplines are made through activities that are integrated and authentic.

$\square \quad$ Learners are guided to reflect upon and critique their work and build upon it through revision and extension.

$\square$ Assessment is multi-faceted, clear and specific, and involves the student.

$\square \quad$ Teacher planning indicates spiraling and continuity between content areas

and grade levels.

$\square \quad$ Teachers build in the transfer of learning between one subject and another. Comments: 
APPENDIX $\mathrm{H}$

PORFOLIO FIELD NOTES FORM 


\section{PORTFOLIO FIELD NOTES}

With example notes, not actual notes

Subject Code:

Gender:

Experience:

Grade:

Date:

\begin{tabular}{|l|l|l|}
\hline Artifact Type & Key findings, patterns & notes \\
\hline Lesson plan & $\begin{array}{l}\text { Difficult, time } \\
\text { consuming }\end{array}$ & $\begin{array}{l}\text { Occurs w/novice } \\
\text { group }\end{array}$ \\
\hline Written reflection & $\begin{array}{l}\text { Vocabulary of } \mathcal{P} \mathcal{L} \\
\text { made debriefing } \\
\text { easier }\end{array}$ & \\
\hline & & \\
\hline & & \\
\hline
\end{tabular}

